\title{
TECHNOLOGY OPPORTUNITIES TO REDUCE U.S. GREENHOUSE GAS EMISSIONS
}

October 1997

Prepared by

National Laboratory Directors

for the

U.S. Department of Energy

On the World Wide Web:

http://www.ornl.gov/climate_change 
The Honorable Federico Peña

Secretary of Energy

Forrestal Building

1000 Independence Ave., SW

Washington, D.C. 20585

Dear Mr. Secretary:

\section{Technology Opportunities to Reduce U.S. Greenhouse Gas Emissions}

The national laboratory directors are delivering our report responding to your request that we identify costeffective technological means to reduce greenhouse gas emissions. This study reinforces our belief that science and technology are key elements in any climate change strategy.

The technology opportunities outlined in this report are intended to serve as input to broader efforts to develop an integrated national climate change strategy. The climate change issue is highly complex and multidimensional. Considerable work remains to be done in determining which technologies are most promising and what the requirements are to further evaluate and undertake the development and deployment of these technologies.

We greatly appreciate the hard work by our friends and colleagues in developing the necessary information and preparing this report on a compressed schedule. We believe that this multi-lab effort represents a mode of cooperation and collaboration that will set a pattem for future efforts by industry, government, universities, and the Department's national laboratories.

Thank you for the privilege of allowing us to lead this effort.

Sincerely,

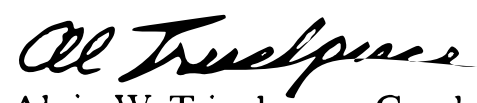

Alvin W. Trivelpiece, Co-chair

Oak Ridge National Laboratory

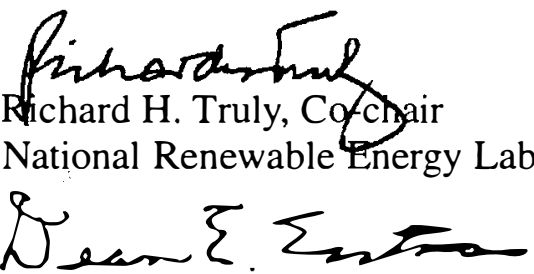

Dean E. Eastman

Argonne National Laboratory

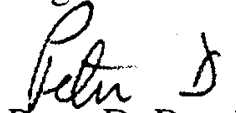

Peter D. Bond

Brookhaven National Laboratory

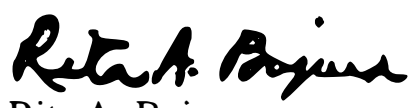

Rita A. Bajura

Pederal Energy Technology Center
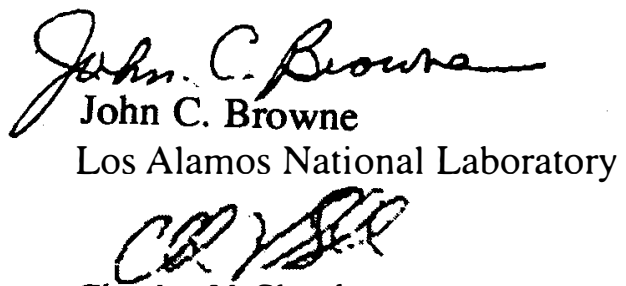

Charles V. Shank

Lawrence Berkeley National Laboratory

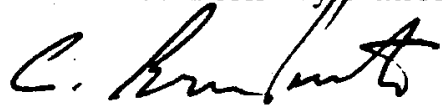

C. Bruce Tarter

Lawrence Livermore National Laboratory

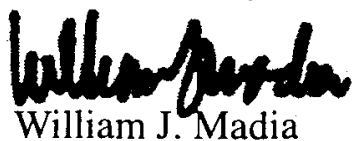

Pacific Northwest National Laboratory

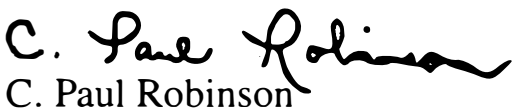

Sandia National Laboratories

Barton Krawetz

Idaho National Engineering and Environmental Laboratory 


\title{
The Secretary of Energy \\ Washington, D.C.
}

April 22, 1998

\author{
Dr. Alvin Trivelpiece \\ Director, Oak Ridge National Laboratory \\ P.O. Box 2008, Mail Stop 6255 \\ Oak Ridge, Tennessee 37830 \\ Admiral Richard H. Truly \\ Director, National Renewable Energy Laboratory \\ U.S. Department of Energy \\ 1617 Cole Boulevard \\ Golden, Colorado 80401 \\ Dear Dr. Trivelpiece and Admiral Truly:
}

Thank you for responding to my request for evaluating technology pathways to reduce greenhouse gas emissions with sustained economic growth. President Clinton framed this issue in his June 1997 United Nations speech, when he said

In order to reduce greenhouse gases and grow the economy, we must invest more in the technologies of the future. I am directing my cabinet to work to develop them.

Government, and universities, business and labor must work together. All these efforts must be sustained over years, indeed over decades.

I am pleased to receive your report, Technology Opportunities to Reduce U.S. Greenhouse Gas Emissions, and ask that you convey my gratitude to all your colleagues who contributed to it.

Your report, together with that of the President's Committee of Advisors on Science and Technology, will help significantly as we shape the Department's R\&D portfolio in response to evolving environmental, economic, and security concerns. It is particularly valuable to have the detailed information that you provide on each of the technologies, including the current status, specific actions being taken now, and the long-term potential for energy savings and emissions reductions.

As your report indicates, substantial further analysis is needed. First, we need to prioritize our increased $\mathrm{R} \& \mathrm{D}$ investments to lay the foundation for future breakthroughs, to accelerate introduction of new technologies, and to complement and stimulate private sector research, development, and deployment. Also, as stated in the report, it is fortuitous that many of these technologies have already been supported by the Administration and Congress in recent years for their broader environmental and economic benefits. For the most promising pathways, the Department, under the auspices of the R\&D Council, will work with stakeholders to produce technology road maps. Your report provides an excellent foundation for this activity, and your assistance will be sought together with that of academia and the private sector. The road maps will themselves evolve over time in the face of new challenges and opportunities. In addition, all proposals for increased R\&D will be evaluated in the context of the complete portfolio of programs designed to spur innovation and meet environmental, economic, and national security goals.

Second, I recognize that your efforts focused solely on the technology pathways, as requested, and that due to the timing of your work, the funding views included in the report were developed in the absence of information about the tax and other policy aspects of the Administration's program. The synergies between 
such incentive approaches and increased research and development will help shape the optimal technology development investments. Nevertheless, many of the research priorities your group identified are reflected in the President's Fiscal Year 1999 Budget, and as we move forward, we will fold your work into the broader policy context in order to achieve long-term greenhouse emission reductions in the most cost effective manner.

I am optimistic that the Department of Energy Laboratories, together with our partners in the private sector and in academia, will make significant contributions to clean and affordable energy sources that meet America's environmental goals for the twenty-first century. I look forward to working with you toward that end.

Sincerely,

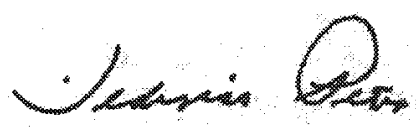

Federico Peña

cc: Dr. Dean E. Eastman

Director, Argonne National Laboratory

Dr. Peter D. Bond

Director, Brookhaven National Laboratory

Dr. Rita A. Bajura

Director, Federal Energy Technology Center

Dr. Barton Krawetz

Executive Vice President

Idaho National Engineering and Environmental Laboratory

Dr. John C. Browne

Director, Los Alamos National Laboratory

Dr. Charles V. Shank

Director, Lawrence Berkeley National Laboratory

Dr. C. Bruce Tarter

Director, Lawrence Livermore National Laboratory

Dr. William J. Madia

Pacific Northwest National Laboratory

Dr. C. Paul Robinson, President and Laboratories Director

Sandia National Laboratories 


\section{PREFACE}

President Clinton directed his cabinet to respond to the challenge of reducing greenhouse gas emissions in the United States. In turn, Secretary of Energy Peña asked the directors of 11 of the Department of Energy's national laboratories to identify technologies that could be used to meet this challenge. In response to this request, scientists and engineers from the Department's national laboratories built upon existing collaborations with technical leaders from industry, government, and universities in doing the work that led to the findings and conclusions reported here. In pursuing the goal of identifying cost-effective means to reduce greenhouse gas emissions, the following questions were used as guidelines:

What technologies can be improved through research and development $(R \& D)$, which are not now deployed or utilized extensively?

What are those new technologies that could be developed in the future, with reasonable effort and cost?

What is the program of research and development which is needed to bring about these results?

In our efforts to answer these questions, we have taken the position that the development of a science-based, cost-effective technological means to reduce greenhouse gas emissions is a prudent step to take independent of the outcome of the continuing scientific debate on the subject of global climate change.

We believe that this report serves as the technology basis of a needed national climate change technology strategy, with the confidence that a strong technology $R \& D$ program will deliver a portfolio of technologies with the potential to provide very substantial greenhouse gas emission reductions along with continued economic growth. Much more is needed to define such a strategy, including identification of complementary deployment policies and analysis to support the scoping and prioritization of R\&D programs. A national strategy must be based upon governmental, industrial, and academic partnerships.

In the final analysis, a combination of well-conceived national policy and the concurrent development of advanced technologies will be needed to achieve the nation's dual strategic goals of reducing greenhouse gas emissions and maintaining a robust economy. While our task was to focus on technology, and not on government policy, we recognize this important link.

We are honored to have been asked to lead this effort. We want to thank all of those who participated in the work upon which this report is based. 


\section{CONTENTS}

LIST OF FIGURES ......................................................................... vii

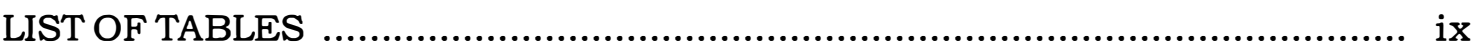

ACRONYMS, ABBREVIATIONS, AND INITIALISMS ............................... xi

EXECUTIVE SUMMARY …................................................................. xiii

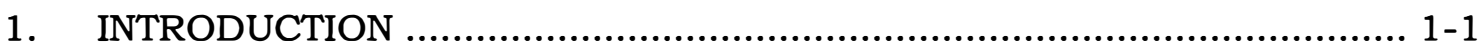

1.1 GREENHOUSE GAS EMISSIONS AND ENERGY .......................... 1-3

1.2 THE ROLE OF TECHNOLOGY ............................................... 1-5

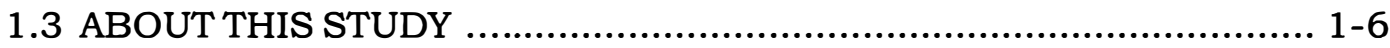

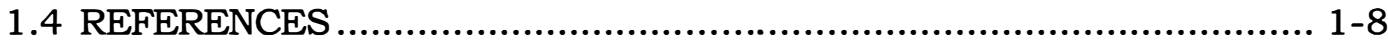

2. TECHNOLOGY PATHWAYS ...................................................... 2-1

2.1 CARBON LEVELS: PRESENT AND FUTURE ............................. 2-3

2.2 STUDY METHODOLOGY AND ASSUMPTIONS ........................... 2-5

2.3 ENERGY EFFICIENCY ..................................................... 2-8

2.3 .1 Buildings ..................................................................... 2-8

2.3.2 Industry ............................................................... 2-12

2.3.3 Transportation ................................................................. 2-16

2.3.4 Agriculture and Forestry ........................................... 2-20

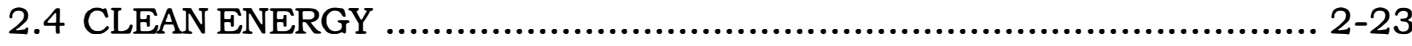

2.4.1 Fossil Resource Development ..................................... 2-24

2.4.2 Fossil Power Generation .............................................. 2-28

2.4.3 Nuclear Energy .......................................................... 2-32

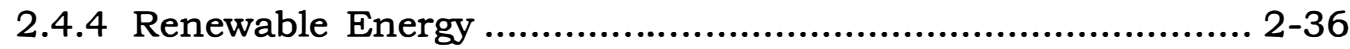

2.5 CARBON SEQUESTRATION AND MANAGEMENT .......................... 2-41

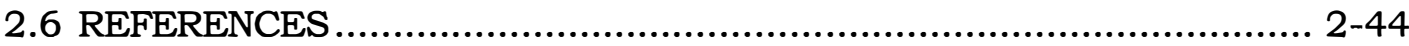

3. BASIC AND APPLIED RESEARCH AND CROSSCUTTING

TECHNOLOGIES ................................................................... 3-1

3.1 RESEARCH TO ADVANCE UNDERSTANDING OF THE

GLOBAL CARBON CYCLE .................................................... 3-3

3.1.1 Global Carbon Cycle Modeling and Measurement ................ 3-3

3.2 BASIC RESEARCH RELATED TO GREENHOUSE

GAS EMISSIONS .................................................................. 3-4

3.2.1 Materials Science ........................................................ 3-5

3.2.2 Chemical Sciences .......................................................... 3-6

3.2.3 Biotechnology ......................................................... 3-7

3.2.4 Geosciences .......................................................... 3-8

3.2.5 Environmental and Ecological Sciences ............................ 3-8

3.2.6 Nuclear Sciences ........................................................ 3-9

3.2.7 Computational Sciences ............................................. 3-9 
3.3 CROSSCUTTING TECHNOLOGIES SUPPORTING

GREENHOUSE GAS REDUCTIONS .......................................... 3-10

3.3.1 Hydrogen and Fuel Cells ........................................... 3-10

3.3.2 Electrical Transmission, Distribution, and Components ........ 3-11

3.3.3 Sensors and Controls .................................................. 3-12

3.3.4 Energy Storage ........................................................... 3-13

3.4 REFERENCES ...................................................................... 4

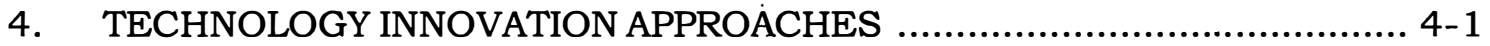

4.1 INTRODUCTION ............................................................... 4-1

4.2 APPROACHES ............................................................... 4

4.2.1 Government Led and Financed Approach ......................... 4-2

4.2.2 Industry Led and Financed Approach .............................. 4-3

4.2.3 Public-Private Strategic Alliances ..................................... 4-3

4.3 STRATEGIC ALLIANCE ROLES ............................................... 4-5

4.4 CONCLUSION .................................................................. 4-6

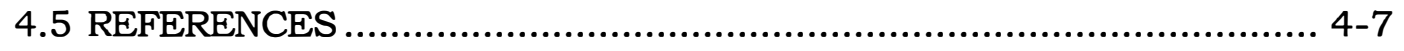

5. SYNTHESIS AND MOVING FORWARD ......................................... 5-1

5.1 SYNTHESIS ...................................................................... 5-1

5.1.1 The RD\&D Path to Carbon Stabilization ........................... 5-1

5.1.2 Factors Influencing GHG Reduction Potential ................... 5-4

5.1.3 The Time-Line of Technology Products .......................... 5-8

5.1.4 Performance Goals ................................................... 5-12

5.1.5 Basic and Applied Research Are Needed ........................ 5-12

5.1.6 Collateral Benefits and Costs ....................................... 5-13

5.1.7 Research, Development, and Demonstration Resources ........ 5-14

5.2 MOVING FORWARD ............................................................. 5-15

5.3 CONCLUSION .................................................................... $5-16$

5.4 REFERENCES ....................................................................... 5 -

Appendix A. Contributors .......................................................... A-1

Appendix B. Technology Pathways Characterization 


\section{FIGURES}

Figure

Page

1.1 Technology and policy components for a climate change strategy $1-3$

1.2 The burning of fossil fuel and changing land use have resulted in human-induced alterations of the global carbon cycle

1.3 Overview of the sources of carbon emissions in the United States in 1995

2.1 Alternative technological opportunities for reducing greenhouse gas emissions

2.2 Sources of greenhouse gas emissions in the United States in 1995 ...... 2-3

2.3 Projected U.S. carbon dioxide emissions ...................................... 2-6

2.4 Four technology pathways to increased industrial efficiency ............... 2-14

2.5 Technology pathways for industry with associated benefits in carbon emission reductions .............................................. 2-14

2.6 Fossil fuels account for most of the energy used in the United States .... 2-24

2.7 Long-term R\&D in major oil companies continues to decline .............. 2-28

2.8 Operable refineries in the United States ...................................... 2-28

2.9 Relationship between $\mathrm{CO}_{2}$ release and electricity production in France, 1973-1996...

2.10 Carbon emissions avoided under various scenarios of nuclear electricity generation

2.11 Renewables have the potential for significant reductions of U.S. carbon emissions $2-36$

2.12 Renewable energy technologies are well along a path of decreasing costs 
3.1 Ceramic composite hot gas candle filters can be used to remove particulates from gas streams in combined cycle fossil and biomass power facilities

3.2 This KIVA prototype 3-D simulation of an advanced diesel engine includes the regions where gas exchange and combustion occur

3.3 Integrating utilities with the hydrogen transportation fuel system would enable greater penetration of renewables into the marketplace at a faster rate

4.1 Interactive model of innovation 4-5

4.2 Linear model of innovation 4-5

5.1 Illustrative time-line of anticipated technology products: $2000-2010$ 5-10

5.2 Illustrative time-line of anticipated technology products: $2015-2030$ 


\section{TABLES}

Table

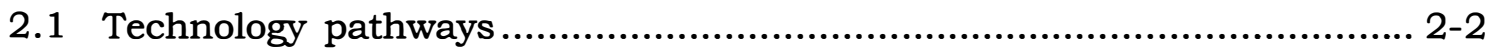

2.2 U.S. carbon dioxide emissions by end-use sector .......................... 2-7

3.1 Most pressing research and enabling technology needs identified for each of the technology pathways

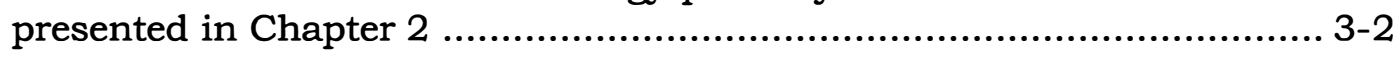

4.1 Approaches to technological innovation ..................................... 4-2

5.1 Potential reduction of U.S. carbon dioxide emissions from nine technology areas

5.2 Potential reduction of U.S. carbon dioxide emissions from selected sectors and technology pathways.... 


\section{ACRONYMS, ABBREVIATIONS, AND INITIALISMS}

\begin{tabular}{|c|c|}
\hline ATS & advanced turbine system \\
\hline $\mathrm{C}$ & carbon \\
\hline $\mathrm{C} / \mathrm{E}$ & carbon intensity \\
\hline $\mathrm{CFC}$ & chlorofluorocarbon \\
\hline $\mathrm{CH}_{4}$ & methane \\
\hline $\mathrm{CO}_{2}$ & carbon dioxide \\
\hline CRADA & cooperative research and development agreement \\
\hline DOE & U.S. Department of Energy \\
\hline $\mathrm{E} / \mathrm{GDP}$ & energy per unit of economic output \\
\hline EIA & Energy Information Administration \\
\hline EPRI & Electric Power Research Institute \\
\hline $\mathrm{EV}$ & electric drive vehicles \\
\hline FCCC & Framework Convention on Climate Change \\
\hline FTTA & Federal Technology Transfer Act \\
\hline GDP & gross domestic product \\
\hline GHG & greenhouse gas \\
\hline GRI & Gas Research Institute \\
\hline GtC & gigatons of carbon ( $10^{3}$ million tons $)^{*}$ \\
\hline GW & gigawatt $\left(10^{3} \mathrm{MW}\right)$ \\
\hline GWe & gigawatt electric \\
\hline $\mathrm{HCFC}$ & hydrochlorofluorocarbon \\
\hline HEV & hybrid electric vehicles \\
\hline $\mathrm{HHV}$ & high heat value \\
\hline HVAC & heating, ventilation, and air conditioning \\
\hline HVDC & high voltage direct current \\
\hline IGCC & integrated gasification combined cycle \\
\hline $\mathrm{I} / \mathrm{O}$ & input/output \\
\hline IOF & Industries of the Future \\
\hline IPCC & Intergovernmental Panel on Climate Change \\
\hline $\mathrm{Vh}$ & kilowatt hour \\
\hline
\end{tabular}

*A tonne, or metric ton, is 1000 kilograms or about $2200 \mathrm{lb}$. 


\begin{tabular}{|c|c|}
\hline LEGO & lifetime extension and generation optimization \\
\hline LIDAR & light detection and ranging \\
\hline low-E & low emissivity \\
\hline mpg & miles per gallon \\
\hline $\mathrm{mph}$ & miles per hour \\
\hline MSW & municipal solid waste \\
\hline $\mathrm{MtC}$ & million metric tons of carbon \\
\hline MWe & megawatt $=10^{6}$ watt, electric \\
\hline MWt & megawatt thermal \\
\hline NA & not applicable \\
\hline NASA & National Aeronautics and Space Administration \\
\hline NCRA & National Cooperative Research Act \\
\hline NFRC & National Fenestration Rating Council \\
\hline NGO & nongovernmental organization \\
\hline $\mathrm{NO}_{\mathbf{x}}$ & nitrogen oxides \\
\hline NRC & Nuclear Regulatory Commission \\
\hline OBTS & $\begin{array}{l}\text { U.S. DOE Office of Building Technology, State and Community } \\
\text { Programs }\end{array}$ \\
\hline OI & other industrial \\
\hline OIT & U.S. DOE Office of Industrial Technologies \\
\hline ORTA & Office of Research and Technology Application \\
\hline PEM & proton exchange membrane \\
\hline PNGV & Partnership for a New Generation of Vehicles \\
\hline ppmv & parts per million by volume \\
\hline PV & photovoltaic \\
\hline PVMat & Photovoltaic Manufacturing Initiative \\
\hline quad & quadrillion $\left(10^{15}\right)$ Btus \\
\hline R\&D & research and development \\
\hline RD\&D & research, development, and demonstration \\
\hline SBIR & Small Business Innovation Research \\
\hline scf & standard cubic feet \\
\hline SEMATECH & Semiconductor Manufacturing Technology \\
\hline SMES & superconducting magnetic energy storage \\
\hline SOM & soil organic matter \\
\hline Tcf & trillion cubic feet \\
\hline TRP & Technology Reinvestment Project \\
\hline TWh & terawatt hour (terawatt $=10^{6} \mathrm{MW}$ ) \\
\hline USCAR & United States Council for Automotive Research \\
\hline USDA & U.S. Department of Agriculture \\
\hline USGCRP & U.S. Global Change Research Program \\
\hline
\end{tabular}




\section{EXECUTIVE SUMMARY}

The rise in greenhouse gas emissions from fossil fuel combustion and industrial and agricultural activities has aroused international concern about the possible impacts of these emissions on climate. Greenhouse gases-mostly carbon dioxide, some methane, nitrous oxide and other trace gases-are emitted to the atmosphere, enhancing an effect in which heat reflected from the earth's surface is kept from escaping into space, as in a greenhouse. Thus, there is concern that the earth's surface temperature may rise enough to cause global climate change.

Approximately $90 \%$ of U.S. greenhouse gas emissions from anthropogenic sources come from energy production and use, most of which are a byproduct of the combustion of fossil fuels. On a per capita basis, the United States is one of the world's largest sources of greenhouse gas emissions, comprising $4 \%$ of the world's population, yet emitting $23 \%$ of the world's greenhouse gases. Emissions in the United States are increasing at around 1.2\% annually, and the Energy Information Administration forecasts that emissions levels will continue to increase at this rate in the years ahead if we proceed down the business-as-usual path.

President Clinton has presented a two-part challenge for the United States: reduce greenhouse gas emissions and grow the economy. Meeting the challenge will mean that in doing tomorrow's work, we must use energy more efficiently and emit less carbon for the energy expended than we do today. To accomplish these goals, President Clinton proposed on June 26, 1997, that the United States "invest more in the technologies of the future."

In this report to Secretary of Energy Peña, 47 technology pathways are described that have significant potential to reduce carbon dioxide emissions. The present study was completed before the December 1997 United Nations Framework Convention on Climate Change and is intended to provide a basis to evaluate technology feasibility and options to reduce greenhouse gas emissions. These technology pathways (which are described in greater detail in Appendix B, Technology Pathways) address three areas: energy efficiency, clean energy, and carbon sequestration (removing carbon from emissions and enhancing carbon storage). Based on an assessment of each of these technology pathways over a 30-year planning horizon, the directors of the Department of Energy's (DOE's) national laboratories conclude that success will require pursuit of multiple technology pathways to provide choices and flexibility for reducing greenhouse gas emissions. Advances in science and technology are necessary to reduce greenhouse gas emissions from the United States while sustaining economic growth and providing collateral benefits to the nation. 
Fortunately, many of these technologies are already the subject of some federally sponsored and private-sector research, development, and demonstration (RD\&E) driven by the collateral benefits they offer. It is worth noting that DOE's applied energy technology programs are already supporting the development of many of the requisite technologies or elements of these technologies (see Appendix B). Similarly, DOE's Office of Energy Research funds basic research in areas that underpin the applied energy technology programs. If developed and widely used, these technologies would also improve air quality, reduce U.S. dependence on imported oil, and increase exports of U.S. technologies to help other nations reduce their greenhouse gas emissions while growing their economies, all of which will sustain national economic growth.

We believe that developing technology solutions sooner rather than later will be more effective in reducing greenhouse gas emissions. Postponing action could close technology options or increase future costs and risks. The laboratory directors and DOE recognize that supportive programs and policies will also be critical to bringing new technologies into the marketplace. New policies and programs to deal with emissions may be needed, such as subsidies or tax incentives or permit trading programs to encourage accelerated adoption of energy efficiency or clean energy technologies. However, these programs and policies are not specified in this study. In addition, the technology pathways are not prioritized in this report in terms of potential for commercialization or research and development $(R \& D)$ funding. Further analysis is required to accomplish that.

Our findings suggest that each decade is distinct in terms of the range of greenhouse gas reduction technologies that could be available.

- In the first decade, significant advances in energy efficiency technologies would deliver substantial near-term carbon-reducing impacts by decreasing the energy intensity (amount of energy used to do work) of the U.S. economy. Clean energy technologies would continue to grow, and carbon sequestration technologies could begin to emerge.

- Along with continued improvements in energy efficiency, research-based advances in clean energy technologies would reduce significantly the carbon intensity (amount of carbon emitted for the energy used) of the U.S. energy economy during the second decade. A wide range of improved renewable, fossil, and nuclear technologies could be introduced and widely deployed in this period. These clean energy options could begin to exceed the carbon reduction impact of increased end-use efficiencies by the year 2025.

- Complementing ongoing advances in clean energy and efficiency technologies well into the third decade, carbon sequestration technologies would add a third important dimension to the package of solutions. Success in this technology area could enable the nation to continue its extensive use of fossil fuels without harming the global climate. We assume that these technologies would not be widely available until the 2030 time frame; however, successful introduction earlier could result in significantly greater reductions in net carbon emissions.

We believe that by 2030 , a vigorous $R D \& D$ program could deliver a wide array of cost-effective technologies that together could reduce the nation's carbon emissions by $400-800$ million metric tons of carbon (MtC) per year. This decrease represents a significant portion of the carbon emission reductions that may be 
targeted by the United States for 2030. Additional reductions would result from the implementation of new policies and deployment programs, particularly in early years when the market penetration of existing and near-term technologies could be accelerated.

Possible goals for an RD\&D program are presented below, along with some of the technologies that could contribute to achieving them.

\section{Energy Efficiency}

- Use electricity more efficiently through the deployment of advanced technologies (e.g., intelligent building control systems, cost-effective refrigerators that use half as much electricity as today's models, and fuel cells for heat and power in commercial buildings).

- Reduce use of gas and oil for space and water heating through building efficiency measures (e.g., super insulation, gas-fired heat pumps that provide highly efficient space heating and cooling, and building envelopes that capture and store solar energy for later use).

- Improve industrial resource recovery and use (e.g., develop an integrated gasification combined cycle power technology, which can convert coal, biomass, and municipal wastes into power and products) and industrial processes to save energy (e.g., advanced catalysis and separations technologies).

- Increase transportation efficiency through new technologies (e.g., a hybrid electric vehicle that is three times more fuel-efficient than today's standard model).

\section{Clean Energy}

- Change the energy mix to increase use of sources with higher generating efficiencies and lower emissions-increased use of natural gas, safer and more efficient nuclear power plants, renewable energy (e.g., solar and wind power; electricity and fuels from agricultural biomass), and hydrogen (to produce electricity through fuel cells).

- Develop "energyplexes" that would use carbon efficiently without emitting greenhouse gases for the integrated production of power, heat, fuels, and chemicals from coal, biomass, or municipal wastes.

- Distribute electricity more efficiently to reduce emissions (e.g., distributed generation using superconducting transformers, cables, and wires).

- Switch transportation to energy sources with lower emissions (e.g., trucks that run on biodiesel fuel; ethanol from cellulosic feedstocks).

- Remove carbon from fuels before combustion.

\section{Carbon Sequestration}

- Efficiently remove carbon dioxide from combustion emissions before they reach the atmosphere.

- Increase the rate at which oceans, forests, and soils naturally absorb atmospheric carbon dioxide.

- Develop technologies for long-term carbon storage in geological deposits, aquifers, or other reservoirs. 


\section{Basic and Applied Research Are Needed}

Meeting the goals described above also depends upon incremental improvements and breakthroughs in the basic sciences. For example, basic research is needed to

- understand the global carbon cycle (i.e., computational modeling and measurements to understand the ocean-atmosphere-terrestrial biosphere interactions) and judge the benefits and risks of sequestration options

- support greenhouse gas reduction technologies (i.e., materials, chemical sciences, biotechnology, geosciences, environmental and ecological sciences, nuclear sciences, and computational sciences)

To support multiple technology pathways, enabling technologies also must be improved, especially transmission/distribution systems that deliver energy faster and more efficiently. Relevant enabling technologies include

- hydrogen production, storage, and distribution

- fuel cells

- electricity transmission, distribution, and components

- sensors and controls

- energy storage systems

\section{Strategic Alliances Are Essential}

Strategic public-private alliances provide the best approach for developing and deploying most greenhouse gas reduction technologies. Although many of these technologies will be able to compete cost-effectively in the marketplace in the future, industry is unlikely to lead and fully finance the innovation process because of the high risk associated with developing technologies that will not be deployed for decades, and because the market currently does not place a high value on carbon mitigation. Using public-private strategic alliances will help maximize the efficiency of the innovation process by bringing together stakeholders who are capable of overcoming the relevant scientific, technical, and commercial challenges.

\section{Research, Development, and Demonstration Resources}

This report describes the carbon emission reductions that could result from an accelerated $R D \& D$ program. It does not consider collateral benefits from initiating complementary deployment programs or policies aimed at stimulating markets for greenhouse gas reduction technologies. It is believed that an integrated approach (i.e., science and technology in combination with deployment programs and supporting policies) is the most cost-effective one.

To achieve the annual emission reductions of 400 to $800 \mathrm{MtC}$ by 2030 described in this report, federal RD\&D budget increments would be necessary in three areas:

- the development of advanced energy technologies

- the development of carbon sequestration technologies, including supporting research on carbon cycle modeling and ecosystems 
- the basic research areas that are the wellspring of future technological breakthroughs.

\section{Moving Forward}

The laboratory directors recommend that the United States develop and pursue a detailed and comprehensive technology strategy for reducing greenhouse gas emissions. By summarizing the status, potential, and fundamental research needs of a broad range of technologies relevant to reducing greenhouse gas emissions, this report provides one key element, namely, the technology basis, for developing a climate change technology strategy. However, full definition of such a strategy requires several additional steps, especially an assessment of alternative programs and policies to promote deployment and an analysis of the costs and benefits of alternative technology and policy options to develop priorities. Further, we propose that DOE lead the development of this strategy because of its energy technology mission, its proven record in developing major national initiatives, and the attendant strategic alliances that are needed to solve complex national problems where science makes a difference. When implemented through focused public-private strategic alliances, this strategy should lead to technological advances that have broad market appeal. We believe that such a technology strategy could significantly reduce U.S. greenhouse gas emissions. Achieving this challenging goal while sustaining economic growth would require a vigorous RD\&D program sustained by strong partnerships among government, universities, and the private sector.

In summary, this report concludes that a national investment in a technology RD\&D program over the next three decades would provide a portfolio of technologies that could significantly reduce greenhouse gas emissions over the next three decades and beyond. To make effective progress against realistic goals and expectations, an outlay of approximately $\$ 1 \mathrm{~B} /$ year above those presently dedicated to these efforts would be a prudent investment of resources. We believe that many technological opportunities exist that could significantly contribute to this goal without harming the nation's economy. A strategic plan that includes deployment policies to complement technology RD\&D will be necessary for success. Plans will need to be formulated that reflect both the economic and technological implications of deploying these technologies. Hence, development of a climate change technology strategy is the recommended next step. The development process should include review of technology policy options to complement technology development options, and a detailed plan for supporting implementation which addresses technology goals, RD\&D program plans, policies that support deployment, and fiscal resources. Development of this RD\&D agenda should be a collaborative effort between government, industry, business, and the scientific communities. The implementation of a technology strategy to reduce greenhouse gas emissions will serve as an investment insurance policy. It should reduce the threat of climate change from fossil fuel use and provide acceptable technologies that produce savings and revenues that would far exceed the cost of an accelerated research program. The DOE's national laboratories stand ready to champion this enterprise. 
In an address to the United Nations on June 26, 1997, President Clinton stated

The science is compelling and clear: we humans are changing the global climate. Concentrations of greenhouse gases in the atmosphere are at their highest levels in more than 200,000 years and climbing sharply.

....Here in the United States, we must do better. With 4 percent of the world's population, we already produce more than 20 percent of its greenhouse gases.

....In order to reduce greenhouse gases and grow the economy, we must invest more in the technologies of the future. I am directing my cabinet to work to develop them. Government, universities, business, and labor must work together. All these efforts must be sustained over years, indeed over decades.

The President's remarks were made on the occasion of the fifth anniversary of the Rio Conference on the Environment. It was also the beginning stage of the public presentation of the position of the United States at the third conference of the parties to the Framework Convention on Climate Change (FCCC), which will be held in December 1997 in Kyoto, Japan.

The goal of the FCCC is "to stabilize the concentration of greenhouse gases in the atmosphere at a level which would prevent dangerous anthropogenic interference with the climate system." The United States was among more than 150 nations of the world that signed the Convention. While the FCCC established an important goal, it provided only minimal tools with which to achieve that goal. The principal tool is a provision for future meetings of the parties to the Convention. Numerous meetings and negotiations have taken place. The upcoming conference of the parties in Kyoto will be a key event 
because of its focus on developing an international protocol for reducing greenhouse gas emissions.

The United States faces a significant challenge and can play an important role in moving negotiations forward. If global atmospheric $\mathrm{CO}_{2}$ concentrations are to be stabilized in the next century, the United States and other developed nations must reduce their emissions significantly. In addition, the developing nations must limit the increase of their emissions while preserving their legitimate aspirations for economic growth.

In response to the President's direction, this report of the national laboratories of the U.S. Department of Energy (DOE) outlines a broad range of technologies with the potential for reducing greenhouse gas (GHG) emissions and recommends their development as an essential component of a climate change technology strategy.

The focus of this report is reduction of U.S. GHG emissions through the development and application of new technologies. ${ }^{1}$ The report delivers two key messages:

- advances in science and technology are necessary to reduce GHG emissions from the United States while sustaining economic growth and providing collateral benefits to the nation

- success will require the pursuit of multiple technology pathways, providing choices and flexibility for reducing GHG emissions

This document describes technology development efforts that need to extend through the first third of the next century. The impact of these efforts would in fact last much longer. Energy-generating resources have lifetimes of many decades: the Grand Coulee Dam created in the 1930 s continues to produce energy 60 years later. The new technologies introduced through the 30-year planning period of this report would have impacts that would extend throughout the next century.

The success of a technology strategy depends on the successful commercialization of new technologies as well as their development. Commercialization may well require programs and policies to encourage the use of new technologies in the marketplace. For example, with the electric utility sector evolving toward competitive markets, technologies with low emissions and high capital costs may need assistance in competing with technologies with low capital costs but higher emissions. Also, carbon sequestration technologies will not be adopted per se unless that sequestration has an economic value. While this report does not discuss alternative policies, it does recognize that they need to be examined and that a climate change technology strategy needs to consider both technology development and its commercialization (Fig. 1.1).

Both technology development and policy decisions also depend on developing a better understanding of the carbon cycle. Modeling and monitoring of the global carbon cycle are essential to understanding emission reduction requirements and the potential contributions of different technologies and policies. (See Fig. 1.2 in sidebar on page 1-4.)

1 This report does not address the relationship between climate and atmospheric concentrations of GHG, nor does it discuss the reduced GHG emission levels required for achieving specified levels of atmospheric concentrations. 


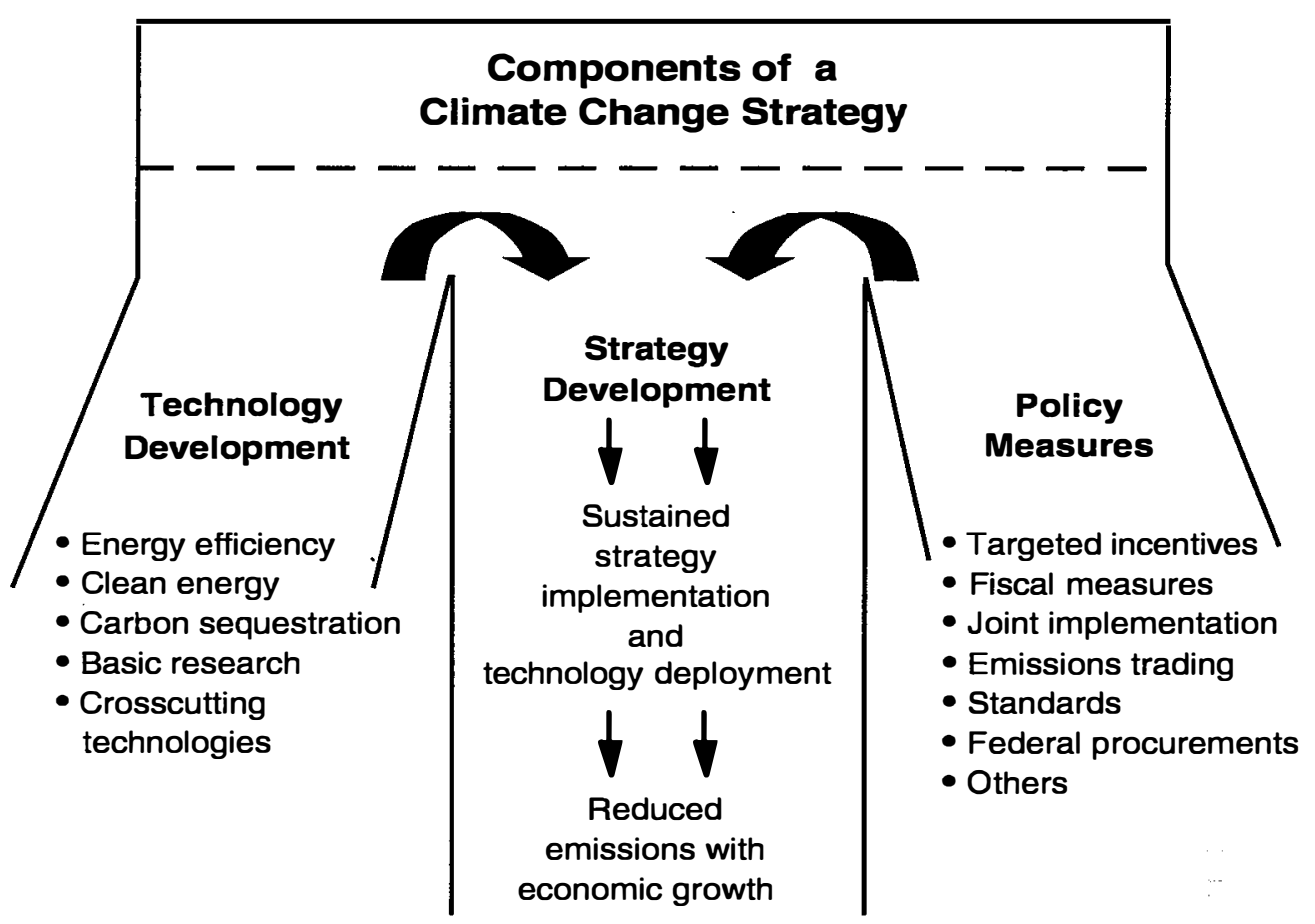

Fig. 1.1. Technology and policy components for a climate change strategy.

The role of this study is to examine the technology basis for a climate change strategy by summarizing the potential of a broad range of technologies to contribute to reducing GHG emissions. It does not discuss or analyze policy measures aimed at reducing GHG emissions. Both advanced technology and policy measures will be needed. The policy measures listed in this figure are for illustration only.

To ensure cost-effective, credible results, a climate change technology strategy also needs to be anchored in science. Much of this science base can be developed by leveraging and expanding existing efforts in the U.S. science and technology complex.

\subsection{GREENHOUSE GAS EMISSIONS AND ENERGY}

In 1995, human activities in the United States resulted in $\mathrm{CO}_{2}$ emissions totaling about 1440 million tonnes of carbon (MtC). Human activity-related (anthropogenic) emissions of other GHGs, such as methane and nitrous oxide, represented the equivalent of another $220 \mathrm{MtC}$. Nearly all of the anthropogenic GHG emissions, about $1500 \mathrm{MtC}$, resulted from energy production and use, primarily the combustion of fossil fuels. Thus the energy sector represents about $90 \%$ of U.S. GHG emissions (EIA 1996a). The GHG emissions related to the sources and uses of this energy are displayed in Fig. 1.3.

These data make it clear that significant reductions in GHG emissions can be accomplished only 


\section{Global Carbon Cycle}

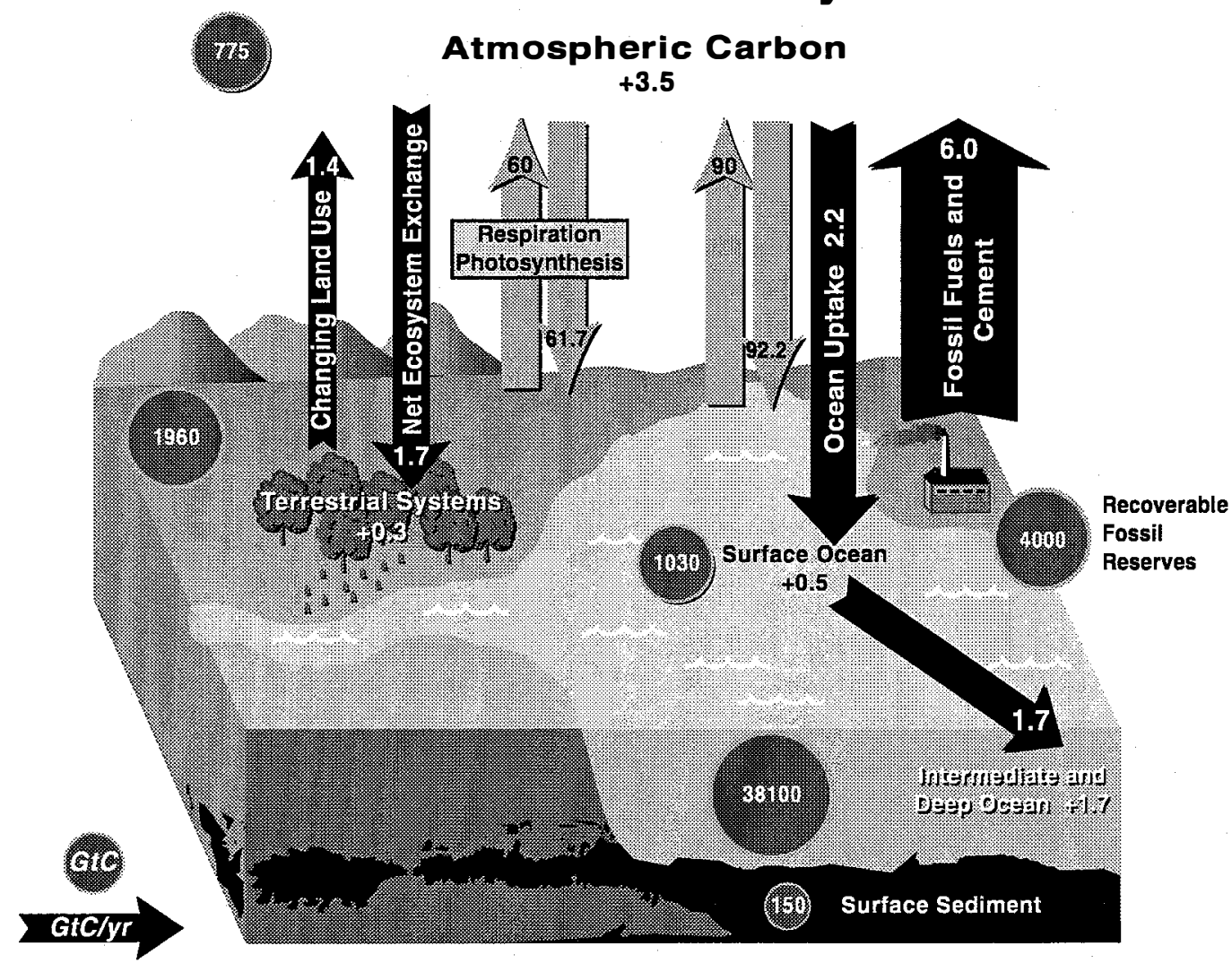

Fig. 1.2. The burning of fossil fuel and changing land use have resulted in human-induced alterations of the global carbon cycle. The solid arrows in this diagram indicate the average magnitude of perturbation in carbon fluxes and the fate of carbon resulting from these activities averaged for the first half of the 1990s. Source: Modified from IPCC 1995.

Human activities contribute to the emission of $7.4 \mathrm{GtC}$ into the atmosphere $(6 \mathrm{GtC}$ from fossil fuel combustion and cement production and 1.4 GtC from land-use changes). These emissions cause an increase of $3.5 \mathrm{GtC}$ in the atmosphere and a 1.7-GtC terrestrial uptake due to the effect of higher $\mathrm{CO}_{2}$ concentrations on photosynthesis and plant growth, resulting in a net increase of $0.3 \mathrm{GtC}$ in terrestrial ecosystems. Oceans take up 2.2 GtC per year, which is distributed throughout the ocean by biological processes combined with advective and diffusive fluxes. In 1997 the atmospheric concentration of $\mathrm{CO}_{2}$ was 363 ppmv. Net fluxes (black arrows) and gross fluxes (gray arrows) are in billions of tonnes of carbon per year. Annual net additions of carbon (shown as + numbers) to the atmosphere, ocean subsystems, and terrestrial systems from anthropogenic sources are in billions of tonnes of carbon per year. Pool sizes (circles) are shown as billions of tonnes of carbon. (Recommended references to this literature are Houghton 1995 and Marland, Andres, and Boden 1977.) 


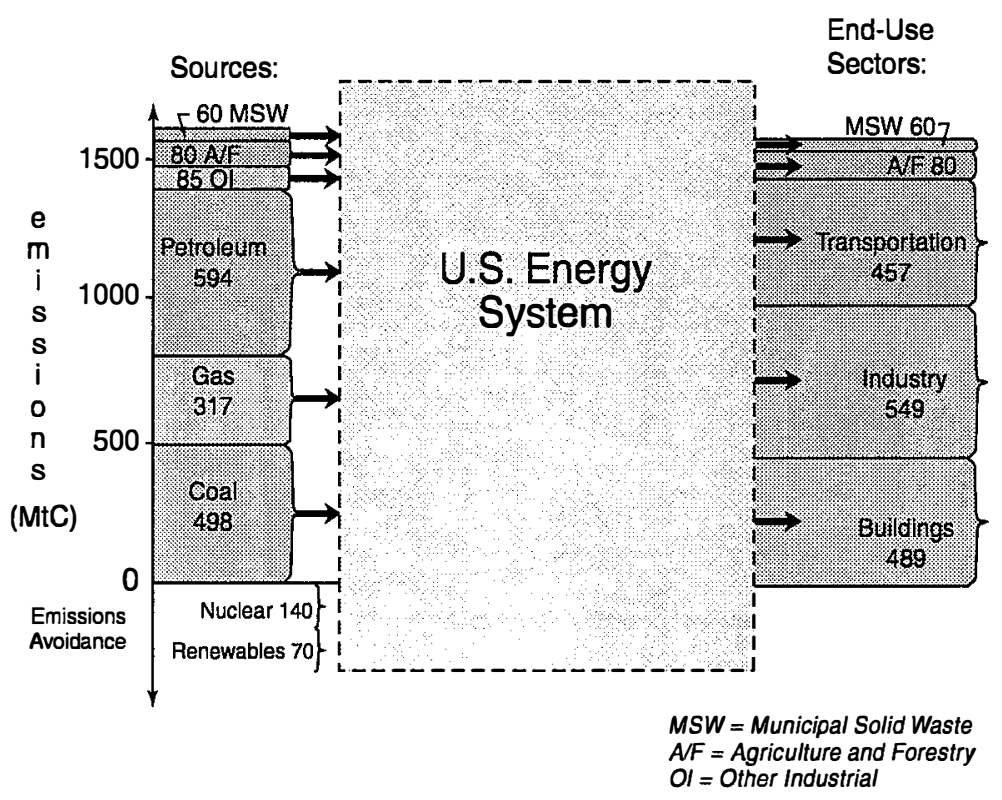

Fig. 1.3. Overview of the sources of carbon emissions in the United States in 1995 (in million tonnes equivalent and including $\mathrm{CH}_{4}$ from MSW, $\mathrm{A} / \mathrm{F}$, and OI). Source: Based on EIA 1996a.

through changes in our energy economy (more effective production, distribution, and use of energy).

\subsection{THE ROLE OF TECHNOLOGY}

A simple equation that expresses carbon emissions in terms of four other parameters provides a good context within which to discuss approaches to reducing carbon emissions:

Net $C=\left[G D P \times(E / G D P) \times\left(C_{\mathrm{a}} / E\right)\right]-S$, where

$$
\begin{aligned}
& \text { Net } C=\text { net carbon emissions } \\
& C_{\mathrm{a}}=\text { anthropogenic carbon } \\
& \text { emissions } \\
& G D P=\text { gross domestic product } \\
& E \quad=\text { total energy use } \\
& S \quad=\text { natural and induced } \\
& \text { sequestration of carbon }
\end{aligned}
$$

Continued economic growth implies that $G D P$, the first factor, continues to rise. Therefore, for the economy to grow while carbon emissions decrease, one or more of the remaining three terms in the equation must change.

$E / G D P$ refers to the "energy intensity" of our economy. It historically has risen as standards of living have improved in the United States. However, between 1973 and 1986, rising energy prices caused the nation's consumption of primary energy to freeze at about 74 quadswhile the GDP grew by $35 \%$ (a quad is 1 quadrillion or $10^{15}$ Btus). As a result of this decrease in energy intensity, nearly 450 MtC in emissions was avoided in 1986. The trend since 1986 has been toward flat or slightly rising energy intensities.

$C / E$ refers to the "carbon intensity" of our energy economy. This ratio has remained fairly constant since 1973, reflecting the transportation sector's continued reliance on petroleum fuels and the slow pace of technological change and capital stock turnover in the electricity sector.

The amount of atmospheric carbon that is removed through natural and induced sequestration, $S$, is the last term in the equation. It represents a third lever that can be used to reduce $\mathrm{CO}_{2}$ levels while at the same time enabling the U.S. economy to grow. These three terms embody distinct technology routes to reducing GHG emissions.

\section{How can energy intensity be}

decreased? Through more efficient use of fossil fuels and electricity from fossil fuel plants, less $\mathrm{CO}_{2}$ is emitted to the atmosphere. Energy-efficient products, 
such as more efficient transportation vehicles and household appliances, provide the same energy services using less fuel or electrical power. Energy requirements can also be reduced through system designs, such as colocating facilities that produce both electrical power and heat (cogeneration systems) with facilities that need them. Such approaches can reduce our national energy intensity without lowering GDP.

\section{How can carbon intensity be} decreased? Carbon emissions from energy production and use can be curbed by increasing the efficiency of energy production or by using fuels that emit less carbon or technologies that use no carbon-emitting fuels, such as nuclear power plants; hydroelectric, wind, and solar power plants; and other renewable energy sources. For example, natural gas emits $14 \mathrm{MtC}$ per quad of energy used compared with $26 \mathrm{MtC}$ per quad for coal. Biomass feedstocks offer an array of low-carbon options, including liquid transportation fuels, chemicals, materials, and electricity. The carbon emissions from biomass combustion are largely offset by $\mathrm{CO}_{2}$ absorption in biomass production (plant growth). Another strategy is to remove carbon from fuels before combustion (decarbonization).

\section{How can carbon sequestration be increased? One approach involves} capturing $\mathrm{CO}_{2}$ after combustion but before it enters the atmosphere and storing it in terrestrial or oceanic repositories that will sequester it over geological time scales. A second approach is to increase the rate at which oceans, forests, and soils naturally absorb $\mathrm{CO}_{2}$ from the atmosphere. Worldwide, human activities have hindered the natural sequestration process through deforestation, soil destruction, and desertification. This trend can be reversed through the development and deployment of advanced technologies.

Of course, there are important relationships among these three approaches. As specific examples, reducing the energy consumed in lighting and building appliances generally also reduces cooling loads; reducing overall electric demand reduces the capital required to meet a fraction of that load with renewables; precombustion removal of carbon from fossil fuels complements both hydrogen production and carbon sequestration; and the science and technologies necessary for sequestration of $\mathrm{CO}_{2}$ in ocean hydrates may also hold the key for economical production of natural gas from the very large gas hydrate deposits that are currently untapped.

To reduce carbon emissions significantly while sustaining economic growth, all three of these technology approaches-decreased energy intensity through energy efficiency technologies, reduced carbon intensity through clean energy technologies, and increased $\mathrm{CO}_{2}$ absorption through increased carbon sequestration-may be needed. They will definitely provide valuable choices and therefore should be pursued.

\subsection{ABOUT THIS STUDY}

This study is focused on the potential role of advanced technologies to reduce $\mathrm{CO}_{2}$ emissions. It presents a survey of a broad range of technology pathways; describes their potential for advances and energy economy contributions that would result from enhanced research, development, and demonstration (RD\&D); and estimates their potential contributions to $\mathrm{CO}_{2}$ emission reductions. 
Note that there are several closely related subjects that this study does not address. First, in estimating carbon emission reductions that advanced technologies might provide, it does not address the role of policy measures to support their adoption. Thus, as examples, it does not discuss such policy approaches as carbon taxes or domestic or international carbon emissions trading programs.

This study also does not discuss the fact that a number of energy efficiency and clean energy technologies are already developed that could make significant contributions to GHG emission reductions through wider adoption. This topic is addressed in the "5-Lab Study," which was also conducted in 1997 (Interlaboratory Working Group 1997). Finally, this study is focused only on potential reductions of $\mathrm{CO}_{2}$, the principal GHG; it does not address reductions in emissions of the other GHGs.

Chapter 2 of this report provides the technological basis for recommending a broad technology development strategy. It provides a credible vision of the technologies that President Clinton is requesting. It discusses the current status of energy conversion and use technologies and their relationship to carbon emissions and then describes, in considerable detail, what can be achieved through technology research and development (R\&D) and what those achievements imply for reducing GHG emissions.

Chapter 3 of this report discusses basic research areas of most relevance to the pursuit of a climate change technology strategy. It also discusses crosscutting technologies that support a number of the technological pathways, and it describes appropriate $R \& D$ for their development.
Chapter 4 recommends establishing strategic public-private $R \& D$ alliances to pursue the RD\&D of GHG reduction technologies. Chapter 5 synthesizes the report's findings and provides recommendations and directions for moving forward.

A technology strategy should be designed to provide a portfolio of technologies that will allow the nation to meet its future emission reduction targets at the least cost to our economy. Both incremental and breakthrough technologies are needed, and basic scientific research is required to provide a foundation for these technological solutions.

New policies and programs will also be needed to ensure the rapid adoption of these technologies in our energy economy.

In developing such a technology strategy, every effort should be made to build on existing information, such as the report by the Task Force on Strategic Energy Research and Development (SEAB 1995) and to coordinate these efforts with closely related activities such as DOE's development of a comprehensive national energy strategy and the national energy strategy review recently completed by the President's Committee of Advisors on Science and Technology (PCAST 1997).

The federal government has a substantial program in energy RD\&D, designed to support the broad national goals of energy security and environmental quality (DOE Strategic Plan draft 1997). Although the existing energy RD\&D programs were not designed specifically to reduce carbon emissions, they will have some benefits for mitigating climate change. The current DOE budget for the 
development of low-carbon energy technologies is approximately $\$ 1$ billion per year. This budget includes the RD\&D portions of DOE's Energy Efficiency and Renewable Energy, Fossil Energy, and Nuclear Energy programs. Federal RD\&D resources, including DOE's Energy Research Programs, are also spent on the basic sciences and crosscutting technologies that undergird the energy technology programs. Additional federal resources of approximately $\$ 1.8$ billion were appropriated in FY 1997 for the U.S. Global Change Research Program. These existing $R D \& D$ programs form the basis for the expanded and accelerated RD\&D efforts outlined here; the financial support needed is discussed further in Chapter 5.

Many other agencies and institutions, national and international, are engaged in related activities. To name just a few, the National Aeronautics and Space Administration has pioneered in global measurements of atmospheric constituents; the National Science Foundation has supported university scientists investigating complex interactions between the sea, atmosphere, and land; the National Oceanic and Atmospheric

Administration has collected essential data; the Environmental Protection Agency has concerned itself with issues of environmental protection and regulation; the Federal Emergency Management Agency is concerned with consequences of climatic variability; and industry and industrial organizations such as the Gas Research Institute and the Electrical Power Research Institute have contributed expertise.

Collaboration of all these contributors, and the many not mentioned, will facilitate a U.S. strategy based on technology. For success, this missionfocused effort must catalyze the scientific and technological expertise of industry, universities, government agencies, and the national laboratories. Therefore, contacts are being made with a broad array of governmental, academic, and industrial institutions, and discussions with them are continuing.

In all, this report provides a solid "technology basis" for a climate change technology strategy. With it, the United States can begin to develop that strategy with the confidence that a strong technology R\&D program will deliver a portfolio of technologies with the potential to provide very substantial GHG emission reductions along with continued economic growth. Clearly, more collaborative planning and analysis are needed to develop and implement the strategy. However, it is vital that the nation carefully plan the role of technology in addressing the climate change issue. We offer this technology report as a key information source to help guide those national policy decisions.

\subsection{REFERENCES}

EIA (Energy Information Administration) 1996a. Emissions of Greenhouse Gases in the United States 1995, DOE/EIA-0573(95), U.S. Department of Energy, Washington, D.C.

EIA (Energy Information Administration) 1996b. International Energy Outlook 1996, DOE/EIA0483(96), U.S. Department of Energy, Washington, D.C.

Houghton, R. A. 1995. "Land-Use Change and the Carbon Cycle." Global Change Biology 1, 275-287. 
Interlaboratory Working Group 1997. Scenarios of U.S. Carbon Reductions: Potential Impacts of Energy-Efficient and Low-Carbon Technologies by 2010 and Beyond, September.

Marland, G., R. J. Andres, and T. A. Boden 1977. Global, Regional, and National $\mathrm{CO}_{2}$ Emission Estimates from Fossil Fuel Burning, Cement Production, and Gas Flaring: 19501994 (revised February 1997).
PCAST (President's Committee of Advisors on Science and Technology) 1997. Federal Energy Research and Development for the Challenges of the Twenty-First Century, U.S. Department of Energy, Washington, D.C., November.

SEAB (Secretary of Energy Advisory Board), (D. Yergin, Chairman) 1995. Energy R\&D: Shaping Our Nation's Future in a Competitive World, U.S. Department of Energy, Washington, D.C. 


\section{TECHNOLOGY PATHWAYS}

Many technological opportunities exist to reduce U.S. GHG emissions. Some involve incremental improvements to existing equipment and processes; others can be realized only through breakthroughs in the fundamental sciences and subsequent technological developments. Some technologies can be translated into market-ready products during the next decade; others may be available as one-of-akind prototypes by 2025 . Some can be inserted into our current energy economy with relative ease; others require major transformations of infrastructure.

This section contains an inventory of climate change technologies. The authors concluded that about 50 technological pathways warrant serious consideration (see Table 2.1 and Appendix B). The pathways are divided into nine technological areas that can be addressed by three major approaches: improving energy efficiency, using more clean energy, and sequestering carbon (Fig. 2.1). Coverage of electric utility technologies is included in the fossil power generation, nuclear energy, and renewable energy areas.

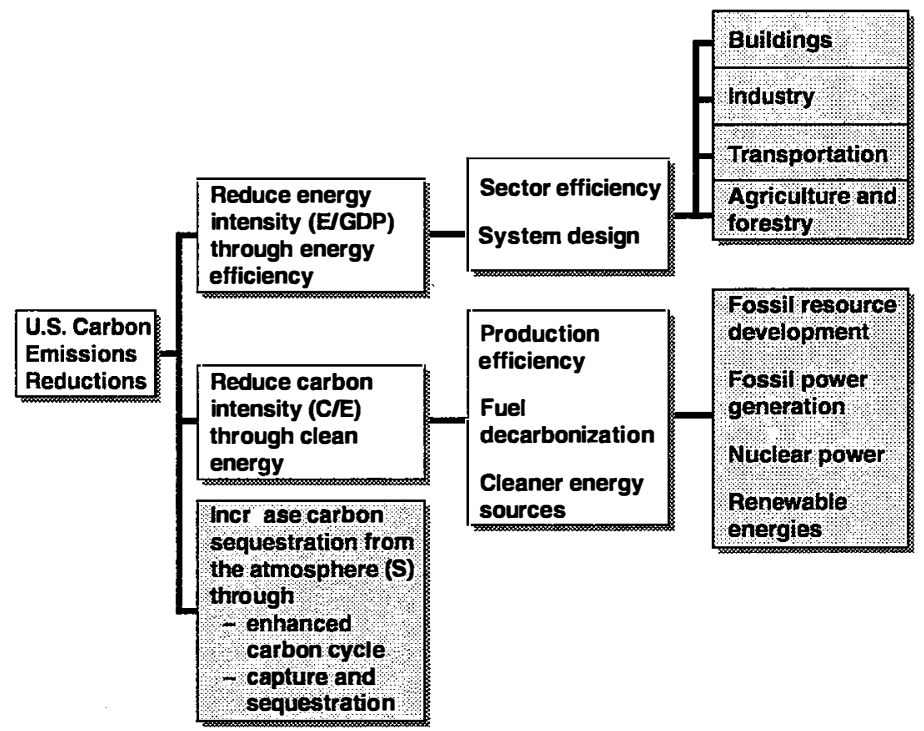

Fig. 2.1. Alternative technological opportunities for reducing greenhouse gas emissions. Electric utility technologies are covered in the fossil power generation, nuclear energy, and renewable energy areas. 
Table 2.1. Technology pathways ${ }^{a}$

1. Buildings

1.1 Equipment and Appliances

1.2 Building Envelope

2. Industry Intelligent Building Systems

2.1 Energy Conversion and Utilization

2.2 Resource Recovery and Utilization

2.3 Industrial Process Efficiency

2.4 Enabling Technologies

3. Transportation

3.1 Advanced Conventional Vehicle

3.2 Freight Vehicles

3.3 Hybrid, Electric, and Fuel Cell Vehicles

3.4 Alternative Fuel Vehicles

3.5 Air and High-speed Ground Transport

4. Agriculture and Forestry

4.1 Conversion of Biomass to Bioproducts

4.2 Advanced Agricultural Systems

4.3 Plant/Crop Engineering

5. Fossil Resource Development

5.1 Energy Efficiency for Crude Oil Refining

5.2 Natural Gas to Liquids

5.3 Increased Natural Gas Production

5.4 Co-production with Integrated Gasification Combined Cycle

5.5 $\mathrm{CO}_{2}$ for Improved Oil and Gas Recovery

6. Fossil Power Generation

6.1 Accelerated Development of High-Efficiency Coal-Based Power Generation Technologies

6.2 Low-Carbon Fuels and High-Efficiency Power Generation

6.3 Ultra-High Efficiency, Zero-Carbon Emission Energyplexes

7. Nuclear

7.1 Lifetime Extension and Generation Optimization

7.2 Next-Generation Fission Reactors

7.3 Fusion Power

8. Renewable Energy

8.1 Biomass Electric

8.2 Wind Energy

8.3 Advanced Hydropower

8.4 Solar Photovoltaics

8.5 Geothermal Energy

8.6 Solar Thermal Electric and Buildings

8.7 Biomass Transportation Fuels

8.8 Solar Advanced Photoconversion

9. Carbon Sequestration and Management

9.1 Augmented Ocean Fertilization to Promote Additional $\mathrm{CO}_{2}$ Sequestration

9.2 Advanced Chemical and Biological Conversion and Sequestration

9.3 Terrestrial Storage of $\mathrm{CO}_{2}$

9.4 Carbon Sequestration in Soils

9.5 Elemental Carbon Sequestration

9.6 Ocean Storage

\footnotetext{
This table does not include basic research needs (i.e., global carbon cycle modeling and measurement, materials science, chemical sciences, biotechnology, geosciences, environmental and ecological sciences, and nuclear sciences) and enabling technologies (hydrogen and fuel cells, electrical transmission, distribution, and components, sensors and controls, and energy storage) needed to support the technology pathways (see Chap. 3).
} 


\subsection{CARBON LEVELS: PRESENT AND FUTURE}

The sources of carbon emissions in the United States must be understood before characterizing the potential benefits of technologies to reduce GHG emissions. For example, in 1995, most anthropogenic (human activity-related) $\mathrm{CO}_{2}$ emissions in the United States were caused by the combustion of coal, natural gas, and petroleum. A fraction (less than $2 \%$ ) came from other sources, including the manufacture of cement and lime. Figure 2.2 shows how these primary fuels are transformed to provide energy and products that are ultimately consumed in homes, office buildings, factories, cars, trucks, and farms.

Energy Efficiency. In 1995, the three major end-use sectors (buildings, industry, and transportation) emitted approximately equivalent levels of carbon. However, the sources of this carbon vary widely. For instance, $80 \%$ of the carbon emissions attributable to the energy used in buildings comes from electricity, whereas $99 \%$ of the energy used for transportation comes directly from consumption of petroleum products. Energy consumption in each of the end-use sectors has grown during the past decade at about the same rate as the nation's GDP, causing significant increases in carbon emissions. The increases illustrate the importance of reducing the amount of energy consumed per unit of economic output, or "energy intensity," of our economy (see Chap. 1). Technology that increases energy efficiency is the key to achieving this goal. It can reduce the energy used per square foot of home or office space, the energy required per unit of industrial output, and the energy consumed per vehiclemile traveled. Through advances in technology, these energy intensities can be decreased without sacrificing any of the services that energy provides.

Clean Energy. "Clean energy" technologies can decrease the amount of carbon produced per unit of energy, or "carbon intensity," of the nation's energy economy. In 1995, coal, natural gas, and a small amount of petroleum were responsible for $494 \mathrm{MtC}$ of emissions in the electricity industry (Fig. 2.2). Nuclear power and renewable sources can be credited with displacing what would have been an additional 140 and $70 \mathrm{MtC}$ of carbon emissions, respectively, if fossil 
fuels had been used. As a result, the electricity sector produced only $0.17 \mathrm{MtC}$ per terawatt hour (TWh), instead of $0.26 \mathrm{MtC} / \mathrm{TWh}$. Switching to low-carbon fuels for transportation is an important means of reducing carbon emissions; for instance, biofuels can replace petroleum-based liquid fuels. Another option for reducing carbon intensity involves fuel decarbonization, in which carbon is removed from fuel and sequestered before the fuel is used. Improving the efficiency of producing energy from fossil fuels is also important.

Carbon Sequestration. Carbon sequestration is another technological route to reducing the magnitude and impacts of U.S. carbon emissions. One approach is to sequester $\mathrm{CO}_{2}$ emissions captured during fossil fuel conversion processes, thus preventing their release into the atmosphere. A second approach is to increase the absorption of $\mathrm{CO}_{2}$ by either the oceans or the terrestrial biosphere.

Synergies and Integrations. While these three approaches of energy efficiency, clean energy, and carbon sequestration are convenient for discussion, the synergies and interdependencies among them and among sectors must be considered as well in further development of a technology strategy. For example, the carbon reductions that result from energy efficient technologies depend on the carbon content of the energy that is being displaced, and reductions from the use of electric vehicles depend on the carbon content of the electricity generated. If electricity continues to be generated largely by inefficient coal plants, end-use efficiency improvements will produce sizeable carbon reductions. Greater reliance on electricity from renewables or nuclear reactors will reduce the carbon benefits resulting from energy efficiency.

Some interactions are potentially positive. Fuel cells using methane require that carbon and hydrogen be separated anyway, so there would be no separation cost in sequestering the carbon. Some interactions are potentially negative, such as the possibility that the heavy use of natural gas for low-carbon electricity production and cogeneration could increase prices for natural gas, if not paired with more efficient natural gas consumption in buildings and industry. Also, increases in energy efficiency can cause lower prices, which can increase demand and potential carbon emissions. Some interactions make it possible for certain technologies to be more effectively adopted, such as integrating intermittent renewables such as solar thermal electric with IGCC using natural gas.

A potentially dramatic synergy is expected between non-carbon electricity generation (e.g., solar, wind, biomass, and nuclear) and vehicles using electricity or hydrogen produced from electricity. The large but flexible electricity demand these technologies could represent $(25-50 \%$ of the electricity market) would enable large reductions in energy storage needed for intermittent renewables to become widely adopted.

This report does not examine these types of synergies in depth, but some examples include the pathways for energyplexes (Fossil Power Generation), resource recovery and utilization (Industry), and hydrogen (Crosscutting). Other integrated systems are mentioned in Chap. 5, Synthesis and Moving Forward. 


\subsection{STUDY METHODOLOGY AND ASSUMPTIONS}

Participants. Compiling detailed information on the potential of a wide range of energy-related technologies to reduce $\mathrm{CO}_{2}$ emissions required the expertise and judgment of a large number of individuals. The laboratory directors first identified representatives from each of the 11 labs involved in this study. These representatives defined the 11 technology areas that formed the structure of the study (9 categories of technology pathways plus crosscutting enabling technologies and related areas of basic research). Each representative then assumed responsibility for a working group corresponding to one of the 11 areas. Each working group, consisting of relevant experts from the various laboratories, identified the individual technology pathways appropriate to its technology area as listed in Table 2.1 and prepared the pathway drafts.

Overall direction for the study was provided by the laboratory directors through a coordinating committee and the group of lab representatives. The coordinating committee and lab representatives provided guidance and assumptions to the working groups for developing the desired information and took on the task of summarizing the information into the main report. Participants in these groups are listed in Appendix A.

In addition, a small focus group served an important role in the overall study methodology by carefully reviewing all of the technology pathways for consistency and credibility and then interviewing their authors to ensure that the material presented had a firm technical basis and had been developed in a reasonable way. This process included ensuring that the guidelines for developing the carbon emission reduction estimates and the risk factor scores had been followed.

The assumptions for the study are given in detail in the introduction to Appendix B and summarized here. In general, the working groups relied upon Delphi method principles to reach their conclusions about the technology pathways. Conditions and assumptions not defined herein were based on a consensus of the working group members.

Information Considered. The technology pathways provide detailed information describing the technology: its developmental status and outlook for technological progress through RD\&D, recent successes, commercialization and deployment prospects, potential benefits and costs, various types and levels of risks the technology faces, and recommendations for federal actions. The potential benefits and costs were quantified, under common assumptions, in terms of the estimated carbon emissions reductions in each of the next three decades and a general estimate of what levels of federal RD\&D support might be needed to fully develop the individual technology pathways over the next three decades.

It is important to note that the descriptive text and the numerical estimates presented in these pathways are based on the judgment of teams from the 11 participating national laboratories (in some cases in collaboration with experts from other organizations across the country). Some of the numerical estimates were supported by analysis; others were simply the best estimates of experts based on available information. The estimates for each technology area were developed independent of the other technology areas; competition 
and interactions among the technology areas were not considered. Therefore, summing carbon reduction estimates from different technology areas would lead to "double counting."

The time frame of this study did not allow analysis of all of the various factors that could affect the performance and market penetration of a new technology. However, the study has compiled a considerable amount of information on a wide range of factors and has taken this information into account in estimating carbon reductions and in drawing conclusions. The working groups and other teams considered the following factors:

- Size of domestic and international markets for the technology

- Turnover rate of capital stock

- Technical risks associated with the RD\&D

- Size of the federal RD\&D resources required

- Magnitude of the technology's capital and operating costs

- Extent of changes in infrastructure required for commercialization

- Size of the resource base available to support the technology

- Technical, commercial, ecological, human health, economic and regulatory risks associated with the development and use of the technology

- Characteristics of competing technologies

The timeframe of the study also did not allow for the important process of prioritizing the technology areas and pathways; thus the study recommends that some type of prioritization be included in the development of a detailed and comprehensive technology strategy for reducing greenhouse gas emissions.
Reference Case. All carbon emission reductions are relative to the "business as usual" scenario outlined by the DOE EIA (Fig. 2.3 and Table 2.2). This scenario assumes that some efficiency and process improvements will offset what would otherwise be a larger rate of $\mathrm{CO}_{2}$ increases. The rise in emissions is driven by a forecasted GDP growth rate of $1.9 \%$. (Underlying this growth rate is the assumption of sustained economic growth and an increasing population.) Without a major intervention, $\mathrm{CO}_{2}$ emissions will increase by almost $50 \%$ from the current annual level of approximately 1.4 billion MtC to about 2.1 billion MtC in 2030 .

The data shown in Fig. 2.3 and Table 2.2 for the period 2015 to 2030 are based on extrapolations of the EIA reference case for 2015. Thus they do not take into account the significant reduction in nuclear power that could occur after 2015 if nuclear power plants are retired according to their current license expiration dates.

Federal Policies. One of the key features of these carbon emission reduction estimates is that they assume no significant changes in existing market policies that would

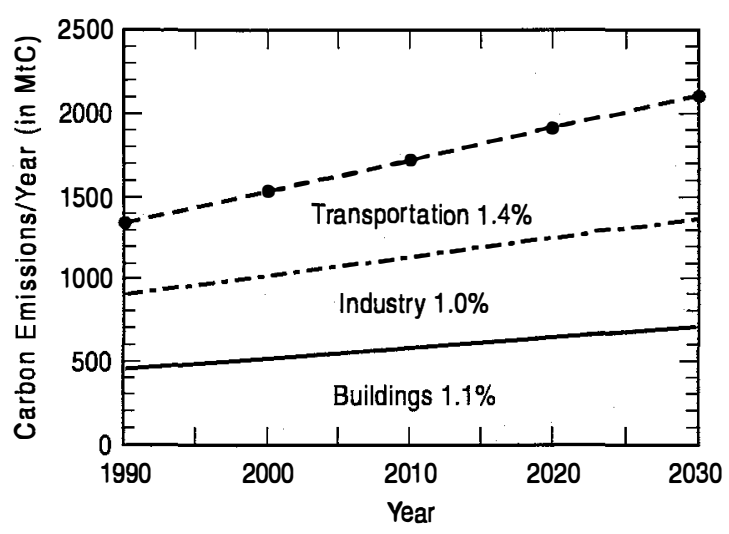

Fig. 2.3. Projected U.S. carbon dioxide emissions (in MtC per year). Source: Based on EIA 1996 b. 
Table 2.2. U.S. carbon dioxide emissions by end-use sector (in MtC per year)

\begin{tabular}{|c|c|c|c|c|c|c|c|}
\hline & \multicolumn{4}{|c|}{ Emissions } & \multicolumn{3}{|c|}{ Change from 1990} \\
\hline & 1995 & 2010 & 2020 & 2030 & 2010 & 2020 & 2030 \\
\hline \multicolumn{8}{|l|}{ Buildings } \\
\hline Fossil & 159 & 170 & 178 & 185 & 22 & 30 & 37 \\
\hline Electricity & 335 & 406 & 463 & 515 & 94 & 151 & 203 \\
\hline Subtotal & 494 & 576 & 641 & 700 & 116 & 181 & 240 \\
\hline \multicolumn{8}{|l|}{ Industry } \\
\hline Fossil & 293 & 335 & 357 & 380 & 49 & 71 & 94 \\
\hline Electricity & 171 & 213 & 241 & 269 & 47 & 75 & 103 \\
\hline Subtotal & 464 & 548 & 598 & 649 & 96 & 146 & 197 \\
\hline \multicolumn{8}{|c|}{ Transportation } \\
\hline Fossil & 464 & 591 & 655 & 727 & 160 & 224 & 296 \\
\hline Electricity & 1 & 7 & 10 & 14 & 6 & 9 & 13 \\
\hline Subtotal & 465 & 598 & 665 & 741 & 166 & 233 & 309 \\
\hline \multicolumn{8}{|l|}{ Total } \\
\hline Fossil & 918 & 1096 & 1189 & 1291 & 231 & 324 & 426 \\
\hline Electricity $^{a}$ & 506 & 626 & 714 & 798 & 147 & 235 & 319 \\
\hline Total & 1424 & 1722 & 1904 & 2089 & 378 & 560 & 745 \\
\hline
\end{tabular}

a The extrapolation beyond 2015 does not take into account the significant reduction in nuclear power that could occur as nuclear power plants are retired according to their current license expirations. Recent results of a new forecast by the Energy Information Administration suggest that carbon emissions will grow at a slightly faster pace through the year 2015. This new forecast is not yet published and is therefore not used in this report. In any event, using the new forecast would not substantially change the results of this report.

Sources: The carbon estimates for 1995 and the forecast for 2010 are taken directly from the Reference Case of EIA 1996a. Carbon emissions for 2020 and 2030 are forecasted using the same growth rates as for 2010. Electric utility emissions are distributed across sectors. GHGs other than $\mathrm{CO}_{2}$ are not included.

affect adoption of advanced technologies. For example, policies such as tax incentives or rebate measures that encourage energy efficiency or clean energy technologies, or carbon charges or carbon emissions trading programs, could provide both additional and earlier reductions in carbon emissions.

Restructuring. The data in Fig. 2.3 and Table 2.2 also do not take into account any long-term impacts that might be precipitated by restructuring of the electric utility industry. If restructuring produces lower electricity rates, energy use will increase and investments in conservation technologies might decrease, with a concomitant rise in GHG emissions.

On the other hand, future utility restructuring legislation calling for renewable portfolio standards and public benefits programs could significantly promote clean power, thereby reducing GHG production. The deregulation issue underscores the uncertainties faced by developers and consumers of advanced energy technologies. Such uncertainties tend to dampen private-sector investments in research on advanced technologies, making the role of government-funded RD\&D that much more critical. In general, the competitive market forces that accompany utility restructuring 
are significantly reducing utility sector investment in $R \& D$, and the focus of that R\&D is shifting to nearterm results and becoming less strategic.

The introduction to Appendix B further discusses the methodology and assumptions relevant to the study. The remaining sections of this chapter describe the nine technological areas that constitute the menu of technological opportunities identified in this report (Fig. 2.1). We note the following for each area:

- the magnitude of carbon-emission reductions that could be realized as a result of successful development and subsequent market adoption of the technologies, without any significant policy changes

- the specific pathways and related scientific and technological challenges that must be met

- the technical, market, and other risks associated with pursuing the technological area

- anticipated collateral benefits

- recommended strategies for moving forward

\subsection{ENERGY EFFICIENCY}

Improving the efficiency of energy use in the United States by developing advanced technologies can offer immediate, significant carbon reductions. Incremental and breakthrough technologies hold the promise of buildings that consume half the energy of current new construction, industries (such as forest products) that can meet all of their energy needs internally, cars that offer three times the fuel economy of current vehicles, and farms that are more productive and enable greater carbon fixation while using less energy.
Many technological opportunities exist for improving the efficiency of the U.S. economy. These are described in the following sections, by end-use sector:

- buildings

- industry

- transportation

- agriculture and forestry

\subsubsection{Buildings}

\section{The Potential for Reduced Emissions}

The buildings sector in the United States accounts for $36 \%$ of the nation's use of primary energy. Buildings are responsible for $66 \%$ of electricity use and $37 \%$ of natural gas use. In 1995 , the energy consumed in the buildings sector accounted for emissions of $489 \mathrm{MtC}$, and this is forecasted to increase to $576 \mathrm{MtC}$ in 2010 and to $700 \mathrm{MtC}$ in 2030. Thus the buildings sector is key to constraining or reducing the nation's use of energywhether the concern is GHG emissions and global climate change, urban and regional air quality, energy security, sustainable development, or any number of other concerns associated with energy use. Also, the "human dimensions" must be kept in mindbuildings exist to house the myriad needs and activities of our civilization: shelter, community involvement, relaxation, office work, industrial processes, and the like. Energy only serves to help meet these needs. Within this broad context, the following are technological approaches for reducing GHG emissions associated with buildings:

- reducing electricity use through energy efficiency measures and thereby reducing GHG emissions from fossil fuel power plants

- reducing natural gas and oil use for space and water heating and other 
domestic uses through energy efficiency measures and thereby reducing on-site GHG emissions

- generating electricity on site and/or providing space and water heating using measures that are inherently more efficient than conventional ones (e.g., advanced cogeneration concepts) or that do not emit GHGs (e.g., building-integrated photovoltaic systems and solar hot water systems).

The status of various building energy technologies and their potential to reduce GHG emissions by the year 2010 are covered in the report Scenarios of U.S. Carbon Reductions: Potential Impacts of Energy-Efficiency and Low-Carbon Technologies, by a group representing five national laboratories (Interlaboratory Working Group 1997). Most of the technological opportunities presented in the following table would have an actual impact on emissions by the year 2020, although in some cases the impacts would not occur until 2030.

Estimated carbon emissions reductions

\begin{tabular}{lccc}
\multicolumn{4}{c}{ (MtC/year) } \\
\hline & 2010 & 2020 & 2030 \\
\hline Total buildings & $25-50$ & $50-100$ & $75-150$ \\
\hline
\end{tabular}

Assumes successful technology development and subsequent marketplace adoption without significant policy changes.

\section{Technology Pathways and Opportunities}

Equipment and Appliances. By definition, all primary energy used in buildings is consumed by equipment that transforms fuel or electricity into end-uses, such as delivered heat or cooling, light, fresh air, vertical transport, cleaning of clothes or dishes, information management, or entertainment. The overall efficiency of this transformation depends largely on the efficiency of the equipment itself.

Numerous opportunities exist to develop equipment that is much more efficient than that currently available. Just a few examples of exciting new prospects include gas heat pumps with twice the efficiency of today's residential furnaces, distribution systems that deliver $50 \%$ more conditioned air, highly efficient lamps with long lifetimes, full-size refrigerator-freezers that use as little power as a 40-W light bulb, fuel cells in the garage, photovoltaics systems integrated into the building envelope, and flat panel displays to replace cathode ray tubes.

Efficient components, by themselves, are not enough, however. It is equally important to ensure that the equipment is properly sized to meet the load, that its operation conforms to varying demands (i.e., controls that vary output as load varies and that minimize standby losses), and that individual pieces of equipment are intelligently integrated into a multifunction unit or into a total building system (to exchange and reuse heat, balance electrical demand, or combine functions to share the use of burners or compressors).

The Building Envelope. The building envelope provides fundamental thermal load control for a building. Walls, roofs, and floors block or delay the flow of heat between a building's interior and exterior. Windows can also block heat flow, provide daylight, transmit solar energy, and provide a view of the outside. High-capacitance internal walls, ceilings, and floors can provide thermal storage that reduces energy use by storing solar energy and reduces peak loads by balancing energy use over a 24-hour period. Improvements in the energy performance of these building 
elements reduce energy use in buildings and thereby reduce GHG emissions.

Decreasing the building thermal load reduces the need for heating and cooling energy. These emerging building envelope technologies will significantly reduce building energy use:

- super insulation, based on vacuum principles

- new-formula high-efficiency foam insulation that uses no CFCs or hydrochlorofluorocarbons

- advanced gas-filled, multipleglazing, low-emittance windows and electrochromic glazing

- self-drying roofs

- passive solar components

- durable high-reflectance coatings

- advanced thermal storage materials

Intelligent Building Systems. The process of designing, constructing, starting up, controlling, and maintaining building systems is very complex. If it is done properly, the final product delivers comfort, safety, and a healthy environment and operates efficiently at reasonable cost. If any part of this process breaks down, the product fails to deliver these benefits. The lost health and productivity in office environments alone costs U.S. businesses over $\$ 400$ billion per year (Cramer-Krasselt Research 1996). In addition, operating these "broken" systems is estimated to cost at least $30 \%$ of commercial building energy use (more than $\$ 45$ billion). The key to designing and operating buildings efficiently is the ability to manage information, deliver it in a timely manner to the proper audience, and use it effectively for building design and operation. More intelligently designed and operated buildings use energy more efficiently and thus reduce GHG emissions.
In the intelligent building systems concept, data from the design of the building, together with sensed data, will be used to automatically configure controls and commission (i.e., start up and check out) and operate buildings. Control systems will use advanced, robust techniques based on smaller, cheaper, and more abundant sensors than are in use today. Intelligent devices will use this wealth of data to ensure optimal building performance by continuously controlling and recommissioning building systems using automated tools that detect and diagnose performance anomalies and degradation. Such systems will optimize operation across building systems, inform and implement energy purchasing, guide maintenance activities, and report building performance while ensuring that occupant needs for comfort, health, and safety are met at the lowest possible cost.

Such human factors as productivity, health, comfort, safety, and aesthetic acceptance can serve as barriers to advanced technologies that adversely affect (or are perceived to adversely affect) these factors. Conversely, technology options that take these factors into account in a positive way (e.g., cause productivity to increase in an office) will be accepted quickly in the market. Most buildings are in an urban or suburban environment; they affect their local community and are affected by it. Thus research on human factors and community systems is a necessary complement to application of energy-efficient technologies if their full potential for reducing GHG emissions is to be realized. The research on intelligent building systems will also require considerable investment in whole-building demonstrations. 


\section{Collateral Benefits}

DOE has a remarkable record of "success stories"-cases of federally supported R\&D leading to products in the marketplace that have resulted in substantial energy and cost savings. Electronic ballasts for fluorescent lighting, low-emissivity windows, design tools, and advanced HVAC equipment are examples of products resulting from $R \& D$ for which the reduction in life-cycle costs from reduced energy use more than compensates for the increase (if any) in first costs. These products have reduced energy costs to consumers by an estimated $\$ 28$ billion through 1996 , many times the cost of all federal R\&D on buildings. Additional benefits typically result from energy-efficiency improvements in buildings, including improved indoor air quality, public health and safety, and worker productivity.

\section{Technical Risks and Other Issues}

The risks associated with a broadly based research program (technical, economic, commercial, ecological, human health, and regulatory) tend to be low, or can be kept low if proper regard is given to these topics in the research program. A building consists of many components and systems that affect energy use. Therefore, a research line that leads to a technical or economic success is likely to more than compensate for a line that is not successful. The historical experience of federal building energy R\&D indicates substantial successes leading to important commercial products that have enabled large reductions in energy use and GHG emissions. There is every indication that continued R\&D will lead to continued commercial success.
The ecological impact of buildings energy use is associated with (1) direct emissions of air pollutants from combustion devices and (2) resource extraction, conversion, transport, and the waste streams of conventional energy sources. Energy efficiency and renewable energy measures that reduce GHG emissions will also reduce the ecological impacts. Regulations can either impede or accelerate the introduction of advanced energy technologies in buildings. For example, energyefficient appliance and building standards are credited with substantial energy savings.

Basic research is very important to buildings technology advances. Areas include "smart" materials for controlling energy flows; optical, thin film, and semiconductor materials for advanced windows, lighting, and flatpanel displays; and advanced techniques for heat transfer.

\section{Strategy and Recommendations}

The report Scenarios of U.S. Carbon Reductions: Potential Impacts of EnergyEfficiency and Low-Carbon Technologies indicates that by the year 2010 a highenergy-efficiency case in the building sector could reduce energy consumption in buildings from 33.7 quads in 1997 to 32 quads in 2010 (relative to the business-as-usual forecast of 36 quads), at a net economic benefit to consumers, if very vigorous efforts are made to bring energyefficient technologies into widespread market acceptance. A vigorous $R \& D$ program is essential to achieve some of the efficiency gains by 2010 and to develop advanced technological options that are cost-effective in the longer term. 


\subsubsection{Industry}

\section{The Potential for Reduced Emissions}

Industry's efficient use of energy is critical to the U.S. economy. Through efficient use of energy, the industrial sector also can be a direct contributor to reducing GHG emissions. Industry consumed 34.5 quads of primary energy in 1995-about 38\% of all energy used in the United States. It was responsible for emitting the equivalent of $549 \mathrm{MtC}$ during that same year (297 MtC from fossil energy consumption, $167 \mathrm{MtC}$ from electricity consumption, and $85 \mathrm{MtC}$ from other industrial emissions). About $83 \%$ of industrial energy is used in the manufacturing sector. Nonmanufacturing industriesincluding mining, oil and gas extraction, construction, and agriculture-account for about $17 \%$. Within manufacturing, about $80 \%$ of the energy used is consumed by a total of just seven highly energy-intensive materials and process industries; the other $20 \%$ is consumed by industries primarily engaged in fabrication and assembly. EIA projects that industrial sector end-use energy consumption will remain roughly constant (between 29.1 and 34.4 quads) in the year 2015 even with economic growth. In the longer term, technological advances will play a key role in reducing industrial energy use and GHG emissions. Experts believe that it is possible for some industries (e.g., forest products) to meet all of their energy needs internally by 2010 without purchasing from outside sources.

EIA forecasts that industrial energy efficiency will improve in the future, contributing to the expected decline in energy intensity. The major factors are gradual restructuring of industry toward knowledge-intensive rather than materials-intensive products, higher-capacity use because of improved computer controls, gains in process efficiency, and just-in-time manufacturing methods. Increased onsite power generation using materials currently sent for disposal and noncombustion technologies, such as fuel cells and gasification, will also play a crucial role in reaching energy reduction targets in the industrial sector. Within manufacturing, materials and process industries account for about $80 \%$ of the hazardous and toxic wastes and about $95 \%$ of nonhazardous wastes. These wastes often impose high cleanup and disposal costs but offer the potential for recovering the "embedded" energy and materials value.

Energy remains an important driver of investment and operating decisions for materials and process industries because of their intensive energy use. Industry spent approximately $\$ 104$ billion on energy in 1993 and approximately $\$ 29$ billion for pollution abatement and control. Although this cost represents less than $5 \%$ of total costs of operation for all industry, the percentage of costs attributable to energy and waste ranges from about $7 \%$ to more than $30 \%$ for materials and process industries. It is clear that industry will deploy an energyreducing technology or process only if it can see the economic benefits. Where such a combination of favorable economics, energy savings, and waste reductions is recognized, the chance of seeing the technology implemented and achieving GHG reductions increases markedly because of accelerated penetration of technologies into the market.

DOE has targeted for its collaborative $R \& D$ program the seven materials and process industries (forest products, chemicals, steel, aluminum, metal casting, glass, and petroleum refining). 
To plan and direct its research effectively, DOE has initiated the Industries of the Future (IOF) program, which encourages industries to identify their collective high-risk, high-payoff technology needs. This analysis allows DOE and other federal $R \& D$ organizations (in particular the Department of Commerce-National Institute of Standards and Technology Advanced Technology Program) to align their resources to best meet those needs. Using this same process, technologies for reducing GHG emissions will be developed in collaboration and cost-shared by industry, thus ensuring accelerated implementation and deployment in industrial processes.

An analysis of the current programs indicates that when implemented, the technologies currently being researched with industrial participation could lead to the following annual reductions.

Estimated carbon emissions reductions (MtC/year)

\begin{tabular}{lrrc}
\hline & 2010 & 2020 & 2030 \\
\hline Total industry & $25-50$ & $65-95$ & $100-140$ \\
\hline
\end{tabular}

Assumes successful technology development and subsequent marketplace adoption without significant policy changes.

Technologies developed through the IOF process and crosscutting technologies under development are likely to be adopted by the seven energy-intensive industries, other nonmanufacturing industries, and, in some cases, all sectors of the U.S. economy. For example, advanced turbine systems (ATSs) are highefficiency, next-generation gas turbines that produce less carbon per kilowatt hour than technologies used in conventional power markets. ATS deployment will reach an electricgenerating capacity of an estimated 24 to $27 \mathrm{GW}$ ( 4 to $6 \mathrm{MtC}$ ) by 2010 . Through the National Industrial

Competitiveness for Energy,

Environment, and Economics program, which DOE is conducting with a more than $55 \%$ industry cost share, innovative technologies are introduced in industrial processes, leading to wider use of these technologies. Full deployment of these technologies (currently in their demonstration stage) is expected to result in energy savings of more than 1 quad by 2010 .

\section{Technology Pathways and Opportunities}

The industrial sector is extraordinarily complex and heterogeneous. The needs are diverse: hundreds of different processes are used to produce millions of different products at many locations throughout the United States. In the U.S. chemicals industry alone, more than 70,000 products are produced at more than 12,000 plants. The primary opportunities to reduce GHG emissions exist in the technologies identified in the IOF program. In addition, redesign of whole facilities with a view toward environmental and energy performance can accelerate the objective of reducing GHGs by completely eliminating some of the production steps now deemed necessary. This new way of thinking may also involve designing for the environment in all steps along the way, from extraction of raw materials through the production stages to the consumption stage.

More than $90 \%$ of the carbon emissions from the industrial sector are associated with the conversion and use of energy. Reviewing the industrial needs and opportunities that lie ahead, four major technological pathways have been identified. Figures 2.4 and 2.5 illustrate the relationship among them for the industrial sector. 


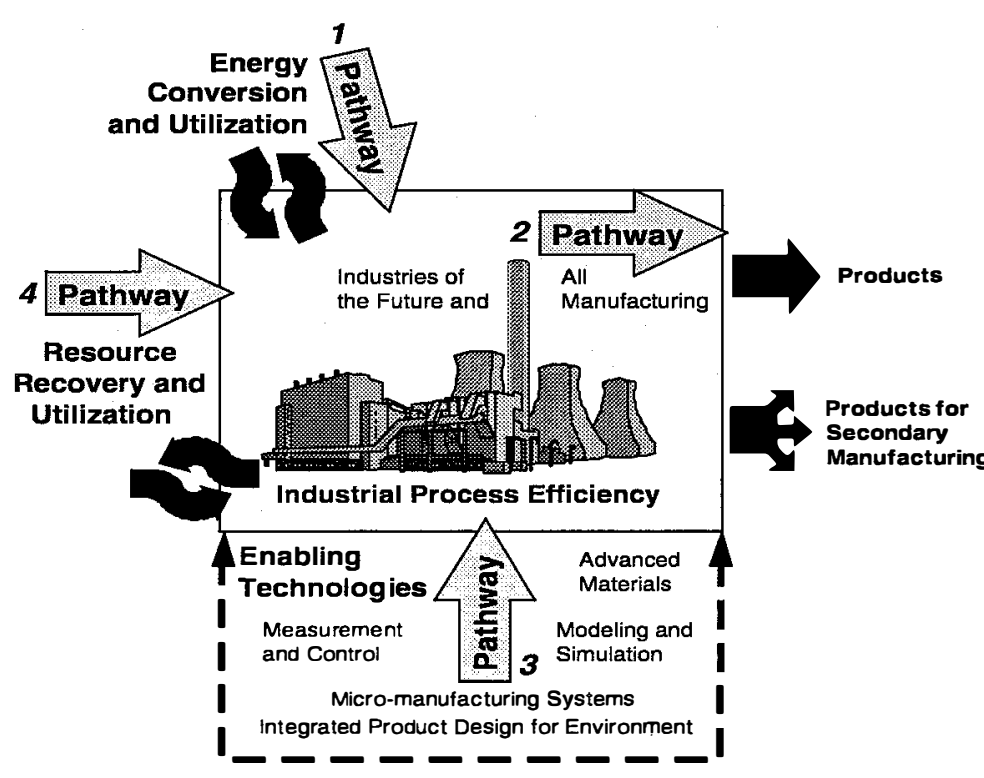

Fig. 2.4. Four technology pathways to increased industrial efficiency.

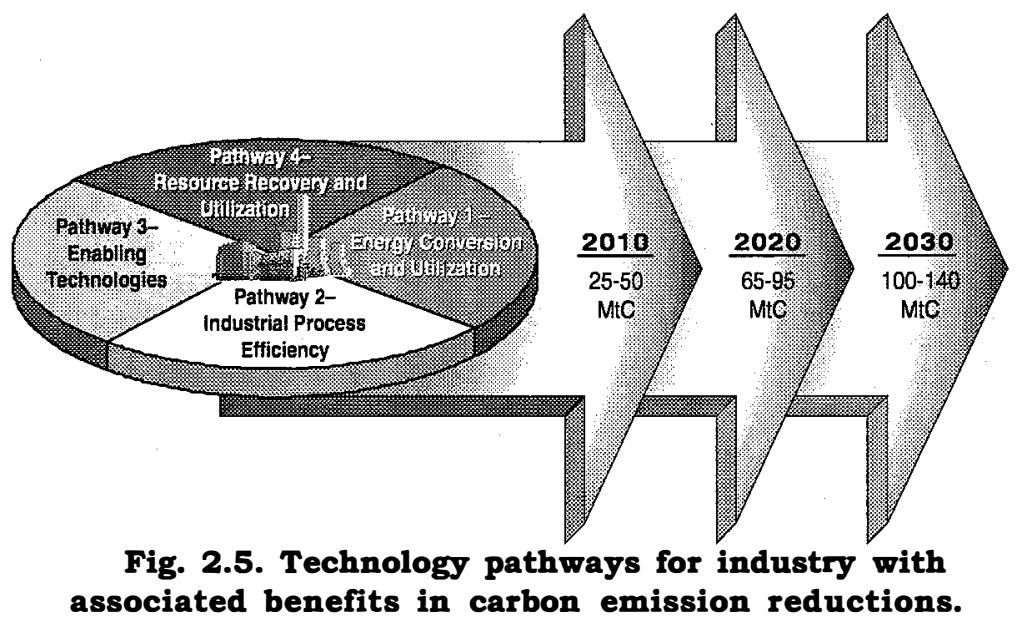

plant residues (e.g., black liquor in the forest products industry).

Biobased materials are also discussed under Agriculture and Forestry (Conversion of Biomass to Bioproducts) and Renewable Energy (Solar Advanced

Photoconversion). Carbon reduction estimates are included only under Conversion of Biomass to Bioproducts.

Industrial Process Efficiency. Emissions from energy use in industrial processes can be substantially reduced by developing new, more efficient processes as well as by the energy conversion processes mentioned earlier. These more efficient processes can encourage new, higherquality products, while generating less waste and fewer undesirable by-products; they also offer the potential for increased economic growth. DOE is pursuing many opportunities for

\section{Energy Conversion and Utilization.} Energy efficiency could be improved through incorporating the best technologies in a systems approach. Technologies include ATSs, fuel cells, higher combustion efficiencies, and using thermal energy in a systems approach to mill/plant design. In the longer term, noncombustion technologies are likely to have a significant impact, such as fuel cells and gasification of biomass and in- improving process efficiency via more selective catalysts, advanced separations, improved measurement and control systems, improved materials, and improved electric motor systems, such as large motors with superconductivity wires. A particularly attractive longer-term opportunity is the use of biotechnology and bioderived materials. DOE is already developing technologies to employ crop and forest materials in the production of chemicals and materials. Other 
agencies such as the U.S. Department of Agriculture are leaders in evaluating new uses for agricultural goods and conducting research on products from biomass. Large chemical companies, such as Eastman Chemicals, Monsanto Chemicals, and DuPont, have announced that they will pursue bioprocessing and plant-based processing as avenues to the production of chemicals and materials in the future.

Enabling Technologies. Increased fundamental understanding in chemistry, metallurgy, and biotechnology will allow the development of novel manufacturing processes. This knowledge, along with advanced modeling and simulation, improved industrial materials, and measurements (sensors) and intelligent control systems, will result in major incremental improvements and lead to fundamental breakthroughs. Likewise, developing and demonstrating micromanufacturing systems (i.e., mini-mills, microchemical reactors) for flexible process configuration and on-site/just-inplace (similar to just-in time) manufacturing can reduce GHG emissions in the long term.

Decentralized manufacturing using locally distributed resources offers the advantage of reduced transport of raw materials and finished goods.

\section{Resource Recovery and Utilization.} This technology pathway is built upon the idea of an industrial ecology, wherein a community of producers and consumers perform in a closed system. Fossil energy is conserved and/or energy is obtained from non-GHG sources; materials are reused or recycled. Through technological advances, the raw materials and resources needed for manufacturing can be obtained by designing products for ease of disassembly and reuse, using more recycled materials in finished goods, and selecting raw materials to eliminate waste discharge or undesirable by-products. Some examples are developing new advanced polymers, composites, fibers, and ceramics engineering through advances in surface techniques and molecular structures. Another approach is to substitute materials such as biomass feedstocks for petroleum feedstocks in producing chemicals. Some longer-term technological approaches will seek to use $\mathrm{CO}_{2}$ as a feedstock and non-GHG reductants as substitutes for carbon. Such fundamental changes in the way raw materials are obtained, the properties they exhibit, and the way they are used in the design process are likely to yield energy and GHG savings. Economic success will depend upon industry's using new design approaches and involving the entire supply chain in thinking about energy reduction in the materials life cycle.

\section{Collateral Benefits}

Numerous environmental benefits would result from improved industrial process efficiency and waste minimization. In addition to reduced carbon emissions, these collateral benefits include reduced ground-level ozone, less demand for landfill space, and decreased emissions from incinerators and hazardous waste sites. U.S. industries would also be better prepared to compete in the $\$ 400$ billion international market for environmental technologies.

\section{Technical Risks and Other Issues}

Industry faces a number of risks (technical, regulatory, financial) in addition to the risk posed by international competitiveness. U.S. industry has met the challenges of higher productivity and increased 
profitability, as evidenced by the increase in market value of U.S. industries. Consolidation and integration in industry is an ongoing process that keeps the industrial sector focused on its costs. The technical risks in general are low, while the regulatory and financial risks are relatively high. International competition is moderate to high, leading U.S. industry to increase production capacity in other countries and increase market share.

Environmental and economic pressures will continue to encourage industry in other countries to employ new technologies also, as the technical and economic risks are reduced through R\&D.

\section{Strategy and Recommendations}

The IOF program provides an excellent foundation of strategic public-private $\mathrm{R} \& \mathrm{D}$ alliances for achieving $\mathrm{GHG}$ reduction goals in the energyintensive industries. These alliances need to be extended to embrace climate change mitigation goals. Different types of public-private R\&D partnerships are needed to reduce GHG emissions in the light manufacturing sector. Finally, utility restructuring may challenge industrial self-generation and power sales using advanced industrial turbines integrated with combined-cycle generation or with noncombustion generation techniques such as fuel cells.

\subsubsection{Transportation}

\section{The Potential for Reduced Emissions}

Accounting for $32 \%$ of U.S. $\mathrm{CO}_{2}$ emissions and $26 \%$ of energy use, and almost totally dependent on petroleum fuels, the transportation sector presents significant opportunities and challenges for advanced technology. Opportunities lie in the continuous improvement of conventional vehicle technologies; in the promise of new, revolutionary propulsion systems and alternative fuels; and in the application of information technologies to manage and integrate intermodal transport systems in innovative and more efficient ways. Advances in information technology create new opportunities to increase system-wide efficiency and substitute communication for transportation to enhance economic well-being and the overall quality of life.

Improvements and new technologies in transportation can make substantial reductions in GHG emissions, as shown in this table.

Estimated carbon emissions reductions (MtC/year)

\begin{tabular}{lrrr}
\hline & 2010 & 2020 & 2030 \\
\hline $\begin{array}{l}\text { Total } \\
\text { transportation }\end{array}$ & $40-70$ & $100-180$ & $200-300$ \\
\hline
\end{tabular}

Assumes successful technology development and subsequent marketplace adoption without significant policy changes.

\section{Technology Pathways and Opportunities}

Advanced Conventional Vehicles. The modern internal combustion engine vehicle has made significant technological advances during the past three decades, yet the potential for technology to further reduce the environmental impacts of conventional vehicles is far from exhausted. The direct-injection stratified-charge gasoline engine and the turbocharged direct-injection diesel engine offer efficiency improvements of $15 \%$ to $30 \%$ over conventional gasoline engines; these technologies are already in commercial production outside the United States. Relatively high $\mathrm{NO}_{\mathrm{x}}$ and particulate emissions 
and additional cost hinder their penetration into U.S. markets; improved $\mathrm{NO}_{\mathrm{x}}$ catalysts must be developed and particulate emissions reduced. Replacing gasoline engines in light trucks, vans, and sport utility vehicles with more efficient diesel engines represents a significant opportunity to reduce carbon emissions from the transportation sector.

Lightweight materials, from aluminum to carbon fiber composites, have the potential to reduce vehicle weight but pose significant problems with respect to low-cost fabrication and recycling. Improved aerodynamic design, lightweight materials, and improved tires could help to double the efficiency of new passenger cars and light trucks during the next 10 to 15 years, cutting the transport sector's carbon emission by one-fourth. Many of these technologies are currently under development by the Partnership for a New Generation of Vehicles (PNGV) program and by foreign competitors, but considering that the expected life of a passenger car is nearly 14 years, implementing such changes would require more than a decade.

\section{Hybrid, Electric, and Fuel Cell} Vehicles. Developing commercially viable, mass-market electric-drive vehicles (EVs) would free the automobile from dependence on carbon-based liquid fuels while simultaneously reducing vehicular emissions. Hybrid vehicles (HEVs), the PNGV design of choice to achieve triple the miles per gallon of the conventional passenger car, combine electric drive with an auxiliary power unit and energy storage device (e.g., battery). A heat engine could be used as the auxiliary power source, but if fuel cell technology could be sufficiently advanced and the infrastructure for supplying hydrogen fuel developed, a potentially pollutionfree propulsion system would be available.

HEVs, EVs, and fuel cell vehicles all face formidable technical hurdles, many of which they share. Developing low-cost, rapidly rechargeable batteries is a critical factor in the success of HEVs and EVs. Fuel cells will also require cost reductions (on the order of 95\%) as well as improvements in energy density and reliability. Recent, dramatic progress in batteries and fuel cells (much of it attributable to the PNGV effort) suggests that commercially competitive EVs can eventually be developed. A U.S. manufacturer has introduced an improved battery-electric vehicle that has been leased to 215 customers; a Japanese manufacturer has introduced a first-generation HEV. Although still prohibitively expensive at U.S. fuel prices, the Japanese HEV showcases the hybrid's potential for very low emissions and high efficiency. Proton-exchange-membrane fuel cells are currently being demonstrated in buses and have shown dramatic improvements during the past few years.

Carbon savings from battery-electric vehicles depend directly on the primary energy sources used to generate electricity. Potential advances in electricity generation technology could make EVs very-lowcarbon vehicles. The power plants for HEVs may be fossil-fuel-burning internal combustion engines that could run on alternative fuels or could someday be replaced by fuel cells. In any case, an HEV that is three times more efficient would cut carbon emissions by at least two-thirds. Fuel cells may initially run on gasoline or alcohol fuels (reformed to produce hydrogen) and ultimately would use hydrogen stored on board the vehicle. 
Which fuels are used and how they are produced will determine whether carbon emissions are reduced by 50 or $100 \%$ over those of conventional vehicles.

Freight Vehicles. Freight vehiclesheavy trucks, railroad locomotives, and ships-are the second largest energy consumers in the transport sector after light-duty vehicles. Heavy trucks and locomotives are universally powered by highly efficient (40-45\%) diesel power plants. The efficiency of diesel engines could be further improved to $55 \%$ by use of such technologies as advanced thermal barrier coatings, high-pressure fuel injection, turbocharging, and reduced-friction and lightweight, highstrength materials. Fuel cells are an especially promising technology for locomotives, where problems of size and fuel storage and reforming are greatly reduced. Emissions of $\mathrm{NO}_{\mathrm{x}}$ and particulates remain the greatest barriers to ultrahigh-efficiency diesels, while for fuel cells, cost and the state of development of mobile fuel cell systems present the biggest challenges.

Improvements to heavy truck fuel economy could reduce carbon emissions by 20 to $33 \%$, or by up to $100 \%$ for hydrogen-powered fuel cells, depending on how the hydrogen is produced. Because freight vehicles and their power plants have useful lives measured in decades, the transition to low-carbon technologies would require decades.

\footnotetext{
Alternative Fuel Vehicles. Alternative transportation fuels are those that require substantial changes in conventional infrastructure, whether in fuel production, distribution, and retailing or in vehicles. Most alternative fuels currently under consideration are being explored for their ability to reduce pollutant emissions or displace petroleum and would have modest GHG reduction
}

potential. Fuels such as compressed natural gas and propane can reduce carbon emissions by 10 to $20 \%$, on a full fuel-cycle basis, over conventional gasoline or diesel fuel.

Far more promising from a GHG reduction perspective are biofuels, such as biodiesel produced from soy or rapeseed oils or ethanol or methanol produced from cellulosic feedstocks. Ethanol from cellulosic feedstocks using conversion processes under development by DOE has been independently estimated to produce essentially zero carbon emissions over the full fuel cycle. Vehicle technology for using ethanol and biodiesel is at a relatively advanced stage of development. The chief barriers to widespread use of these fuels are cost and limitations on feedstock production. Recent estimates by DOE indicate that by 2010,5 to 10 billion gal of cellulosic ethanol could be produced in the United States per year at prices that would make it economical for refiners to use it as an octane-enhancing, oxygenating blend stock, although ethanol still would not be competitive with gasoline as a neat fuel. This 5 to 10 billion gal would produce zero net carbon emissions and displace imported petroleum. (Biomass fuels are also discussed in Renewables Sect. 2.4.4.)

\section{Air And High-speed Ground}

Transport. Commercial air travel is the second largest and fastest growing energy-using mode of transport. It is also the mode that has achieved the greatest improvements in energy efficiency during the past three decades. Yet commercial air transport is also the most petroleum-dependent mode. Opportunities to replace kerosene jet fuel appear to be many decades away. In the meantime, petroleum displacement in high-speed intercity transport may be achievable 
by integrating high-speed rail systems with the commercial air network. Operating at 180 to $300 \mathrm{mph}$, magnetically levitated or steel wheel rail cars could substitute electricity for kerosene in short-distance intercity travel, at the same time relieving both air traffic and highway congestion.

Although air transport has already more than doubled its energy efficiency over the past quarter century, opportunities remain for at least another 50\% improvement during the next 25 years. Propfan technology, improved thermodynamic efficiency of turbine engines, hybrid laminar flow control and other aerodynamic improvements, and greater use of lightweight materials could accomplish this $50 \%$ improvement, and they are currently under development by NASA and aircraft and engine manufacturers. A potentially important issue for civil aviation will be the advent of a new generation of far more energy-intensive supersonic highspeed civil transports. The unique requirements of supersonic and hypersonic aircraft could eventually drive the development of alternative fuels for commercial transport.

Having the best and most efficient commercial aircraft technology not only would reduce carbon emissions and petroleum use, but also will be critical to keeping the U.S. aircraft industry competitive. The principal impediment to continued efficiency improvement and lower carbon emissions is likely to be the relatively low cost of jet fuel, providing an inadequate incentive to adopt new, more complex, and possibly more costly aircraft technology.

\section{Technical Risks and Other Issues}

There are technical challenges to be met in certain areas, including reducing pollutants and improving performance, but there are clear ways to address these challenges. Also, while smaller and lighter vehicles may result from advanced vehicle development, R\&D program goals generally specify equal or improved performance, comfort, and safety. Therefore, ecological and human health risks are expected to be low for these advanced technologies. Commercial risks are moderate, led by the success of existing transportation systems and determined global competitors that are investing heavily in the race to develop sustainable transportation technology for the expanding global economy. The ability of U.S. industry to develop clean, efficient, environmentally sustainable technologies for global transport markets will be critical to the competitiveness of the U.S. transportation industry, an industry that accounts for more than one-tenth of U.S. GDP and directly or indirectly employs one U.S. worker in ten. Social risks are moderate in some areassuch as high-speed ground transportation, which may require public subsidy to be economical-and demand reduction-which to date has achieved only modest success.

The revolution in information technology is creating expanding opportunities for efficient transportation alternatives to improve the efficiency of transportation systems and reduce the vehicle miles traveled. Already, railroads, trucking firms, and shipping and air freight companies are using advanced information

technology to more efficiently plan and manage their operations. Development of more comprehensive frameworks for intermodal integration could produce still greater efficiency benefits, leading to improved service with less energy use. Telecommuting and electronic marketing are well known examples of virtual travel. 
Advances in information technology create new opportunities to increase system-wide efficiency and substitute communication for transportation to enhance economic well-being and the overall quality of life. R\&D activities in these areas include continued development of the concept of transportation as an integrated network of physical and electronic services that can be coordinated by systems engineering approaches, by development of such analysis tools as the National Transportation System initiative, and by research that encourages the infusion of information and network technology into transportation operations.

\section{Collateral Benefits}

In addition to reducing emissions, the development of these transportation options would reduce pollutant emissions, improve human health, and reduce the nation's dependence on imported petroleum.

\section{Strategy and Recommendations}

Advanced technologies offer enormous potential to reduce U.S. and world carbon emissions from transport. Efficiency improvements of 50 to $200 \%$ across all modes appear to be possible for new equipment over the next two to three decades. Beyond that point, use of electricity and hydrogen that are not derived from fossil fuels could virtually eliminate carbon emissions from the transport system during the next century, if the necessary technological advances could be made in other sectors. Significant cost and technical barriers remain; however, a technological pathway from the present fossil fuel-dependent transport system to a future globally sustainable system is in sight.

The comprehensive R\&D programs described in the transportation pathways would produce substantial economic benefits in the form of avoided costs of GHG mitigation. The concept of efficient transportation alternatives may also have the potential to develop as a significant technology pathway. There would also be important benefits in the form of cleaner air and reduced national dependence on petroleum. To achieve these goals, a significantly greater investment in federal transportation energy $R \& D$ budgets would be necessary. Because of the importance of the endeavor and the magnitude of its cost, estimates should be made not in haste, but after carefully and thoroughly planning the full range of $R \& D$ efforts required.

\subsubsection{Agriculture and Forestry}

\section{The Potential for Reduced Emissions}

Sustained economic growth depends on having a secure supply of raw materials. Agriculture and forestry can supply additional and renewable resources for industrial production and energy needs. Currently, managed forest and agricultural lands in the United States fix 3.6 billion tonnes of carbon annually from the atmosphere. Most of this carbon is rereleased in short-lived products, and little is used to substitute for fossil-based products.

The primary opportunities to reduce GHG emissions in the agriculture and forestry sector lie in technologies that remove GHG from the atmosphere (carbon sequestration in durable biobased products, soils, and standing crops) and substitution of biomassbased products for fossil-based products. The carbon sequestration and renewable energy sections of this report cover carbon sequestration and biomass-based energy. The focus of this section is on development of biomass to bioproducts technologies 
(other than fuel) that can further reduce GHG emissions through both biomass substitution and reduced energy and fertilizer consumption.

Technology pathways that offer the best opportunities to realize these GHG emission reductions are conversion of biomass to bioproducts, advanced agricultural systems, and plant/crop engineering, as shown below.

Estimated carbon emissions reductions (MtC/year)

\begin{tabular}{llll}
\hline & 2010 & 2020 & 2030 \\
\hline $\begin{array}{l}\text { Total agriculture } \\
\text { and forestry }\end{array}$ & $3-7$ & $15-25$ & $30-45$ \\
\hline
\end{tabular}

Assumes successful technology development and subsequent marketplace adoption without significant policy changes.

\section{Technology Pathways and Opportunities}

Conversion of Biomass to Bioproducts. Annual crops, perennials, and shortrotation woody species represent plant/crop-based resources that are renewable source materials in the food, feed, and fiber industries (National Corn Growers Association 1997). The use of such biomass-based processes to produce materials and products provides a modest but significant reduction in GHGs because biomassbased feedstocks are synthesized from the $\mathrm{CO}_{2}$ in the atmosphere and petroleum-based feedstocks are not.

Historically, plant/crop resources have seen limited use as industrial feedstocks in fossil material processing systems. However, in the future, biomass-based products are likely to become functional replacements for fossil-derived products with the same level of performance. The technology needs involve the following challenges:

- to use plant/crop-based inputs in modified processing systems
- to develop modified plant/crop production systems to provide desirable feedstocks

- to integrate these approaches to create optimized systems that generate a new economic platform based on the use of plant/cropderived inputs

The use of plant/crop-based resources requires the development of concepts around "alternative processing" rather than just "alternative sources" for existing processes. New advances in biotechnology and plant genetics, new discoveries in organic synthesis using carbohydrates, and novel materials and micromanufacturing technologies should drive development of these new "alternative processing" options.

Substitution of biomass-based products for fossil-based products has significant potential to reduce U.S. GHG emissions. Additional emissions reductions could come from new markets, chemical production, process improvements, and energy savings. The forest products industry is 63\% energy self-sufficient, and the cogeneration techniques it uses could be adapted to other bioindustries.

The barriers to use of biomass-based processes arise from the history of our country's use of its indigenous resources. While biomass-based feedstocks are employed at competitive costs by the paper- and grainprocessing industries, chemical manufacturing systems are optimized for petroleum and natural gas and are not designed to process alternative feedstocks. A successful scenario for using biomass-based processes involves the development of viable manufacturing platforms based on renewable forestry/crop feedstocks. These industries would produce materials and chemicals, such as cosmetics, textiles, and pharmaceuticals, that either would fill 
their own particular niche or would be integrated into the mainstream fossilbased chemical-processing industry.

Conversion of biomass to bioproducts is also discussed under Industry (Resource Recovery and Utilization) and Renewable Energy (Solar Advanced Photoconversion). Carbon reduction estimates are included only in Resource Recovery and Utilization.

\section{Advanced Agricultural Systems.}

Agriculture and forest management practices have achieved significant increases in productivity and carbon fixation with decreased energy use. However, intensive agriculture and forestry production continue to add to the emissions of GHG and significantly affect nitrogen, soil carbon, and water biogeochemical cycles. Research should focus both on technologies that continue to increase productivity without increasing GHG emissions and on those which offer the possibility of significantly reducing GHG emissions. Advanced agricultural systems involve ways to deliver adequate quantities of nutrients that are efficiently assimilated by plants and water to maintain photosynthesis and support plant growth. Advanced agricultural systems include sensors, controls and monitoring, improved fertilizers and pesticides, improved delivery systems, genetic design of pest-resistant crops, and control of microbial processes. These technologies will result in increased biomass production for a given area of land with reduced nutrient, water, and energy inputs.

Advanced agricultural systems will lead to small but significant reductions in GHG emissions along with reduced energy consumption and fertilizer use. Currently, 3\% of U.S. fossil fuel emissions result from agricultural crop production and only $27 \%$ of U.S. agriculture uses low- or no-till systems. Advanced agricultural systems technologies have the potential to significantly increase the use of no- or low-till systems. In addition, technologies that lead to improved fertilizer efficiency could result in significant carbon savings.

Some components of advanced agricultural systems, such as the use of global positioning systems to map yields, are in or close to commercial use. Others, such as real-time monitoring of water and nutrient status, are not. Although fertilizer delivery and chemistry have significantly improved during the last 10 years, advancements in biologically released fertilizers and control of microbial processes still require significant efforts. Detailed real-time and small-area geographic matching of fertilizers and other agricultural chemicals to plant requirements are in the early stages of development. Technologies involving biocontrol of pests are evolving; some are to the point of commercial development.

Plant/Crop Engineering. Plant/crop engineering is expected to contribute to reductions in GHG emissions through improvements in biomass production, carbon sequestration, and biomass conversion to bioproducts. Technologies include

- engineering plants with improved carbon-use efficiency, and therefore increased yield and carbon fixation

- control of physiological processes that determine a plant's ability to grow on low nitrogen and to recycle nitrogen

- manipulation of cell wall structure and assembly to create crops and to produce high-strength structural wood and composites for use in construction

- genetic transformation of desirable genes into target biomass plant species for specific biomass-tobioproduct conversions 
To successfully develop these technologies, basic research is necessary for better understanding of the metabolic pathways that control how plant productivity responds to changes in nutrients, water, and $\mathrm{CO}_{2}$ concentrations. Research on gene insertion efficiency is also needed across the wide range of species relevant to bioproducts. In addition, gene identification to improve biomass quality is needed and will result from functional genomics research (sequencing and characterization of gene function).

Successful deployment of these technologies will occur only through integration with the development of bioproducts technologies and advanced agricultural technologies. Transgenic varieties and common crops are being introduced that are resistant to specific diseases and pests and that require smaller amounts of nutrients and water. They constitute a significant advancement in this field. Ecosystem assessments are needed as these new varieties are introduced. Because of the strong interdependency among advanced agricultural systems, the production of bioproducts, and plant/crop engineering, the carbon savings that can be realized with plant engineering are incorporated into the carbon savings reported in this section.

\section{Strategy and Recommendations}

Integrated research, both basic and applied, needs to be pursued in cooperation with commercial agricultural and forest sectors as well as with manufacturing industries. Key objectives should include integrated systems management and improvement of agriculture and forestry sustainability and costcompetitiveness.

\section{Technical Risks and Other Issues}

The rate of fundamental plant engineering research is limiting; it is inherently slow because of the life cycles of plants (especially trees). Ecological, commercial, and economic risks include the availability of and competition for land among agriculture, forestry, cities, and recreational areas. Trade-offs between food-feed-fiber and chemicals production have not been fully evaluated, and the environmental impacts of increased land cultivation will have to be carefully considered.

\subsection{CLEAN ENERGY}

The development and use of advanced energy production technologies has a large potential for reducing GHG emissions without increasing energy costs. Technological approaches include using fuels with lower or zero carbon content; increasing the useful energy output per unit of carbon emitted; and capturing carbon emissions to prevent their entry into the atmosphere. With successful development, these advanced technologies generally have the potential to reduce carbon emissions by 25 to $50 \%$ or more in the time frame beyond 2020. Their potential for carbon emission reductions by 2010 is considerably more limited because of stock turnover rates in energy production.

These advanced energy production technologies are described in four technology areas:

- fossil resource development

- fossil power generation

- nuclear energy

- renewables 


\subsubsection{Fossil Resource Development}

\section{The Potential for Reduced Emissions}

Fossil energy dominates the nation's and the world's energy supplies and is likely to do so for the foreseeable future. It provides more than $87 \%$ of the nation's energy ( $40 \%$ oil, $25 \%$ natural gas, and $22 \%$ coal; Fig. 2.6) and about $90 \%$ of the world's energy (40\% oil, $23 \%$ natural gas, and $27 \%$ coal). Because the nation's economy is so heavily reliant on each of these three fuels, altering this fuel mix will require at least two decades of dedicated technical and infrastructure development.

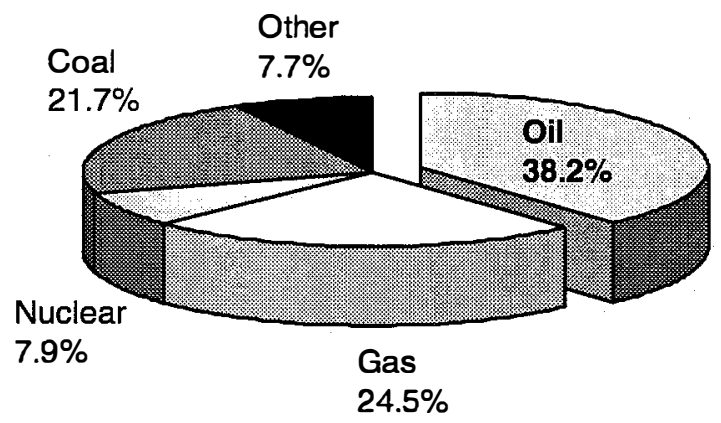

Fig. 2.6. Fossil fuels account for most of the energy used in the United States.

Because of the desire to reduce $\mathrm{CO}_{2}$ emissions per unit of energy expended, fossil fuels containing a lower carbon:hydrogen ratio need to be developed. Therefore, any major clean fossil-fuel-based alternative energy plan must center on enhanced production of natural gas and the efficient conversion of abundant fossil feedstocks into electricity, clean liquid transportation fuels, and chemical feedstocks whose impact would be to reduce net $\mathrm{CO}_{2}$ emissions compared with current sources for these commodities. Coal reserves are expected to last for many hundreds of years, and increasing amounts of natural gas are being discovered. Estimates of the impact of new technologies on carbon emissions are shown in this table.

Estimated carbon emissions reductions (MtC/year)

\begin{tabular}{|c|c|c|c|}
\hline & 2010 & 2020 & 2030 \\
\hline \multicolumn{4}{|c|}{ Total fossil resource } \\
\hline development & $15-30$ & $80-115$ & $115-225$ \\
\hline
\end{tabular}

\section{Technology Pathways and Opportunities}

\section{Energy Efficiency for Crude Oil}

Refining. Developing technology to increase the efficiency of converting crude oil to transportation fuels, and separating and using valuable components of refinery off-gases (light hydrocarbons) would have a significant impact on increasing liquid hydrocarbon utilization efficiency. Because the United States produces significant quantities of heavy oil, an improved refining process could add $\$ 1$ to $\$ 2$ per barrel to the value of this oil. Capturing off-gases produced during refining adds value to the process and eliminates GHGs that are more damaging per molecular weight than $\mathrm{CO}_{2}$.

Natural Gas to Liquids. The costeffective conversion of natural gas to clean liquid transportation fuels and commodity chemicals offers a significant potential for GHG emissions reduction while allowing greater use of domestic natural gas supplies. Breakthrough technologies under development include deriving diesel fuel from natural gas (far exceeds conventional diesel fuels in emission reductions), converting natural gas or synthesis gas to methanol or gasoline, and converting gas to liquefied natural gas in remote areas at commercial 
efficiencies using thermoacoustic refrigeration technology.

Increased Natural Gas Production. The nation (and North America) has abundant natural gas resources that help to fuel the industrial and electric power sectors. It needs only the development of new technology to make natural gas available as a substitute for some oil consumption in transportation fuel markets and for coal use in electricity generation. Current U.S. natural gas supplies can be augmented in the near term through secondary gas recovery (230 tcf); in the mid-term through lowpermeability formation development (500 tcf), offshore supplies (100 tcf), and coalbed methane (400 tcf); and in the long term by exploiting currently untapped methane hydrates (2700 tcf) and deep-source gas (3000 tcf). Only a moderate success rate would be needed to effectively meet the expected demand of $28 \mathrm{tcf}$ in 2010.

\section{Co-Production with Integrated} Gasification Combined Cycle. To make full use of abundant supplies of lowcost solid fuels, the integrated gasification combined cycle (IGCC) process represents a unique combination of technologies that offers industry low-cost, highly efficient options for meeting a variety of market requirements. Compared with today's commercial and advanced technologies, IGCC is one of the most efficient and environmentally friendly technologies for the production of lowcost electricity and is capable of processing a number of feedstocks including coal, petroleum coke, biomass, and municipal wastes. The IGCC system, operated in conjunction with steam reforming, is capable of producing a stream rich in $\mathrm{H}_{2}$ with only a $\mathrm{CO}_{2}$ byproduct (which is ready for sequestration). In combination with synthesis gas conversion technologies, it is the only advanced power generation technology that is capable of coproducing a wide variety of commodity and premium products in addition to power to meet future market requirements.

Through coproduction, other products can be obtained either by processing the feedstock before gasification to extract valuable components or by converting the synthesis gas to products. With feedstocks such as coal, valuable precursors can be extracted for the production of high-strength, lightweight carbon fibers and of anode coke for manufacturing industries. Clean synthesis gas can be catalytically converted into environmentally superior transportation fuels, high-value chemicals, or hydrogen.

Numerous IGCC gasification demonstration projects using coal, petroleum coke, or other petroleum refinery wastes are currently in operation or under construction both in the United States and worldwide. Many of these facilities have been designed for operation in the coproduction mode, whereby improved thermal efficiencies can be gained.

The conversion of coal-based synthesis gas to transportation fuels has been the subject of investigation for several decades; however, significant recent advances in catalysis and reactor design are generating considerable interest from industry. The environmental superiority of the resulting transportation fuels-which have substantially reduced emissions of hydrocarbons, carbon monoxide, and particulates-has been demonstrated; and they are recognized as a key ingredient for meeting future environmental regulations in the transportation sector.

$\mathrm{CO}_{2}$ for Improved $\mathrm{Oil}$ and Gas Recovery. From a carbon management 
perspective, improvements in reducing GHG emissions could be attributed to flooding petroleum reservoirs with recycled $\mathrm{CO}_{2}$ and minimizing fugitive gas emissions from pipelines and other remote sites. $\mathrm{CO}_{2}$ is pumped into oil reservoirs to enhance the recovery of petroleum. Instead of present practice, $\mathrm{CO}_{2}$ that would otherwise be emitted to the atmosphere (from fossil fuel combustors) could be captured and used to enhance energy recovery. In the future, $\mathrm{CO}_{2}$ contained within power plant stack gases could also be pumped into coal seams to recover methane economically or to replace base gas in storage wells. Estimates have placed the sequestration potential of this approach at $50 \mathrm{MtC} /$ year.

Tracers can be developed to identify fugitive emissions of methane from refineries and pipelines. Backscatter absorption gas imaging and light detection and ranging (LIDAR) technologies have recently proved effective in imaging methane plumes at remote distances and concentrations in the part-per-million range. Recent improvements in LIDAR systems for national security missions should be applicable to fugitive gases as well. The GHG reduction potential of eliminating leaks has been estimated at $12 \mathrm{MtC} /$ year in the United States.

\section{Crosscutting Technologies.}

Technologies that affect the conversion of abundant fossil fuels to liquids are very important for reducing GHG emissions. Some of the most significant challenges are the identification of new catalyst compositions to promote the efficient synthesis of diesel fuel and the production of chemical feedstocks from natural gas or coal. Additionally, the use of predictive simulation and concurrent process development of various schemes to determine the most economical configuration merit further attention.
The following areas should also be investigated:

- optimizing an integrated process using ion-transport membranes for conversion of natural gas to synthesis gas, followed by the conversion of synthesis gas to transportation fuels

- addressing the broad range of technical issues related to commercial scale-up in remote locations

- demonstrating high daily production of liquefied natural gas from sources previously vented to the atmosphere, using improved thermoacoustic refrigeration

Increased natural gas production in the short term will result from incremental improvements in drilling, completion, and stimulation technology; improved seismic imaging of natural fracture systems; fracture access to low-permeability formations; and enhanced methane drainage from coalbeds (perhaps stimulated by $\mathrm{CO}_{2}$ or flue gas injection). In the intermediate time frame, conversion of natural gas from the North Slope of Alaska or other remote sites into a high-quality liquid fuel that is moved by pipeline to a distribution infrastructure would have the greatest impact on increasing natural gas production. (This technique will be keyed to the success of the gas-to-liquids effort.)

In the long term, entirely new technology will be required to map and produce undersea methane hydrates and perhaps even deep-source gas. Gas hydrates are physical combinations of hydrocarbon gas (predominantly methane) and water that are classified as clathrates. They represent a potential energy source greater in volume than all known oil, gas, and coal deposits combined. No technology exists to extract methane from these 
undersea deposits, but there recently has been some resurgence of interest in this resource in the United States and internationally.

Efficiency improvements in crude oil refining and processing will be keyed to new catalysts with improved efficiencies and selectivities, advanced membrane separation methods with high throughputs and high separation factors, and the development of pretreatment conversion technologies that would allow more heavy oil to be converted to higher-value, efficient transportation fuels. Advanced inorganic membranes that could be used to separate and utilize refinery off-gases would be particularly valuable.

An extension of this work would be improved gas-gas separations, particularly the separation of air into oxygen and nitrogen and the separation of $\mathrm{CO}_{2}$ from nitrogen in very large-scale flows. Development of these high-throughput gas separation technologies would allow recycled $\mathrm{CO}_{2}$ from fossil fuel combustors to replace $\mathrm{CO}_{2}$ that is produced from dedicated production wells.

\section{Collateral Benefits}

Improved crude oil refining processes would eliminate GHGs that are considerably more damaging than $\mathrm{CO}_{2}$. Converting coal-based synthesis gas to transportation fuels would reduce several pollutants compared with conventional fuels, as would using $\mathrm{CO}_{2}$ for improved oil and gas recovery. Increased natural gas production would enhance energy security, as would IGCC systems. IGCC would also coproduce a variety of products in addition to power, creating new jobs.

\section{Technical Risks and Other Issues}

Technical and commercial risk ranges from low to challenging, depending on the pathway. For example, natural gasto-liquids conversion and crude oil efficiency improvements face scale-up problems; increased natural gas production may require demonstrations; and IGCC requires advanced materials and technologies for membranes and filters. Ecological risk is generally low to moderate, and human health risks would be lower than for current technology.

\section{Strategy and Recommendations}

While natural gas is expected to capture an increasing share of the new market for fossil fuels during the next decade, the 2010-2020 time frame should usher in a significantly larger potential for natural gas and for more highly efficient coal-based IGCC technologies. If research efforts were well funded and successful, breakthrough developments in catalysts, simulations, membrane separations, and overall gas-to-liquids conversion (including IGCC-based) technology would be pilot-scale tested by 2010 . Allowing for further improvements and scale-up to commercial size plants, a major impact could be expected by 2020 .

Increased natural gas production to satisfy these needs can be seen as taking place over three time periods. Near term improvements would be seen through incremental improvement of extractive technologies, such as drilling, completion, and reservoir stimulation technology; seismic imaging of fracture systems; access to low-permeability formations; and enhanced methane drainage from coalbeds (via $\mathrm{CO}_{2}$ injection). 
Intermediate term improvements in production would occur through increased use of Alaskan natural gas, or natural gas from other remote resources, via the transport of a liquefied product. Finally, long-term contributions can be expected from the use of vast undersea methane hydrates. Currently, no known technology exists to extract methane from these undersea deposits.

Liquid fuels from Alaskan natural gas may even be ahead of this schedule. The commercial success of the gas-toliquids industry would spur even greater increases in natural gas production beyond 2020, including the first contributions from undersea methane hydrates.

Development of a large-scale, oilcompetitive, commercial gas-to-liquids industry (natural gas and coal-based) offers the highest technical risk. Research on this topic has been ongoing for decades, and although some commercial plants are in operation, much remains to be accomplished. In addition, long-term $\mathrm{R} \& \mathrm{D}$ in major oil companies continues to decrease (Fig. 2.7), which does not bode well for the implementation of new high-technology programs.

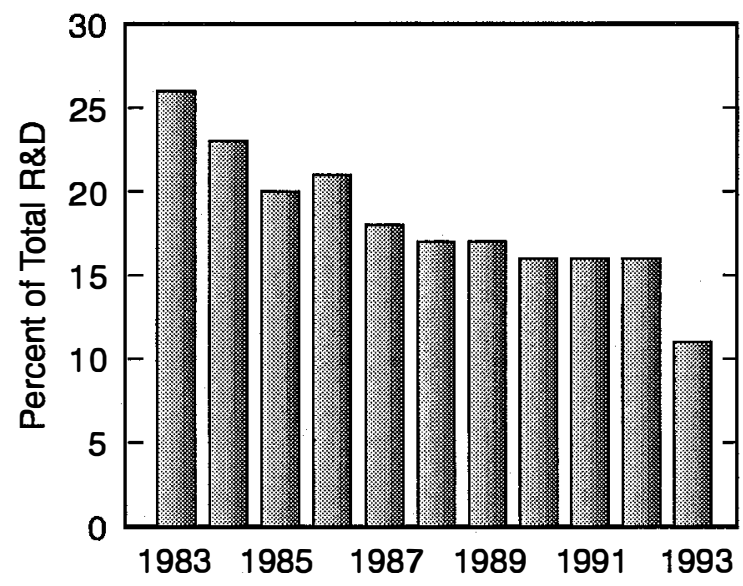

Fig. 2.7. Long-term $R \& D$ in major oil companies continues to decline.
Efficiency improvements in crude oil refining and processing pose a high level of commercial risk. As shown in Fig. 2.8, $46 \%$ of domestic refineries have closed since 1981, many because of perceived environmental problems. Reconfiguring a new domestic refinery industry will entail very significant commercial risks.

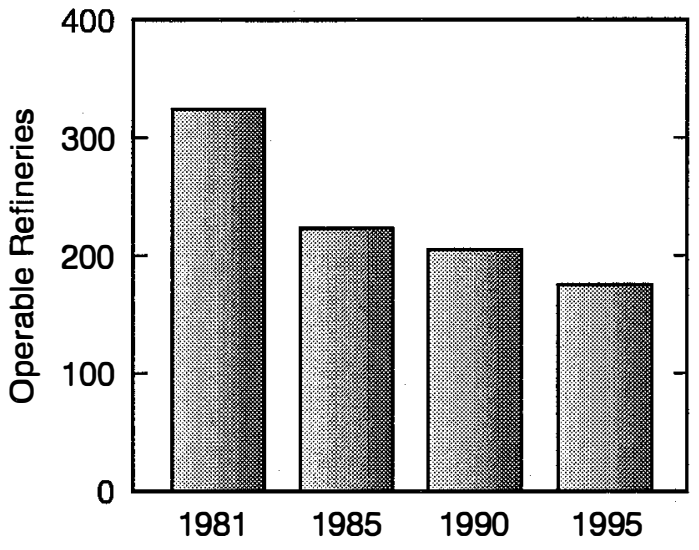

Fig. 2.8. Operable refineries in the United States.

\subsubsection{Fossil Power Generation}

Today, coal supplies $55 \%$ of electricity, while natural gas makes a small contribution to U.S. electricity needs. By 2015, EIA predicts that coal will still account for $50 \%$ of electricity, but that the contribution of natural gas will rise to $20 \%$. EIA also predicts that, barring significant technology developments or policy changes, carbon emissions from coal will rise from 460 to $550 \mathrm{MtC}$ between 1995 and 2015, while carbon emissions from natural gas for power generation will rise from 50 to $125 \mathrm{MtC}$ during that period.

\section{The Potential for Reduced Emissions}

To reduce this projected increase in carbon emissions, several approaches are being studied. Low-cost approaches 
to reduce emissions from existing plants include cofiring with natural gas or biomass; rebuming to reduce $\mathrm{NO}_{x}$; and land-based capture of $\mathrm{CO}_{2}$ to be used in aquaculture, pharmaceuticals, or waste encapsulation. However, for a major impact on emissions, more advanced technologies are being developed that have excellent potential to reduce carbon via more efficient power generation in the near, mid, and long terms, based on the success of ongoing research and development efforts. Estimates are shown in the table below.

Estimated carbon emissions reductions

\begin{tabular}{cccc}
\multicolumn{4}{c}{ (MtC/year) } \\
\hline & 2010 & 2020 & 2030 \\
\hline Total fossil power & $0-20$ & $40-90$ & $110-185$
\end{tabular}

Assumes successful technology development and subsequent marketplace adoption without significant policy changes.

\section{Technology Pathways and Opportunities}

The three fossil power generation pathways that are outlined in Appendix $B$ represent a broad technology portfolio that could reduce GHG emissions in the near term and accelerate these reductions as new technologies are phased in at normal or near-normal replacement rates in the mid and long terms. All technologies within this portfolio are targeted for availability within the first third of the next century, but the success of these pathways depends on the success of ongoing R\&D efforts.

\section{High-Efficiency Coal-Based}

Technologies. It is unlikely that highefficiency coal-based technologies would achieve significant market penetration before 2010 . But by 2020 , introduction of high-efficiency coalbased technologies could significantly reduce carbon emissions. By 2050, total carbon emissions could be below those produced from the electricity sector in 1990 (a reduction of about $210 \mathrm{MtC} /$ year).

The high-efficiency coal-based pathway increases power generation cycle efficiency by combining two or more advanced energy conversion cycles. Ideas being developed include low-emission boiler systems, pressurized fluidized bed combustion, IGCC, and high-efficiency power systems. Goals are to increase conversion efficiencies from around $33 \%$ to $42 \%$ in 2000 to more than $55 \%$ in 2010 , at a cost considerably lower $(\$ 0.03 / \mathrm{kWh})$ than today's pulverized coal costs and with pollutant emissions at one-third to one-tenth of current new-source performance standards. These technologies may have additional potential for performance improvement of up to $60 \%$, depending on the success of ongoing basic research. An area where primary technology development is needed is high-temperature materials that are stable and that resist corrosion, erosion, and decrepitation so that they can be used for heat exchangers, turbine components, particulate filters, and $\mathrm{SO}_{\mathrm{x}}$ removal. Other challenges include the use of alternate working fluids for turbine and heat-exchange cycles, cycle optimization environmental control technologies with low energy penalties, and solids handling.

Low-Carbon Fuels. Low- or no-carbon fuels-such as natural gas, synthesis gas, or hydrogen-used in the technologies being proposed for accelerated development in this initiative could lead to a significant reduction of carbon emissions after 2020.

Fuel cells and gas turbines are currently in use, taking advantage of plentiful supplies of natural gas. 
However, neither technology has reached its potential. For gas turbines, the R\&D goals are to lower bus-bar energy costs to $10 \%$ less than costs for current state-of-the-art technology and to develop ATSs and gasification adaptation technology by 2010 . Improvements in blade cooling and materials will be required to move these technologies beyond the current practice, and considerable development is required before they will be capable of high performance when firing hydrogen. Also, further improvements are needed to avoid increasing $\mathrm{NO}_{x}$ emissions as operating temperatures rise. For industrial applications, small and medium-sized turbines are being developed to achieve a $15 \%$ improvement in efficiency over vintage equipment. These may supply distributed generation of power to serve customers unable to obtain needed power from the transmission grid, or they may be employed in industry to contribute both power and heat. Advanced turbines and industrial cogeneration are important technologies for both industrial efficiency and fossil power and are counted for the purpose of emissions projections in industrial efficiency.

Fuel cells represent another gas-fueled technology. Recent successes have shown the potential to build larger stacks of fuel cells, leading to larger generating capacity, but costs need to be reduced to make them competitive. Performance targets include developing market-ready fuel cell systems with efficiencies higher than $50 \%$; adapting them to operate on synthesis gases from coal and other solids; and validating the hybrid fuel cell/advanced gas turbine system that could have efficiencies approaching $70 \%$ by 2010 . Demonstration of advanced turbines on hydrogen alone or in some hybrid cycle is expected to occur between 2020 and 2030.
Additional effort would be required to address all the system integration issues identified in these two validation steps.

Energyplexes. These two pathways, high-efficiency coal and low-carbon fuels, converge in a third group of technologies that integrates production of power, fuels, and /or chemicals, maximizing use of available energy. It would create "energyplexes," a type of industrial ecosystem. An energyplex is a series of modular plants capable of coproducing power and chemicals or fuels that can be integrated to use local sources of carbon (coal, biomass, municipal solid waste) as fuel and feedstocks.

Eventually, modules would be included for capture and sequestration of $\mathrm{CO}_{2}$.

These energyplexes would feature high efficiencies of carbon use, essentially zero carbon emissions, and costcompetitive power. Unlike the first two pathways, which focus on electricity generation, this pathway strives to optimize the entire cycle of carbon utilization by incorporating coprocessing concepts and the tenets of industrial ecology. Energyplexes would have essentially zero carbon emissions and could result in 100\% reduction of carbon after 2030 .

Substantial benefits are possible when carbon sequestration strategies are coupled with advanced energy production systems. Fossil fuel production and conversion facilities that either integrate cost-effective sequestration into the facility design or incorporate an equivalent offset can achieve zero net $\mathrm{CO}_{2}$ emissions. If this zero emission strategy were applied to all new fossil fuel energy production facilities after 2010, the cumulative reductions (carbon emissions avoided), in addition to those realized from advanced efficiency systems, would be 
about 4 GtC by 2030 in the United States alone. This estimate was derived by extrapolating the EIA Annual Energy Outlook 1997 projection to 2050 as the baseline, or business-as-usual, scenario (EIA 1996a). Commensurate benefits could be realized if sequestration were implemented worldwide for fuels production as well.

This pathway challenges the R\&D community to make significant technology breakthroughs - or "grand challenges"-such as novel industrial process configurations, novel power cycles, and coproduction of heat and power, with suitable energy-efficient reuse or disposal options for carbon and $\mathrm{CO}_{2}$. A series of activities are envisioned that would develop a portfolio of breakthrough technologies by 2015 , including coal liquefaction, development and validation of combinations of fuel cells and advanced gas turbines, and validation of fuel cell systems incorporating carbon capturing and/or reuse methods. Between 2015 and 2030, system integration issues and largerscale testing would be needed to bring this approach to the point of commercialization.

Along with developing cost-effective $\mathrm{CO}_{2}$ capture methods for this pathway, including similar methods in the technologies from the first two pathways could lead to additional reductions. Typically, $\mathrm{CO}_{2}$ may be captured by chemical, biological, or physical means. $\mathrm{CO}_{2}$ capture is a common practice in some process industries, where the process usually occurs in some type of chemical absorber. In addition, biological systems capture $\mathrm{CO}_{2}$ by conventional means and use it as a nutrient for growth of algae or other simple organisms. Finally, cryogenic processes, membrane processes, and adsorption using molecular sieves are physical means to capture $\mathrm{CO}_{2}$, but these are only cost effective if the $\mathrm{CO}_{2}$ exists at a high concentration in the effluent stream.

Research needs that have been identified in $\mathrm{CO}_{2}$ capture include (1) means to concentrate the $\mathrm{CO}_{2}$ which will facilitate existing capture processes and (2) improvements in chemical absorption, including identification of improved solvents and advances in contacting methods to reduce the size and cost of process vessels. Means to concentrate $\mathrm{CO}_{2}$ could include use of a blend of pure oxygen and recycled $\mathrm{CO}_{2}$ as a replacement for air in the combustion processes under development. Furthermore, IGCC system concepts could be carried to the point where they produce a product stream of only $\mathrm{CO}_{2}$ and hydrogen. Improved separation techniques for the hydrogen would then leave a concentrated $\mathrm{CO}_{2}$ stream, which would be available for further processing.

Currently, $\mathrm{CO}_{2}$ capture technologies would impose an energy penalty of approximately $30 \%$ on a coal-fired plant if one sought $90 \%$ capture. Improvements in existing approaches could reduce this penalty to $9 \%$. This pathway would encompass research to blend high-efficiency power production with fuel and chemical production. This synergistic approach is based on analyses that indicate that a closed carbon system could be developed having a competitive levelized cost of electricity for the period after 2025.

\section{Technical Risks and Other Issues}

The highest risks associated with the high-efficiency coal-based pathway are commercial and economic because of formidable competition with domestic natural gas and international coal technologies. There is a near-term critical window of time to achieve long- 
term carbon reduction and capture international market share arising from the 50-year service life of power plants. The low-carbon fuels pathway faces moderate risks both technologically and commercially, although ATSs for stand-alone systems are probably low risk. The energyplex pathway faces low to moderate technical risk related to the challenges for system integration, and moderate to high risk related to the breakthroughs in capture, including those related to novel combustion configurations. The health and ecological risks are considered low to moderate.

Supporting science and crosscutting technologies needed to achieve these pathways include combustion; materials for high-temperature and corrosion-resistant performance; industrial ecology; hydrogen separation or production, transportation, and storage; improved processes for low-cost separation of oxygen; advances in fuel cells; and identification of alternative working fluids and determination of their thermodynamic properties.

\section{Collateral Benefits}

These pathways not only will reduce GHG emissions but also will provide a clean, secure energy future and help the nation respond to its international commitments. An accelerated RD\&D program will enable the United States to capture a larger share of the . $\$ 1.4$ trillion export market for coal technologies between now and 2010 and help the U.S. economy grow by creating an energy technology export business. An accelerated R\&D program would also allow U.S. industry to take advantage of the domestic markets for ATSs and fuel cells, which are estimated to be worth tens of billions of dollars between now and 2010 .

\section{Strategy and Recommendations}

For the high-efficiency coal-based pathway, about $\$ 70$ million per year is currently being spent on DOE programs. For the low-carbon fuel pathway (fuel cells and advanced turbines), about $\$ 90$ million per year is currently being spent on DOE programs. As part of this initiative, accelerating and completing the development of these technologies is recommended. For the energyplexes pathway, relevant technical ideas (such as fuel cells and coal liquefaction) are currently being funded at various levels. Pursuing the grand challenges envisioned both for this pathway and for additional options is recommended for the next two decades.

In summary, the technology pathways described provide a range of options for using coal, natural gas, and other solid fuels-such as biomass, synthesis gas, and hydrogen - to generate power at competitive power costs, to reduce emissions of criteria pollutants and $\mathrm{CO}_{2}$ to the atmosphere, and to develop strong positions in crucial technologies important to economic growth in the next century. Not all of these will necessarily enjoy widespread commercialization; however, they represent a family of options that spread technology risks, address fuel flexibility, and hedge against upsets in fuel prices. They include both improvements on familiar technologies, which should pose reduced commercialization risks, and bold new concepts that may pose as yet unrecognized commercialization risks.

\subsubsection{Nuclear Energy}

Nuclear power is deployed worldwide to produce $20 \%$ of world electrical generating capacity (in some 
countries, as much as $80 \%$ ). Electricity generation using nuclear power results in very small emissions of GHGs, so nuclear power is an important tool in reducing global $\mathrm{CO}_{2}$. In the period when France converted $70 \%$ of its electricity generation to nuclear, all related emissions were reduced dramatically. $\mathrm{CO}_{2}$ was reduced by $80 \%, \mathrm{SO}_{2}$ by $90 \%, \mathrm{NO}_{x}$ by $60 \%$, and particulates by $97 \%$

(Fig. 2.9). Today, in the United States, 109 nuclear power plants generate nearly $22 \%$ of U.S. electrical capacity (100 GWe). This nuclear generating capacity avoids the emission of about $140 \mathrm{MtC} /$ year compared with generating this electrical capacity by burning fossil fuels.

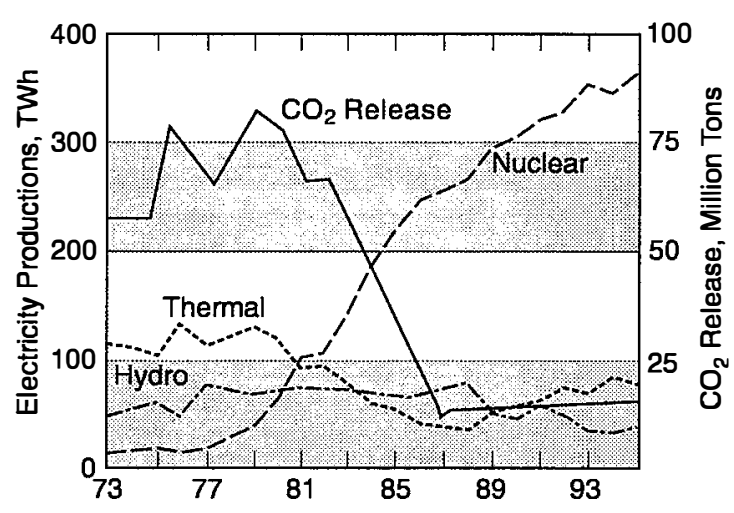

Fig. 2.9. Relationship between $\mathrm{CO}_{2}$ release and electricity production in France, 1973-1996.

\section{The Potential for Reduced Emissions}

In the near term, the development and use of technologies for lifetime extension and for generation optimization (LEGO) of existing nuclear power plants could reduce carbon emissions by increasing nuclear electricity contributions from existing plants over the next several decades. A modest carbon reduction is also assumed for new nuclear plants in 2020 and 2030. Total potential reductions are shown in the following table.
Estimated carbon emissions reductions (MtC/year)

\begin{tabular}{|c|c|c|c|}
\hline & 2010 & 2020 & 2030 \\
\hline Total nuclear & $0-15$ & $30-70$ & $70-150$ \\
\hline
\end{tabular}

If the current $100 \mathrm{GWe}$ of nuclear electrical generating capacity were eventually replaced by nextgeneration nuclear plants, the United States would continue to avoid emissions of more than $100 \mathrm{MtC} /$ year. If, in addition, electrical demand in the United States continued to grow at $1.5 \%$ per year and the installed nuclear generating capacity grew along with it to maintain its current share of the U.S. market (22\%), then this new nuclear capacity could result in the avoidance of about $160 \mathrm{MtC} /$ year by 2030 . If the market for nuclear generated electricity expanded to $30 \%$, then the result would be an avoidance of about $250 \mathrm{MtC} /$ year by 2030 (see Fig. 2.10).

In the long term, by 2030 , the development and use of evolutionary and advanced fission reactors are projected to reduce carbon emissions by about an additional $100 \mathrm{MtC} /$ year. In the longer term, the second half of

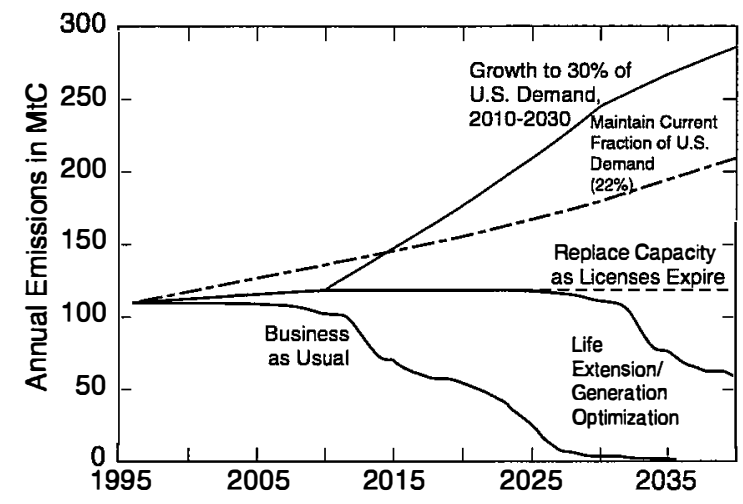

Fig. 2.10. Carbon emissions avoided under various scenarios of nuclear electricity generation. 
the twenty-first century, fusion energy systems may become a significant economic power generation source, free of GHG emissions. The actual amount of nuclear-generated electricity will depend on the future financial viability of the nuclear option.

\section{Technology Pathways and Opportunities}

Lifetime Extension and Generation Optimization. The near-term approach to the use of nuclear energy should be to provide technologies to increase electricity generation and extend lifetimes of the existing set of 108 nuclear power plants. The initial 40-year license period for these reactors will expire roughly from 2005 to 2030. If the United States is faced with replacing this capacity with fossilfueled generating plants, $\mathrm{CO}_{2}$ emissions will increase more than $100 \mathrm{MtC} /$ year. Both the renewal of plant licenses and increases in plant capacity factors can be enabled by new nuclear and nonnuclear technologies. With targeted R\&D investments in monitoring, diagnostic, and materials technologies, these nuclear plant lifetimes could be extended for an additional 20 years, and the efficiency and output of the plants could be incrementally increased, thus avoiding the GHG emissions that would result from replacing this nuclear capacity with other power generation systems.

Examples of generation optimization technologies include advanced technologies for on-line monitoring of cables and conventional equipment (pumps, valves, etc.) to minimize losses of production because of unplanned outages. In addition, improved materials measurement and diagnostic technologies could reduce scheduled downtime for diagnostics and repairs. Plants could be operated at higher net power output to the grid by using sensors and controls that more accurately measure operational parameters, thereby reducing in-plant power demands, improving the thermal-to-electric conversion efficiency, and increasing the core power.

Nuclear power plant life extension hinges on the resolution of issues related to the aging of key components, including reactor pressure vessel embrittlement, stress corrosion cracking of reactor internals, degradation of instrumentation and power cables, and steam generator tube cracking. The effort to resolve these issues could also benefit from improved instrumentation and materials characterization technologies. In addition, R\&D on in situ component annealing and on materials cladding processes could provide effective and economical repair technologies. Specific examples of approaches that offer the promise of resolving these issues include gasfired thermal annealing, water chemistry control to avoid stress corrosion cracking, and various approaches to the deposition of lining materials.

Next-Generation Fission Reactors. The mid-term approach to the use of nuclear energy is to develop and install next-generation fission reactors. Even if LEGO technologies were fully utilized, a major increase in carbon emissions could only be avoided through new nuclear capacity after 2015, which would replace existing reactors that reach the end of their lives.

Evolutionary designs for nextgeneration fission reactors have received Nuclear Regulatory Commission licensing certification and are available for construction today without significant research; 
several have been built in Japan. These designs are simple and rugged, and they incorporate passive safety features intended to provide safer, more trouble-free operation over 60-year design lifetimes. Advanced fission reactors, which use fuel cycles that are proliferation resistant, are also designed for higher efficiencies coupled with improved safety compared with currently operating plants.

The long-term (beyond 2030) approach to the use of nuclear energy would likely use nuclear reactor concepts, such as the liquid-metal cooled fastspectrum reactor, that extract far more of the energy available in the uranium fuel than the $1 \%$ currently used and that produce less waste per GWe, thus extending the resource. In addition, efforts are under way to develop accelerator-driven systems using highenergy protons to produce nuclear energy from subcritical targets.

Finally, one can conceive of a new set of technologies that could be implemented in the next century. The concept of a hybrid nuclear-hydrogen cycle in which nuclear heat is used for production of hydrogen, with subsequent use of hydrogen as an energy source, has considerable potential. R\&D on fission heat-tohydrogen conversion technologies and on hydrogen distribution technologies has the longer-term potential to produce fundamental changes in the world's energy supply approach and make it consistent with our ecological goals.

Fusion Power. Fusion power, when developed and deployed, would be a carbon-free energy source. The U.S. domestic fusion energy sciences program is concentrating on science and innovation supporting the development of attractive fusion systems based on toroidal magnetic configurations. It also supports a small $R \& D$ effort on driver systems for inertial fusion energy. Most of the research effort for the inertial approach to fusion energy is supported for its defense applications. The development of technologies required for fusion, and the pursuit of ignited or burning plasmas, are being pursued through international collaboration.

\section{Collateral Benefits}

One collateral benefit of the continued pursuit of nuclear power would be the economic benefit of serving as a domestic and international supplier for this major electric power technology. The increased use of nuclear energy is foreseen around the developing world, especially in the Pacific Rim countries. As of today, the United States has invested $\$ 200$ billion in nuclear power plants and has 400,000 nuclear-related jobs. In addition, a benefit of pursuing LEGO technologies would be enhanced safety and reduced worker radiation dose at existing plants.

Furthermore, if the United States did not pursue research into nextgeneration reactors, there would be several negative impacts. The first would be the loss of the technical infrastructure to support the nuclear enterprise, which also supports nuclear medicine, isotope production, and neutron science. This loss could also lead to increasing safety concerns for existing reactors. The second would be the decreased ability to design and construct fission, and eventually fusion, plants to export or to replace the existing ones in the United States at the end of their lives. Finally, with the loss of U.S. infrastructure, the ability to influence the nuclear policy of other countries would disappear. 


\section{Technical Risks and Other Issues}

Nuclear power faces environmental risks and issues, including the disposal of nuclear wastes. But most of all, the risk is economic. Nuclear power shares the same economic attributes of many renewable technologies - a high fixed cost and a low variable cost-that make market penetration difficult today in the United States. Technology R\&D along the technology pathways outlined here could have a major impact on alleviating all of these risks.

\section{Strategy and Recommendations}

Nuclear technology is currently offsetting approximately $140 \mathrm{MtC}$ emissions per year. Pursuit of technologies for both LEGO and nextgeneration nuclear power would allow this offset to continue, as well as provide additional GHG emission reductions in the future. Successful development and use of improved nuclear power technologies could also have a major impact on global GHG emissions.

This study recommends pursuit of nuclear energy $R \& D$ to provide the United States and the world with an improved nuclear technology option to help address the very challenging climate change issue. Continued support of a broad base of concepts in fusion $R \& D$ is required, and, as these concepts mature, investment will be necessary and appropriate.

\subsubsection{Renewable Energy}

\section{The Potential for Reduced Emissions}

Renewable energy pathways-using energy from sunlight, wind, rivers and oceans, the hot interior of the earth (geothermal energy), and biomass (agricultural and industrial wastes, municipal solid waste, energy crops) to produce electricity, fuels, and heathold significant potential for reducing GHG emissions in the next century by displacing fossil-fuel-generated electricity or petroleum transportation fuels. This potential is shown in the table below and is compared with the business-as-usual carbon projections in Fig. 2.11.

Estimated carbon emissions reductions (MtC/year)

\begin{tabular}{lccc}
\hline & 2010 & 2020 & 2030 \\
\hline $\begin{array}{l}\text { Total renewable } \\
\text { energy }\end{array}$ & $30-60$ & $75-130$ & $135-260$ \\
\hline Assumes successful technology development
\end{tabular}
and subsequent marketplace adoption without significant policy changes.

All regions of the United States have renewable resources of one type or another. Renewable resources currently account for about 8 to $10 \%$ of the energy consumed in the United States; most of this is from hydropower and traditional biomass sources. Solar, wind, and geothermal technologies are cost-effective today in small and niche markets, which are important steps to full commercialization.

- In the electricity sector, renewable power avoids emission of about

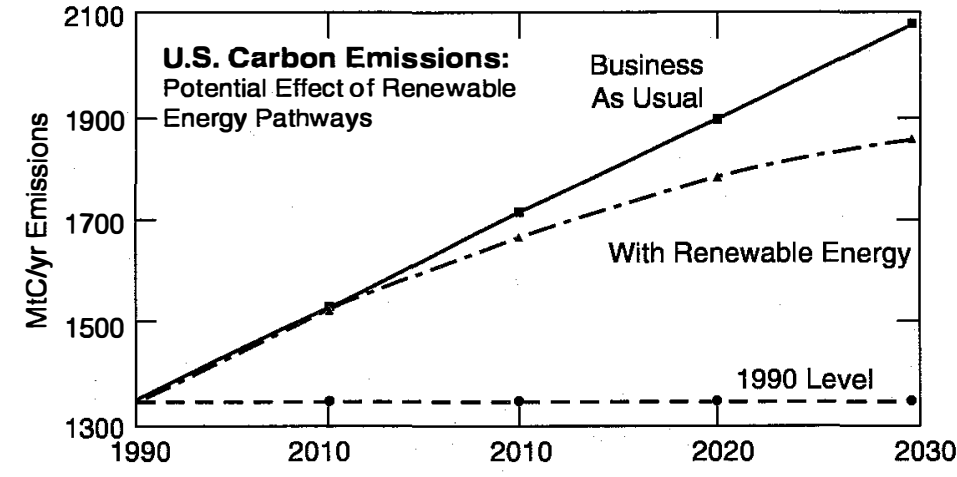

Fig. 2.11. Renewables have the potential for significant reductions of U.S. carbon emissions. 
$70 \mathrm{MtC}$ per year at the present emissions rate of $0.17 \mathrm{MtC} / \mathrm{TWh}$ for electricity.

- Renewable energy technologies are well along a path of decreasing cost (Fig. 2.12), making their expanded commercialization prospects very realistic for early in the next century.

- A level of $20 \%$ use in 2025 and $50 \%$ use in 2050 is foreseen for the world in a number of projected energy scenarios from, for example, Shell Petroleum Limited (1996), the World Energy Council, and the International Panel on Climate Change (1995). A group of U.S. environmental organizations has also projected the future uses of renewables in the United States in a just-released report, Energy Innovations (1997).

Each of the renewable energy technologies is in a different stage of research, development, and commercialization; and all have differences in current and future expected costs, current industrial base, resource availability, and potential impact on GHG emissions. Appendix B describes each of these aspects of the various technologies.

While today's renewables are usually more expensive than the conventional competition on a first-cost basis, they are cost-effective in certain niche markets, especially on a life-cycle-cost basis. Several technologies produce electricity from renewable sources; those nearing commercialization face common problems such as difficulty in obtaining capital, uncertainties related to future electric utility restructuring, and current competition from natural gas. Those technologies further from commercialization need more emphasis on $R \& D$, from fundamental research to resolution of process scaleup issues.
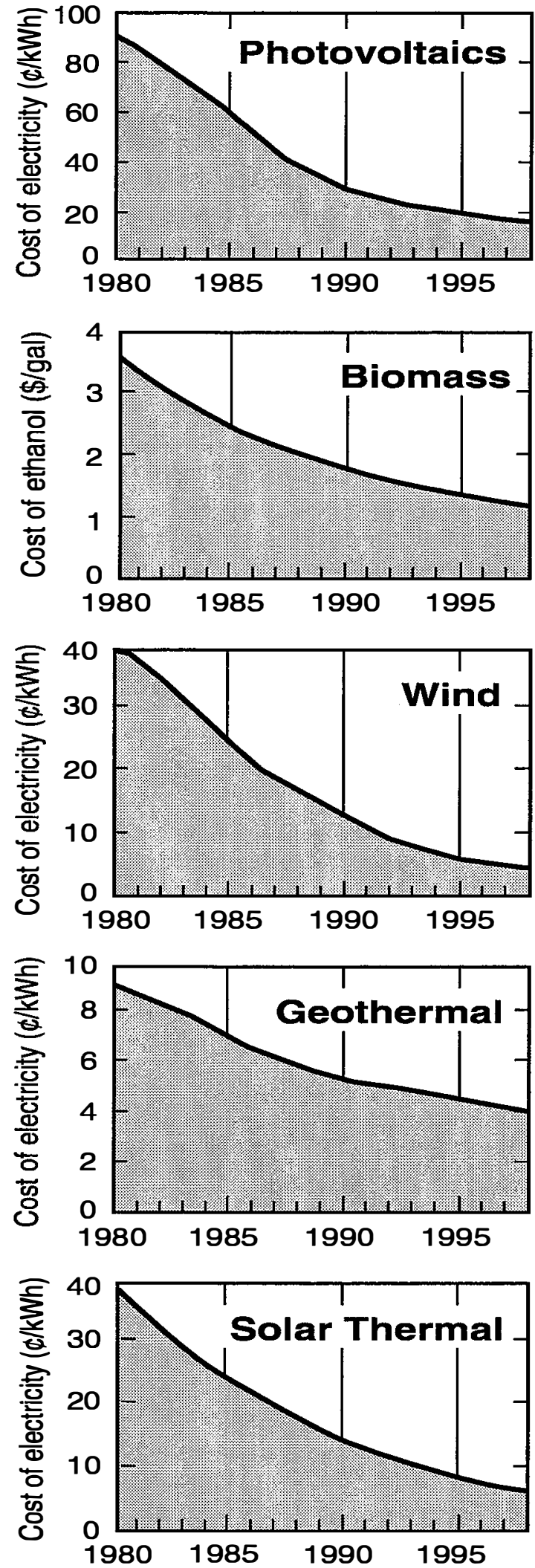

Fig. 2.12. Renewable energy technologies are well along a path of decreasing costs. 


\section{Technology Pathways and Opportunities}

Biomass Electric refers to technologies that generate electric power from such biomass resources as cofiring biomass with coal, using biomass as the sole fuel in new power plants, or gasifying biomass to replace natural gas. From now through 2010, new biomass electric technologies (including landfill gas) are likely to be commercialized and should have a strong impact on $\mathrm{CO}_{2}$ emissions. Biomass cofired with coal could also replace a significant portion of coal in electricity production in the near term. Biomass gasification could have a major impact in the forest products industry during the next 10 to 15 years, when many existing boilers will be replaced. RD\&D challenges include resolving issues around ash chemistry and $\mathrm{NO}_{\mathrm{x}}$ reduction, demonstrating long-term operation of gas turbines on synthesis gas, improving materials, developing sufficient energy crops for feedstocks, and demonstrating advanced technologies.

Wind Energy systems today are very close to being cost-competitive, on a levelized cost basis, with projects at $\$ 0.04$ to $\$ 0.07$ per $\mathrm{kWh}$; nearly $1800 \mathrm{MW}$ are installed in the United States, and another $6000 \mathrm{MW}$ in other nations. High-quality wind resources are available in 34 of the 50 states and could provide major carbon off sets before 2010. Technology challenges to achieve lower cost and increased reliability include further advances in the understanding of wind flow, aerodynamics, structural dynamics, advanced power conversion devices, and development of durable and lightweight structural components. In the near term, up to 10 to $20 \%$ of a region's electrical capacity could be from wind power without any adverse operating or economic effects. Larger market penetrations in the mid to long term would require addressing the impact of the variation of wind through modification of systems operation, hybrids with other technologies, energy storage, transmission and infrastructure, and improved wind forecasting.

Studies on the effects of avian-wind turbine interactions have shown that when wind turbines are properly sited in areas of low avian usage (away from high resident local populations and migratory flyways), then bird fatalities are negligible.

Hydropower currently generates $10 \%$ of the nation's electricity, but generation is declining. Current technology often has adverse effects on fish and downstream water quality and quantity; the goal is to generate electricity without these adverse effects. R\&D challenges include quantifying the biological response of fish affected by hydropower projects, modeling the forces inside turbines to predict stress levels on fish, and demonstrating the cost-effectiveness of retrofits.

Solar Photovoltaic (PV) technology uses semiconductor-based cells and modules to directly convert the energy of sunlight to electricity. PV can be used to produce electricity on almost any scale, depending only on how many PV modules are connected together. About $100 \mathrm{MW}$ of PV modules were sold in 1997; annual growth has been 15 to $20 \%$. Hundreds of U.S. applications are currently costeffective for off-grid electric power needs, such as powering remote telecommunications installations and utility sectionalizing switches. International interest is also very high. PV costs are currently too high for bulk power generation, but costs are decreasing rapidly. Goals are to 
compete for peak power shaving by 2010 , then daytime utility electricity by 2020 . RD\&D challenges including improving the fundamental understanding of materials and processes to provide a technology base for advanced PV options, optimizing cell and module materials and design, scaling up cells to product size, validating performance in outdoor and accelerated conditions, and improving manufacturing processes.

Geothermal Energy technologies use energy from within the earth to produce electricity or provide heat for industrial processes. Geothermal heat pumps use the thermal mass of the earth as a heat sink for airconditioning and heating.

Hydrothermal reservoirs produce about $2100 \mathrm{MWe}$ in the United States and about $6000 \mathrm{MWe}$ worldwide. In the United States, direct-use applications produce about $400 \mathrm{MWt}$; heat pumps produce $4000 \mathrm{MWt}$ and are increasing by $25 \%$ per year. Only a small fraction of the huge geothermal resource can be used economically today. With research and policy support, electricity production could be doubled, and thermal production (including heat pumps) could be tripled or more. Geothermal RD\&D challenges include improved methods for predicting reservoir performance and lifetime, innovative low-cost drilling technologies, new concepts to expand the use of the resource, improved energy conversion through thermal and fluids science and modeling, and lowering costs through thermal science and process chemistry.

Solar Thermal Electric and Buildings includes technologies that concentrate the heat of the sun to generate electricity or use the heat directly. Solar thermal electric technologies have been successfully demonstrated in nine commercial plants (354 MW) operating in California. Using existing, relatively conventional technology, including unique cost-effective storage, hundreds of additional megawatts of peaking power could be on-line by 2005; and evolutionary R\&D improvements will allow bulk power market penetration by 2020 . Solar hot water systems are commercially available, and ventilation preheat systems using unglazed transpired collectors have made significant progress in commercial/industrial markets. RD\&D challenges include improving performance and lifetime and reducing manufacturing costs with improved designs and manufacturing technologies, and addressing commercialization challenges similar to those facing wind energy.

Biomass Transportation Fuels include methanol, ethanol, and hydrogen, which can displace petroleum in internal combustion engines. Biomass sources, including agricultural and other wastes, energy crops, and microalgae, are converted to fuels through biotechnology methods (using microbes) or through thermochemical processes. $R \& D$ goals are to demonstrate a biomass waste-to-fuels process with an industrial partner by 2000 and larger-scale production and conversion technologies by 2005 . By 2010 , energy crops should begin to be available, allowing biofuels to compete with petroleum for direct fuel replacement. $R \& D$ challenges include low-cost production of enzymes, development of microorganisms for consolidated processes, improved performance of thermochemical processing, and advances in energy crop productivity, cultivation, and harvesting. Biomass transportation fuels are also discussed in Transportation Sect. 2.3.3. 
Solar Advanced Photoconversion technologies use the energy of sunlight to directly produce fuels, materials, chemicals, and electricity from renewable sources such as water, $\mathrm{CO}_{2}$, and nitrogen. Most of these technologies-involving photobiological, photochemical, and photoelectrochemical approaches-are in the fundamental research stage where technical feasibility must be demonstrated. Examples of these natural and artificial photosynthesis processes include producing hydrogen from water or biomass and producing biodiesel, methane, and methanol from water, waste, and $\mathrm{CO}_{2}$.

\section{Collateral Benefits}

A significant increase in the use of renewable energy pathways would provide benefits beyond reducing GHGs, such as lessening the reliance on foreign oil (especially biomass for transportation fuels), contributing little to waste storage or safety problems, and reducing pollutants. Renewable resources are widespread around the world, are highly attractive to developing countries, and represent a huge potential market for U.S. companies.

\section{Technical Risks and Other Issues}

The technical risks vary among the pathways, but there are clear R\&D paths to address these risks. Overall, ecological and human health risks are low. Commercial, regulatory, and economic risks are generally moderate to high. In many cases, first costs are higher than for conventional energy choices, while the benefits of renewables do not currently motivate and reward private investment.

Mechanisms are required that acknowledge the public value of renewables and help to attract private capital to develop these technologies.
Small renewable energy companies in the United States face very strong international competition. Finally, decisions made under utility restructuring will have a major impact on market penetration for renewable electricity technologies.

Supporting $R \& D$ is needing in a variety of basic science and crosscutting areas, such as photosensitive materials, innovative semiconductors, corrosion-resistant and highertemperature materials, biotechnology, catalysts and separations systems, sustainable agriculture, sensors and controls, electrical components, and computational modeling. A wide range of energy storage and transmission systems-along with the production of hydrogen as transportation fuelwould broaden the opportunities for the deployment of intermittent renewable energies, such as wind, solar photovoltaic, and solar thermal electric.

\section{Strategy and Recommendations}

Eventually, the private sector is likely to complete the development and commercialization of renewable energy technologies. But well-considered and sustained government investments, both in the underlying R\&D and in actions that will remove deployment barriers, are critical. This is the most important step in realizing the full potential that renewable energy pathways can contribute to reducing carbon emissions early in the next century.

Significant investment would be required from both the private and the public sectors. Currently, the annual federal investment is about $\$ 250$ million for these pathways. Increased federal investments to reduce carbon emissions would also return additional environmental 
benefits and the opportunity for U.S. companies involved in the area to be key players in the $\$ 1$ trillion global energy market and the $\$ 400$ billion market for environmental technologies.

\subsection{CARBON SEQUESTRATION AND MANAGEMENT}

This section discusses the reduction of net carbon emissions by capturing and sequestering $\mathrm{CO}_{2}$ after combustion, decarbonizing fuel before combustion, or increasing the absorption of $\mathrm{CO}_{2}$ from the atmosphere. These approaches are required for the continued use of fossil fuels as energy sources with reduced impacts on concentrations of atmospheric $\mathrm{CO}_{2}$. For both approaches, there are a number of technological options, ranging from storage of $\mathrm{CO}_{2}$ in the ocean or in geologic formations to chemical or biological stimulation of the absorption of $\mathrm{CO}_{2}$ from the atmosphere.

The eventual path to stabilization of atmospheric $\mathrm{CO}_{2}$ concentrations would require portfolios of GHG reduction technologies, portfolios that would vary from nation to nation and require systems-level analysis. Risks associated with any one pathway suggest that developing an effective approach to large-scale carbon sequestration would require evaluation of a number of alternatives as described in this report. These ideas and technologies should have a sound basis in science, both for understanding each technology and for evaluating the effectiveness of the technologies in actually ameliorating the atmospheric carbon loading. Thus it is imperative that we have a sciencebased model of the carbon cycle (atmospheric, oceanic, and terrestrial ecosystems) and that we verify the actual effectiveness of our model through measurements. One set of essential elements are models of each part of the carbon cycle, anchored with georeferenced measurements and verified by checking performance predictions against data gathered using remote sensing technologies on local, regional, and global scales. The resulting science-based program would permit us to direct our investments with greater confidence and with improved cost-effectiveness.

\section{The Potential for Reduced Emissions}

The developmental status of the carbon sequestration technologies discussed in this report varies widely. For example, the injection of $\mathrm{CO}_{2}$ into oil wells or coal seams to enhance oil or methane production is a commercial practice today, whereas the understanding of soil biochemistry is not yet adequate to identify the most promising means for increasing soil uptake of atmospheric $\mathrm{CO}_{2}$. Therefore, estimating the potential impacts of these carbon sequestration technologies on net carbon emissions is difficult. It is generally believed that net carbon emission reduction from carbon sequestration could be very high in the time frame of the late 2030s and beyond. In the nearer term, carbon sequestration potentials are uncertain, but they may range from low to medium. All of these estimates should be considered possible targets and should only be considered within an order of magnitude indication of what might be likely to result from $R \& D$ on these technologies.

\section{Technology Pathways and Opportunities}

$\mathrm{CO}_{2}$ and Carbon Storage Technologies. Promising concepts for reducing $\mathrm{CO}_{2}$ emissions are the storage of $\mathrm{CO}_{2}$ in the ocean or in geologic formations. The technical feasibility of both of these 
storage concepts has been established, and it is believed that the $\mathrm{CO}_{2}$ escape rates in both cases could be low enough to consider the carbon as permanently sequestered. However, the ecological impacts of various specific approaches-which are likely to depend on the location and type of storage media-are not known, nor are the economics of different oceanic or terrestrial $\mathrm{CO}_{2}$ injection technologies.

For ocean storage, the most critical $R \& D$ questions include the stability of $\mathrm{CO}_{2}$ clathrates and hydrates at various temperatures and ocean depths, as well as the diffusivity of $\mathrm{CO}_{2}$ in the ocean, again as a function of temperature, depth, and concentration. In addition, the biological impacts of oceanic injection need to be studied.

Terrestrial storage of $\mathrm{CO}_{2}$ in depleted oil or gas wells, coal seams, or underground aquifers deserves analysis. For the injection of $\mathrm{CO}_{2}$ into oil or gas wells or coal seams, which has enhanced oil and gas production (as well as, perhaps, mine safety), to be commercially motivated, the critical research questions center on understanding the total potential storage capacity and the economics of different specific candidate sites. Answers to these questions will depend on proximity to $\mathrm{CO}_{2}$ sources, as well as on the size and other characteristics of the site.

For storage in underground aquifers, the critical research questions include fluid, thermal, geological, and chemical properties of aquifers and the implications of that environment for injected $\mathrm{CO}_{2}$. For example, would the formation of complex carbonates result from $\mathrm{CO}_{2}$ injection, and at what rate? The economics of such $\mathrm{CO}_{2}$ storage also needs to be analyzed.

A third approach to reducing net emissions through storage is the terrestrial storage of elemental carbon. This concept basically entails removing some or all of the carbon from a fossil fuel and then storing the carbon as a solid. For this approach, the challenge is primarily economic, because the carbon component of the starting fossil resource represents a major part of the energy value of that resource. Not using the carbon fraction in effect increases the energy cost of the remaining hydrogen-rich energy fraction. The advantage of this approach is that it should be less expensive to store carbon than to store $\mathrm{CO}_{2}$. It may also be possible to market the carbon as a materials commodity to offset the increased energy cost. If carbon is placed in retrievable storage, the carbon energy may be used at a later date under less severe $\mathrm{CO}_{2}$ emission control conditions.

Currently, storage is believed to be relatively less expensive than capture technologies, but neither is being employed on a large scale. This, however, will change with time as combustion processes are reengineered to facilitate capture. As the cost of capture comes down, storage becomes a greater part of the cost equation. Managing this cost suggests that storage near the point of combustion is advantageous because it reduces the transportation cost of the waste carbon.

Which of the storage pathways is best matched to any single combustion or conversion location will vary, so parallel development is required. As discussion of the individual technology pathways highlights, it is important to emphasize that very clear technological and environmental risks are associated with these technologies. The R\&D agenda must therefore be very aggressive if cost-effective technologies are to be in place in time. 
Advanced Chemical and Biological Sequestration. There are also several advanced chemical and biological concepts for $\mathrm{CO}_{2}$ sequestration, including

- chemical sequestration as a mineral carbonate

- direct solar conversion of $\mathrm{CO}_{2}$ to methanol or other benign products

- reducing the carbon/hydrogen ratio of fossil fuels and capturing the excess carbon

- microalgae sequestration

Advanced chemical and biological sequestration is aimed at permanent stable sequestration and at recycle of carbon to new fuels and chemical feedstocks. Reduction of emissions is accomplished through converting $\mathrm{CO}_{2}$ into an environmentally benign product, reducing atmospheric $\mathrm{CO}_{2}$ while generating liquid fuels, generating hydrogen as a fuel from coal without $\mathrm{CO}_{2}$ emissions, and converting $\mathrm{CO}_{2}$ into organic compounds. The major advantage of these technologies is that they eliminate the hazards to humans and to the environment that are intrinsic in the disposal of gaseous $\mathrm{CO}_{2}$. Carbonate disposal accomplishes this by forming environmentally benign and

thermodynamically stable waste forms; the other approaches instead generate viable products. All of these are at a research stage, with conceptual engineering design currently being completed. A better understanding of the basic processes is needed before practical achievable technology performance or cost levels can be estimated. However, because of the inherent attractiveness of these sustainable solutions, further work is merited.

Technologies for Removing $\mathrm{CO}_{2}$ from the Atmosphere. The annual exchange of $\mathrm{CO}_{2}$ between the atmosphere and the combination of the ocean and terrestrial biosphere is very large (IPCC 1995):

- gross annual atmosphere-ocean exchange-approximately 92 GtC

- gross annual atmosphere-terrestrial exchange-approximately 63 GtC (IPCC 1995)

- oceans currently hold 44,000 GtC

By comparison, the total annual anthropogenic emissions of $\mathrm{CO}_{2}$ are only around $7 \mathrm{GtC}$. This suggests that small increases in the absorption of $\mathrm{CO}_{2}$ as a manipulation of the global carbon cycle could have a very significant effect on net GHG emissions.

Dissolved $\mathrm{CO}_{2}$ in the oceans is removed by the growth of phytoplankton. When carbon is thus removed, it is ultimately replaced by $\mathrm{CO}_{2}$ drawn from the atmosphere. Two concepts have been proposed for enhancing oceanic uptake of atmospheric $\mathrm{CO}_{2}$. These are iron enrichment or nitrogen enrichment, both targeted at stimulating the growth of phytoplankton. The general understanding of these approaches is in its infancy. While some experiments on iron fertilization have been conducted, no such studies of nitrogen fertilization exist. Key questions include what rates of $\mathrm{CO}_{2}$ uptake can be achieved, what the biological impacts are, and to what extent the gains would be offset by carbon or methane emissions resulting from increasing harvests or decay of higher levels of the food chain. The economics of these approaches, which depend directly on the costs and efficacy of different fertilization approaches and rates, also need to be studied. An important risk factor is that of anoxia, or oxygen depletion, which needs to be understood as a function of site characteristics and fertilization rates. 
An important component of terrestrial uptake of $\mathrm{CO}_{2}$ is plant growth, which is treated in the Agriculture and Forestry technology pathway. However, carbon sequestration in soils is also a key of the carbon cycle. The fundamental concept here is the level of "soil organic matter" (SOM). Many agricultural practices, such as breaking of grasslands for crop farming or draining of wetlands, tend to decrease SOM. Technologies that can increase SOM include minimum tillage agriculture, increased return of crop residues to the soil, use of irrigation and fertilizers at levels that maximize crop and root biomass, and return of lands to forests or perennial plants. The most critical R\&D needs include research on soil productivity (including the interactions of fertilization levels), tillage practices, water management practices, different plant species, regional soil biochemistry and climate, and the implications of these for affecting SOM. A better understanding of these factors and their interactions can then enable the analysis of the economics of specific technological approaches to increasing SOM.

\section{Collateral Benefits}

The most important benefit of successes with these carbon sequestration technologies would be that they could help to enable the continued extensive use of fossil fuels without harm to the climate. Thus they could indirectly have a major impact on global economics, given that economic growth is highly dependent on energy use, about $75 \%$ of which is derived from fossil fuels.

\section{Technical Risks and Other Issues}

The most important risks for these carbon sequestration technologies are environmental and economic. Each has the potential for environmental damage, and developing means to prevent that is a primary research need in each case. The economics for all of these technologies should be analyzed to determine their actual carbon sequestration potential and their associated costs.

The risks that are difficult to quantify today, however, are those associated with scaling up limited but promising field experiments to full-scale practice. The global infrastructure requirements for realizing large net carbon sequestration rates from carbon sequestration technologies would require a system of technologies that match or exceed the infrastructure requirements of the fossil fuel combustion enterprise of the next century. It will only be through an aggressive $R \& D$ program that we can develop a fundamental understanding of these risks.

\subsection{REFERENCES}

Cramer-Kresselt Research 1996. Facilities and Real Estate Strategies, prepared for the National Summit on Building Performance, November.

EIA (Energy Information Administration) 1996a. Annual Energy Outlook 1997: with Projections to 2105, DOE/EIA-0383 (97), U.S. Department of Energy, Washington, D.C., December.

EIA (Energy Information Administration) 1996b. Emissions of Greenhouse Gases in the United States 1995, DOE/EIA-0573 (95), U.S. Department of Energy, Washington, D.C.

Energy Innovations 1997. Energy Innovations: A Prosperous Path to a Clean Environment, Alliance to Save 
Energy, American Council for an Energy-Efficient Economy, Natural Resources Defense Council, Tellus Institute, and Union of Concerned Scientists, Washington, D.C.

Interlaboratory Working Group 1997. Scenarios of U.S. Carbon Reductions: Potential Impacts of Energy-Efficient and Low-Carbon Technologies by 2010 and Beyond, September.

IPCC (Intergovernmental Panel on Climate Change) 1995. Climate Change 1995: The Science of Climate
Change, ed. J. T. Houghton, L. G. Meira Filho, B. A. Callander, N. Harris, A. Kattenberg, and K. Maskell, Cambridge University Press, Cambridge, U.K.

Shell Petroleum Limited 1996. World's Energy Systems, Group Internal Affairs, Shell Centre, London.

The National Corn Growers Association and Inverizon International, Inc. 1997. Plant/Crop Biobased Renewable Resources 2020. 
3. BASIC AND APPLIED RESEARCH AND CROSSCUTTING TECHNOLOGIES
Scientific research and the technological advances associated with it have been the basis for a multitude of new technologies that have appeared in the last 20 years. Many of the most successful and globally competitive industries in the United States (e.g., semiconductors, pharmaceuticals, aeronautics, biotechnologies) have strong ties to the products of U.S. R\&D. The future security of our energy resources, the quality of our lives and health, and the competitiveness of our industries increasingly depend on further scientific and technological advances (R\&D Magazine 1997). To create the innovative technologies required for energy systems with reduced carbon emissions requires (1) a broad interdisciplinary and visionary research program that develops the scientific understanding of the problem and (2) a strong industrial base.

Are there critical paths forward that require technological advances? If so, what types of research will enable those advances? At a workshop on R\&D integration, Dr. Mary Good, until recently an undersecretary for technology for the U.S. Department of Commerce, concluded that basic research is the major factor that will determine the long-term outcomes of the technologies used to control carbon emissions. But reducing the levels of carbon emissions in the United States will require a commitment to both basic and application-driven research. In addition, disparate technologies for emissions control often will require work in the same critical basic research areas. Advances in both crosscutting basic research and enabling technologies are required to provide technological options like those outlined in Chap. 2 to reduce GHG emissions (Table 3.1).

This chapter addresses basic research needs and identifies a set of enabling technologies that will support the development of a wide range of technology pathways. Basic research needs and crosscutting technology developments are aggregated in the following list. 
ORNL 97-125605

Table 3.1. Most pressing research and enabling technology needs identified for each of the technology pathways presented in Chapter 2. Shaded boxes indicate a strong need for specific basic science or enabling technologies to advance a specific technology pathway. White boxes indicate that work in that basic research or technology area could be useful to develop a technology pathway

\begin{tabular}{|c|c|c|c|c|c|c|c|c|c|}
\hline & \multicolumn{4}{|c|}{ Energy efficiency } & \multicolumn{4}{|c|}{ Clean energy } & \multirow[b]{2}{*}{ CS } \\
\hline & Bld & Ind & Trn & $A \& F$ & FRD & FPG & Nuc & Ren & \\
\hline $\begin{array}{l}\text { Modeling } \\
\text { and } \\
\text { measurements }\end{array}$ & 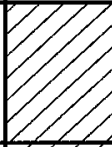 & Engy & Pp/py & DPpP, & DPFAקA & ENop & Hep/ & Bp/py & PAPA \\
\hline Materials & B/Pק/P & Eng & HpApt & & DPPAPA & Enpy & Dקp/p & BPfPA & Ppy \\
\hline $\begin{array}{l}\text { Chemical } \\
\text { sciences }\end{array}$ & D/p/p & Dysty & P/p/A & DPPAPAP & DPfy & ENpy & & Hpy & PAPA \\
\hline Biotechnology & & Enyty & & BPfPA & & & & 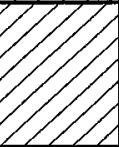 & Hpy \\
\hline Geosciences & & & & DPFP & EPFPA & & & & HAf \\
\hline $\begin{array}{l}\text { Environmental } \\
\text { and ecological } \\
\text { sciences }\end{array}$ & & Engy & & Defpy & EPPAP & & & 7 & HPAPA \\
\hline $\begin{array}{l}\text { Nuclear } \\
\text { sciences }\end{array}$ & & & & & & & D & & \\
\hline $\begin{array}{l}\text { Computational } \\
\text { sciences }\end{array}$ & & & & & & & & & PPAPA \\
\hline $\begin{array}{l}\text { Hydrogen } \\
\text { and } \\
\text { fuel cells }\end{array}$ & E/P & & Pp/pA & & & & Dy & & \\
\hline $\begin{array}{l}\text { Electrical transmission } \\
\text { distribution, and } \\
\text { components }\end{array}$ & & & & & & & & Pि/קAק & \\
\hline $\begin{array}{l}\text { Sensors } \\
\text { and } \\
\text { controls }\end{array}$ & & & Pp/py & & & & 81 & & \\
\hline $\begin{array}{l}\text { Energy storage } \\
\text { and } \\
\text { retrieval }\end{array}$ & W/Pק/P & 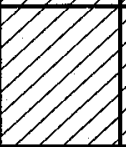 & Pp/PA & & & & & & PPPAPA \\
\hline $\begin{array}{l}\text { Bld = buildings, Ind = in } \\
\text { FRD = fossil resource d } \\
\text { CS = carbon sequestrat }\end{array}$ & $\begin{array}{l}\text { dustry } \\
\text { evelo }\end{array}$ & 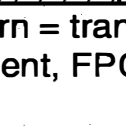 & spol & & 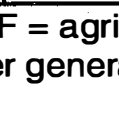 & ultur & $\mathrm{no}$ & try, & \\
\hline
\end{tabular}


- basic research to understand the global carbon cycle (i.e., computational modeling and measurements to understand the ocean-atmosphere-terrestrialbiosphere interactions)

- basic research supporting GHG reduction technologies (i.e., materials, chemical sciences, biotechnology, geosciences, environmental and ecological sciences, nuclear sciences, and computational sciences)

- enabling technologies supporting GHG reduction technologies (i.e., hydrogen and fuel cells; electrical transmission, distribution and components; sensors and controls; and energy storage)

The sections of this chapter of the report draw heavily upon the draft white paper, Carbon Management: Fundamental Research Needs Assessment (August 6, DOE-OER) and the report of the Secretary of Energy Advisory Board (SEAB 1995).

\subsection{RESEARCH TO ADVANCE UNDERSTANDING OF THE GLOBAL CARBON CYCLE}

$\mathrm{CO}_{2}$ emissions from fossil fuels are divided among the atmosphere, ocean, and terrestrial biosphere.

Measurements indicate that the atmosphere is storing carbon at a rate roughly equivalent to $60 \%$ of the emissions being produced by fossilfuel consumption. Additional quantities of the excess carbon emissions are being stored in the ocean, where they do not affect the earth's radiation balance. Carbon storage changes in the terrestrial biosphere are difficult to measure and/ or model; but there is reason to suspect that, while some areas are losing their ability to store carbon as a result of land-use changes, carbon storage is increasing in other areas. Therefore, a satisfactory balance of the contemporary global carbon budget has not yet been reached. In order to plan, assess, and verify the performance of $\mathrm{CO}_{2}$ sequestration strategies, the fate of emitted $\mathrm{CO}_{2}$ must be understood and quantified on a global scale.

Verification of the fate of anthropogenic $\mathrm{CO}_{2}$ via direct measurement programs is now technically feasible in both the atmosphere and the oceans. It is becoming possible to infer changes in terrestrial carbon storage using tracer methodologies, remote sensing, and modeling.

In general, $\mathrm{CO}_{2}$ sequestration strategies and scenarios must be based on the assumption that the natural carbon cycle will function largely as it has over the past several thousand years. However, in the context of elevated $\mathrm{CO}_{2}$ levels and perhaps of altered climates in the future, this assumption is not necessarily valid. Basic research is therefore required to identify and evaluate possible feedback on future atmospheric levels of $\mathrm{CO}_{2}$. This feedback could arise from either direct effects (e.g., $\mathrm{CO}_{2}$ fertilization of terrestrial plant growth, ocean ecosystem changes due to $\mathrm{CO}_{2}$-related $\mathrm{pH}$ changes) or indirect effects (e.g., climate-related changes in deep-ocean circulation that might alter the sequestration of fossil-fuel $\mathrm{CO}_{2}$ ).

\subsubsection{Global Carbon Cycle Modeling and Measurement}

Coupled atmospheric, terrestrial, and oceanic models are required for basic understanding of the integrated response of the global environmental system and for predicting changes in the global carbon cycle (see Fig. 1.1). This level of complex systems modeling demands high-performance computing (e.g., Accelerated Strategic Computing 
Initiative) and fundamental research in the earth and ecological sciences. High-performance computing is critical to increase spatial and temporal resolution, to implement coupling between subsystems, and include important processes in the global systems model needed to assess carbon mitigation strategies. Research is necessary to quantify feedback among the terrestrial, atmospheric, and oceanic subsystems-including the implications of global changes for local and regional environments and economies and, conversely, local and regional inputs to the global systems. These models can be used to evaluate the effectiveness of carbon mitigation technologies and, through integrated assessments, to determine the costeffectiveness and ecological impacts of carbon mitigation strategies.

In conjunction with the modeling activities, observations of the global environment are critical to document changes in the carbon cycle and to provide the basis for how and why changes are occurring. The strategy for systematic monitoring of $\mathrm{CO}_{2}$ storage is now based on direct measurements of changes in atmospheric $\mathrm{CO}_{2}$, oceanic storage of $\mathrm{CO}_{2}$, and the inferred terrestrial carbon storage. The atmospheric and oceanic measurements should be continued, and measurement systems that directly estimate terrestrial storage must be developed. These measurements must then be used to verify the predictions and to suggest continuous improvement of the models.

The U.S. Global Change Research Program (USGCRP) is implementing a global observing and monitoring system for certain key physical measurements. This should be augmented with global and regional measurements that are especially pertinent to the global carbon cycle. These efforts should be coordinated and should take advantage of all available technologies and measurement systems in addition to those of the USGCRP.

\subsection{BASIC RESEARCH RELATED TO GREENHOUSE GAS EMISSIONS}

Scientific discovery is difficult to mandate or even predict. It can, however, be stimulated by the nature of basic R\&D. The returns on investments in basic research have been immense. Who could have anticipated the profound impacts on society of the revolutionary technologies enabled through the development of, for example, antibiotics, gene therapy, transistors, structural polymers, nuclear fission, and superconductivity. Areas of visionary research that could be profitably explored to reduce GHG emissions might include developing a hydrogenbased economy, producing electric power from nuclear energy without any radioactive by-products, developing global electrical transmission using high-temperature superconductors, and significantly increasing photosynthesis processes via genetic engineering.

Scientific understanding from basic research efforts will provide the United States with a sound basis to advance technological options. Creating a strong science base makes it likely that the United States will be capable of developing a portfolio of technological options to meet GHG reduction targets. Discoveries resulting from basic research will almost certainly provide the United States with technologies that today might seem highly uncertain and unrealistic but that tomorrow might be essential problemsolving tools. Our long history of scientific progress has shown that basic scientific research alters the technological options available for 
responding to threats to our environment, security, and quality of life.

The following examples of progress in the areas of materials science, chemical sciences, biotechnology, environmental and ecological sciences, geosciences, nuclear sciences, and computational sciences could offer vastly improved or completely new technologies for reducing GHG emissions. We have already seen the pull of technology in Chap. 2; here is the push of basic science and its promise for the future.

\subsubsection{Materials Science}

Improvements in materials can significantly impact the production of GHGs and wastes. Materials found in systems that produce energy (e.g., combustors and turbines), store energy (e.g., batteries and fuel cells), and use energy (e.g., vehicles and industrial/chemical processing) can improve system efficiencies, extend component lifetimes, and increase performance or capacity (Fig. 3.1).

Furthermore, the production and processing of materials consumes the largest fraction of the energy used by U.S. industry. Reducing the energy required to supply materials is essential to reducing GHG production.

Basic research into materials synthesis and processing is needed to provide new ways to produce the materials currently used and enable the creation of new materials for energy systems. Areas in which breakthroughs are needed include nonequilibrium thermodynamics, microstructureproperties characterization, interface science, optical and electronic property optimization, and computational modeling of materials processes. Examples of potential nearterm improvements include hightemperature-tolerant materials that allow improvements in the efficiency of combustion processes, heterogeneous catalysts that increase yields and selectivity, high-temperature superconductors to reduce energy losses in electrical systems, lightweight materials to decrease vehicle weight, improved magnets for sensors and motors, improved coatings and surface treatments to reduce wear and surface degradation, improved insulation to reduce heat loss, and miniaturization of equipment to improve efficiency and reduce cost.

Interdisciplinary theoretical and experimental research in condensed

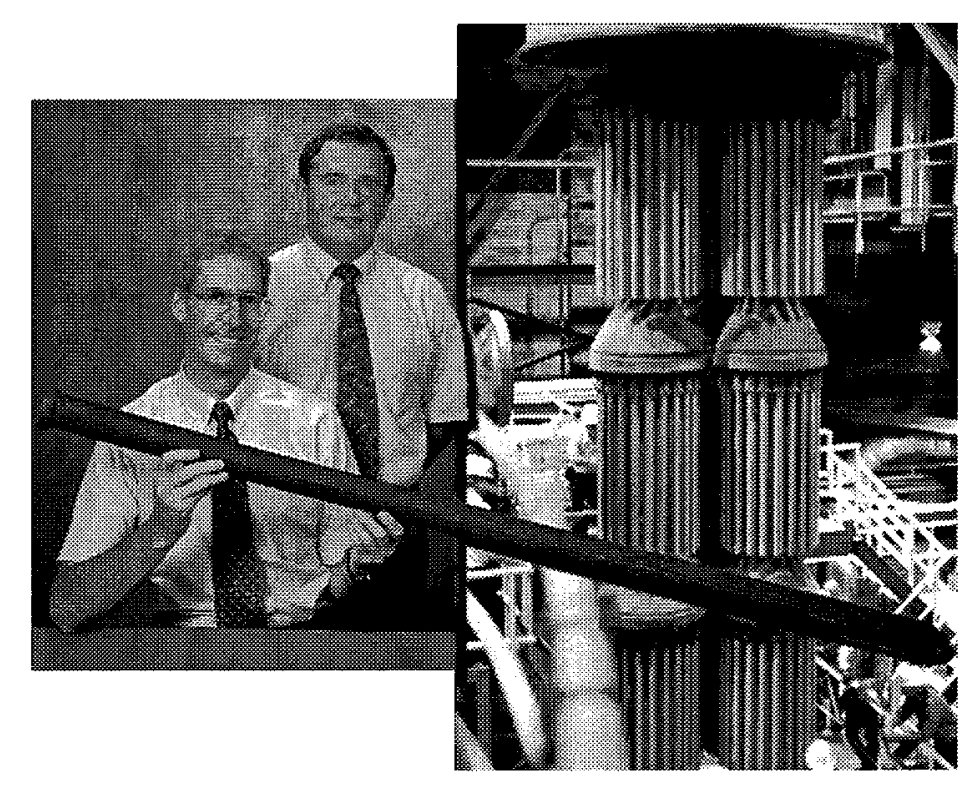

Fig. 3.1. Ceramic composite hot gas candle filters can be used to remove particulates from gas streams in combined cycle fossil and biomass power facilities. The filter is made up of an oxide fiber structure into which silicon carbide is deposited by a chemical vapor infiltration process. 
matter physics, metallurgy, bioscience, and materials chemistry are key components of a long-term research strategy. For example, crossdisciplinary efforts are needed to develop bio-inorganic composite materials systems or "smart" materials that are self-constructing or selfadapting. Interdisciplinary biological and materials research is needed to create biomimetic materials-materials patterned after nature. The development of materials engineered at the nano-scale requires the merger of materials science and condensed matter physics; the result will be optoelectronic, organic-electronic, thin film, and semiconductor materials for use in energy generation and distribution (e.g., solar cells, sensors in power plants, and power grid control circuits) and in energy-efficiency applications (e.g., engine sensors and processors, solid-state lighting and displays, advanced windows).

\subsubsection{Chemical Sciences}

Chemistry is central to the design and synthesis of a wide range of useful materials, as well as to the conversion of energy into heat, work, and light. Advances in the chemical sciences in key areas of separations, catalysis, and combustion are necessary for significant GHG reductions.

Separation processes are used to punify raw materials, separate by-products, and remove contaminants. The membrane materials market alone is currently $\$ 1$ billion. Improved separation techniques using membranes, novel separating agents, or hybrid processes could make many industrial processes more efficient while enhancing productivity and reducing environmental impacts. For example, distillation, which consumes more than $40 \%$ of the energy used in chemicals and petroleum manufacturing, seldom exceeds a thermodynamic efficiency of $10 \%$. It would benefit greatly from improved separations technology. Other industries, such as microelectronics, require new standards in separation performance to improve the purity of the components and materials used. Adsorption and ion exchange processes are attractive for removing and recovering materials from dilute systems. Pharmaceuticals, biotechnology, food processing, and pulp and paper processing use separation technologies for product preparation or waste recovery and reuse. Waste treatment and recovery constitute another potentially large market for membrane and adsorption or ion exchange systems.

Catalysts and catalytic processes account for nearly $20 \%$ of the U.S. gross domestic product and nearly $20 \%$ of consumer products. Improved catalysts could increase efficiency to shrink energy requirements, while increasing product selectivity and thereby decreasing wastes and emissions. New catalytic processes could also reduce GHG emissions in alternative fuel resources, electricity production, transportation, and carbon sequestration. Several studies (e.g., the Council on Chemical Research's Vision 2020 document) have cited critical areas for innovation in catalysis including

- the development of theoretical and experimental tools to improve understanding of catalytic processes at the molecular level, and to enhance predictive capabilities and the ability to design catalysts and develop industrial catalytic processes to increase yield, selectivity, and reliability

- methods to improve the speed of catalyst discovery 
- novel reactors and reaction engineering including reactive separation concepts

- low-temperature selective oxidation of fuel-value feedstocks to highvalue chemicals

- conversion of gases (e.g., methane) to liquid fuels and chemical feedstocks

- novel methods for producing recyclable polymers and other materials with specific designed properties

- new catalyst systems for achieving high regio- and/or stereo-selectivity, including supported catalysts

- biomimetic synthesis of chemicals and materials,

- fuel cells for cogeneration of chemicals and energy

- new, more economical abatement technologies

- on-line monitoring and in situ catalyst characterization technologies

Combustion is employed in the conversion of $90 \%$ of primary energy to end uses in the United States. It powers practically all electric power and provides most heating and process heating (either directly or indirectly, by electricity). Key R\&D needs include improved basic understanding and advanced analysis of combustion processes; nonintrusive (e.g., laser and microwave) diagnostics to improve understanding of the chemical, heat transfer, and fluid mechanics relationships that characterize combustion processes; understanding of processes that control flame shape and stability under different conditions; and flame chemistry to control emissions.

\subsubsection{Biotechnology}

Biotechnology as a crosscutting technology affects four of the nine major technology impact areas shown in Table 3.1: industry, agriculture/ forestry, renewables, and carbon sequestration. However, under the broad realm of biotechnology as it applies to reducing carbon emissions, the status of research and technologydevelopment efforts varies greatly.

The range of technological areas where biotechnology could have an impact on GHG/global carbon cycle issues is broad and includes crop improvement (including energy crops), alternative fuels other than biomass (noncellulosic), carbon cycle manipulation/sequestration, bioprocessing for fuels and chemicals, and biological/biochemical hydrogen production. Energy crop production and efficiencies in the agriculture and forest products sectors will result from advances in genetics and cropping systems. In addition to biomass energy crops, biotechnological approaches offer promise for production of other alternative fuels, including oils/lipids from algae and certain higher plants, and hydrogen from photosynthesis or enzymatic conversion of cellulosic biomass. The recent discovery of a onephoton photosynthesis system and protein engineering of the carboxylase/decarboxylase pathway offers the promise of increases in the efficiencies of carbon fixation by plants.

Fundamental studies of global carbon cycles and the importance of the biosphere as a major sink could lead to major breakthroughs in deploying biological phenomena in strategies to sequester $\mathrm{CO}_{2}$. Bioprocessing of cellulosic biomass into alternative fuels is necessary in order to realize the full value of biomass-based energy. In addition, cells and enzymes are capable of synthesizing many organic chemicals of industrial interest. Because of mild reaction conditions, unique specificity, and selectivity, 
biocatalytic conversions are now being considered for many industrial uses. Organic-phase bioprocessing, a particularly promising application, employs microorganisms and enzymes in nonaqueous media such as organic liquids, gases, or supercritical fluids. This technique could provide alternatives for processing fossil fuels, synthesizing organic chemicals, and converting alternative feedstocks to fuels and chemicals.

\subsubsection{Geosciences}

The geosciences play a central role in understanding and mitigating the impacts of carbon emissions. A better understanding of the terrestrial, atmospheric, and ocean carbon cycles-and the interactions among them-will lead to new ideas for managing excess carbon and provide the foundation for comparing alternative technologies that could contribute to carbon emissions reductions. Moreover, evaluating the feasibility of most of the mitigation technologies under consideration today will require new knowledge in such disciplines as geophysics, flow and transport, geomechanics and geochemistry. For example, the geosciences are critical for developing or enhancing technologies to inject $\mathrm{CO}_{2}$ into oil reservoirs, aquifers, and the deep oceans; increasing production of clean fuels such as natural gas; tapping into the huge natural gas supplies found in methane hydrates; and enhancing the natural carbon cycle to capture and sequester more carbon. In addition, closing the nuclear fuel cycle through geologic disposal of nuclear waste is critical to the widespread future use of nuclear power generation.

A fundamental research program in the geosciences would include studies of transport phenomena and the movement of fluids, the kinetics of geochemical systems, and the modeling of complex interactive systems.

\subsubsection{Environmental and Ecological Sciences}

Ecological and environmental sciences provide the fundamental knowledge of the structure and function of ecosystems (carbon and nutrient cycling) and, therefore, understanding of the responses of ecosystems to the effects of increased GHG emissions. Ecological science is fundamental to quantify the role of the world's ecosystems as net carbon sources or sinks, and to predict ecosystem response to future climate change events and/or carbon mitigation strategies.

Key research goals in ecological and environmental science include

- quantifying current carbon sequestration potential in both managed and unmanaged ecosystems, including soils

- understanding the response of ecosystems to increased atmospheric concentrations of $\mathrm{CO}_{2}$

- understanding how future changes in climate variables will affect ecosystems and their role in carbon cycling

- developing carbon cycle models to predict future carbon sequestration

- understanding how land use changes and land management options affect carbon storage and exchange

- developing biological productivity potentials to offset fossil fuel usage with biomass energy 


\subsubsection{Nuclear Sciences}

From the birth of nuclear power to the present, the United States has been the technological and policy leader. U.S. technology has been exported and adapted for use throughout the world. U.S. nuclear plant technology is among the safest and most reliable of nuclear technologies available worldwide.

Nuclear science and engineering is a discipline that is rapidly disappearing in the United States. If the United States is to maintain nuclear fission as an option for its future energy generation and is committed to avoiding additional carbon emissions, then a vital nuclear science basic research program is essential. It is likely that nuclear power will continue to be developed globally, with or without U.S. technology.

Research on nucleonics, new fission reactor concepts, proliferationresistant technologies, fusion and fission-fusion hybrids, hybrid accelerator-driven subcritical systems, advanced fuel cycle technologies, advanced component design, waste transmutation (both accelerator and reactor based) and fast neutron burning, and systems safety are all vital to a successful industry in the future and to U.S. viability in this important area. In addition, research reactors form a vital component in this system and in our national research and educational infrastructure. They are essential and critical to many national priorities in addition to reducing carbon emissions, such as health care, environmental science and education, and technology transfer. Perhaps the most important goal of nuclear science is to improve the acceptance - by the public and by industry-of nuclear energy as a safe, reliable, and cost-effective resource for a sustainable future.

\subsubsection{Computational Sciences}

Advanced energy technologies with low carbon emissions can benefit greatly from modern simulation technology, particularly in the areas of combustion modeling, airborne particulates, and global carbon cycle modeling. High-fidelity simulations of manufacturing and power generation operations and the distribution of gases resulting from internal combustion engines (Fig. 3.2) can be used to predict the behavior of pollutants in the atmosphere at scales ranging from a few rooms in a building all the way to global simulation of the buildup of GHGs. Process design and optimization using simulations including social and economic components can result in improved processes and reduced environmental impact, without the expense of trialand-error experimental designs. These tools can aid development of advanced energy technologies by allowing advanced modeling and visualization

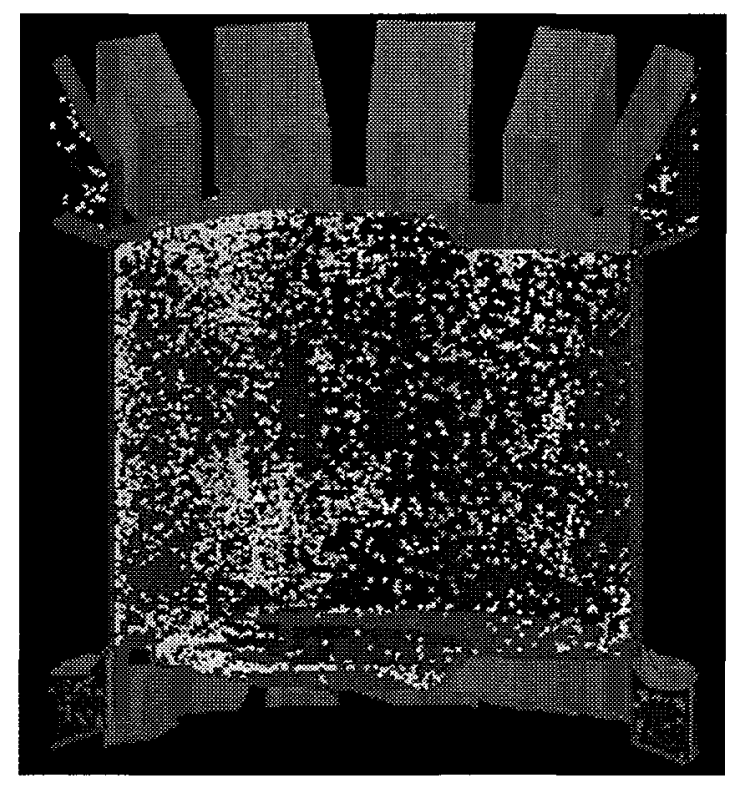

Fig. 3.2. This KIVA prototype 3-D simulation of an advanced diesel engine includes the regions where gas exchange and combustion occur. The simulation includes the flow of gases, heat transfer, combustion, and creation of pollutants. 
where direct experimentation or prototyping is very expensive, inaccessible, or otherwise unfeasible.

Predictive modeling and simulation involves the use of the most advanced parallel computers-in speed, memory capacity, and I/O capability. By the year 2000, U.S. vendor systems will be capable of 10 thousand billion floating point operations per second. Advanced visualization and analysis techniques, including virtual reality, will be necessary for scientists and decision makers to understand the huge amounts of data generated by these simulations and to compare these simulations with observational and experimental data. Advanced network communications will allow the establishment of national and international collaborations, as well as enabling the remote operation of unique experimental facilities.

Effective use of this immense capability will require development of new mathematical models of relevant physical, biological, social, and economic processes; stable programming paradigms that supportover a decade or more-changing hardware capabilities; algorithms and computational techniques that can efficiently make use of parallel, distributed computing resources; software frameworks that allow rapid prototyping of new capabilities; and, perhaps most important, a verification and validation methodology that provides both qualitative and quantitative assurance of what can and cannot be predicted.

\subsection{CROSSCUTTING TECHNOLOGIES SUPPORTING GREENHOUSE GAS REDUCTIONS}

In addition to the broad portfolio of technological opportunities for reducing GHG emissions presented in
Chap. 2, a number of technologies crosscut a wide range of applications, including those which impact U.S. carbon emissions. Advancing these enabling technologies integrates the pull of technology with the push of basic science.

This subsection presents four crosscutting technology areas: hydrogen and fuel cells; electrical transmission, distribution, and components; sensors and controls; and energy storage.

\subsubsection{Hydrogen and Fuel Cells}

Hydrogen is a carbon-free energy carrier that can be used to fuel every aspect of society. For example, it can fuel transportation vehicles (air and ground), provide process heat for industrial processes, supply domestic heating needs through cogeneration or

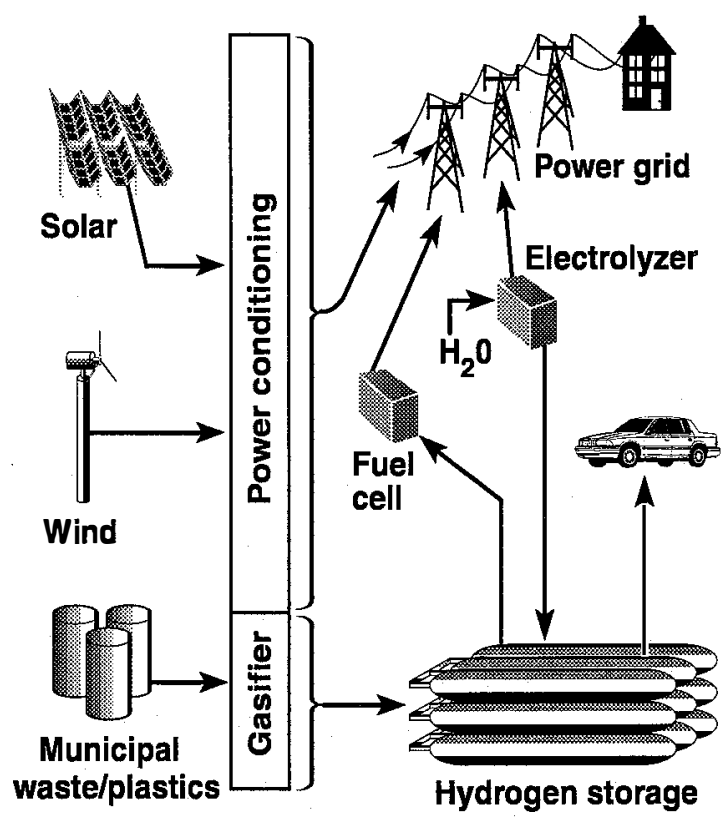

Fig. 3.3. Integrating utilities with the hydrogen transportation fuel system would enable greater penetration of renewables into the marketplace at a faster rate. 
heat recovery systems, and fuel power plants for centralized or distributed electrical generation (Fig. 3.3). Hydrogen is an energy carrier that must be produced efficiently from a primary energy source. Depending on the source, its production may or may not involve $\mathrm{CO}_{2}$ emissions. Hydrogen also burns cleanly and efficiently, an advantage that lowers the operating cost. Expanded production-related $R \& D$ is needed on biological, thermochemical, and electrochemical processes. Goals of the RD\&D for production include a 10 ton/day process demonstration using municipal solid waste by 2000 and the development of advanced steam electrolysis, photobiological, and photoelectrochemical processes by 2010.

Hydrogen can be used in modified conventional combustion energy conversion devices (e.g., engines) to ease the transition to a completely new energy infrastructure where hydrogen will be used in fuel cells for energy conversion. Fuel cells promise potentially higher system efficiency and solid-state operation with water as the only effluent.

Lack of suitable hydrogen storage technologies is the greatest obstacle to its use as a transportation fuel. For 2000, the RD\&D goals are to develop an automotive on-board hydrogen storage system capable of a 300 to 400 mile range and to demonstrate a fuel cell or hydrogen-powered internal combustion engine hybrid vehicle fleet with associated infrastructure. For 2010, the goals are to develop (1) advanced solid-state storage systems based upon such innovative materials as carbon fibers and structures and metal hydrides and (2) a conversion system for waste and biomass capable of producing hydrogen at a cost of $\$ 10 / G J$ (lower heat value of hydrogen).
Fuel cells convert chemical energy directly into electrical energy; no combustion is involved. They are significantly more efficient than other power-generation technologies or internal combustion engines operating on conventional fuels. Individual cells produce less than $1 \mathrm{~V}$ and are stacked in electrical series to produce higher voltages for utility, industrial, transportation, and residential use. Fuel cells span all important energy use sectors. Molten carbonate and phosphoric acid fuel cells target power generation, both large-scale and distributed power production. Solidoxide fuel cells, which in stacks have recently reached the $100-\mathrm{kW}$ size, are mostly considered for stationary application. Proton exchange membrane fuel cells target transportation as well as distributed power applications.

Key targets for R\&D are materials and fabrication issues concerning the catalyst/electrode/membrane designs, as well as the cell stacking design.

Future improvements in manufacturability will strive to reduce the currently high cost of fuel-cell fabrication to levels competitive with combustion devices.

\subsubsection{Electrical Transmission, Distribution, and Components}

Many proposed GHG reduction technologies involve alternative ways of producing electricity. In most cases, the U.S. electric transmission and distribution system is the means by which these alternative approaches will be made available to energy users. Almost $40 \%$ of the capital investment currently required to produce and deliver electricity goes to construct transmission and distribution facilities, and the availability of reasonably priced transmission capacity will be crucial in determining 
the commercial success of alternative generation strategies. This is particularly a concern for large-scale development of such remote resources as renewable generation, which could require significant investments in new transmission capacity because of the distances between the best resource areas and load centers. At the same time, public opposition to the construction of conventional transmission lines for environmental reasons has focused attention on opportunities for increasing the capacity of existing corridors, as well as on development of transmission technologies that are compatible with public concerns and therefore present a minimum of permitting risk. In addition, the importance of other collateral benefits of these technologies cannot be overlooked, especially their contribution to improving power quality.

$R \& D$ is needed on automated system control technologies that better use the capacity of existing systems, as well as advanced composite-reinforced highstrength overhead line conductors to increase the capacity of individual lines. Developments in power electronics-including wide-bandgap semiconductors for high-power switching devices and advanced converter designs-are needed to improve power management on existing systems and to enable highvoltage DC transmission for longdistance power transfers.

Improvements in superconducting materials and associated refrigeration technologies will lead to development of superconducting cables and power transformers that offer half the energy losses and many times the capacity of conventional devices while taking up less space and reducing environmental impact.

While electrical transmission and distribution system improvements are essential to enable deployment of alternative electrical generating strategies, power system component development also offers significant opportunities to reduce GHG production. Energy losses in U.S. transmission and distribution systems were $7.2 \%$ in 1995 , accounting for 2.5 quads of primary energy and $36.5 \mathrm{MtC}$ of carbon emissions. Roughly $70 \%$ of these losses are due to the resistance of the conductors used on transmission and distribution lines, while $20 \%$ are in the distribution transformers used by utilities and commercial building owners to provide the last step of voltage reduction for customer equipment. In addition, the bulk of U.S. electricity production goes to drive motors-most commonly the ubiquitous polyphase induction motor, whose limited speed control reduces associated process efficiency by as much as $30 \%$.

Research needed to improve the efficiency of power system components includes the development of superconducting generators, motors, and transmission cables, as well as low-cost methods for manufacturing amorphous metal materials for highefficiency distribution transformers. $R \& D$ on advanced power electronic converters and controls for variablespeed motor drives, integrated with high-efficiency motors, could substantially improve industrial process efficiency and product quality.

\subsubsection{Sensors and Controls}

Sensors and controls will play a significant role in any technological advances for reducing $\mathrm{CO}_{2}$ emissions and in $\mathrm{CO}_{2}$ sequestration processes. Each primary area of clean energy production, energy efficiency, and carbon-cycle/carbon sequestration, will require sensors and controls technology for ensuring maximum efficiency at minimal cost. 
$R \& D$ is needed to develop sensors that can improve the efficiency of primary energy production. For example, chemical sensors capable of operation in boreholes can improve fossil fuel recovery. Both refining processes and fossil fuel reforming for $\mathrm{CO}_{2}$ sequestration require substantial chemical processing that can be enhanced through real-time process sensors and controls. Sensors and controls that more accurately measure operational parameters can be used to increase the output of nuclear power plants.

In the area of energy efficiency, transportation remains a major factor in energy consumption. Novel sensors are needed to enable the use of more efficient engine technologies. Almost all industrial processes depend on sensors and controls to ensure the quality of goods produced, and advanced sensors can help to reduce wasted energy and thus $\mathrm{CO}_{2}$ emissions. In carbon cycle/carbon sequestration, innovative sensors for analyzing photochemical processes and carbon fixation are needed. They may also be required for efficient biomass energy production.

Often a single fundamental sensor technology will meet the needs of different applications, so sensors are a true crosscutting technology. The best example is the solid-state oxygen sensor developed for the space program in the 1960s. This sensor is now universally used in gasoline engine control and is common in industrial combustion control, touching virtually every major energy-consuming industry.

A large variety of novel sensor technologies that are robust, sensitive, cost-effective, and capable of supporting real-time control will be required in a successful climate change technology development program, as will commensurate methods of data analysis and fusion for control. Across the industrial arena, sensors are needed that can be used in harsh environments and that will measure such on-line process parameters as viscosity, moisture, chemical composition, density, flow, temperature, and pressure. Research is also needed in the development of multi-analyte sensors and in the integration of sensors and microtechnologies, such as microflow devices. Further RD\&D is necessary in the development of "smart controllers" that couple a multitude of sensors and/or sensor arrays to sophisticated data analysis systems that can provide real-time on-line process control and improve process efficiencies.

\subsubsection{Energy Storage}

Stationary energy storage is now primarily in the form of bulk storage of fossil fuels (piles of coal, oil in tanks, gas in pipelines) and water in reservoirs. Reversible energy storage technologies in use today include pumped hydropower, compressed air, and chemical batteries for small uninterruptible power. Advanced storage technologies under active development include processes that are mechanical (flywheels, pneumatic), electrochemical (advanced batteries, reversible fuel cells, hydrogen), and purely electrical (ultracapacitors, superconducting magnetic storage). The major hurdle for all storage technologies is cost reduction.

In transportation, hybrid powertrains that use batteries, flywheels, or ultracapacitors in conjunction with engines allow the reduction of engine size. A hybrid powertrain can increase overall efficiency by up to $100 \%$ without a loss in vehicle performance (acceleration, range, and passenger capacity). When combined with other 
vehicle improvements, such as weight reductions, aerodynamic improvements, and rolling friction, this efficiency increase results in up to three times the equivalent mileage of current direct-drive automobiles, which is the current goal of the PNGV.

Key R\&D needs for energy storage include developing

- new electrocatalysts, electrode materials, and structural materials for electrochemical systems

- higher specific-energy composite rotors, magnetic bearings, fail-safe designs, and lightweight containment for flywheels

- better corrosion-resistant materials for higher power-density batteries

- commercial high-temperature superconductors (operating at liquid nitrogen temperatures) for superconducting magnetic energy systems

- higher energy-density ultracapacitors for light-duty vehicles

- improved power conditioning systems.
The greatest value of advanced energy storage for electric utilities is that it can enable better use of intermittent renewable energy sources, such as solar PVs and wind, that produce no direct $\mathrm{CO}_{2}$.

\subsection{REFERENCES}

Carbon Management: Fundamental Research Needs Assessment 1997. (Draft), DOE-Office of Energy Research, August 6.

R\&D Magazine 1997. "Basic Research White Paper: Defining Our Path to the Future," R\&D Magazine,
A. Cahners Publication, Des Plaines, Ill.

SEAB (Secretary of Energy Advisory Board) (D. Yergin, Chairman) 1995. Energy R\&D: Shaping Our Nation's Future in a Competitive World, U.S. Department of Energy, Washington, D.C. 
4. TECHNOLOGY INNOVATION APPROACHES

\subsection{INTRODUCTION}

Previous chapters of this report identified a set of technology pathways that we believe offer the United States affordable options to reduce GHG emissions to sustainable levels. We have emphasized that R\&D, both fundamental and applied, needs to be continued and/or initiated to advance the technologies identified within the pathways, thereby moving them closer to the goal of deployment in the marketplace. This section discusses three technology innovation approaches and presents several factors for consideration in deciding which approach to use to develop a particular technology. While each of the approaches provides a viable option, we believe that in most cases public-private strategic alliances are the best approach for developing and deploying these technologies.

\subsection{APPROACHES}

In this section, we evaluate the pros and cons of three approaches for advancing the RD\&D of GHG reduction technologies. These approaches can be characterized as

- government led and financed

- industry led and financed

- public-private strategic alliances

Although we recommend public-private strategic alliances as the best approach for developing and deploying most of the technologies discussed in the technology pathways section, in some cases one of the other approaches may be more appropriate.

When selecting an approach to pursue the RD\&D of a technology, we recommend the following factors be considered:

- national strategic value of the technology

- target market of the technology

- return on private-sector investment 
A technology has strategic value to the nation when it provides a significant benefit to national security, economic well-being, environmental quality, and/or public health. National defense is the casebook example of high strategic value to the nation. Historically, the strategic value criterion has also been a justification for government support of technologies in the areas of space, health, energy, and agriculture.

The target market factor refers to the expected end-user or consumer of the technology. In some cases, a technology is developed for a specific target market or end-user (e.g., the federal government), and the technology has little application beyond that market. For example, technologies to process uranium have had little application beyond the nuclear industry. In other cases, a technology, such as the transistor, has applications in multiple markets and industries. Technologies that are applicable to a variety of markets and industry are sometimes referred to as "generic technologies" (Bloch 1991).

The third criterion refers to whether the private sector believes it can attain a large enough return on its $R D \& D$ investment within a reasonable time frame and at acceptable levels of risk to warrant supporting the innovation process. The complexity and the length of time needed to develop and deploy a technology are key variables considered by private industry when it is deciding whether to invest in a technology, because both factors can increase the risk of not receiving the expected return on investment. Of the three factors presented, expected return on investment is the key factor companies consider when deciding whether to invest in the development of a technology. Although this factor is of primary importance to the private sector, it is not necessarily mutually exclusive from the national strategic value criterion. In many cases, companies have led and financed the development of technologies that have underpinned the formation of industries with a high strategic value to the nation (e.g., computer software, drug, and automobile industries).

The following sections discuss the characteristics and relationship among the three approaches to technology innovation in an effort to provide selection criteria for determining the optimum approach to achieving the RD\&D goals for individual technologies (Table 4.1).

\subsubsection{Government Led and Financed Approach}

The government typically leads and finances projects throughout the RD\&D process when a technological innovation has a high strategic value to the nation, the public sector is the intended end-user of the technology, and the expected return on investment is too low to warrant the private sector's bearing the RD\&D costs (Table 4.1). Examples of projects led and financed primarily by the federal government include the Manhattan Project, which

Table 4.1. Approaches to technological innovation

\begin{tabular}{llll}
\hline & $\begin{array}{c}\text { National strategic } \\
\text { value }\end{array}$ & $\begin{array}{c}\text { Target } \\
\text { market }\end{array}$ & $\begin{array}{c}\text { Return on } \\
\text { private sector } \\
\text { investment }\end{array}$ \\
\hline Government led and financed & High & Public sector & Low \\
Industry led and financed & Low-medium & Specific market & High \\
Public-private alliance & Medium-high & Multiple markets & Low-medium \\
\hline
\end{tabular}


developed the atomic bomb in World War II, and the Apollo Project, which put a man on the moon in 1969.

Government led and financed projects have been very successful in meeting their goals when the conditions warrant government leadership and it has been able to focus the best resources of the nation on solving a problem with clearly defined technological goals and large public benefits and support.

The government led and financed approach could be applied to reducing GHGs, but it contains some inherent barriers to full effectiveness. In contrast to the examples given earlier, the government is not the primary target market for GHG reduction technologies, and there is no single technological solution to stabilizing atmospheric concentrations of $\mathrm{CO}_{2}$. Therefore, significant GHG reductions will be achieved only if a number of technologies penetrate a broad spectrum of commercial target markets. In addition, some of the GHG technologies will have economic benefits in reduced fuel use, higher productivity, and reduced waste generation. Therefore, we expect the private-sector return on investment in the innovation process to be at a sufficiently high level for some of the technologies to warrant private-sector RD\&D cost sharing.

\subsubsection{Industry Led and Financed Approach}

The private sector typically leads and finances projects throughout the RD\&D process when a technological innovation has a high potential return on investment from specific commercial markets, regardless of its national strategic value. Historically, technological innovation leading to products for the commercial market has been primarily the responsibility of the private sector. Numerous examples exist of technology innovation led and financed primarily by industry, including plastics, pharmaceuticals, scientific instrumentation, information systems, and robotics. These technologies were driven by the demands of consumers in target markets, not by the federal government. Market-driven technology development is critical to continued economic growth because it enables companies, through the deployment of technological innovations, to profit by meeting the demands of consumers.

The strong relationship between technological development and quality of life in America in the twentieth century is a testament to the value of the industry led and financed approach to innovation. However, for this to be the primary approach for developing and deploying GHG reduction technologies, carbon mitigation would have to be highly valued in the marketplace to enable private companies to profit from their RD\&D investments. Some technologies that result in GHG reduction may attract sufficient private-sector investment because they offer additional benefits that consumers are willing to pay for to amortize the RD\&D costs and to provide adequate profits. However, short of policies that create a large economic incentive for reducing carbon emissions, industry is not likely to lead and finance RD\&D on a broad spectrum of GHG reduction technologies.

\subsubsection{Public-Private Strategic Alliances}

Public-private alliances are typically established to share the costs of RD\&D and deployment of technologies that have a strategic value to the nation and have value for multiple markets and industries, but do not promise sufficient return on investment to 
motivate the private sector to bear all the RD\&D costs. Many of the technology pathways for reducing GHGs have these characteristics, making public-private strategic alliances the optimum approach for promoting their development and deployment.

The Clinton administration has been a strong advocate of forming partnerships to advance science and technology in America and has "forg[ed] a closer working partnership among industry, federal and state governments, workers and universities" (Clinton and Gore 1993, p.1). During the past decade, the process by which federally funded technology makes its way to the private sector for commercial use has improved substantially. In addition, the federal government is now working hand-inhand with industry, combining resources to achieve common technology objectives (OSTP 1997).

Numerous examples of public-private alliances exist, such as SEMATECH, PNGV, IOF, the International Energy Agency Greenhouse Gas R\&D Programme, the Clean Coal Technology program, the Advanced Light Water Reactor program, and PVMaT. In the case of PNGV, technologies to increase the fuel efficiency of automobiles have a high strategic value to the nation because they reduce our consumption of oil, thereby increasing our economic and national security, and mitigate GHG emissions, thereby reducing global warming and improving the quality of the air we breathe. In addition to being deployed in the automobile industry, many of the technologies being developed by the PNGV consortia are likely to be deployed in multiple markets. For example, one of the goals of PNGV is to increase fuel economy threefold. In order to meet this goal the vehicle weight must be reduced $40 \%$; therefore, a significant portion of the steel and cast iron components in these vehicles must be replaced with aluminum and polymer composites. These new lightweight, high-strength materials will be deployed in other transportation markets (e.g., aircraft and rail), as well as multiple segments of our infrastructure (e.g., bridges, buildings, energy). Finally, although the technologies being developed by PNGV have a high strategic value, the market return on fuel efficiency investments is currently very small because the cost of gasoline in the United States has been decreasing at an average annual percentage rate of $1.8 \%$ (in constant dollars) since 1978.

The combination of high strategic value, multiple target markets, and expected low return on investment makes public-private strategic alliances the optimal approach for developing and deploying GHG reduction technologies. This approach will allow sharing of costs and pooling of resources, thereby motivating private companies to invest in the technology even though the return on investment is likely to be low in the short term, and encouraging government agencies to support the RD\&D process even though the public sector may not be the targeted end-user of the technology.

The interactive nature of the innovation process is another reason to use public-private alliances to develop and deploy GHG reduction technologies. It is now widely recognized (Kline 1991; OTA 1995; Branscomb et al. 1997; R\&D Magazine $1997)$ that most complex technological innovations advance through a nonlinear, interactive innovation process (Fig. 4.1), in which there is synergy between scientific research, technology development, and deployment activities. The interactive process is a more effective model for developing and deploying technology than the linear model that depicts the innovation process as starting with 
basic scientific research and then advancing sequentially through the technology development and deployment phases (Fig. 4.2). This linear approach can take longer and can result in potential innovations being delayed or never making it to the marketplace. The interactive process has several advantages in that it provides the following:

- a continuous feedback loop for development and use of new scientific capabilities and facilities that can expedite the innovation cycle

- effective dialog between the research and user communities on innovation needs

- an effective basis for focusing research in the highest priority areas and evaluating progress along the technology pathways

\subsection{STRATEGIC ALLIANCE ROLES}

One of the major benefits of strategic alliances is that they help maximize the efficiency of the innovation process by bringing together an interdisciplinary team of scientists, engineers, and analysts (e.g., market, social, and financial) from industry, government laboratories, universities, and nongovernment organizations who can ensure that the scientific, technical, and commercial challenges that arise throughout the innovation process are successfully resolved. We recognize that there will be many stakeholders in a climate change technology strategy and that over the course of time, some of the technology pathways will dramatically restructure the nation's energy, buildings, industrial, and transportation sectors. International customers and suppliers will be concerned about their costs and their markets. The financial community, insurance industry, and

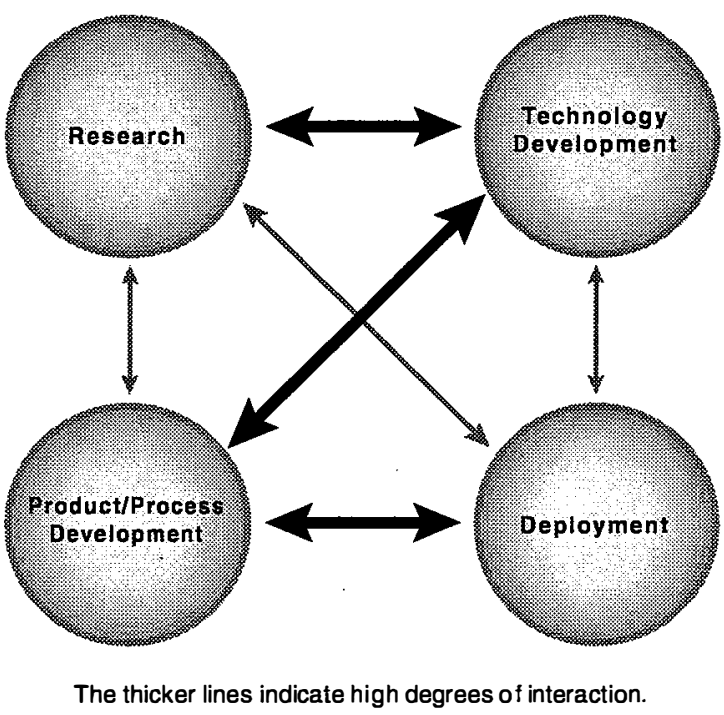

Fig. 4.1. Interactive model of innovation.

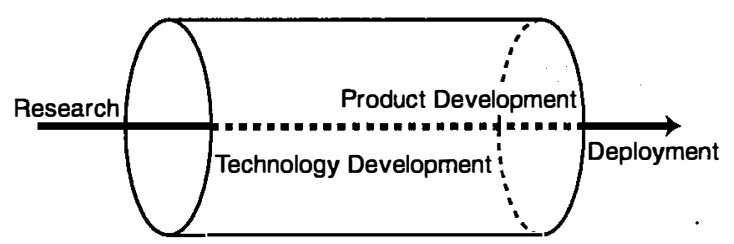

Fig. 4.2. Linear model of innovation.

standards organizations all have a stake in the process; the list is long. Their input will be important for formulating effective public-private alliances, monitoring progress toward GHG reductions, and sustaining interest in the climate change technology strategy over the decades that will be required to implement it.

In many respects, the whole is greater than the sum of its parts in strategic alliances, for while private companies, universities, federal laboratories, government organizations, and nongovernment organizations each have unique capabilities, a synergy results when their resources are applied strategically toward a common goal, such as developing technologies to reduce GHG emissions. For example,

- Private companies and industrial consortia, such as the Electric Power 
Research Institute and the Gas Research Institute, play a key role in the innovation process by identifying requirements for technologies that help ensure their commercial viability, by performing $\mathrm{R} \& \mathrm{D}$ in collaboration with federal laboratories and universities, and eventually by demonstrating and deploying the technologies.

- Government laboratories and nongovernment research organizations provide scientific staff who have conducted and managed research for more than 50 years. These laboratories have conducted much of the research that provides the scientific underpinning for many technological breakthroughs. This scientific resource can provide new approaches to reducing emissions in the future. The national laboratories also provide unique facilities for use by researchers from industry and academia, as well as by their own researchers, in the development of these technologies.

- Universities provide a wealth of scientific talent to undertake the scientific research required to understand the role of GHGs in global climate change and to understand the basic mechanisms of biological and chemical processes that might be used to reduce GHG emissions. The linking of science and technology in the interactive process of innovation makes the scientific resources of universities and laboratories critical throughout the innovation process. In addition to providing scientific resources, universities are the training ground for future scientists and engineers needed for a sustained national effort to minimize the effect of GHGs on climate change.

Along with private companies, federal laboratories, and universities, it is important that government agencies, international organizations, and other nongovernmental organizations that are stakeholders in global climate change have a role in strategic alliances.

- Government agencies at the federal, state, and local levels contribute financial resources that are critical for advances in scientific research and basic technologies, as well as legislative mechanisms that can play an important role in removing barriers to the deployment of climate change technologies. In addition, government institutions can help educate the American public about climate change and can provide a forum for stakeholders to express their views on this subject.

- Climate change is a global issue, and international collaborative RD\&D efforts will be needed. Japan has recently announced a national program to support international R\&D on technologies to mitigate global climate change and pollution. Other efforts involving the U.S. federal government and U.S. companies are under way (e.g., the International Energy Agency Greenhouse Gas R\&D Programme).

- Nongovernment organizations, including end-users, environmental organizations, financial institutions, and other interest groups, possess expertise that can be valuable to scientists, engineers, and market analysts as they work to better understand climate change and market issues.

\subsection{CONCLUSION}

Three specific approaches for implementing RD\&D and deployment activities on GHG technologies are considered: (1) government led and financed, (2) industry led and financed, and (3) public-private strategic alliances. In selecting an 
implementation approach, we encourage the consideration of three factors: strategic value to the nation, target market, and expected return on private-sector investment. A systematic assessment of the relationship between the technology being developed and the three implementation approaches will allow selection of the optimum approach.

For most of the GHG emission reduction technologies discussed in this report, we believe that the publicprivate strategic alliance approach is the best choice. Although many of these technologies will be able to compete cost-effectively in the marketplace in the future, industry may not be willing to lead and finance the innovation process for many of these technologies because of the high risk associated with developing technologies that will not be deployed for decades and because the market currently does not place a high value on carbon mitigation. Additional factors favoring public-private strategic alliances include the interactive nature of the innovation process and the need to develop and deploy a variety of technologies in a number of target markets to reduce GHG emissions significantly. A public-private alliance will enhance the efficiency of the innovation process by bringing together stakeholders who can meet the scientific, technical, and commercial challenges involved in developing and deploying the required technologies. In this context, institutional efforts, such as collaborative RD\&D enterprises, that help bring together industries, government laboratories, universities, government agencies, and nongovernment organizations to focus on common technological issues will be of great value in fostering the development of public-private alliances.
While public-private strategic alliances are only one part of the nation's climate change technology strategy, we feel they are a vital element if we hope to efficiently and effectively develop and deploy the GHG reduction technologies discussed in this report.

\subsection{REFERENCES}

Bloch, Erich 1991. "Science and Technology: The False Dichotomy," Powernomics: Economic and Strategy After the Cold War, ed. Clyde Prestowitz Jr., Ronald Morse, and Alan Tonelson, Economic Strategy Institute, Washington, D.C.

Branscomb, Lewis et al. 1997. Investing in Innovation: Creating a Research and Innovation Policy That Works, MIT Press, Cambridge, Mass., in press.

Clinton, Bill and Albert Gore 1993. Technology for America's Economic Growth, A New Direction to Build Economic Strength, February 22.

Kline, Stephen 1991. "Styles of Innovation and Their Cultural Basis," Chemtech, 473-480, August.

OSTP (Office of Science and Technology Policy) 1997. Science and Technology Shaping the 21st Century, Washington, D.C., April.

OTA (Office of Technology Assessment) 1995. Innovation and Commercialization of Emerging Technologies, U.S. Government Printing Office, OTA-BP-ITC-165, Washington, D.C., September.

R\&D Magazine 1997. "Basic Research White Paper: Defining Our Path to the Future," R\&D Magazine,
A. Cahners Publication, Des Plaines, Ill. 


\section{SYNTHESIS AND MOVING FORWARD}

\subsection{SYNTHESIS}

In this report to Secretary of Energy Peña, the directors of $11 \mathrm{DOE}$ national laboratories conclude that

1. Advances in science and technology are necessary to reduce GHG emissions from the United States while sustaining economic growth and providing collateral benefits to the nation.

2 . Success will require the pursuit of multiple technology pathways, providing choices and flexibility for reducing GHG emissions.

One cost-effective strategy for reducing long-term GHG emissions while continuing economic growth is to develop and deploy a portfolio of new and improved technologies (as described in Chapter 2). Successful development of these technologies would require advances in many fields of basic science (as described in Chapter 3) along with strong publicprivate strategic alliances (as described in Chapter 4). Rapid and widespread deployment may also require the development and implementation of supportive programs and policies. The features of such programs and policies are not specified in this report.

\subsubsection{The RD\&D Path to Carbon Stabilization}

Chapter 2 described the broad menu of technology pathways that could significantly reduce U.S. carbon emissions over the next three decades. If a vigorous, accelerated RD\&D program were pursued, these pathways would enable the transformation of our nation's energy system. Given the breadth of technology options, this transformation could take place in an orderly fashion. Industry and consumers would be able to recover their investments in the nation's current energy infrastructure, while new energy and carbon sequestration technologies were gradually absorbed, as they became profitable, through the normal process of capital stock turnover. 
By offering a technology-based, evolutionary-not revolutionary-path to a sustainable energy future, this report outlines the possibility of a transition that could be profitable to a wide array of potential constituents.

Over a 30-year planning horizon, implementing a climate change technology strategy could quickly expand the portfolio of options available for reducing U.S. GHG emissions. The three decades of this planning horizon appear to be distinct in terms of the dominant climate change technology opportunities.

- In the first decade, significant advances in energy efficiency technologies would reduce carbon emissions substantially by reducing the energy intensity (E/GDP) of the U.S. economy. Based on the fivelaboratory study, the increased use of these technologies could offer energy-savings benefits that exceed their implementation costs (Interlaboratory Working Group 1997). Clean energy technologies would continue to gain market share, and carbon sequestration technologies could begin to emerge.

- Along with continued improvements in energy efficiency, research-based advances in clean energy technologies would begin to reduce the carbon intensity (C/E) of the U.S. energy economy significantly during the second decade. A wide range of renewable, fossil, and nuclear technologies could be introduced and widely deployed in this period. These clean energy options could begin to overshadow the impact of increased end-use efficiencies by the year 2030 .

- Complementing ongoing advances in clean energy and efficiency technologies well into the third decade, carbon sequestration technologies would add a third important dimension to the package of solutions. We assume that these would not be widely available until the 2020 to 2030 time frame; however, successful introduction earlier could result in significantly greater reductions in carbon emissions. Success in this technology area could enable the nation to continue its extensive use of fossil fuels without changing the climate.

This technological progression can be seen in Table 5.1, which summarizes the carbon reduction estimates of each of the nine technology areas described in Chapter 2. Estimates of carbonsaving potential are difficult because of the many factors that can affect the performance and market penetration of a new technology. Consistent with these uncertainties, the values shown in Table 5.1 are provided in five ranges from low to high.

These estimates of carbon reduction potential were made relative to the Annual Energy Outlook 1998 reference (business-as-usual) case (EIA 1997). They assume an accelerated federal RD\&D program and a continuation of current federal programs and policies. The estimates do not presume the creation of any new incentives. The carbon reduction estimates were made individually for each technology area; competition between technologies and other effects of one technology on the success of another were not fully considered.

Because of the uncertainties associated with the carbon impacts of each pathway and the complexities associated with aggregation across pathways, our estimate of the combined potential effects of all of the pathways has a wide range. In total, it is estimated that an accelerated RD\&D effort could provide advanced technologies with the potential to reduce U.S. carbon emissions by 400 
Table 5.1. Potential reduction of U.S. carbon dioxide emissions from nine technology areas

(in $\mathrm{MtC}$ )*

\begin{tabular}{llll}
\hline & 2010 & 2020 & 2030 \\
\hline Energy efficiency & $\mathrm{I} / \mathrm{M}$ & & \\
$\quad$ Buildings & $\mathrm{L} / \mathrm{M}$ & $\mathrm{M} / \mathrm{H}$ & $\mathrm{H}$ \\
Industry & $\mathrm{M}$ & $\mathrm{M} / \mathrm{H}$ & $\mathrm{H}$ \\
Transportation & $\mathrm{L}$ & $\mathrm{H}$ & $\mathrm{H}$ \\
Agriculture and forestry & $\mathrm{L}$ & $\mathrm{L} / \mathrm{M}$ \\
Clean energy & $\mathrm{L}$ & $\mathrm{M} / \mathrm{H}$ & $\mathrm{H}$ \\
Fossil resource development & $\mathrm{L}$ & $\mathrm{M}$ & $\mathrm{H}$ \\
Fossil power generation & $\mathrm{L}$ & $\mathrm{M}$ & $\mathrm{H}$ \\
Nuclear energy & $\mathrm{L} / \mathrm{M}$ & $\mathrm{H}$ & $\mathrm{H}$ \\
Renewables & $\mathrm{NA}$ & $\mathrm{NA}$ & $\mathrm{NA}$ \\
Carbon sequestration & & & \\
\hline
\end{tabular}

*Assumes successful technology development and subsequent marketplace adoption without significant policy changes. Greater impacts could be expected with the addition of vigorous new policies and deployment programs, particularly in early years when the market penetration of existing and near-term technologies could be accelerated.

$\mathrm{L}=0-25 \mathrm{MtC}, \mathrm{L} / \mathrm{M}=25-50 \mathrm{MtC}, \mathrm{M}=50-75 \mathrm{MtC}, \mathrm{M} / \mathrm{H}=75-100 \mathrm{MtC}$, and $\mathrm{H}=100+\mathrm{MtC}$. Shaded areas show significant additions to the technology routes to reducing greenhouse gases. $\mathrm{NA}=$ Not applicable because the carbon reductions require policy changes.

'The 2020 and 2030 estimates for nuclear energy ( $M$ and $\mathrm{H}$, respectively) are relative to an adjusted reference case forecast, which takes into account the large capacity of nuclear power scheduled for retirement after 2010. By extending the operation of one-third to one-half of these plants, significant carbon emissions can be avoided.

to $800 \mathrm{MtC} /$ year in the year 2030. This represents a significant portion of the carbon emission reductions that may be targeted by the United States for 2030.

Table 5.1 and the discussions of each pathway in Chapter 2 also indicate that no single area or pathway can deliver sufficient GHG emission reductions; success will require pursuit of multiple technology pathways. The lower range of the estimated impact ( $400 \mathrm{MtC}$ per year) could result from major technological advances and market success in several of the pathways. Achieving the upper range $(800 \mathrm{MtC}$ per year) would require technological breakthroughs and market success in a wider spectrum of pathways. This higher, more optimistic range is viewed as unlikely without also strengthening the policies and deployment programs that exist today. We did not attempt to quantify the potential reductions from a combination of accelerated RD\&D and more vigorous deployment programs, policies, and financial incentives. However, it is believed that such a combination could drive U.S. carbon emissions down much further than the 400 to $800 \mathrm{MtC}$ range described in this report.

This report's estimates of carbon reduction potential are quite modest compared with the estimates produced by many other studies. The smaller overall impacts estimated by this report are due primarily to our focus on the potential of accelerated RD\&D within the context of today's policies and programs. Additional reductions would result from the implementation of new policies and deployment programs, particularly in early years when the market penetration of existing and nearterm technologies could be accelerated. 
The 1991 report by the Office of Technology Assessment titled Changing by Degrees (OTA 1991) analyzed the potential for energy efficiency to reduce carbon emissions by the year 2015, starting with the base year of 1987. Its "moderate" scenario results in a $15 \%$ rise in carbon emissions, from $1300 \mathrm{MtC} /$ year of carbon in 1987 to $1500 \mathrm{MtC} /$ year of carbon in 2015 (compared with a business-as-usual forecast of $1900 \mathrm{MtC} /$ year). Its "tough" scenario results in a $20 \%$ to $35 \%$ reduction in emissions relative to 1987 levels, or emissions levels of 850 to $1000 \mathrm{MtC} /$ year of carbon in 2015 .

Scenarios of U.S. Carbon Reductions by the Interlaboratory Working Group (1997) modeled three scenarios of carbon emissions in the year 2010 based on an array of assumptions about increased RD\&D efforts, supporting policies, and deployment programs (see Chapter 1 for further details). The results were carbon reduction estimates of 120,230 , and $390 \mathrm{MtC}$ in the year 2010. The most aggressive scenario reduces carbon emissions in 2010 to their levels in 1990 and reduces energy consumption in 2010 to 1997 levels.

Energy Innovations (1997) provides a third point of comparison. It estimates the levels of carbon emissions that are possible in 2010 and 2030 as the result of vigorous RD\&D, deployment, and policies. It estimates that by 2010 , carbon emissions could drop to a level that is $10 \%$ below emissions in 1990 . By 2030, it suggests, carbon emissions could possibly be reduced to $728 \mathrm{MtC}$ per year, which is almost half of the 1990 benchmark and well below the estimates provided in this report.

A fourth study by the National Academy of Sciences (NAS), Policy Implications of Greenhouse Warming
(1992), identified a set of energy conservation technologies that would have either a positive economic return or a cost of less than $\$ 2.50$ per tonne of carbon. Altogether, NAS concluded that these technologies offer the potential to reduce carbon emissions by 463 million tonnes, with more than half of the reductions arising from costeffective investments in building energy efficiency. The NAS study characterized the current technological potential available at the time; thus it did not take into account stock turnover rates and other factors that prevent the instantaneous, full market penetration of technologies. Nor did it describe the role of RD\&D in expanding future technology opportunities.

\subsubsection{Factors Influencing GHG Reduction Potential}

Many factors influence the ability of technology development efforts to reduce future U.S. GHG emissions. These include the magnitude of available $R \& D$ resources, technological risk, market size, stock turnover rates, and public acceptance issues. While this study has not attempted to analyze the effects of all of these various factors, it has compiled a considerable amount of information on them in its review of nearly 50 technology pathways. That information can be found in Appendix B, which includes a two-page description of each pathway that explains many of the factors.

Table 5.2 summarizes some of this information for technology areas grouped as energy efficiency, transportation fuels, electricity, and carbon sequestration. The table expands on the information in Table 5.1 in two ways. First, it includes information for those specific sectors and technologies that at this time 
appear to represent the largest potential carbon emission reductions over the 30-year planning period. For example, in the transportation sector, light-duty vehicles represent $58 \%$ of the $\mathrm{CO}_{2}$ emissions in the transportation sector. Therefore, one entry in Table 5.2 summarizes information for the two technology pathways that address light-duty vehicles: (1) advanced conventional technologies for light-duty vehicles and (2) hybrid, battery-electric, and fuel cell vehicles.

Second, Table 5.2 provides information on several of the key factors that will influence future carbon emission reductions. This includes a column listing some of the significant issues or opportunities that will impede or enable the realization of potential carbon reductions. These issues and opportunities are selected from a more comprehensive accounting in Appendix B.

Altogether, Table 5.2 provides the reader with an indication of the most important results of this study in the form of the sectors and technologies that can play the largest role, as well as the factors and considerations that will determine their future contributions to GHG emission reductions.

The key factors that are used in Table 5.2 are defined as follows:

- Total market size: current total market in terms of carbon emissions ( $\mathrm{MtC} /$ year) that is relevant to the technology

- Turnover rate: rate of retirement of the current stock of energy equipment or systems displaceable by this technology, with

"Fast" corresponding to less than 10 years average lifetime "Moderate" corresponding to 11 to 20 years average lifetime
"Slow" corresponding to greater than 20 years average lifetime

- Estimates of carbon emissions reductions: best estimate of the carbon emissions reductions (in $\mathrm{MtC}$ /year) that are likely to be achieved given this accelerated RD\&D effort and continuing government deployment programs and policies. The estimates are based on the overall market size, the stock turnover rate, some consideration of the expected competitive position of the technology, and so on. For energy efficiency and clean energy technologies, the estimates assume no new fiscal incentives such as a carbon charge. See Sect. 2.1.2 for a more complete description of the study's assumptions. The entries are defined as follows:

"High" corresponding to $>100 \mathrm{MtC} /$ year

"Medium" corresponding to 50 to $100 \mathrm{MtC} /$ year

"Low" corresponding to 0 to $50 \mathrm{MtC} /$ year

- Technological risk: subjective estimate of the risk that the technology will not be developed to the point that it can compete in its market as expected with

"High" reflecting research that is still at the basic sciences level or involves complex systems integration

"Moderate" reflecting research that is currently at both the basic research and technology prototype level

"Low" reflecting development activities for technologies at the prototype or more advanced stage

- Significant issues or opportunities: illustrative major factors particularly noteworthy for this technology 
Table 5.2. Potential reduction of U.S. carbon dioxide emissions from selected sectors and technology pathways*

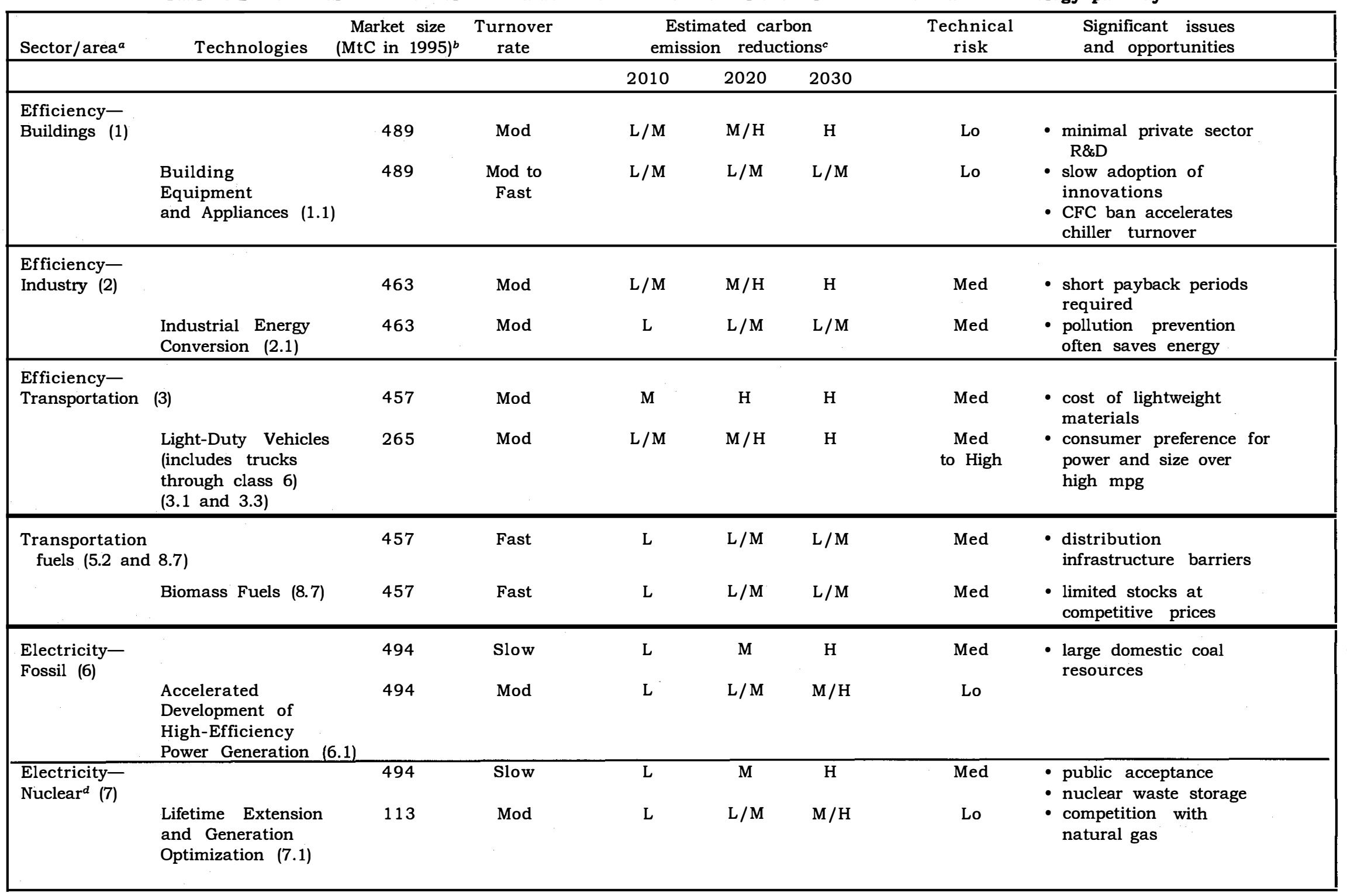


Table 5.2. (continued)

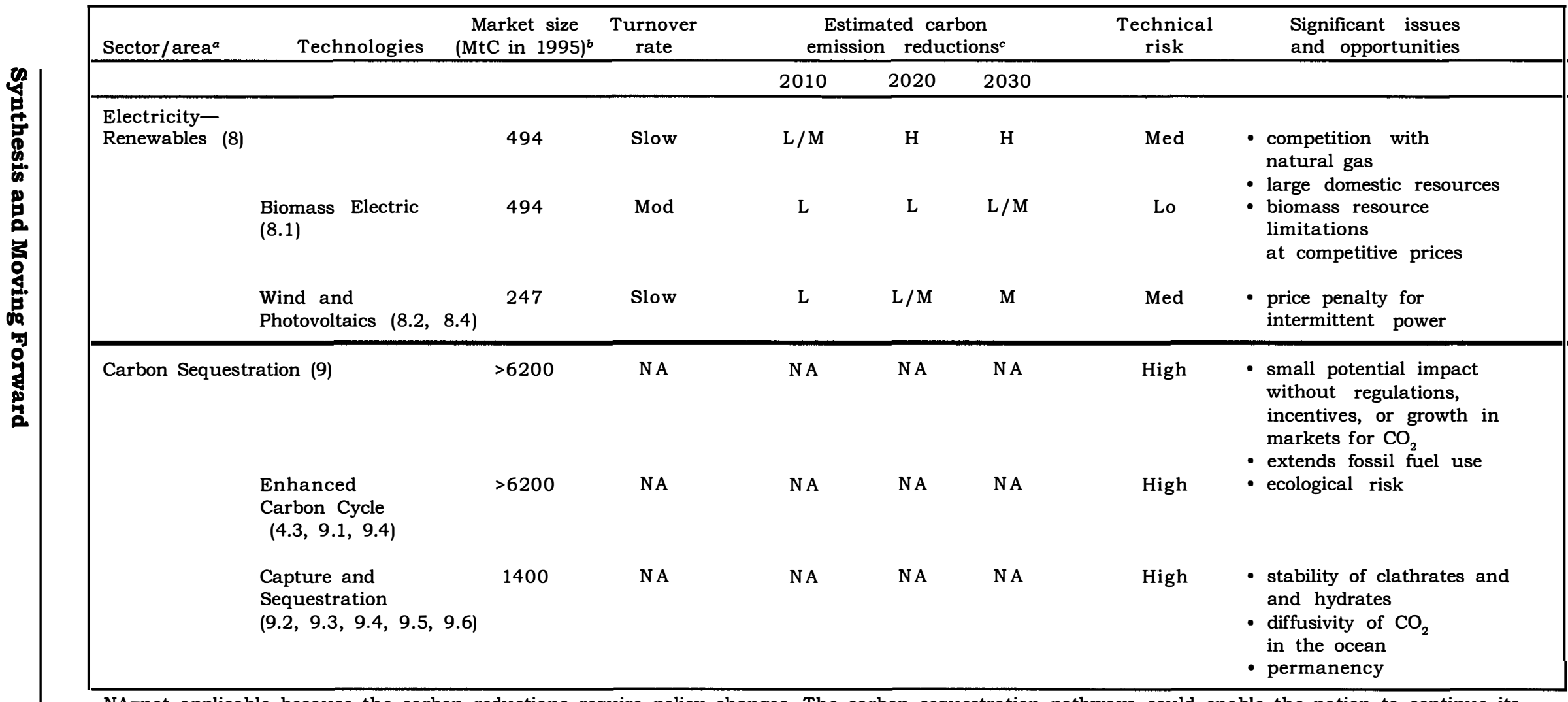

NA=not applicable because the carbon reductions require policy changes. The carbon sequestration pathways could enable the nation to continue its extensive use of fossil fuels without changing the climate.

*Assumes successful technology development and subsequent marketplace adoption without significant policy changes. Greater impacts could be expected with the addition of vigorous new policies and deployment programs, particularly in early years when the market penetration of existing and near-term technologies could be accelerated.

a Technology pathways identified in ( ) are cross-referenced to Table 2.1

${ }^{b}$ The technologies and sectors shown in this table overlap in terms of the carbon reductions they can deliver. For instance, decarbonization of the electricity sector through the introduction of clean energy technologies will reduce the potential carbon reductions from end-use sector efficiency technologies. As a result, it is not valid to simply add either the market size or the carbon reduction estimates.

${ }^{\circ} \mathrm{L}=0-25 \mathrm{MtC}, \mathrm{L} / \mathrm{M}=25-50 \mathrm{MtC}, \mathrm{M}=50-75 \mathrm{MtC}, \mathrm{M} / \mathrm{H}=75-100$, and $\mathrm{H}=100+\mathrm{MtC}$. These estimates assume an enhanced federal $\mathrm{RD} \& \mathrm{D}$ program aimed at developing GHG reduction technologies. They do not presume the creation of any new financial incentives for reducing carbon emissions. The technologies covered in this table could deliver even greater GHG reductions if incentives, such as a carbon emissions trading program, or more vigorous deployment programs and policies, were implemented.

${ }^{d}$ Estimated carbon emission reductions are relative to the reference case in the Annual Energy Outlook 1997 (EIA 1996 ), extended to 2020 and 2030 by extrapolating current carbon emission growth rates. The exceptions are the 2020 and 2030 estimates for nuclear energy (M and $\mathrm{H}$, respectively). These are relative to an adjusted reference case forecast, which takes into account the large capacity of nuclear power scheduled for retirement after 2010. 
The estimates of potential GHG reductions shown in Table 5.2 are consistent with the conclusions that were offered in conjunction with Table 5.1; that is, substantial reductions are available by 2030 , and many technology areas can be contributing to these savings at that point.

Table 5.2 also shows that technology areas face different challenges, opportunities, and issues. Many of the technology issues can be addressed by the technology RD\&D outlined in this report.

Technical risks are low to moderate in each of the energy efficiency areas and especially in the buildings sector. Counterbalancing this advantage in terms of delivering carbon impacts is the low level of private-sector R\&D, the slow pace of adoption of innovations by builders, and the moderate rate of stock turnover in the buildings sector. The transportation and industrial sectors face generally moderate levels of technical risk. In transportation, economic risk is increased by consumer preferences for power and size over efficiency; and in industry, economic risk results from high discount rates that impede investments in efficient equipment.

Many of the clean energy options for generating electricity are threatened by the uncertainty of utility industry restructuring and competition with inexpensive natural gas combinedcycle technology. Nuclear power also has the additional institutional risks of a long-term waste repository solution and concerns over proliferation.

Carbon sequestration technologies face high technical risks because of the exploratory stage of their development. In addition, environmental and economic issues need to be resolved. However, these technologies hold the potential to extend the continued use of fossil fuel.

In most cases, risk can be reduced by technology and basic research programs that include analysis of economic and social consequences. Modeling tools and analyses are needed to complement the technology RD\&D process to assess the potential acceptance of developmental technologies, identify likely concerns, and develop mechanisms to address those concerns. Such efforts to understand the social and economic risks are critical.

\subsubsection{The Time-Line of Technology Products}

Consistent with the notion of an orderly technology evolution, the products of a vigorous RD\&D program to develop GHG reduction technologies could be adopted and implemented in time frames that mirror the typical pace of capital stock turnover. As a result, improvements in energy efficiency, clean energy, or carbon sequestration technologies would typically be available long before their impact on carbon emissions could be discerned. Thus, it is useful to forecast when different incremental improvements and breakthrough technologies will be available as cost-effective alternatives, recognizing that many years will typically be required before they are mature technologies.

Figures 5.1 and 5.2 present time lines of selected technology products. They illustrate the steady stream of important accomplishments that the vigorous $R D \& D$ program could produce. (Many more technology products are identified in Appendix B.) The technology products shown in these figures are consistent with the trend in carbon savings from energy efficiency gains in the first decade, to 
significant contributions by a variety of clean energy technologies in the second decade, followed by the emergence of carbon sequestration technologies in the third decade.

A second trend illustrated in these figures is the transition from the development of individual components to the emergence of novel, integrated systems. Over the next two decades, many components will be designed and engineered that can be woven into existing technology and capital infrastructures to improve their performance while reducing carbon emissions. Ultimately, these components will overhaul many of the systems that exist today. Such orderly sequencing of component development, with the ultimate goal of creating entirely new systems, can minimize the costs of capital displacement and economic disequilibrium. Two examples are provided below.

- The gasoline/electric hybrid vehicle (envisioned for development before 2005) is a precursor to the hydrogen fuel cell vehicle, which could be available by 2015 . Following breakthroughs in hydrogen production, such as the manufacture of hydrogen from the solar conversion of water (perhaps by 2020), we envision a transformed transportation system by 2025 with a mature hydrogen supply infrastructure fueling multiple modes of transportation

- By 2010, we envision that biofuels could be cost-competitive with transportation fuels and that they could be distributed by the existing infrastructure of filling stations (worth hundreds of billions of dollars) with only modest modifications. By 2015, RD\&D could enable the widespread production of chemicals from biomass feedstocks.
Ultimately, 2030 could see a broadbased biomass industry with new crops, feedstocks, and distribution systems producing food, transportation fuels, chemicals, materials, and electricity, and possibly an entirely new distribution system at the wholesale and retail levels

The two examples illustrate the need for pursuing multiple technology pathways in critical areas (e.g., for alternative transportation fuels), because the success of any single pathway cannot be guaranteed. In addition, no single pathway appears able to deliver the amount of GHG reductions that may be needed.

Figures 5.1 and 5.2 portray a possible time line for the commercial introduction of new technology. The technologies themselves will endure much longer than the 30-year horizon indicates. They will become the legacy of the technology strategy that eventually is followed. With many of these technologies is an infrastructure and a whole economic system. Just as the introduction of the mass-produced Model-T Ford and the interstate highway system transformed transportation, these technologies will have comparable enduring effects.

Of course, RD\&D programs by their very nature cannot guarantee that anticipated outcomes will result. Many technical and market risks prevent laudable efforts from producing successful technologies. However, there will also be important technological successes not foreseen at this time. If we invest in a portfolio of RD\&D activities, historic data indicate that the winners will more than compensate for the cost of the failures (Brown 1997). 


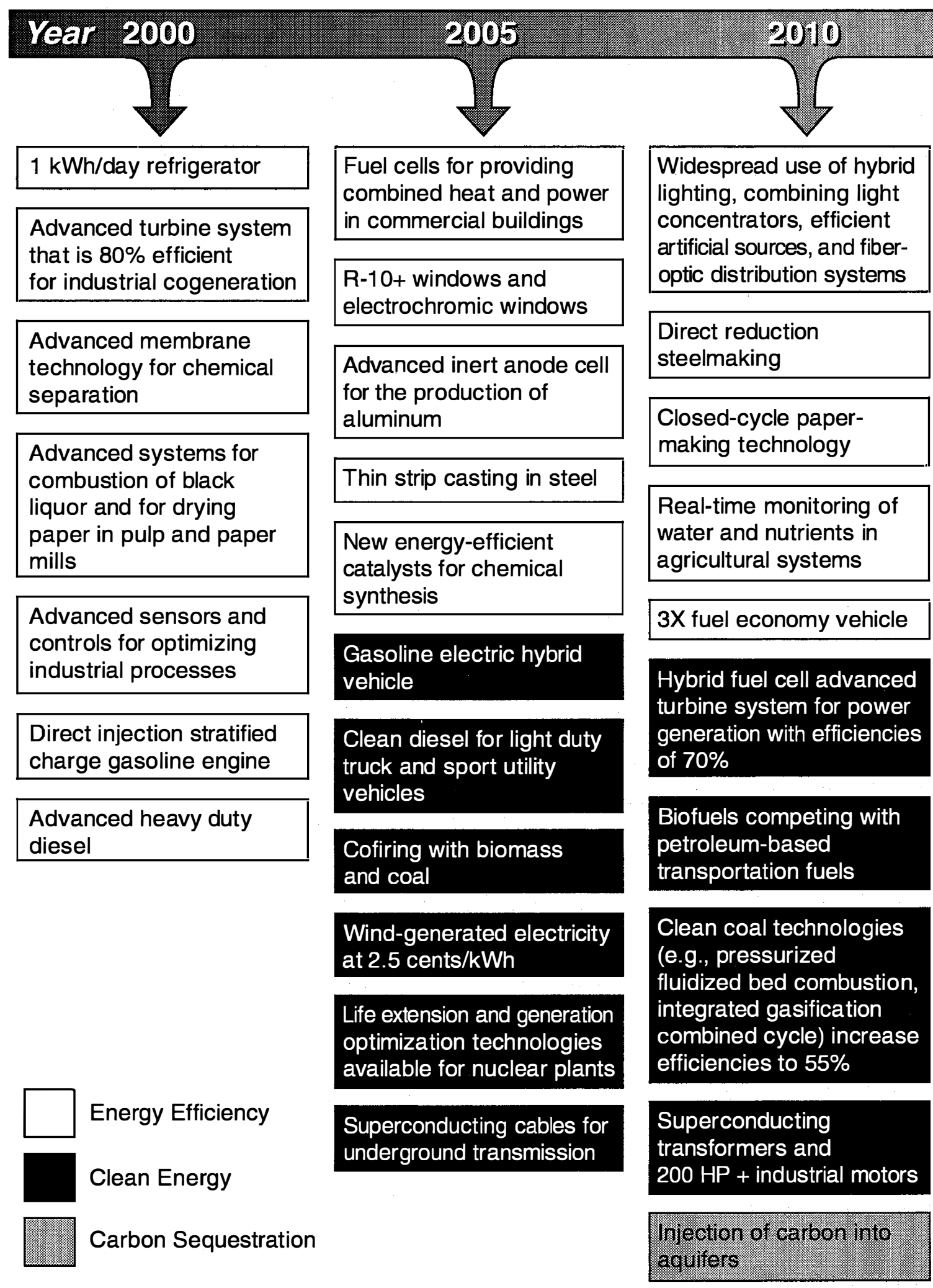

Fig. 5.1. Illustrative time-line of anticipated technology products: 2000-2010. 


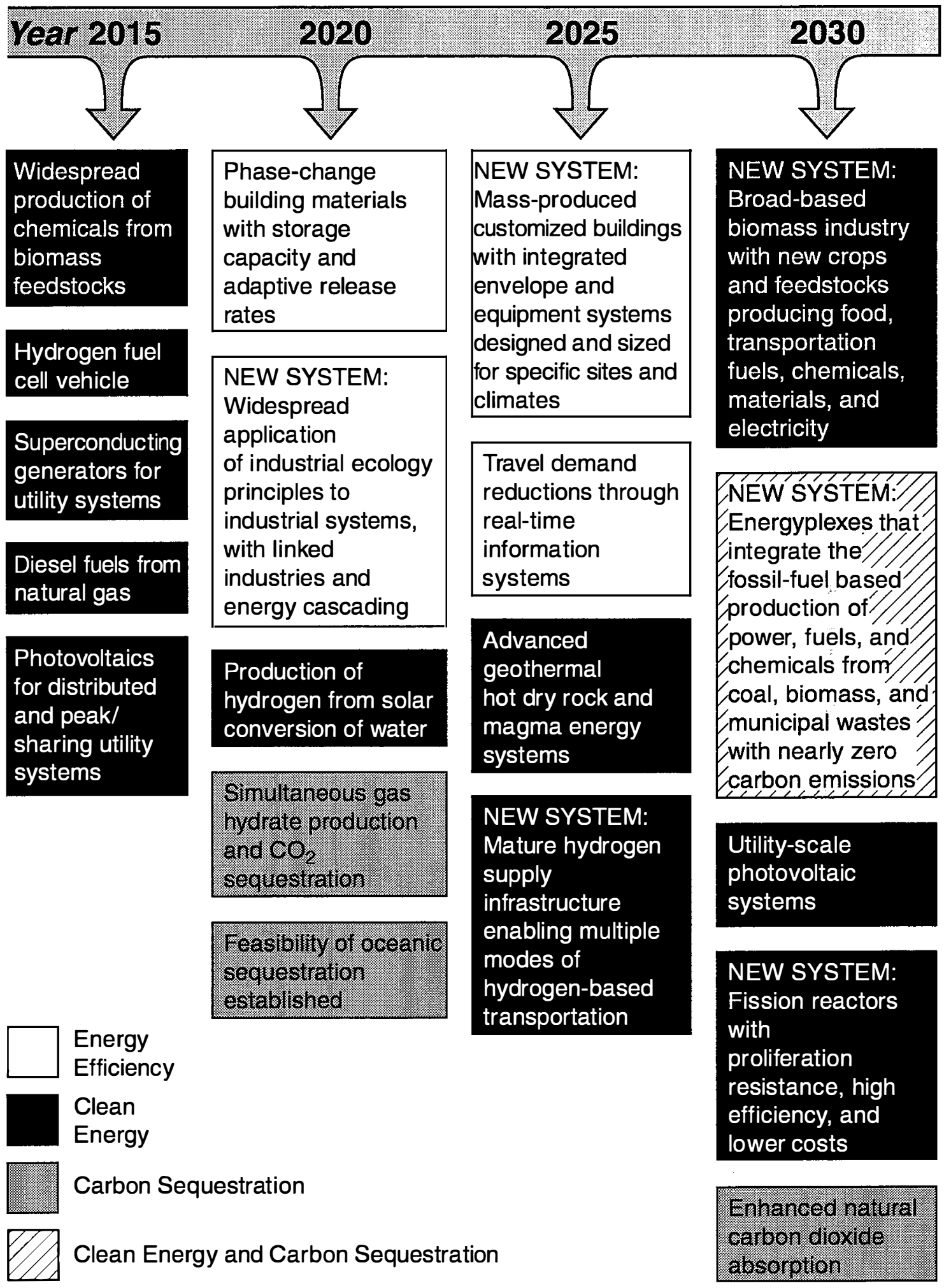

Fig. 5.2. Illustrative time-line of anticipated technology products: 2015-2030. 


\subsubsection{Performance Goals}

Another way of viewing the products of the proposed technology pathways is by specifying performance goals they could achieve. These goals do not rely on particular technology developments; rather, they specify performance criteria that could be met by many alternative technologies. Recommended goals are presented, along with some of the technologies that could contribute to meeting them.

\section{Energy Efficiency}

- Use electricity more efficiently through the deployment of advanced technologies (e.g., intelligent building control systems, costeffective refrigerators that use half as much electricity as today's models, and fuel cells for heat and power in commercial buildings).

- Reduce the use of gas and oil for space and water heating through building efficiency measures (e.g., super insulation, gas-fired heat pumps that provide highly efficient space heating and cooling, and building envelopes that capture and store solar energy for later use).

- Improve industrial resource recovery and use (e.g., develop an IGCC power technology, which can convert coal, biomass, and municipal wastes into power and products) and industrial processes to save energy (e.g., advanced catalysis and separations technologies).

- Increase transportation efficiency through new technologies (e.g., a hybrid electric vehicle that is three times more fuel efficient than today's standard model).

\section{Clean Energy}

- Change the energy mix to increase the use of sources with higher generating efficiencies and lower emissions-natural gas, safer and more efficient nuclear power plants, renewable energy (e.g., solar and wind power; electricity and fuels from agricultural biomass), and hydrogen (to produce electricity through fuel cells).

- Develop "energyplexes" that would use carbon efficiently without emitting GHGs for the integrated production of power, heat, fuels, and chemicals from coal, biomass, or municipal wastes.

- Distribute electricity more efficiently to reduce emissions (e.g., distributed generation using superconducting transformers, cables, and wires).

- Switch transportation to energy sources with lower emissions (e.g., trucks that run on biodiesel fuel; ethanol from cellulosic feedstocks).

- Remove carbon from fuels before combustion.

\section{Carbon Sequestration}

- Sequester $\mathrm{CO}_{2}$ in large-capacity geological formations in deep oceans.

- Efficiently remove $\mathrm{CO}_{2}$ from combustion emissions before they reach the atmosphere.

- Increase the rate at which oceans, forests, and soils naturally absorb atmospheric $\mathrm{CO}_{2}$.

- Develop carbon storage technologies sufficient for geologic times.

\subsubsection{Basic and Applied Research Are Needed}

Meeting the goals described above also depends upon incremental improvements and breakthroughs in the basic sciences. These basic research needs include

- basic research to understand the global carbon cycle (i.e., computational modeling and 
measurements to understand the ocean-atmosphere-terrestrial biosphere interactions) and judge the benefits and risks of sequestration options

- basic research supporting GHG reduction technologies (i.e., materials, chemical sciences, biotechnology, environmental and ecological sciences, geosciences, nuclear sciences, and computational sciences)

To support multiple technology pathways, enabling technologies also must be improved, especially those that enhance the utilization of energy carriers and systems. Relevant enabling technologies include

- hydrogen production/storage/ distribution

- fuel cells

- electrical transmission, distribution, and components

- sensors and controls

- energy storage systems

\subsubsection{Collateral Benefits and Costs}

In addition to the benefits of GHG avoidance, the technology pathways described in this report could have significant secondary effects, as such pathways have in the past. For example, in the buildings area, there is a remarkable record of success in federally supported RD\&D leading to products in the marketplace that have generated energy savings far exceeding their costs of development. In addition to reducing energy costs, the pathways would lead to improved environmental quality and public health, reduced U.S. dependence on imported oil, and increased exports of U.S. technologies to help other nations reduce GHG emissions, all of which will sustain economic growth.
The environmental and public health benefits of new and improved GHG reduction technologies could be very large. Clean energy options for generating electricity offer the prospect of significantly reducing air pollution. The development of efficient lowcarbon transportation fuels would reduce pollutant emissions and abate ground-level ozone. Pollution prevention and waste minimization are important hallmarks of improved industrial process efficiencies. These collateral benefits would lead directly to major improvements in public health (Romm and Ervin 1996).

These environmental and public health benefits would not be limited to the United States. Better technology options would help to control the GHG emissions of other countries for many decades to come. They could also position the United States as the provider of choice for these new energy and environmental systems, with major economic growth consequences. The global energy market is estimated at $\$ 1$ trillion, and the market for environmental technologies is estimated to be

$\$ 400$ billion. Renewable resources are widespread around the world, are highly attractive to developing countries, and represent a huge potential market for U.S. companies. An important collateral benefit of continued pursuit of nuclear power is the economic benefit of serving as an international supplier. The increased use of nuclear energy is foreseen around the developing world, especially in the Pacific Rim countries. The international market for ATSs and fuel cells is also likely to grow rapidly. Thus, implementation of a technology strategy would help to grow the U.S. economy by creating an energy technology export business. 
The reductions in petroleum use that would result from the technology pathways would cut U.S. oil import dependence and could lower oil prices to consumers (Interlaboratory Working Group 1997, p. 5.47). It is estimated that efficiency improvements and alternative fuels in the transportation sector could result in reductions of one billion barrels per year by 2010 .

Some of the pathways might also spawn significant collateral costs. For instance, increased nuclear waste might result in negative environmental repercussions, large-scale biomass production might cause soil and water contamination, and ocean fertilization might precipitate ecosystem damage.

Regions that flourish in today's energy economy might be negatively impacted by shifts in the resource and labor requirements of new energy systems. The workplace requirements associated with advanced energy technologies might strain the nation's capacity to train and educate its labor force. History has shown that such challenges often can be managed. Further, if multiple pathways are pursued, those judged unacceptable can be set aside in favor of those that are preferred.

\subsubsection{Research, Development, and Demonstration Resources}

This report describes the carbon emission reductions that could result from an accelerated $R D \& D$ program. It does not consider collateral benefits from initiating complementary deployment programs or policies aimed at stimulating markets for GHG reduction technologies. It is believed that an integrated approach (i.e., science and technology in combination with deployment programs and supporting policies) is the most cost-effective one.
To achieve the annual emission reductions of 400 to $800 \mathrm{MtC}$ by 2030 described in this report, absent any additional deployment or policy thrusts, federal RD\&D budget increments would be necessary in three areas:

- The annual federal RD\&D budget for the development of advanced energy technologies would need to grow to produce a sufficient number of the technological solutions.

- Additional resources are needed to initiate research into carbon sequestration technologies, which would also require supporting research on carbon cycle modeling, monitoring, and ecosystems.

- Supplemental RD\&D support is needed to strengthen the basic research areas that are the wellspring of future technological breakthroughs.

The projects listed in Appendix B represent a catalog of promising technologies without prioritization. We believe that effective progress toward greenhouse gas emission reductions can be made with an additional RD\&D investment of approximately $\$ 1 \mathrm{~B} /$ year once priorities are established. Any budget decisions should be based on more detailed planning and analysis than was possible during development of this report. Initiation of that analysis and planning, which is a primary recommendation for moving forward, is discussed further in Sect. 5.2.

Actual budgets should be ramped up over several years in a way consistent with sound program development. Also, resource requirements for the outyears obviously would be affected by developments between now and then. Finally, it is anticipated that additional privatesector research effort would be leveraged by this federal increment. 


\subsection{MOVING FORWARD}

This report identifies in general terms a set of future technologies that appear to hold great promise for reducing U.S. GHG emissions. By summarizing the status and potential of a broad range of technologies relevant to reducing GHG emissions, this report provides one key element, namely, the "technology basis," for developing a climate change technology strategy. However, full definition of such a strategy requires several additional steps, including

- an assessment of alternative programs and policies to promote deployment

- analysis of the costs and benefits of alternative technology and policy options to develop priorities

- development of technology goals and performance metrics for measuring progress

- identification of key players for pursuing these promising technology pathways

- estimation of budget requirements and appropriate allocation for each technology pathway

- mechanisms for ensuring strong ties between technology development activities and supporting basic sciences

- delineation of public- and privatesector responsibilities

- linkages to related ongoing activities in the United States and abroad

- a plan for managing the technology RD\&D programs to be pursued over the years and decades ahead

The strong recommendation of this report is that the United States should develop and pursue a detailed and comprehensive climate change technology strategy.

Further, the planning process should begin immediately, and implementation of the strategy should occur quickly.
As the federal agency with the most involvement in the full range of technologies described in this report, the U.S. DOE should initiate and lead the planning required for implementation of this strategy. However, that planning effort must include significant participation from industry and business, the university community, Congress, and other federal agencies, as well as DOE and the national laboratories. Indeed, this planning should be a collaborative effort, just as is recommended for implementation of the technology RD\&D programs.

While not all of the details of this planning and strategy implementation can be defined here, two clear needs should be explicitly addressed. The first is establishing a collaborative national planning effort to provide leadership and guidance to meet the RD\&D challenges of a climate change technology strategy. The second is initiating an analysis activity to provide the information necessary for making sound decisions on the issues indicated. Both of these steps should be taken immediately.

Several other issues deserve immediate attention. One of these is the connection between developing promising technology pathways and designing policies to promote their deployment. There are many tradeoffs among how fast one pushes development, how much emphasis is placed on deployment of technologies that are ready to contribute to reduced emissions, and the timetable for achieving different reduced emission levels.

Another issue requiring study is the relationship between the implementation of promising technology pathways and the phenomenon of climate change, as 
well as the need for a better understanding of the phenomenon itself. This report strongly endorses the need to continue to improve our understanding of GHG emission levels, atmospheric concentrations of GHGs, climate change, and their impacts on our biosphere. A science-based understanding of the carbon cycle is essential as a framework for guiding our technology investments and ensuring their cost-effectiveness.

A third issue is consideration of the organizational structure of the technology RD\&D programs. The recommendation to use strategic alliances recognizes the need to move away from the technology partnerships of the past. While there is no single organizational structure for creating strategic alliances, the traditional roles of users, industry, federal agencies, universities, states, national laboratories, and not-for-profit organizations may require redefinition as strategic alliances are formed to develop and deploy climate change technologies. Flexibility and adaptability in the structure of these partnerships is critical to the most effective pursuit of technology development programs to reduce GHG emissions.

A fourth issue is that of relating and coupling this domestic technology strategy with related international GHG emission reduction efforts.

International collaboration can provide important domestic savings and global benefits.

Finally, it is important to understand the consequences of not developing and pursuing a technology strategy. Perhaps one of the greatest risks is underestimating the magnitude of the impact we are attempting to achieve. Energy is central to development and modern civilization. We are talking about transforming a national and global infrastructure that currently includes all of the things that support combustion as a means of energy generation. This is not a trivial matter. The generation of $\mathrm{CO}_{2}$ is embedded deeply in the social infrastructure of this nation and is being embedded in the developing world right now.

The availability of advanced technologies on a timely basis to address future GHG emission reduction commitments requires initiation of the RD\&D now and a commitment to following through on all the pathways that continue to show promise. Technologies not pursued are likely to result in lost opportunities to apply them to mitigating climate change, as well as a loss of their collateral benefits.

\subsection{CONCLUSION}

This report concludes that a national investment in a technology RD\&D program over the next three decades would provide a portfolio of technologies that could significantly reduce GHG emissions well into the twenty-second century. Many technology opportunities exist that could accomplish this goal without harming the nation's economy. A strategic plan that includes deployment policies to complement technology R\&D will be necessary for success. Hence, development of a climate change technology strategy is the recommended next step. Based on the conclusions of this report, the strategy should specify an approach that pursues multiple technology pathways, that emphasizes publicprivate strategic alliances, and that is designed in close coordination with supportive government policies and deployment programs. 
By delivering a portfolio of highly promising technologies, a climate change technology strategy could produce savings and revenues that far exceed the cost of an accelerated research program. The bottom line: with the help of technology and appropriate government programs and policies, we can slow GHG emissions and grow the economy. DOE's national laboratories stand ready to champion this enterprise.

\subsection{REFERENCES}

Brown, M. A. 1997. "Performance Metrics for a Technology Commercialization Program," Int. J. of Technology Management, 13 (3): 229-244.

EIA (Energy Information Administration) 1996. Annual Energy Outlook 1997: With Projections to 2015, DOE/EIA0383(97), U.S. Department of Energy, Washington D.C., December.

Energy Innovations 1997. Energy Innovations: A Prosperous Path to a
Clean Environment, Alliance to Save Energy, American Council for an Energy-Efficient Economy, Natural Resources Defense Council, Tellus Institute, and Union of Concerned Scientists, Washington, D.C.

Interlaboratory Working Group 1997. Scenarios of U.S. Carbon Reductions: Potential Impacts of Energy-Efficient and Low-Carbon Technologies by 2010 and Beyond, September.

NAS (National Academy of Sciences) 1992. Policy Implications of Greenhouse Warming: Mitigation, Adaptation, and the Science Base, National Academy Press, Washington, D.C.

OTA (Office of Technology Assessment) 1991. Changing by Degrees: Steps to Reduce Greenhouse Gases, OTA-0482, U.S. Government Printing Office, Washington, D.C., February.

Romm, J. J., and C. A. Ervin 1996. "How Energy Policies Affect Public Health," Public Health Reports 5, 390-399. 
Appendix A Contributors
The following are the principal DOE National Laboratory staff participating in the committees and working groups supporting the development of this report. Many other individuals in the federal and private sector contributed but are not acknowledged here.

\section{COORDINATING COMMITTEE}

Stanley R. Bull, NREL, Co-chair

David E. Reichle, ORNL, Co-chair

William M. Babiuch, NREL

Arnold B. Baker, SNL

Lynn L. Billman, NREL

Eldon C. Boes, NREL

Marilyn A. Brown, ORNL

Brenda W. Campbell, ORNL

Michael P. Farrell, ORNL

Robert San Martin, DOE Liaison

John Sheffield, ORNL

Walter D. Short, NREL

\section{EDITORIAL SUPPORT GROUP}

Deborah M. Counce, ORNL

Vickie L. Beets, ORNL

Judy H. Benton, ORNL

Judy H. Campbell, ORNL

Vickie L. Conner, ORNL

Walter S. Koncinski, ORNL

Carolyn H. Krause, ORNL

Sandra C. Lyttle, ORNL

Jamie P. Payne, ORNL

Brenda Barlow, Lockheed Martin Energy Systems

Gloria Llanos, Temp Systems

Mary E. Marshburn, CDI

Linda O'Hara, CDI 


\section{LAB REPRESENTATIVES AND ALTERNATES}

Dan E. Arvizu, SNL Arnold B. Baker, SNL

Stanley R. Bull, NREL Lynn L. Billman, NREL

David Cauffman, INEEL Melinda A. Hamilton, INEEL

Harvey Drucker, ANL David J. Hill, ANL

James M. Ekmann, FETC Charles E. Schmidt, FETC

Mark D. Levine, LBNL Donald F. Grether, LBNL

Leonard Newman, BNL James W. Davenport, BNL

David E. Reichle, ORNL John Sheffield, ORNL

Alfred P. Sattelberger, LANL Edward L. Joyce, LANL

Robert N. Schock, LLNL Anthony K. Chargin/Jill L. Watz, LLNL

Gerald M. Stokes, PNNL John F. Clarke, PNNL

\section{WORKING GROUPS}

\author{
Buildings \\ Mark D. Levine, LBNL, Chair \\ John W. Andrews, BNL \\ Douglas Balcomb, NREL \\ Marilyn A. Brown, ORNL \\ James D. Cavallo, ANL \\ George E. Courville, ORNL \\ Richard Diamond, LBNL \\ Donald F. Grether, LBNL \\ Jeffrey P. Harris, LBNL \\ Jeffrey A. Johnson, PNNL \\ Ronald Judkoff, NREL \\ Marion L. Scott, LANL \\ Industry \\ Alan P. Sylwester, SNL, Chair \\ Pete Angelini, ORNL \\ Dan E. Arvizu, SNL \\ Carol Burns, LANL \\ Donald G. Foster, LBNL \\ Thomas D. Foust, INEEL
}

Michael J. Furey, BNL

Bim Gupta, NREL

Nancy Jackson, SNL

Gretchen Jordan, SNL

Edward L. Joyce, LANL

Carol Kyle, SNL

Jeff S. Logan, PNNL

Mitch Olszewski, ORNL

Mildred B. Perry, FETC

Gene Petersen, NREL

Mike Petrick, ANL

Anthony C. Schaffhauser, ORNL

Tom Schmidt, ORNL

Jill L. Watz, LLNL

\section{Transportation}

David E. Reichle/E. Kaye Johnson, ORNL, Chair

Basil A. Barna, INEEL

Larry S. Blair, LANL

Barbara Joan Goodman, NREL

Donald F. Grether, LBNL

Larry R. Johnson, ANL

Jeff S. Logan, PNNL

William J. McLean, SNL

Steven E. Plotkin, ANL

Frank J. Tokarz, LLNL

James E. Wegrzyn, BNL

Agriculture and Forestry

David P. Cauffman, INEEL, Chair

Helena L. Chum, NREL

Arthur B. Denison, INEEL

James R. Frank, ANL

Robin L. Graham, ORNL

Melinda A. Hamilton, INEEL

George R. Hendrey, BNL

Sheridan C. Johnston, SNL

Willy R. Makundi, LBNL

Gene Peterson, NREL

Norman J. Rosenberg, PNNL

Michael J. Scott, PNNL

Pat J. Unkefer, LANL

Fossil Resource Development

Robert J. Hanold, LANL, Chair

Greg A. Bala, INEEL

Edward L. Joyce, LANL

Ann F. Meinhold, BNL

Larry R. Myer, LBNL

David A. Northrop, SNL 
John Reynolds, LLNL

Alfred P. Sattelberger, LANL

Tom W. Schmidt, ORNL

Alan M. Wolsky, ANL

Albert B. Yost II, FETC

Fossil Power Generation

James M. Ekmann, FETC, Chair

William A. Apel, INEEL

Steven R. Booth, LANL

Nancy J. Brown, LBNL

Kevin R. Craig, NREL

Robert E. Hall, BNL

Donald R. Hardesty, SNL

Roddie R. Judkins, ORNL '

Brady D. Lee, INEEL

Dave K. Schmalzer, ANL

Charles E. Schmidt, FETC

Nuclear Energy

Harvey Drucker, ANL, Chair

William A. Barletta, LBNL

Steven G. Hauser, NREL

David J. Hill, ANL

John R. Ireland, LANL

Peter Klemkowsky, FETC

Jim Lake, INEEL

Gordon E. Michaels, ORNL

Nestor R. Ortiz, SNL

Trevor Pratt, BNL

Keith I. Thomassen, LLNL

Renewables

Stanley R. Bull/Lynn L. Billman, NREL, Chair

Marilyn A. Brown, ORNL

Sue Jacobsen Goff, LANL

Philip M. Goldberg, FETC

Paul Kasameyer, LLNL

Paul C. Klimas, SNL

Chris Marnay, LBNL

Paul D. Moskowitz, BNL

Joel L. Renner, INEEL

William W. Schertz, ANL

Carbon Management and

Sequestration

Gerald M. Stokes, PNNL, Chair

Sally M. Benson, LBNL

David J. Borns, SNL
Helena L. Chum, NREL John F. Clarke, PNNL

Richard D. Doctor, ANL

LaMar J. Johnson, INEEL

Edward L. Joyce, LANL

Gregg H. Marland, ORNL

John A. Ruether, FETC

Meyer Steinberg, BNL

Jill L. Watz, LLNL

Basic Research

Leonard Newman, BNL, Chair

Joel W. Ager, LBNL

Mark Alper, LBNL

Anthony K. Chargin, LLNL

John F. Clarke, PNNL

James W. Davenport, BNL

Satyen Deb, NREL

Arthur B. Denison, INEEL

Wilhelm B. Gauster, SNL

Linda L. Horton, ORNL

Edward L. Parsons, FETC

Mark E. Reeves, ORNL

Marion C. Thurnauer, ANL

William Tumas, LANL

Albert F. Wagner, ANL

Leland W. Younker, LLNL

Cross-Cutting Technologies

Robert N. Schock, LLNL, Chair

William V. Chandler, PNNL

Anthony K. Chargin, LLNL

Cathy Gregoire Pedro, NREL

Jay O. Keller, SNL

John B. Kerr, LBNL

Gilbert V. McGurl, FETC

Kevin Michael Myles, ANL

James J. Reilly, BNL

John Sheffield, ORNL

John M. Slater, INEEL

James Van Coevering, ORNL

P. Henrik Wallman, LLNL

David Watkins, LANL

Jill L. Watz, LLNL

Analysis Team

Walter Short, NREL

Ron A. Bradley, ORNL

T. Randall Curlee, ORNL 


\title{
TECHNOLOGY OPPORTUNITIES TO REDUCE U.S. GREENHOUSE GAS EMISSIONS
}

\author{
Appendix B \\ Technology Pathways Characterization \\ (Working Document)
}

October 1997

Prepared by

National Laboratory Directors

for the

U.S. Department of Energy

On the World Wide Web:

http://www.ornl.gov/climate_change 



\section{INTRODUCTION AND METHODOLOGY}

\section{Overview}

A major objective of this study was to compile information on the potential of a wide range of energyrelated technologies to reduce carbon dioxide emissions through additional RD\&D. This was done by identifying a large team of individuals with relevant energy technology expertise, organizing them into 11 working groups to address 11 technology areas, and providing them with guidance for developing the desired information. The 11 technology areas included 9 categories of technology pathways, plus crosscutting technologies and related areas of basic research.

Each working group was responsible for identifying the individual technology pathways appropriate to their technology, drafting the text for Chapter 2 of the main report, and preparing the two-pagers contained in this appendix. In order to complete all of these tasks, the working groups developed a large amount of information about the technologies in their area in the context of the 30-year timeframe that underlies this study. This information was critical in estimating which technologies provided the best opportunities for reducing GHG emissions in the U.S.

In addition to discussing the technical aspects of the best technological pathways for reducing GHGs, the working groups sought to develop general estimates of the potential costs and benefits of each technology pathway. It is important to note that the cost-benefit estimates are only approximate, relative indicators of what might be achievable if the technological goals are met.

The working groups relied upon Delphi Method principles to reach their conclusions about the technology pathways. Conditions and assumptions not defined in this Appendix were based on a consensus of the working group members.

An important part of the overall study methodology took the form of a "consistency scrubbing" exercise. A small group carefully reviewed all of the technology pathways for consistency and credibility, and then interviewed working group representatives to ensure that the technology pathway information had a firm technical basis and was developed through a sound analytic process. In addition, the small group reviewed how the carbon emission reduction estimates and the risk factor scores were developed to ensure that all the working groups followed the agreed upon guidelines.

\section{Technology Pathway Two-Pagers}

This appendix contains two-page descriptions of 47 climate change technology pathways. The appendix is not a comprehensive inventory of every possible technology that could reduce GHG emissions. Rather, it focuses on 47 pathways that were judged by the working groups to be sufficiently promising to warrant serious consideration. The attributes of the technologies comprising each pathway area were assessed independently by the working group responsible for that area. Thus further analysis would be required to prioritize all 47 technology pathways based on their likely costs and benefits.

Each two-page pathway provides a technology description (covering system concepts, representative technologies, and the technology's current status), describes current research, development, and demonstration (RD\&D) activities (including RD\&D goals and challenges), and presents one or more recent successes. Each pathway also discusses the prospects for commercialization and deployment of the technology and describes potential benefits and costs (including carbon reductions, market impacts, 
nonenergy benefits and costs, and RD\&D expenditures). Finally, six types of risk factors are assessed, and study recommendations in the form of key federal actions are made.

The descriptive text and the numerical estimates presented in these pathways are based on the judgment of the working groups formed from the 11 national laboratories participating in this effort and in some cases, in collaboration with experts from other organizations across the country. Analysis supports some of the numerical estimates provided in the two-pagers. In other cases, the estimates were the best estimates of experts based on available information. Standardized protocols and assumptions were used by each working group to promote consistency in defining terms and in estimating values. As an additional mechanism for increasing overall consistency among the technology pathways, a small focus group discussed drafts of each pathway with the working group that drafted the two-pager. Although this was a lengthy and time-consuming process, it resulted in numerous clarifications and improvements to the pathways, including their numerical estimates. Finally, numerous DOE program managers reviewed preliminary versions of the report, as well as the technology pathways.

A discussion of the guidance provided to the teams and other relevant issues regarding assumptions and interpretation of the pathways is presented by topic.

\section{Estimation of Carbon Emission Reductions}

The estimated carbon emission reduction of each pathway is the portion of the cost-effective potential that could reasonably be expected to result from an enhanced RD\&D effort, with no significant changes to government policies or deployment programs. These reductions are an estimate of reasonable expectations, not inherent capacity. Estimates of carbon reduction are provided in terms of millions of metric tons of carbon ( $\mathrm{MtC}$ or $10^{12} \mathrm{gC}$ ) that could be displaced annually by the technology, above and beyond the reference case forecast, for each of the decades ending in the years 2010, 2020, and 2030.

The time frame of this study did not allow analysis of all of the various factors that could affect the performance and market penetration of a new technology. However, the study has compiled a considerable amount of information on a wide range of factors and has taken this information into account in estimating carbon reductions. The factors that the teams considered include the following:

- $\quad$ size of domestic and international markets for the technology

- turnover rate of capital stock

- technical risks associated with the RD\&D

- $\quad$ size of the federal RD\&D resources required

- magnitude of the technology's capital and operating costs

- extent of changes in infrastructure required for commercialization

- size of the resource base available to support the technology

- environmental and health risks associated with the technology

- $\quad$ public perception and acceptance risks

- characteristics of competing technologies

Reference Case. U.S. $\mathrm{CO}_{2}$ emissions are projected by the U.S. DOE Energy Information Administration (EIA) to increase at a rate of $1.2 \%$ per year under a "business-as-usual" scenario. This scenario assumes that some efficiency and process improvements will offset what would otherwise be a larger rate of $\mathrm{CO}_{2}$ increases. The rise in emissions is driven by a forecasted GDP growth rate of $1.9 \%$. (Underlying this growth rate is the assumption of sustained economic growth and an increasing population.) Without a major intervention, $\mathrm{CO}_{2}$ emissions will increase by almost $50 \%$ from the current annual level of approximately 1.4 billion $\mathrm{MtC}$ to about 2.1 billion $\mathrm{MtC}$ in 2030. The data shown in Table B.1 for the 
period 2015 to 2030 are based on extrapolations of the EIA reference case for 2015. Thus they do not take into account the significant reduction in nuclear power that could occur after 2015 if nuclear power plants are retired according to their current license expiration dates.

Table B.1. U.S. carbon dioxide emissions by end-use sector (in $\mathrm{MtC}$ per year)

\begin{tabular}{|c|c|c|c|c|c|c|c|}
\hline & \multicolumn{4}{|c|}{ Emissions } & \multicolumn{3}{|c|}{ Change from 1990} \\
\hline & 1995 & 3020 & 2020 & 2030 & 2010 & 2020 & 2030 \\
\hline \multicolumn{8}{|l|}{ Buildings } \\
\hline Fossil & 159 & 170 & 178 & 185 & 22 & 30 & 37 \\
\hline Electricity & 335 & 406 & 463 & 515 & 94 & 151 & 203 \\
\hline Subtotal & 494 & 576 & 641 & 700 & 116 & 181 & 240 \\
\hline \multicolumn{8}{|l|}{ Industry } \\
\hline Fossil & 293 & 335 & 357 & 380 & 49 & 71 & 94 \\
\hline Electricity & 171 & 213 & 241 & 269 & 47 & 75 & 103 \\
\hline Subtotal & 464 & 548 & 598 & 649 & 96 & 146 & 197 \\
\hline \multicolumn{8}{|l|}{ Transportation } \\
\hline Fossil & 464 & 591 & 655 & 727 & 160 & 224 & 296 \\
\hline Electricity & 1 & 7 & 10 & 14 & 6 & 9 & 13 \\
\hline Subtotal & 465 & 598 & 665 & 741 & 166 & 233 & 309 \\
\hline \multicolumn{8}{|l|}{ Total } \\
\hline Fossil & 918 & 1096 & 1189 & 1291 & 231 & 324 & 426 \\
\hline Electricity $^{a}$ & 506 & 626 & 714 & 798 & 147 & 235 & 319 \\
\hline Total & 1424 & 1722 & 1904 & 2089 & 378 & 560 & 745 \\
\hline
\end{tabular}

"The extrapolation beyond 2015 does not take into account the significant reduction in nuclear power that could occur as nuclear power plants are retired according to their current license expirations. Recent results of a new forecast by the Energy Information Administration suggest that carbon emissions will grow at a slightly faster pace through the year 2015. This new forecast is not yet published and is therefore not used in this report. In any event, using the new forecast would not substantially change the results of this report.

Sources: The carbon estimates for 1995 and the forecast for 2010 are taken directly from the Reference Case of EIA 1996a. Carbon emissions for 2020 and 2030 are forecasted using the same growth rates as for 2010. Electric utility emissions are distributed across sectors. GHGs other than $\mathrm{CO}_{2}$ are not included.

Federal RD\&D Efforts. The federal government has a substantial program in energy RD\&D, designed to support the broad national goals of energy security and environmental quality. Although the existing energy RD\&D programs were not designed specifically to reduce carbon emissions, they also will have significant benefits for mitigating climate change. The carbon emission reduction estimates presented in Appendix B and the main report are based on the assumption of an enhanced federal RD\&D program. Because the current federal RD\&D effort is taken into account in the reference case, the pathway 
estimates of carbon reductions are incremental to the reductions that would result from a continuation of current levels of federal RD\&D funding. The estimated RD\&D support needed to achieve these incremental carbon reductions is based on the judgment of the working groups from the 11 participating national laboratories (and in some cases in collaboration with experts from other organizations across the country).

The RD\&D budget estimates are expressed in 1997 dollars. R\&D priorities and any budget decisions should be based on more detailed planning and analysis than was possible during development of this report. Initiation of that analysis and planning is one of this report's primary recommendations.

Private-sector Efforts. Federally funded RD\&D is certainly not the only effort that will be needed to develop and demonstrate the technologies described in these pathways. Private-sector collaboration is a major element of many federal RD\&D programs and will need to continue and expand along with the federal commitment to enable the nation to achieve the advances described in this report. Private-sector expenditures are not included in the estimates of the required federal RD\&D expenditures.

Federal Policies. The technology pathways — and the main report-assume a continuation of existing federal programs and policies. The estimates do not presume the creation of any new incentives such as investment tax credits, a carbon charge, or a domestic or international $\mathrm{CO}_{2}$ trading system.

Non-additivity. The effects of the market success of one technology pathway on the market success of another technology pathway were generally considered within one particular technology area, such as within nuclear energy or within buildings efficiency. The effects of competition among technology areas could not be fully evaluated; therefore, carbon reduction estimates from different technology areas (such as nuclear and buildings efficiency) cannot simply be summed. The problem is that the technology areas compete and interact with each other. For instance, if enhanced natural gas production should cause electricity generation to shift from coal to gas, new coal technologies would generate fewer carbon savings. If carbon emissions from the generation of electricity were reduced, the carbon reduction potential from saving electricity in the buildings and industrial sectors would also decline.

Secondary Demand Effects. The estimates of carbon reduction potential do not reflect possible changes in demand for energy services resulting from the introduction of the technology. Improved energy efficiency and more competitive low-carbon energy sources suggest lower energy prices and costs of energy services. These would likely increase demand for energy services and "take back" some portion of the reported savings. Should the demand for energy services and the energy cost of these services change, so would the competitiveness of the technologies explored. These secondary demand effects are not incorporated in the carbon reduction potentials.

Restructuring. The carbon reduction estimates do not take into account any long-term impacts that might be precipitated by restructuring of the electric utility industry. If restructuring produces lower electricity rates, energy use will increase and investments in conservation technologies might decrease, with a concomitant rise in GHG emissions. On the other hand, future utility restructuring legislation calling for renewable portfolio standards and public benefits programs could significantly promote clean power, thereby reducing GHG production.

\section{Description of Risk Factors}

The technology pathways consider six risk factors that are labeled: "technical," "commercial," "ecological," "human health," "economic," and "regulatory." These risk factors are defined as follows. 
Technical Risk: Refers to the risk that the federal R\&D dollars will not result in the commercialization of the technology for cost or performance reasons. Technologies that require only incremental innovation generally have lower technical risk than technologies that require a major breakthrough. Technical risk also generally increases as the number and complexity of associated technologies increase. Thus a technology that is a stand-alone product tends to have lower risk than a technology with many components that need to be developed. In addition, technical risk is negatively correlated with the availability of necessary resources. Therefore, a technology that can be developed with readily available resources (i.e., equipment and/or skills) involves less technical risk than a technology that requires more demanding types of resources. This risk factor takes into account the probability of achieving the cost reductions necessary for a technology to be cost-competitive.

Commercial Risk: Reflects the magnitude and likelihood of commercial vulnerabilities that could hinder successful deployment. Examples of high commercial risk include the need to make massive infrastructure investments or the need to establish a new system of operations and maintenance support for a product. Thus the more changes that are needed in the infrastructure and the more training that will be required by the operations and maintenance providers, the higher the commercial risk. Commercial risk also depends upon the size of the resource base relative to the technology's requirements: limited resources will constrain commercial deployment, and risks are especially high when a technology is strongly dependent on foreign sources.

Ecological Risk: Refers to the probability that a technology could cause significant effects on nonhuman species and aquatic and terrestrial ecosystems. Ecological risk is calibrated in comparison with the new technology's competitors and is generally positively correlated with the severity of the possible effects and their spatial and temporal extent. Examples of high severity include the release of highly toxic byproducts from a technology or the severe modification of habitats as a result of land conversion or water depletion. Spatial extent includes land area or aquatic system length or volume, normalized to the importance of the ecological resource. The temporal extent includes both the time for which the ecological resources would be affected and the time to recovery given the persistence of contaminants and the rate of recovery and adaptation of the affected ecosystem.

Human Health Risk: Refers to the probability of adverse human health consequences as a result of the commercialization and deployment of the technology. As in the case for estimating ecological risk, human health risk is calibrated in comparison to the new technology's competitors. Thus the human health risk of high-efficiency coal-based power generation is considered relative to alternative sources of electricity, including conventional coal generation, natural gas systems, nuclear power, and electricity from renewable resources. Occupational hazards associated with the manufacture of a technology are included in this risk factor.

Economic Risk: Refers to the probability that a technology could be rejected because competing technologies are preferred by consumers. Economic risk is lower when consumers do not have to change their behavior when using, purchasing, or servicing the product. In addition, economic risk is reduced when the new technology's costs compare favorably with the costs of the product that would be displaced, so that the economic decision makers don't need to change their investment behavior. Public preferences can be strongly supportive (as with energy-efficient industrial technologies that also reduce pollution), or they may impede implementation of a technology, leading to economic penalties.

Regulatory Risk: Refers to the probability that current or future U.S. regulations will prevent the technology from meeting its commercialization and deployment targets. For existing technologies, onerous regulations would increase regulatory risk. For technologies that have not yet been 
commercialized, the absence of regulations such as codes and standards may suggest a high regulatory risk.

The study teams assessed the risk factors for each pathway using a 10-point scale. Values on this scale should be interpreted as follows:

- Scores of 9-10 are considered to be so high as to render a technology infeasible over the next half century. All of the pathways in this report are considered feasible during this time frame, so none have been rated with risk scores above 8 .

- A score of 1 is considered to be very close to no risk at all. Since some uncertainty is inherent in all research, few of the pathways received this score in any risk category.

- Scores of 2-3 are considered low risk; scores of 4-6 are considered moderate risk; and scores of 7-8 are considered high risk.

The scores apply to the pathways over the 30-year range of the study, reflecting the results of strongly supported RD\&D but assuming today's policies (consistent with the rest of the report). The scores represent the best judgments of the national laboratory participants. "N/A" or "not available" was assigned in cases where it was not possible to anticipate what the risk levels might be in the future. 


\section{APPENDIX B CONTENTS}

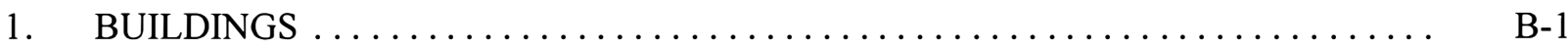

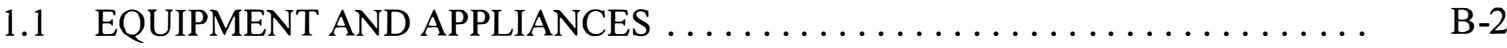

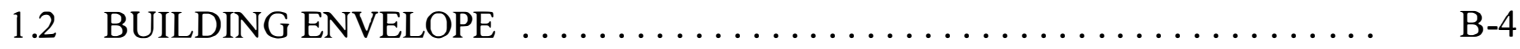

1.3 INTELLIGENT BUILDING SYSTEMS $\ldots \ldots \ldots \ldots \ldots \ldots \ldots \ldots \ldots \ldots \ldots \ldots \ldots$

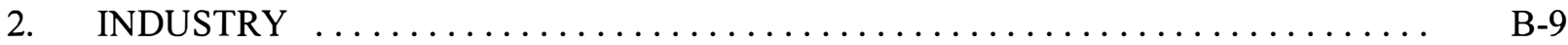

$2.1 \quad$ ENERGY CONVERSION AND UTILIZATION $\ldots \ldots \ldots \ldots \ldots \ldots \ldots \ldots \ldots . . \ldots \ldots$

2.2 RESOURCE RECOVERY AND UTILIZATION $\ldots \ldots \ldots \ldots \ldots \ldots \ldots \ldots \ldots . . \ldots \ldots$

2.3 INDUSTRIAL PROCESS EFFICIENCY $\ldots \ldots \ldots \ldots \ldots \ldots \ldots \ldots \ldots \ldots \ldots \ldots \ldots \ldots \ldots$

2.4 ENABLING TECHNOLOGIES $\ldots \ldots \ldots \ldots \ldots \ldots \ldots \ldots \ldots \ldots \ldots \ldots \ldots \ldots \ldots \ldots \ldots$

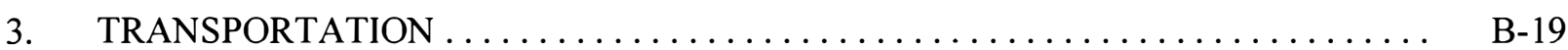

3.1 ADVANCED CONVENTIONAL VEHICLE $\ldots \ldots \ldots \ldots \ldots \ldots \ldots \ldots \ldots \ldots \ldots \ldots \ldots$

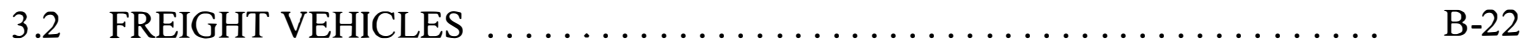

3.3 HYBRID, ELECTRIC, AND FUEL CELL VEHICLES $\ldots \ldots \ldots \ldots \ldots \ldots \ldots . \quad$ B-24

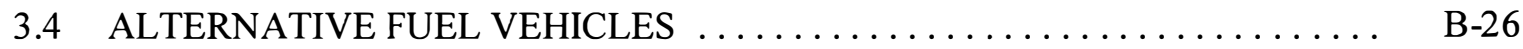

3.5 AIR AND HIGH-SPEED GROUND TRANSPORT $\ldots \ldots \ldots \ldots \ldots \ldots \ldots \ldots$ B-28

4. AGRICULTURAL AND FORESTRY $\ldots \ldots \ldots \ldots \ldots \ldots \ldots \ldots \ldots \ldots \ldots \ldots \ldots$

4.1 CONVERSION OF BIOMASS TO BIOPRODUCTS $\ldots \ldots \ldots \ldots \ldots \ldots \ldots \ldots$ B-32

4.2 ADVANCED AGRICULTURE SYSTEMS $\ldots \ldots \ldots \ldots \ldots \ldots \ldots \ldots \ldots \ldots \ldots \ldots \ldots$ B-34

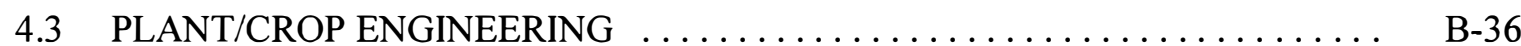

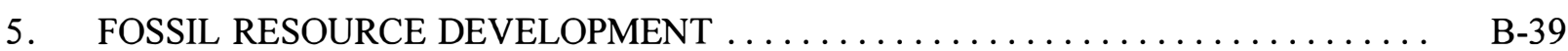

$5.1 \quad$ ENERGY EFFICIENCY FOR CRUDE OIL REFINING $\ldots \ldots \ldots \ldots \ldots \ldots \ldots$ B-40

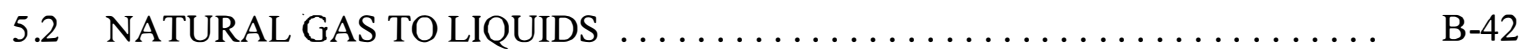

5.3 INCREASED NATURAL GAS PRODUCTION $\ldots \ldots \ldots \ldots \ldots \ldots \ldots \ldots \ldots . \quad$ B-44

5.4 CO-PRODUCTION WITH INTEGRATED GASIFICATION
COMBINED CYCLE $\ldots \ldots \ldots \ldots \ldots \ldots \ldots \ldots \ldots \ldots \ldots \ldots \ldots \ldots \ldots \ldots \ldots \ldots \ldots$
B-46

5.5 CARBON DIOXIDE FOR IMPROVED OIL AND GAS RECOVERY $\ldots \ldots \ldots$. . .

6. FOSSIL POWER GENERATION $\ldots \ldots \ldots \ldots \ldots \ldots \ldots \ldots \ldots \ldots \ldots \ldots \ldots \ldots \ldots \ldots \ldots$

6.1 ACCELERATED DEVELOPMENT OF HIGH-EFFICIENCY

6.2 LOW-CARBON FUELS AND HIGH-EFFICIENCY POWER

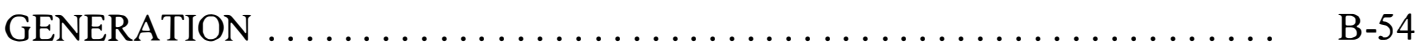

6.3 ULTRA-HIGH EFFICIENCY, ZERO-CARBON EMISSION

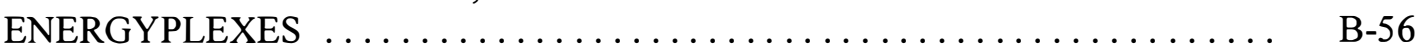

7. NUCLEAR ..................................... B-59

7.1 LIFETIME EXTENSION AND GENERATION OPTIMIZATION . . . . . . . B-60

7.2 NEXT-GENERATION FISSION REACTORS $\ldots \ldots \ldots \ldots \ldots \ldots \ldots \ldots \ldots \ldots \ldots$ B-62

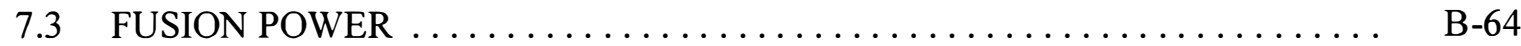

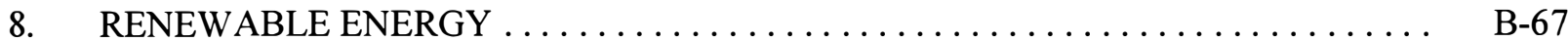

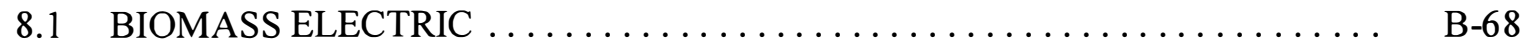

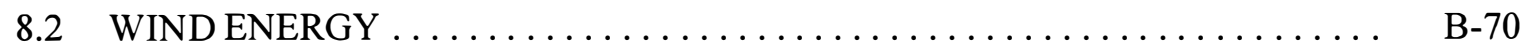




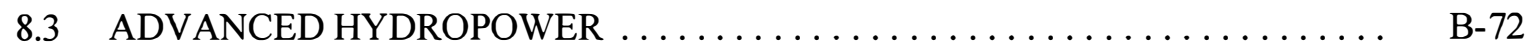

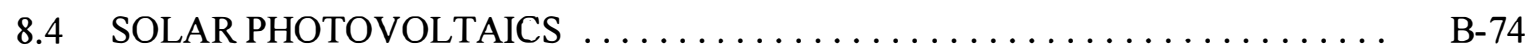

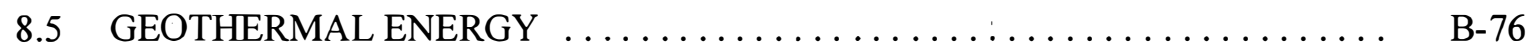

8.6 SOLAR THERMAL ELECTRIC AND BUILDINGS $\ldots \ldots \ldots \ldots \ldots \ldots \ldots \ldots \ldots$ B-78

8.7 BIOMASS TRANSPORTATION FUELS $\ldots \ldots \ldots \ldots \ldots \ldots \ldots \ldots \ldots \ldots \ldots \ldots \ldots \ldots \ldots \ldots$

8.8 SOLAR ADVANCED PHOTOCONVERSION $\ldots \ldots \ldots \ldots \ldots \ldots \ldots \ldots \ldots$, B-82

9. CARBON SEQUESTRATION AND MANAGEMENT $\ldots \ldots \ldots \ldots \ldots \ldots \ldots \ldots \ldots$ B-85

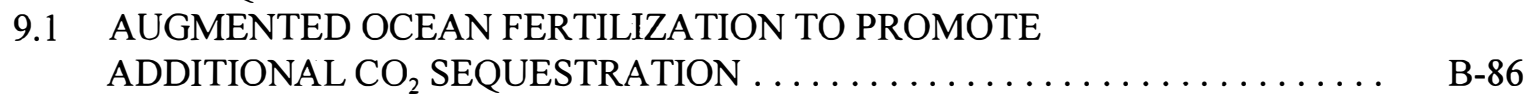

9.2 ADVANCED CHEMICAL AND BIOLOGICAL CONVERSION

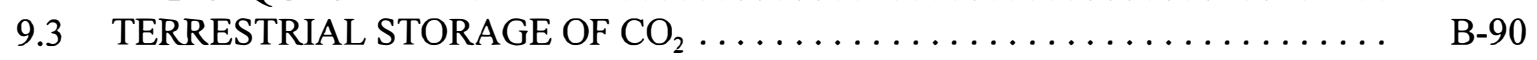

9.4 CARBON SEQUESTRATION IN SOILS $\ldots \ldots \ldots \ldots \ldots \ldots \ldots \ldots \ldots \ldots \ldots \ldots \ldots \ldots \ldots$

9.5 ELEMENTAL CARBON SEQUESTRATION $\ldots \ldots \ldots \ldots \ldots \ldots \ldots \ldots \ldots \ldots \ldots \ldots \ldots \ldots$, B-94

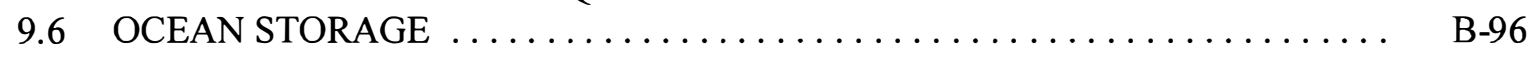

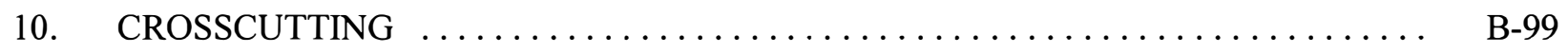

10.1 FUEL CELL SYSTEMS FOR STATIONARY AND

TRANSPORTATION APPLICATIONS $\ldots \ldots \ldots \ldots \ldots \ldots \ldots \ldots \ldots \ldots$, B-100

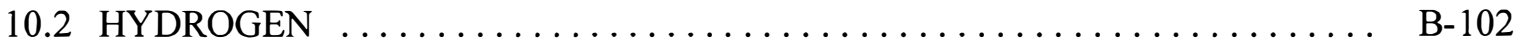

10.3 SENSORS AND CONTROLS $\ldots \ldots \ldots \ldots \ldots \ldots \ldots \ldots \ldots \ldots \ldots \ldots \ldots \ldots \ldots \ldots \ldots$, B-104

10.4 TRANSMISSION AND DISTRIBUTION TECHNOLOGIES $\ldots \ldots \ldots \ldots \ldots$ B-106

10.5 POWER ELECTRONICS AND ELECTRIC MACHINERY $\ldots \ldots \ldots \ldots \ldots \ldots$ B-108

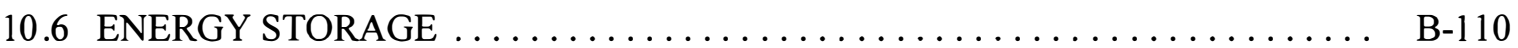

10.7 MODELING, SIMULATION, AND ANALYSIS $\ldots \ldots \ldots \ldots \ldots \ldots \ldots \ldots$ B-112

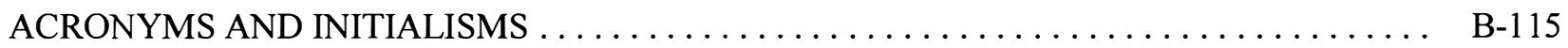




\title{
Energy-Efficient Technologies
}

\author{
1. Buildings
}

1.1 Equipment and Appliances

1.2 Building Envelope

1.3 Intelligent Building Systems 


\subsection{EQUIPMENT AND APPLIANCES}

Technology Description

All energy use in buildings depends on equipment to transform fuel or electricity into end-use services such as delivered heat or cooling, light, fresh air, vertical transport, cleaning of clothes or dishes, and information processing. There are energy-saving opportunities within individual pieces of equipment - as well as at the system level—-through proper sizing, reduced distribution and standby losses, heat recovery and storage, and optimal control. Another promising opportunity lies in multifunction devices ranging from heat pumps that provide both refrigeration and hot water, to an office appliance that serves as a networked printer, copier, scanner, and paperless fax machine.

System Concepts

- Major categories of end-use equipment include heating, cooling, and hot water; ventilation and thermal distribution; lighting; home appliances; miscellaneous (process equipment and consumer products); and on-site energy and power.

- Key components vary by type of equipment, but some cross-cutting opportunities for efficiency are improved materials and applications, efficient low-emissions combustion and heat transfer, advanced refrigerants and cycles, electrodeless and solid-state lighting, smart sensors and controls, improved small-power supplies, variable-capacity systems, reduction of thermal standby losses and leaking electricity, and modular fuel cell-based micro-cogeneration.

Representative Technologies

- Residential gas-fired absorption heat pumps, desiccant pre-conditioners for treating ventilation air, proton exchange membrane (PEM) fuel cells, horizontal axis clothes washers, and low-power sulfur lamps.

Technology Status/Applications

- Technology improvements over the past 20 years - through quality engineering, new materials, and better controls-have improved efficiencies in many types of equipment by 15 to $20 \%$. Electronic equipment is an outlier with order-of-magnitude efficiency gains, at the microchip level, every 2 to 3 years.

- Continued technical innovation, spurred by government/industry co-investment in R\&D and effective, sustained market-pull policies, could at least match and potentially double these prior efficiency gains over the next 20 years.

Current Research, Development, and Demonstration

RD\&D Goals

- By 2002, commercial introduction of full-size refrigerator-freezers that use as little power as a $40-\mathrm{W}$ light bulb.

- By 2010 , heat pumps for residential and small commercial applications with $40 \%$ improvement over conventional gas furnaces.

- By 2010 , reduced standby losses, improved heat pump water heating, and application of heat recovery techniques reduce energy use for domestic water heating by $60 \%$ over conventional devices.

- By 2010, commercial introduction of hybrid lighting systems (high-efficiency centralized light sources and controlled application of daylighting).

- By 2010, fuel cells, photovoltaics, and microturbines offer cost-competitive alternatives to grid electricity. By 2020, distribution systems deliver $50 \%$ more conditioned air.

- By 2020, commercial introduction of alternative refrigeration equipment with low greenhouse warming potential (e.g., Stirling cycle, Brayton cycle, acoustic, magnetic. thermal electric).

- By 2020, prototype development of advanced cleaning technologies (e.g., electrolytic, ultrasonic, ozonated).

- By 2030, adaptation of HVAC equipment to a new generation of power sources.

R\&D Challenges

- The basic RD\&D needed ranges from materials science to solid-state electronics, and from a better understanding of combustion fundamentals to advances in control theory. Research is also needed on behavioral and ergonomic dimensions of the user-machine relationship.

- Building equipment and appliance efficiency will benefit from improvements in a wide range of thermal, mechanical, and electronic technologies (see System Concepts), as well as better systems integration, more cost-effective and reliable fabrication methods, and sustainable design concepts (e.g., use of recyclable and environmentally preferred materials, modular design, ecologically sound manufacturing).

RD\&D Activities

- $\quad$ Most federal R\&D on building equipment is performed by DOE.

- No systematic data have been compiled on international funding levels, although activities such as the IEA Heat Pump Centre represent a potential source of such data for selected equipment types.

\section{Recent Success}

- Recent DOE-sponsored R\&D, often with industry participation, has produced a prototype refrigerator that uses less than half the energy of the current best designs; an improved air-conditioning cycle to reduce oversizing and improve efficiency; high-performance insulating materials for demanding thermal applications; and a replacement for inefficient, high-temperature halogen up-lights (torchieres) which uses only $25 \%$ of the power, lasts longer, and eliminates a potential fire hazard. 
Building equipment and appliances often vary in efficiency by 20 to $40 \%$ from the least efficient model on the market to the most efficient; this efficiency range is narrower where successful appliance standards have previously eliminated the least efficient models.

- The stock and energy intensity of equipment are growing faster than the building stock itself, as manufacturers introduce and consumers and businesses eagerly accept new types of equipment, more sophisticated and automated technologies, and increased levels of end-use services.

- The rapid turnover and growth of many types of building equipment---especially electronics for computing, control, communications, and entertainment-represent major growth in electricity demand and thus carbon emissions, but also an important opportunity to rapidly introduce new, efficient technologies and quickly propagate them throughout the stock.

- Provided that they are implemented without a significant reduction in amenities, the market success of most new equipment and appliance technologies is virtually ensured if the efficiency improvement has a 3-year payback; technologies with payback of 4 to $8+$ years can also succeed in the market provided that they offer other customer-valued features (e.g., reliability, longer life, improved comfort or convenience, quiet operation, smaller size, lower pollution levels).

- Applications extend to every segment of the residential and nonresidential sectors. Major government, institutional, and corporate buyers represent a special target group for voluntary early deployment of the best new technologies.

\section{Potential Benefits and Costs}

\section{Carbon Reductions}

In MtC/year for buildings overall and for this pathway

$\begin{array}{llll} & 2010 & 2020 & 2030 \\ \text { Buildings } & 25-50 & 50-100 & 75-150 \\ \text { Equipment and appliances } & 15-35 & 20-40 & 25-45\end{array}$

\section{RD\&D Expenditures}

- Federal RD\&D expenditures are required because the buildings industry does little R\&D. DOE funding has been about $\$ 20 \mathrm{M} /$ year in recent years out of a total Buildings R\&D budget of about $\$ 50 \mathrm{M} /$ year. A vigorous pursuit of this pathway would take an annual DOE RD\&D budget of 2000-2010, $\$ 60 \mathrm{M} /$ year; 2010-2020, \$90M/year; 2020-2030, \$60M/year.

\section{Market}

- Building equipment and appliances represent an annual market in the United States alone of well over \$200B, involving thousands of large and small companies. Certain technologies, such as office and home electronics, compete in global markets with little or no change in performance specifications.

Non-energy Benefits and Costs

- Major benefits, other than energy savings and reduced GHG emissions, include better control of indoor comf ort conditions; improved health and productivity; potential for replacing CFC-based refrigeration equipment with efficient, non-ozone-depleting models; reduced air pollutant emissions.

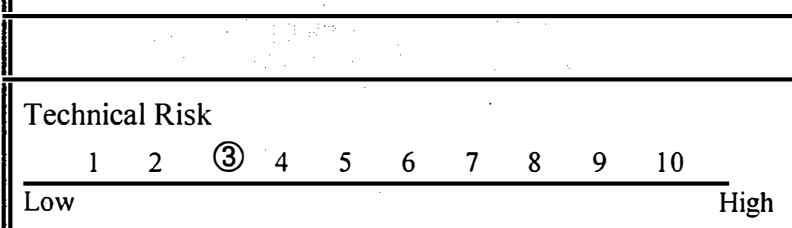

\section{Risk Factors}

- Track record of federally funded R\&D leading to commercial products.

- Small-scale units allow easier field testing, performance verification, and refinement before large-scale deployment.

Commercial Risk

\begin{tabular}{|c|c|c|c|c|c|c|c|c|c|c|}
\hline 1 & & & (3) & 4 & 5 & 6 & 7 & 8 & 9 & 10 \\
\hline
\end{tabular}

- Existing infrastructure for design, manufacturing, installation, and so on.

- Labeling, government procurement, and voluntary programs can reduce market risk to innovative suppliers.

- Minor dependence on foreign sources is easily overcome.

Ecological Risk

\begin{tabular}{llllllllll}
1 & (2) & 3 & 4 & 5 & 6 & 7 & 8 & 9 & 10 \\
\hline Low & & & & & & & & & \\
High
\end{tabular}

Human Health Risk

\begin{tabular}{llllllllll}
1 & (2) & 3 & 4 & 5 & 6 & 7 & 8 & 9 & 10 \\
\hline Low & & & & & & & & &
\end{tabular}

- Improved indoor air quality with better ventilation and controls can reduce health risk and improve productivity.

Economic Risk

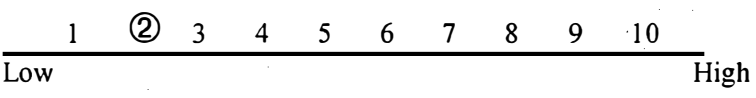

- Cost-effective products will encounter less market resistance, provided functional and quality/reliability requirements are met.

- Public perception is favorable to introducing advanced equipment.

Regulatory Risk

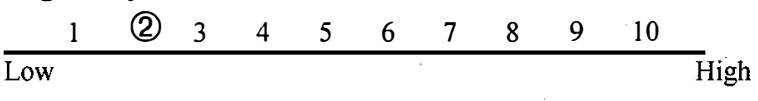

- Regulations on production, marketing, and installation of building products can impede new technologies.

- Modest ecological risk from electronics and other equipment and materials manufacturing.

- Positive impact on air and water pollution.

\section{Key Federal Actions}

- Deployment programs to leverage the RD\&D investment.

- Equipment and appliance standards developed with industry.

- Federal procurement to create demand. 


\subsection{BUILDING ENVELOPE}

Technology Description

The building envelope is the interface between the interior of a building and the outdoor environment. In most buildings, the envelope-along with the outdoor weather-is the primary determinant of the amount of energy used to heat, cool, and ventilate. A more energy-efficient envelope means lower energy usage in a building and lower GHG emissions. Advances in materials research and fenestration systems, better building practices, and increased use of renewable technologies promise to significantly lower the energy required to maintain high-quality building interior climate conditions.

\section{System Concepts}

- Control of envelope characteristics provides control over the flow of heat, air, moisture, and light into the building. These flows and the interior energy and environmental loads determine the size and energy usage of HVAC and distribution systems.

- Materials for exterior walls, roofs, foundations, windows, doors, interior partition walls, ceilings, and floors that can impact future energy use include insulation, with innovative formula foams and vacuum panels; optical control coatings for windows and roofs; and thermal storage materials, including lightweight heat storage systems.

\section{Representative Technologies}

- Superinsulation: Vacuum powder-filled, gas-filled, and vacuum fiber-filled panels; structurally reinforced beaded vacuum panels; and switchable evacuated panels with insulating values over four times those of the best currently available materials will soon be available for niche markets. High-thermal-resistance foam insulations with acceptable ozone depletion and global warming characteristics will allow for continued use of this highly desirable thermal insulation.

- Advanced window systems: Krypton-filled triple-glazed low-E windows and electrochromic glazing and hybrid electrochromic/PV films and coatings will provide improved lighting and thermal control of fenestration systems. Advanced techniques for integration, control, and distribution of daylight will significantly reduce the need for electric lighting in buildings. Self-drying wall and roof designs will allow for improved insulation levels and increase the lifetimes for these components. More durable high-reflectance coatings will allow better control of solar heat on building surfaces.

- Advanced thermal storage materials: Dry phase-change materials and encapsulated materials will allow significant load distribution over the full diurnal cycle and significant load reduction when used with passive solar systems.

\section{Technology Status/Applications}

- Building insulations have progressed from the $2-4^{\circ} \mathrm{F} \cdot \mathrm{h} \cdot \mathrm{ft}^{2} / \mathrm{Btu} / \mathrm{in}$. fibrous materials available before 1970 to foams reaching $7^{\circ} \mathrm{F} \cdot \mathrm{h} \cdot \mathrm{ft}^{2} / \mathrm{Btu} / \mathrm{in}$ Superinsulations of over $25^{\circ} \mathrm{F} \cdot \mathrm{h} \cdot \mathrm{ft}^{2} / \mathrm{Btu} / \mathrm{in}$. will be available for niche markets soon. It is critical to find acceptable replacements for HCFCs in foams in order not to backslide in the use of this insulation in buildings. Improvements in window performance have been even more spectacular. In the $1970 \mathrm{~s}$, window thermal resistance was 1 to $2^{\circ} \mathrm{F} \cdot \mathrm{h} \cdot \mathrm{ft}^{2} / \mathrm{Btu}$. Now, new windows have thermal resistance of up to $6^{\circ} \mathrm{F} \cdot \mathrm{h} \cdot \mathrm{ft}^{2} / \mathrm{Btu}$ (whole window performance). Windows are now widely a vailable with selective coatings that reduce infrared transmittance without reducing visible transmittance. In addition, variable-transmittance windows under development will allow optimal control to minimize heating, cooling, and lighting loads.

\section{Current Research, Development, and Demonstration}

\section{RD\&D Goals}

- $\quad 30 / 30$ (R/30 insulation and 30-year life) low-slope roof options.

- Windows with $70 \%$ of adjacent wall thermal resistance and variable, controllable light transmittance.

- Mass-produced (factory-built) customized buildings with integrated envelope and equipment systems designed and sized for specific sites and climates.

- Vacuum insulations dominating several niche markets (mobile homes and freezer walls).

- On-site renewables replacing $15 \%$ of purchased energy [see photovoltaics pathway].

- $\quad 50 \%$ of building materials containing $50 \%$ recyclable materials.

- A $30 \%$ decrease in the average envelope thermal load of existing residential buildings and a $66 \%$ decrease in the average thermal load of new buildings.

RD\&D Challenges

- Foam insulations that retain high thermal resistance while using blowing agents with zero ozone depletion potential and negligible global warming effect.

- Self-drying wall and roof designs to avoid moisture problems such as materials degradation.

- Electrochromic window films and electrochromic/PV hybrid window films to control energy flows and generate electricity on site.

- Techniques to distribute and control daylight to reduce electrical energy use for artificial lighting.

- Advanced durable cost-effective superinsulations to reduce heating/cooling loads.

- Advanced building simulation tools to permit better design, construction, commissioning, and operation.

- Self-calibrating multi-function micro-sensors for in situ performance and air quality monitoring.

- Thermal storage materials: typically, thermal storage in building components is achieved with heavyweight materials such as masonry. Advanced thermal storage materials need to be lightweight to integrate with elements similar to drywall, floor, and ceiling panels.

\section{RD\&D Activities}

- Key agencies doing R\&D on building envelopes are DOE, NIST, and several state agencies such as the Florida Solar Energy Center and the Iowa Ames Laboratory.

- DOE funding has been about $\$ 8 \mathrm{M} /$ year in recent years. Funding from other agencies has been significantly less. No attempt has been made to estimate funding for private sector $\mathrm{R} \& \mathrm{D}$, although it is thought to be considerably more than that of agencies and is typically directed toward specific products and problems. Total international support is also significant. Most developed countries have one to several laboratories doing research, often more fundamental than that in U.S. labs. International participants typically are $20 \%$ or more of those attending U.S. conferences on envelope research. 
- A DOE-sponsored RD\&D partnership with the Polyisocyanurate Insulation Manufacturers Association, the National Roofing Contractors Association, the Society of the Plastics Industry, and EPA helped the industry find a replacement for CFCs in polyisocyanurate foam insulation. This effort enabled the buildings industry to transition from CFC-11 to HCFC-141b by the deadline required by the Montreal protocol.

\section{Commercialization and Deployment}

- The market potential is significant for building owners taking some actions to improve building envelopes. Currently, $40 \%$ of residences are well insulated, $40 \%$ are adequately insulated, and $20 \%$ are poorly insulated. Over $40 \%$ of new window sales are of advanced types (low-E and gas-filled). In commercial buildings, over $17 \%$ of all windows are advanced types. Over $70 \%$ of commercial buildings have roof insulation; somewhat fewer have insulated walls.

- Building products are mostly commodity products. A number of companies produce them; and each has a diverse distribution system, including direct sales, contractors, retailers, and discount stores.

- A critical challenge is improving the efficiency of retrofits of existing buildings. Retrofitting is seldom cost-effective on a stand-alone basis. New materials and techniques are required.

- Many advanced envelope products are cost-competitive now, and new technologies will become so on an ongoing basis. There will be modest cost reductions over time as manufacturers compete.

\section{Potential Benefits and Costs}

\section{Carbon Reductions}

In $\mathrm{MtC} /$ year for buildings overall and this pathway

$\begin{array}{llll} & 2010 & 2020 & 2030 \\ \text { Buildings } & 25-50 & 50-100 & 75-150 \\ \text { Envelopes } & 5-10 & 15-30 & 30-60\end{array}$

\section{RD\&D Expenditures}

- Federal RD\&D expenditures are required because the buildings industry does little R\&D. DOE funding has been about $\$ 8 \mathrm{M} /$ year in recent years out of a total Buildings $R \& D$ budget of about $\$ 50 \mathrm{M} /$ year. A vigorous pursuit of this pathway would take about an annual DOE RD\&D budget of 2000-2010, \$30M/year; 2010-2020, \$45M/year; 2020-2030, \$30M/year.

\section{Market}

- Building structures represent an annual market in the United States of over \$70B/year and involve thousands of large and small product manufacturers and a large, diverse distribution system that plays a crucial role in product marketing. Exporting is not an important factor in the sales of most building structure products.

\section{Nonenergy Benefits and Costs}

- Major benefits, other than energy savings and reduced GHG emission, include more affordable housing; improved comfort, health, and productivity; a significant increase in recycled materials; reduced ozone depletion potential with non-CFC/HCFC foam insulations; reduced air pollutant emissions.

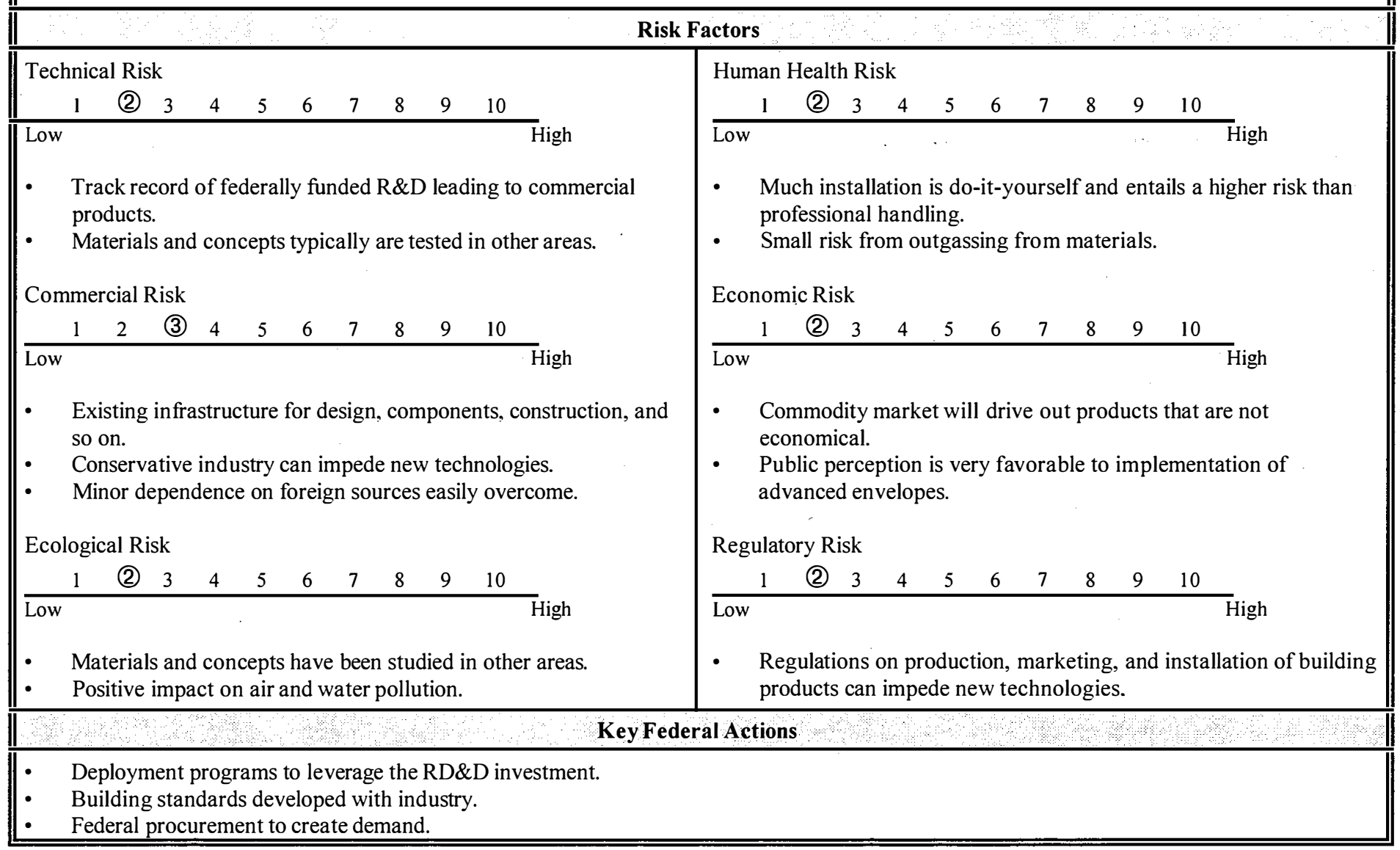




\subsection{INTELLIGENT BUILDING SYSTEMS}

\section{Technology Description}

Intelligent building systems (IBSs) would use data from design, together with sensed data, to automatically configure controls and commission (i.e., start up and check out) and operate buildings. Control systems would use advanced, robust techniques and would be based on smaller, cheaper, and more abundant sensors. These data would ensure optimal building performance by controlling building systems and continuously recommissioning them using automated tools that detect and diagnose performance anomalies and degradation. IBSs would optimize operation across building systems, inform and implement energy purchasing, guide maintenance activities, and report building performance, while ensuring that occupant needs for comfort, health, and safety were met at the lowest possible cost.

\section{System Concepts}

- The system would consists of design tools, automated diagnostics, interoperable control systems, and sensors.

- These components would work together to collect data, configure controls, monitor operations, and correct out-of-range conditions that contribute to poor building performance.

- IBSs would ensure that essential information, especially the design intent and construction implementation data, would be preserved and shared across many applications throughout the lifetime of the building.

- Equipment and system performance records would be stored as part of a networked building performance knowledge base that would grow over time and provide feedback to designers, equipment manufacturers, and building operators and owners.

\section{Representative Technologies}

- DOE is developing computer-based building commissioning and operation tools to improve the energy efficiency of existing buildings. It is also investing in the next generation of building simulation programs that could be integrated into design tools.

\section{Technology Status/Applications}

- Savings from improved operation and maintenance procedures could save more than $30 \%$ of the annual energy costs of existing commercial buildings, even in many of those buildings thought to be working properly by their owners/operators. These technologies would have very short paybacks because they would ensure that technologies were performing as promised, for a fraction of the cost of the installed technology.

\section{Current Research, Development, and Demonstration}

\section{RD\&D Goals}

- Design environments with fully and seamlessly integrated building design tools that support all aspects of design and provide rapid analysis; design suggestions; quick and easily understood data interpretation; automatic generation of all design documents; and a building electronic data structure that supports start-up, operation, maintenance, and renovation of the building by IBS.

- Automatic operation of buildings by automatically sensing installed equipment, checking for proper installation, generating control algorithms, implementing optimal adaptive control, diagnosing and correcting operating episodes that produce inefficient or uncomf ortable conditions, managing maintenance, and providing performance data in usable forms for operators of new and existing buildings, facility managers, and owners.

\section{RD\&D Challenges}

- Design tools: enhanced analytical capabilities, integration with the design environment, automated design and analysis capability, design databases, visualization, and high-level monitoring and reporting tools.

- Automated diagnostics: diagnosticians, plug and play capabilities, automated real-time purchasing, and advanced data visualization.

- System interoperability and controls: integrated control networks; adaptive, optimized, self-generating control algorithms; and advanced control techniques.

- Sensors: materials properties, microscale sensors, microelectronic sensors, multiple-sensor arrays, protocols for using new sensors, and new sensing technologies.

- Visualization: use of supercomputers, advanced computational methods, and virtual reality systems to permit real-time visualization of designs and design changes, including lighting, thermal flows, and air quality.

- Early priorities include enhancing design tool integration, developing automated diagnosticians, implementing remote data collection and visualization, and developing sensors.

\section{RD\&D Activities}

- DOE is funding work along with the California Institute for Energy Efficiency, Honeywell, Johnson Controls, Landis and Staefa, EPRI, and Pacific Gas and Electric Company. International efforts include a European Union-funded effort to develop adaptive control techniques for improving the thermal environment for JOULE III-SEC.

\section{Recent Success}

- $\quad$ Energy 10: models passive solar systems in buildings.

- DOE 2: international standard for whole building energy performance simulation has thousands of users worldwide.

- The International Alliance for Interoperability is setting international standards for interoperability of computer tools and components for buildings. 
- Design tools for energy efficiency are used by less than $2 \%$ of the professionals involved in the design, construction, and operation of commercial buildings in the United States. A larger fraction of commercial buildings have central building control systems. Few diagnostic tools are available beyond those used for air balancing or integrated into equipment (Trane Intellipack System). About 12 software vendors develop, support, and maintain energy design tools; most are small businesses. Another 15 to 20 building automation and control vendors exist in the marketplace; the major players include Johnson Controls, Honeywell, and Landis and Staefa.

- Deployment involves two major aspects: seamless integration into existing building design and operation platforms, and a focus on benefits that are desirable in the marketplace (not only energy efficiency).

Potential Benefits and Costs

\section{Carbon Reductions}

In $\mathrm{MtC} /$ year for buildings overall and this pathway

$\begin{array}{llll} & 2010 & 2020 & 2030 \\ \text { Buildings } & 25-50 & 50-100 & 75-150 \\ \text { Intelligent building systems } & \sim 5 & 10-20 & 20-45\end{array}$

\section{RD\&D Expenditures}

- Federal RD\&D expenditures are required because the buildings industry does little R\&D. DOE funding for building systems R\&D has been about $\$ 20 \mathrm{M} /$ year in recent years out of a total buildings R\&D budget of about $\$ 50 \mathrm{M} /$ year. A vigorous pursuit of this pathway would take an annual DOE RD\&D budget of 2000-2010, \$60M/year; 2010-2020, \$90M/year; 2020-2030, $\$ 60 \mathrm{M} /$ year. In addition to funding RD\&D on IBSs, this budget would support RD\&D on human factors and community systems.

\section{Market}

- These technologies would apply to all buildings. but especially to existing commercial buildings and new buildings. In addition, new technologies would be integrated into the building design process using this technology.

\section{Nonenergy Benefits and Costs}

- Human health, safety, and comfort would be greatly enhanced using these technologies. In addition, major growth markets in India, Southeast Asia, and Latin American could use these technologies to develop their next-generation buildings.

\begin{tabular}{|c|c|c|c|c|c|c|c|c|c|}
\hline \multicolumn{10}{|c|}{ Technical Risk } \\
\hline 1 & (2) & 3 & 4 & 5 & 6 & 7 & 8 & 9 & 10 \\
\hline
\end{tabular}

\section{Risk Factors}

- $\quad$ Track record of federally funded R\&D leading to products used by the design community.

- Much of the needed technology exists in other sectors.

Commercial Risk

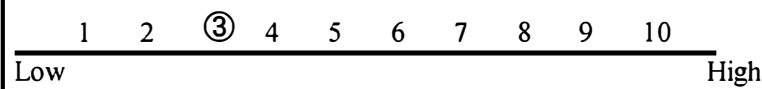

- Amenable to design community, but requires integration into existing construction practices.

- Increase in design fees, but could be offset by lower construction costs.

Ecological Risk

\begin{tabular}{|c|c|c|c|c|c|c|c|c|c|}
\hline (1) & 2 & 3 & 4 & 5 & 6 & 7 & 8 & 9 & 10 \\
\hline
\end{tabular}
High

Human Health Risk

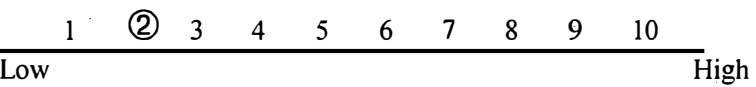

- Improved indoor air quality with better sensors and controls can reduce health risk and improve productivity.

Economic Risk

$\begin{array}{lllllllllll}1 & \text { (2) } & 3 & 4 & 5 & 6 & 7 & 8 & 9 & 10 & \text { High }\end{array}$

- Would be cost-effective in reducing labor and energy costs.

- Public perception is favorable to introducing intelligent systems.

Regulatory Risk

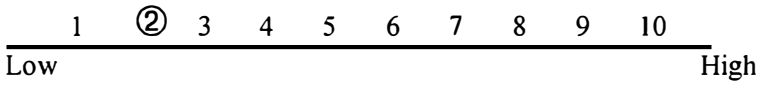

- Would not require changes to existing buildings regulations.

- Positive impact on air and water pollution.

\section{Key Federal Actions}

- The focus of the building design, control, and operation industry is service, not research. In its quest to serve its customers, it does not perform R\&D. The federal government could provide this industry with the R\&D necessary to demonstrate the viability of this systemi and work with the industry to transfer the technology to its markets.

- The government could also work with voluntary standards organizations to require energy analysis, building commissioning, and proof of operation in conjunction with building energy codes. Federal buildings could also be showcase facilities for the demonstration of these new technologies. 



\title{
Energy-Efficient Technologies
}

\author{
2. Industry \\ 2.1 Energy Conversion and Utilization \\ 2.2 Resource Recovery and Utilization \\ 2.3 Industrial Process Efficiency \\ 2.4 Enabling Technologies
}




\subsection{ENERGY CONVERSION AND UTILIZATION}

Technology Description

A significant portion of the carbon emissions from the industrial sector are associated with the conversion and utilization of energy. A systems approach to energy conversion and utilization incorporating the best technologies could have a significant impact on GHG emissions and improve the competitive posture of the industrial sector. Many opportunities exist for improving the efficiency of energy generation, including ATS, fuel cells, gasification technologies, and advanced combustion technologies. As many opportunities exist in energy utilization, including economical use of waste heat and thermal cascading by using a systems approach to mill/plant design to minimize generation of low level heat.

System Concepts

- The industrial sector could significantly reduce GHG emissions by a combination of improvements in energy utilization efficiency, switching to low-GHG fuels, gasification of waste materials into useful fuels, advanced on-site high-efficiency, and low-GHG-emissions generation technologies such as advanced combustion turbines and fuel cells.

- Modern design techniques and a whole systems approach to mill/plant design could minimize the generation of excessive low-level heat that cannot be removed easily and economically.

\section{Representative Technologies}

A range of technologies and process improvements under development are promising:

- ATS

- Fuel cells

- Gasification of biomass and in-plant process streams (i.e., black liquor in the pulp and paper industry)

- Waste heat utilization

- Systems approach to mill/plant design

- Co-firing of biomass

- Advanced combustion technologies

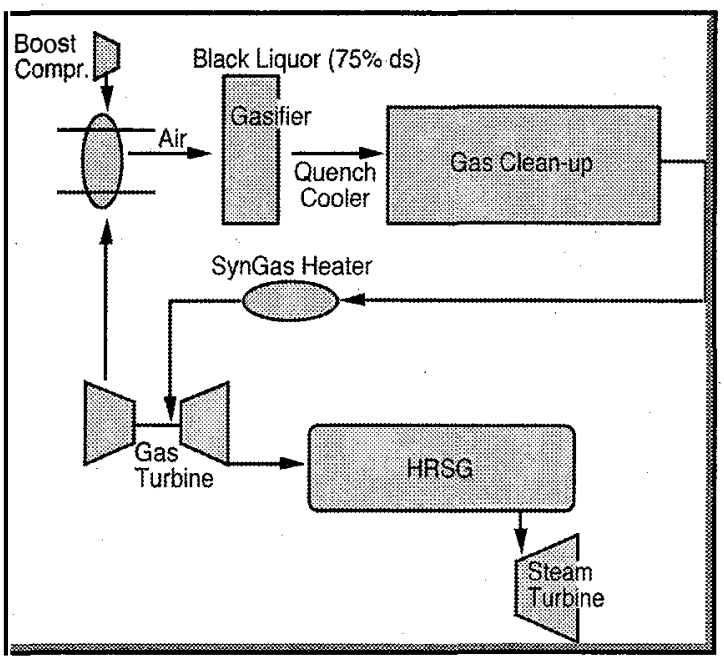

\section{Technology Status/Applications}

- Energy generation technologies currently used by industry typically have thermal efficiencies ranging from 25 to $55 \%$; the next generation of energy generation technologies promises thermal efficiencies ranging from 45 to $80 \%$. This average $20 \%$ improvement would significantly reduce the amount of fuel required, and hence GHG emissions, to generate the energy required. Additionally, aggressive development and deployment of distributed on-site generation technologies could avoid transmission and distribution losses, which average approximately $\mathbf{7 \%}$.

- Energy utilization gains of as high as $30 \%$ could result from advanced energy utilization technologies and more integrated mill/plant designs.

- Use of in-plant wastes and residues from production processes to generate energy is a promising area for reducing energy intensity and GHG emissions. RD\&D is needed to increase the use of this technology and make it more cost-effective.

\section{Current Research, Development, and Demonstration}

\section{RD\&D Goals}

- Significant gains in energy generation efficiency and GHG reductions could result from aggressively switching to highly efficient on-site generation technologies, such as advanced combustion turbines in combined cycle and fuel cells. Switching to low-carbon fuels such as natural gas or zero-carbon fuels such as biomass could bring additional GHG reductions.

- The chemical, petroleum refining, forest products, and steel industries account for over $2 / 3$ of the energy use of the industrial sector. Therefore, efforts will continue to focus on these four industries.

\section{RD\&D Challenges}

- Basic and applied research into advanced, low- or zero-GHG-emission generation technologies.

- In the near term, advanced industrial turbines with combined cycle generation, higher combustion efficiencies, waste heat utilization, a systems approach to mill/plant design, and biomass and black liquor gasification.

- Also in the near term, improvements in manufacturing such as advanced drying, more efficient lighting, and high-efficiency motor systems and drives for higher energy utilization efficiency.

- In the long term, continued work on advanced industrial turbines and noncombustion techniques such as fuel cells for high-efficiency energy generation.

\section{RD\&D Activities}

- RD\&D activities related to this pathway are sponsored by DOE, EPA, NIST-ATP, and other federal agencies. This pathway will work closely with and leverage past investments in these program areas.

\section{Recent Success}

- A major carbon-reducing technology for industry between now and 2010 is a high-efficiency, environmentally superior, natural gas-fired turbine that cogenerates electricity and steam. The ATS program is developing these turbines for industry and electrical generation. When introduced in 2001, they will have $\mathrm{CO}_{2}$ emissions 21 to $61 \%$ lower and thermal efficiencies $15 \%$ higher than conventional turbines and will reduce electrical generation costs by $10 \%$. 
- Integrated gasification of biomass and black liquor combined cycle technologies will impact the pulp and paper industry in two ways: by improving energy self-generation and use of waste biomass produced at mill sites and by improving forest management practices. The waste biomass and the black liquor are gasified and fired in an advanced gas turbine for high-efficiency electrical and steam generation. Black liquor gasification was demonstrated at the pilot scale in a pulp mill in 1995, and a near-commercial-scale biomass gasifier is under construction and expected to be operational in 1997.

\section{Commercialization and Deployment}

- Industry is already making substantial investments in commercializing and deploying economical technologies: combusting wastes and residues, fuel switching in combustion systems, better understanding of large energy consuming processes, and energy cascading from high temperature to lower temperature uses within plants. Availability of capital and the competition for R\&D funds will impact deployment of new technology. Cost competitiveness with existing technologies will be achieved when the newer technologies have completed their R\&D cycles.

\section{Potential Benefits and Costs}

\section{Carbon Reductions}

Industrial sector

$\begin{array}{lllll} & 1997 \text { (base) } & 2010 & 2020 & 2030 \\ \text { BAU case quads } & 34.4 & 39.7 & 43.8 & 48.5 \\ \text { Eff. case(mod) quads } & & 36.6 & 38.3 & 40.5 \\ \begin{array}{l}\text { MtC reductions } \\ \text { (35\% allocation to this pathway) }\end{array} & & & & \\ \text { MtC reductions } & & 9-18 & 23-33 & 35-50\end{array}$

The estimated $\mathrm{MtC}$ reductions for the sector have wide ranges to account for uncertainties in market adoption and economics.

$\mathrm{MtC}$ reductions

Assumptions (for all industrial sector):

- Growth rate in manufacturing output of $2.1 \%$ /year.

- For BAU case, energy intensity decreases by $1.1 \%$ year $(0.5 \% /$ year increases in efficiency and $.6 \%$ composition).

- For the efficiency case, there is an additional $0.35 \% / y e a r$ increase in energy intensity.

- Additional 10-12, 22-25, and 30 $40 \mathrm{MtCe} /$ year in 2010, 2020, and 2030, respectively, attributable to accelerated use of new technologies: ATS, biomass, and black liquor gasification.

- $\quad 35 \%$ of energy savings and carbon reductions in industrial sector attributable to the energy conversion and utilization pathway. This pathway has the potential for the largest impact in the industrial sector because of the use of new, more efficient energy technologies.

\section{RD\&D Expenditures}

- $\quad$ Total federal expenditures in FY 1997 are estimated to be approximately \$50M.

- Substantial R\&D resources are required to accomplish the objectives of this technology pathway. A number of promising technologies will need cost sharing from the federal program for industry to obtain the needed information from the R\&D process and then commercialize the technologies.

- Annual federal RD\&D budget required for this pathway: 2000-2010, \$140M/year; 2010-2020, \$210M/year; 2020-2030, \$140M/year.

\section{Market}

- The markets for the technologies developed in this pathway will be industry in general; however, the primary focus will be on the largest energy users: chemicals, steel, petroleum refining, and forest products.

\section{Nonenergy Benefits and Costs}

- More competitive industrial sector; export potential for advanced turbines, industrial fuel cells, and black liquor and biomass gasifiers; lower energy costs

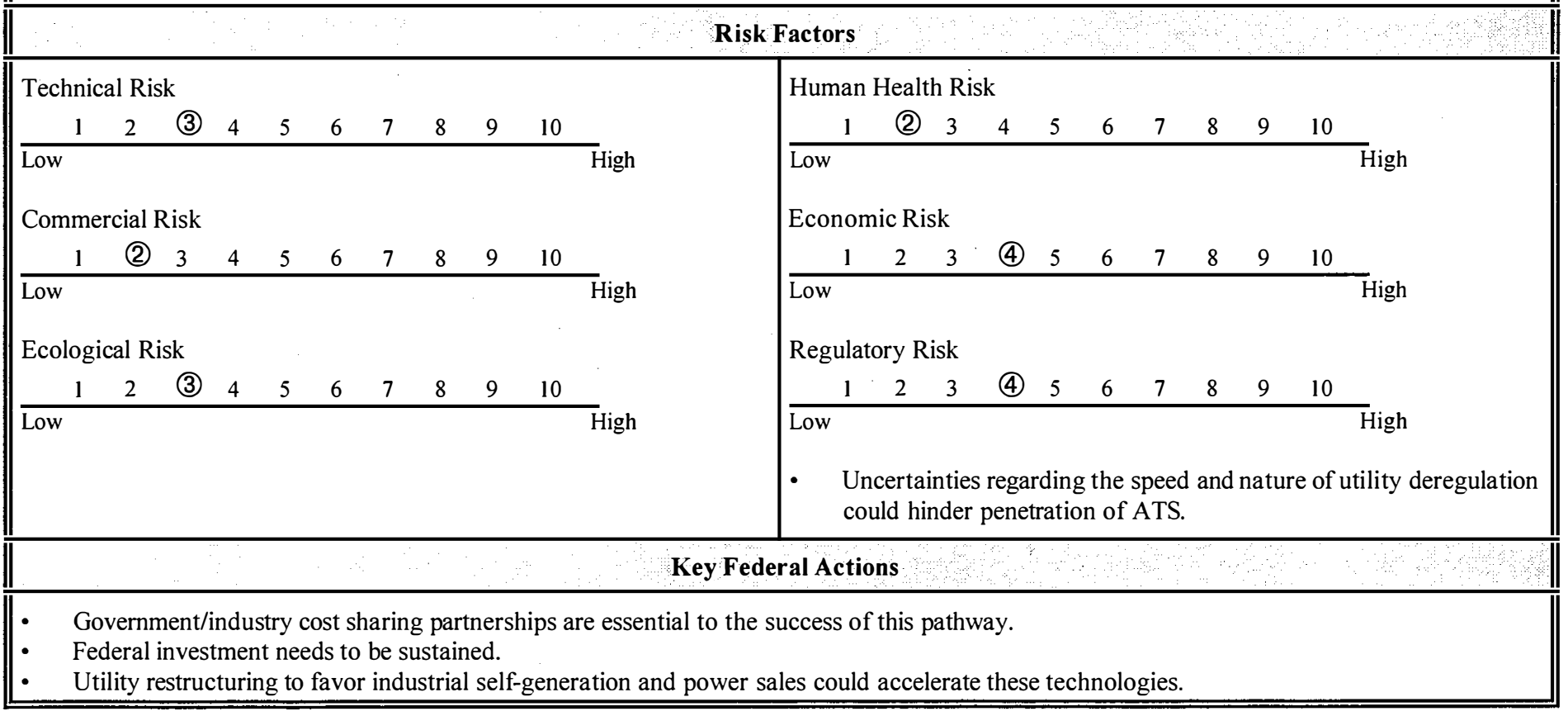




\subsection{RESOURCE RECOVERY AND UTILIZATION}

\section{Technology Description}

Resource recovery and utilization is waste minimization through recovery within the industrial process (treated largely under process efficiency) and/or end-of-pipe and post-consumer recovery and use of materials, process byproducts, chemical reactants, gases, solvents, diluents, steam, cooling water, and other waste. These materials can be reprocessed to reduce the burden on feedstocks, to make different products, to be used as fuels, or to be recycled. The practice mitigates $\mathrm{CO}_{2}$ by eliminating the energy costs for replaced feedstocks and waste treatment and by improving plant efficiency. An example of recovery, recycle, and reuse is a process used at a cement kiln owned and operated by the Pasamaquoddy Tribe (see photo) wherein a waste $\left(\mathrm{K}_{2} \mathrm{O}\right)$ is used in a scrubber and converted to $\mathrm{K}_{2} \mathrm{SO}_{4}$, which is sold as fertilizer. Distilled water is recovered from the crystallizer, and waste heat from the kiln is used to operate the crystallizer.

\section{System Concepts}

- $\quad$ Resource recovery and utilization involves cradle-to-grave stewardship over industrial products. In the example cited, the reuse of $\mathrm{K}_{2} \mathrm{O}$ mitigates $\mathrm{CO}_{2}$ emissions because it displaces fertilizer production elsewhere and avoids the cost of disposing of the waste.

- Components of the technology are advanced separations, improved chemistry, improved catalysts, advanced materials, optimal process and engineering design, sensors and controls, biotechnology, post-consumer processing, market sensitivity, and close integration between producers, users, and post-consumer processors.

- This pathway includes technologies that impact the other three industry technology pathways, particularly energy conversion and utilization and industrial process efficiency.

\section{Representative Technologies}

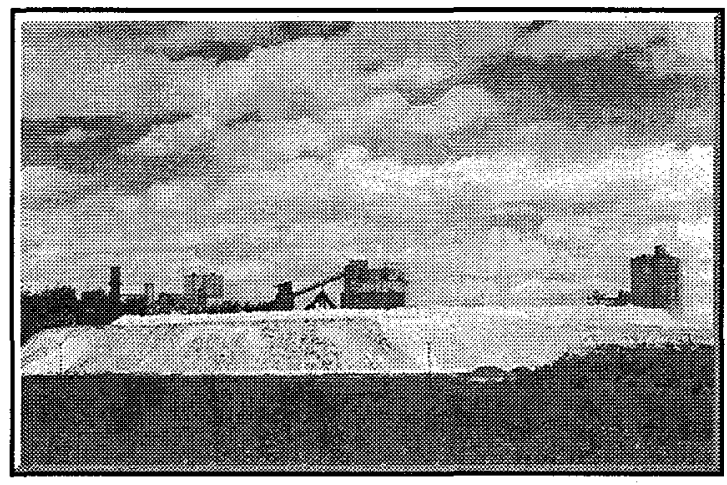

- Recovery-filters, advanced separations, improved chemistry, sensors and controls.

- Reuse-recycling, improved chemistry, new markets, industrial ecology.

- Improved understanding of fundamental chemistry and biotechnology advances allow use of $\mathrm{CO}_{2}$ and other recovered byproducts as feedstocks: algae to form carbonates, bioenzymes for biodegradable polymers, biomanufacturing, biomembranes for selective separations, bioremediation of wastes, biomass and agricultural waste for use as chemicals and as fuels when co-fired with fossil fuels, chemicals from $\mathrm{CO}_{2}$, and fuels from plastics and rubber. Capture of methane (coal beds, landfills, agricultural), capture of $\mathrm{CO}$ and $\mathrm{N}_{*}$.

- Industrial ecology integrates producers and consumers closely to minimize waste; one plant's waste is another's feedstock. Transportation costs are avoided by siting plants in close proximity. Synergetic cost-effective relationships can result in energyplexes or ecoplexes where utilities, producers, and consumers are part of an integrated community.

\section{Technology Status/Applications}

- $\quad$ Major industry groups a void $39.9 \mathrm{MtC} /$ year (potential is $140.5 \mathrm{MtC} /$ year).

- Industry recovers about $28 \%$ of potentially recoverable waste; thus $28 \%$ recovery must be viewed as cost-effective.

\section{Current Research, Development, and Demonstration}

\section{RD\&D Goals}

- Identifying nontoxic alternative reagents through improved chemistry; improving separations to capture and recycle materials, byproducts, solvents, and process water; identifying new uses and markets for recovered materials, including ash and other residuals such as scrubber sludges.

- Industries of the future, agriculture, textiles manufacturers, utilities, and municipal waste facilities.

\section{RD\&D Challenges}

- Better understanding of fundamental chemistry, advances in biotechnology, advanced computing and modeling capabilities for improved process and engineering design, and technology transfer.

- Improved chemistry, improved separations, new markets, improved sensors and controls, improved process and engineering design, and durable advanced materials.

\section{RD\&D Activities}

- Industries of the Future solicitations have funded projects to improve energy efficiency and reduce waste; participants include industry, DOE laboratories, and academia. DOE has cooperative agreements with the Energy and Environmental Research Center and the Western Research Institute that require $50 \%$ cost sharing by industry; many of these projects focus on waste reduction.

- Ongoing activities include use of biomass feedstocks as an alternative to use of oil for deriving industrial chemicals, feedstock preparation so industry can confidently use recovered along with virgin materials in the production processes, and techniques for effective separation of materials in plant and post-consumer streams for recovery and reuse. Recovery of plastics and conversion to chemicals used in the manufacture of new polymers is another area of ongoing R\&D.

\section{Recent Success}

- Recovery of methanol from industrial process, eliminating disposal of spent methanol via combustion.

- On-site recycling of chips resulting from machining of aluminum.

- Continuous preheating of steel scrap using furnace heat during steel production.

- An electrochemical de-zincing process that removes zinc from galvanized steel and recovers it for reuse.

- $\quad$ Recovery of salt from process brines to enable cost-effective saltcake recycling. 
Technologies that compete with resource recovery and utilization include waste disposal in landfills, incinerators, and approved hazardous waste disposal sites.

- Advantages - initially less expensive and more convenient. Disadvantages-industry and the public do not realize the benefits of recovery, recycle, and reuse. Eventually, environmental cleanup, remediation, and brownfields-type recovery projects may be required.

Improved chemistry, sensors and controls, materials, process and engineering design, biotechnology, and technology transfer are needed to develop alternative recovery, recycle, and reuse options, including new markets.

\section{Potential Benefits and Costs}

Carbon Reductions:

(All industrial sector)

1997 (base) $2010 \quad 2020 \quad 2030$

$\begin{array}{lllll}\text { BAU case quads } & 34.4 & 39.7 & 43.8 & 48.5\end{array}$

$\begin{array}{llll}\text { Eff. case(mod) quads } & 36.6 & 38.3 & 40.5\end{array}$

$\begin{array}{lllll}\text { MtC reductions } & 0 & 25-50 & 65-95 & 100-140\end{array}$

(15\% allocation to this pathway)

$\mathrm{MtC}$ reductions

$4-8 \quad 10-14 \quad 15-18$

- Assumptions (for all industrial sectors):

- Growth rate in manufacturing output of $2.1 \%$ year.

- For BAU case, energy intensity decreases by $1.1 \% /$ year $(0.5 \% / y e a r$-increases in efficiency and $0.6 \%$-composition).

- For efficiency case, energy intensity increases by an additional $0.35 \% /$ year.

- Additional 10-12, 22-25, and 30-40 MtC/year in 2010, 2020, and 2030, respectively, attributable to accelerated use of new technologies:

ATS, biomass, and black liquor gasification.

$15 \%$ of energy savings and carbon reductions in industrial sector are attributable to this resource recovery and utilization pathway.

RD\&D Expenditures

- $\quad$ Total federal RD\&D expenditures in FY 1997 are estimated to be approximately \$23M.

- Substantial R\&D resources are required to accomplish the objectives of this technology pathway. Several promising technologies will need cost sharing from the federal program for industry to obtain the needed information from the R\&D process and then commercialize the technologies.

- Annual federal RD\&D budget required for this pathway: 2000-2010, \$60M/year; 2010-2020, \$100M/year; 2020-2030, \$60M/year.

Market

- Seven major industries - including rubber and oils, chemicals and plastics. wood and paper, textiles, food and agriculture, and construction-offer the potential to save $140 \mathrm{MtC} /$ year; they mitigate $40 \mathrm{MtC} /$ year using existing technologies.

Nonenergy Benefits and Costs

- Reductions of $\mathrm{CH}_{4}, \mathrm{CO}$, and $\mathrm{N}_{x}$ as surrogates for $\mathrm{CO}_{2}$ as well as $\mathrm{GHG}$ results in equivalents of 8 , 40 , and 21 tons, respectively, per ton of $\mathrm{CO}_{2}$, as well as benefits to the environment, particularly ground-level ozone reduction. Reduced impacts on remaining landfill capacity and reduced need for incinerators and approved hazardous waste sites.

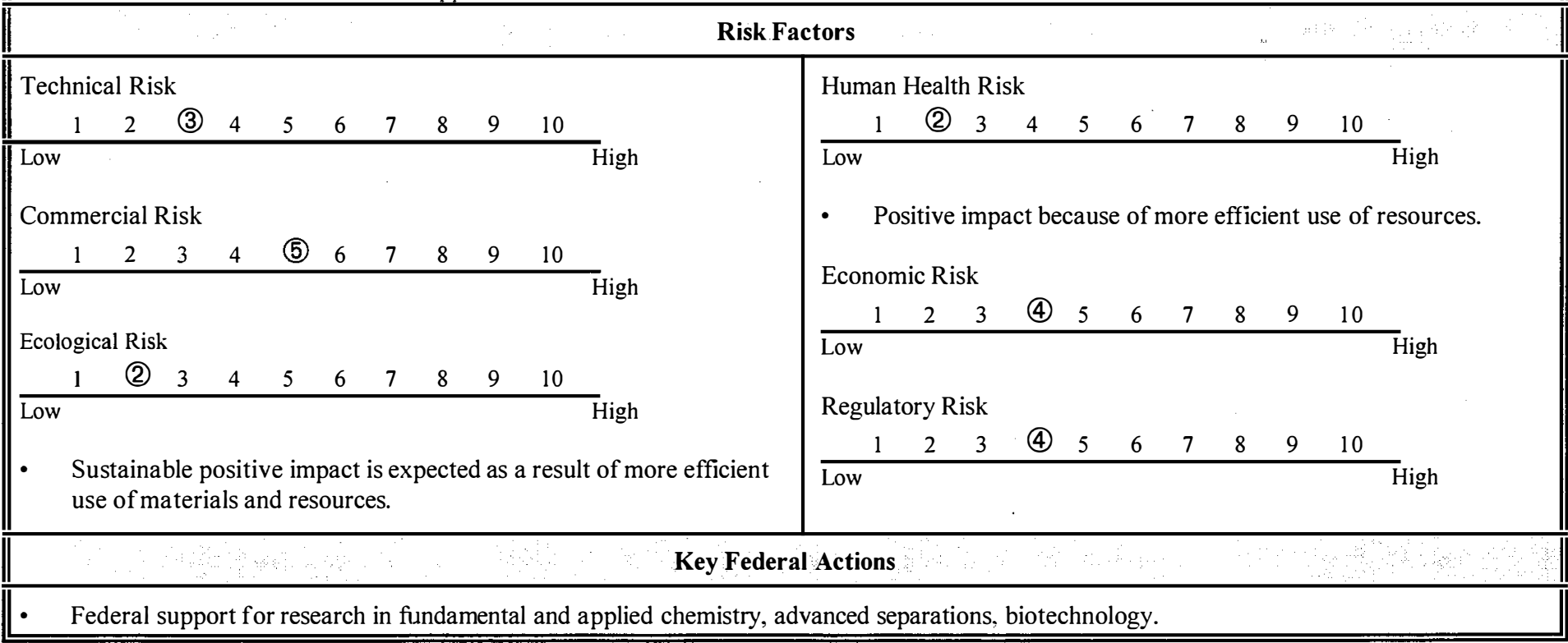




\section{Technology Description}

A significant source of carbon emissions from the industrial sector may be process material and energy inefficiencies in primary or secondary manufacturing. These contribute to GHG emissions through both excess energy expenditures (increasing fossil fuel consumption) and generation of waste byproducts. Waste generation represents inadequate use of carbon-containing feedstocks and requires energy expenditure for treatment/abatement. Increases in unit process efficiency through individual process optimization or new process introduction will reduce GHG emissions and offer the potential for increased growth at reduced

environmental risk.

System Concepts

- Process efficiency is enhanced through single-process optimization or process substitution in the principal manufacturing steps of raw material primary conversion, secondary or value-added processing, and product separation. It also results from overall optimization of a manufacturing chain with resulting improvements in material and energy balance.

\section{Representative Technologies}

- Many opportunities exist for improving process energy and materials efficiency in unit operations via new or more selective catalysts, advanced separations, new material- and energy-efficient reactor concepts, and the further development and introduction of biotechnology/bio-derived materials.

Technology Status/Applications

- Technologies such as catalysts, membranes for separations, and

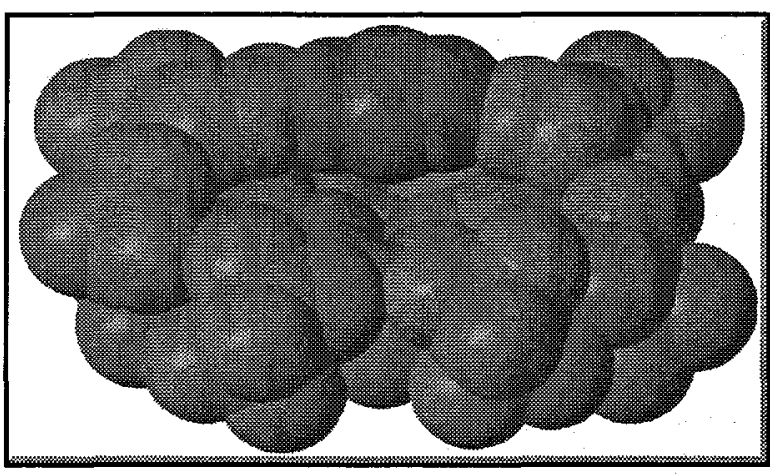

$\mathrm{CO}_{2}$ conversion catalysts. bio-derived materials are already in the marketplace in the production of both commodity and specialty products, particularly in the materials and chemical processing industries. Such technologies already allow the manufacture of many common products today (see Commercialization section). The biggest gains to be made in GHG reduction in industrial process energy or carbon-feedstock efficiency, however, will still come from introducing these technologies into new processes (e.g., membranes as substitutes for energy-intensive distillation separations or new process introduction using bio-based feedstocks) or enhancements in current practices (e.g.. enhancing selectivity in partial catalytic hydrocarbon oxidation or developing more energy-efficient process reactors). These technologies will benefit both commodity production (in the form of incremental process improvement yielding gains in energy efficiency) and the generation of specialty products (where more significant savings in waste generation are likely to result).

\section{Current Research, Development, and Demonstration}

\section{RD\&D Goals}

- Catalysis - target processes for improvement are selective oxidation, hydrocarbon activation, byproduct and waste minimization, stereoselective synthesis, functional olefin polymerization, alkylation, living polymerization, and alternative renewable feedstocks.

- Advanced separations-membrane separations (advanced inorganic membranes, ruggedized membranes, selective membranes, antifouling), reactive separations, separative reactors.

- Development of biotechnology/bio-derived materials-biof eedstocks that directly displace fossil-derived products (modified or alternative processes), improving the performance of biocatalysts.

- Advanced chemical reactors - short contact-time reactors, reactors for nonthermal processes (plasma, microwave, photochemical), reactors for alternative media or dry processing, flexible processing units.

\section{RD\&D Challenges}

- Specific R\&D needs that impact these technology areas include improved understanding and prediction of chemical and material behavior, materials fabrication methods, in situ and/or rapid analytical protocols and process screening procedures, and computational tools.

\section{RD\&D Activities}

- $\quad$ RD\&D activities relating to these technology areas are sponsored by DOE, DOC, DOD, NSF, and EPA. Comparable investments in these technology areas are made abroad.

\section{Recent Success}

- Many recent examples of industrial successes and implementation of new technology exist. For example, in the membrane area, Pittsburgh Plate Glass has successfully installed an ultrafiltration and reverse osmosis system to remove paints and reuse the water in the process. Caterpillar has developed and installed, in a cost-shared project with DOE, a system for recovery and reuse of paints in its production process. Improvement in catalysts and their uses is another area where industry has implemented improved processes and is working on other processes involving converting polymers and deriving chemicals from biomass feedstocks. 
- Applications of many of the described technologies already have an impact in the marketplace. For example, catalytic processes are responsible for about $75 \%$ of chemical and petroleum processing products by value. Catalytic processes generate about $\$ 900 \mathrm{~B}$ in products annually. The ready acceptance of certain applications of these technologies reduces barriers to implementation of process improvements or their application in new processes. Powerful drivers still exist for implementing advancements in these technologies for GHG reduction. The estimated total annual consumption of energy (fuels and electricity) by the U.S. chemical process industries is 5.8 quads; nearly $43 \%$ of that ( 2.5 quads) is required for separation processes, including distillation, extraction, adsorption, crystallization, and membrane-based technologies. Any process facilitating such separations will result in enormous savings of both energy and waste. The chief barriers to deploying of technologies are likely to be capital expenditures required for any substantial process modification, given the scale of many relevant industrial processes.

\section{Potential Benefits and Costs}

Carbon Reductions

(All industrial sector)

$\begin{array}{lllll}\text { BAU case quads } \quad 34.4 & 39.7 & 43.8 & 48.5\end{array}$

$\begin{array}{llll}\text { Eff. case(mod) quads } & 36.6 & 38.3 & 40.5\end{array}$

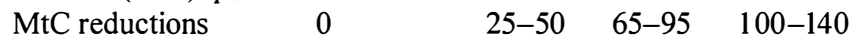

( $30 \%$ allocation to this pathway)

$\mathrm{MtC}$ reductions

$$
8-15 \quad 20-29 \quad 30-42
$$

Assumptions (for all industrial sectors):

- $\quad$ Growth rate in manufacturing output of $2.1 \% /$ year.

- For BAU case energy intensity decreases by $1.1 \% /$ year $(0.5 \% /$ year-increases in efficiency and $0.6 \%$-composition).

- For the efficiency case, there is an additional $0.35 \% / y e a r$ increase in energy intensity.

- Additional 10 to 12, 22 to 25, and 30 to $40 \mathrm{MtC} /$ year in 2010, 2020, and 2030, respectively, attributable to accelerated use of new technologies: ATS, biomass, and black liquor gasification.

- $30 \%$ of energy savings and carbon reductions in industrial sector are attributable to this industrial process efficiency pathway.

\section{RD\&D Expenditures}

- Total federal RD\&D expenditures in FY 1997 are estimated to be approximately \$46M.

- Substantial R\&D resources are required to accomplish the objectives of this technology pathway. Several promising technologies will need cost sharing from the federal program for industry to obtain the needed information from R\&D process and then commercialize the technologies.

- Annual federal RD\&D budget required for this pathway: 2000-2010, \$120M/year; 2010-2020, \$160M/year; 2020-2030, \$120M/year.

Market

- Application of the industrial processes described is central to the energy- and material-intensive industries with the largest energy consumption factors (chemicals, petroleum, forest products), shipping products valued at over $\$ 700 \mathrm{~B}$.

Nonenergy Benefits and Costs

- Implementing these technologies will likely result in substantial economic benefits (reduced pollution abatement costs) and result in enhanced export potential (based on the global nature of the market).

\section{Risk Factors}

Technical Risk

$\begin{array}{lllllllllll}1 & 2 & 3 & 4 & 5 & 6 & 7 & 8 & 9 & 10 & \text { High }\end{array}$

- Initial gains likely to be incremental.

Commercial Risk

\begin{tabular}{lllllllllll}
1 & 2 & 3 & 4 & $(5)$ & 6 & 7 & 8 & 9 & 10 & \\
\hline Low & & & & & & & & & &
\end{tabular}

- May mandate capital investment.

Ecological Risk

$\begin{array}{lllllllllll}1 & 2 & 3 & \text { (4) } & 5 & 6 & 7 & 8 & 9 & 10 & \text { High }\end{array}$

Sustained positive impact due to efficient use of materials and resources.
Human Health Risk

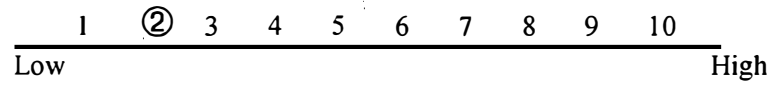

- Does not add substantially to current practices.

Economic Risk

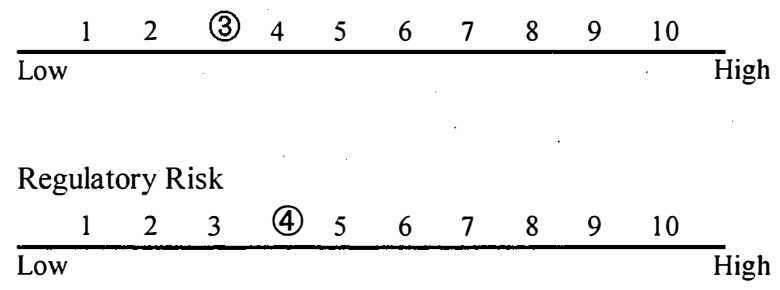

\section{Key Federal Actions}

- Government/industry partnerships are recommended to move precompetitive research forward.

- Incentives for capital investment would speed implementation. 


\subsection{ENABLING TECHNOLOGIES}

Technology Description

Enabling technologies are new systems requiring R\&D that impact all other pathways and that can provide significant improvements and new operational capabilities in many types of industries. GHGs can be reduced by increasing the efficiency of industrial processes, reducing waste and rework of products, and achieving a longer and more controlled operating life time for industrial components. Increased understanding of processes and systems required to make products will permit improvements and new manufacturing processes. The technologies range from advanced chemical reactions, materials, and measurement and controls systems, to systems and product-oriented design and processing that incorporate environmental and energy benefits in their initial and overall implementation. These types of activities will impact the reduction and more efficient use of fossil and electrical energy in current and new industrial processes.

\section{System Concepts}

- Technologies developed through enabling technologies programs will complement and be developed cooperatively with those of other pathways, in particular energy conversion and utilization and the industrial process efficiency. Technologies included in this pathway will have positive impact in many industrial areas.

- Increased understanding of processes and application of new methods in fabricating products will impact the entire industrial sector.

\section{Representative Technologies}

- A number of enabling technologies can have positive impacts on GHG emissions, including

- Advanced materials

- Measurements and controls

- New chemical reactions

- Modeling and simulations

- Holistic product/process design (including environment and energy).

- Just-in-place processing.

Technology Status/Applications

- Increased understanding of processes and energy generation

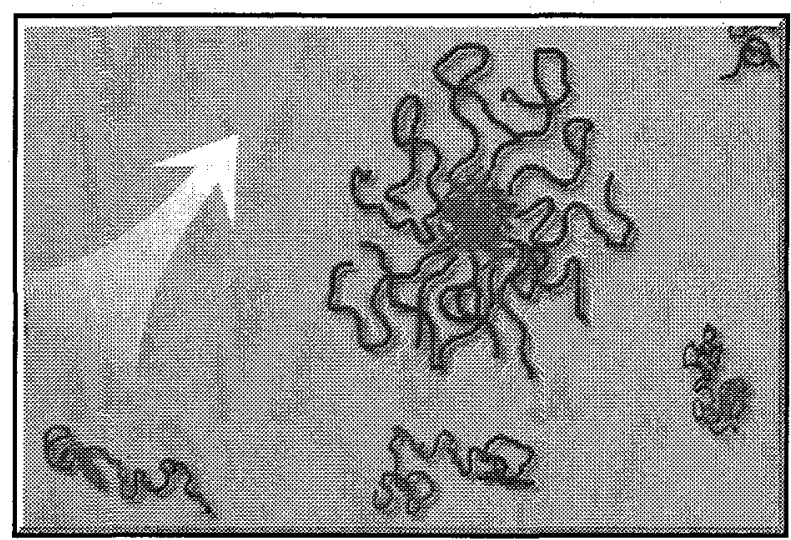

Neutron scattering aids the design of environmentally friendly ways to make polymers. technologies can lead to both incremental and revolutionary improvements.

- Increased efficiencies and impact on reducing GHG emissions will be obtained by increasing the efficiency of processes:

- Raising operational temperatures.

- Developing higher temperature corrosion resistant advanced materials.

- Finding new ways to determine and then monitor the most important process parameters affecting processes and the intelligent control of those processes.

- Developing more efficient heat recovery and utilization.

- Developing completely new processes.

- Making products or energy where needed, including new and holistic design technologies incorporating environmental and energy needs from initial concepts.

\section{Current Research, Development, and Demonstration}

\section{RD\&D Goals}

- New enabling technologies have a range of cost goals depending on the technologies and on the applications where they are to be used.

- Cost targets when considered on a system basis are expected to be between 0.5 to 2 times those of typical technologies.

- Applications for enabling technologies are many and encompass the various industrial segments of the economy. Every industry segment will benefit from the activities, and the efforts will be coordinated with other pathways.

\section{RD\&D Challenges}

Research areas include

- New materials compositions.

- Measurement technologies and intelligent control and predictive maintenance systems.

- Increased understanding of chemicals metallurgical and biotechnology processes.

- Validated mathematical models to enable improved and integrated design and operations.

- Methods and design concepts that will enable fabricating or producing energy where it is required.

- Industrial systems components including high-temperature and corrosion-resistant production systems used for melting, heat treating, or combustion systems; chemicals and pulp and paper processing systems; processing including boilers and gasifiers; and industrial cogeneration systems.

\section{RD\&D Activities}

- $\quad$ Ongoing R\&D activities on enabling technologies include the Advanced Industrial Materials, Continuous Fiber Ceramic Composite, and ATS programs in DOE. Additional activities are in the DOC ATP program and in EPA.

\section{Recent Success}

- A high-efficiency, recuperated industrial gas turbine for the generation of electricity recently was announced. The increased firing temperature was made possible through developments in the casting of advanced single crystal superalloy airfoils.

- Currently an advanced intermetallic alloy, $\mathrm{Ni}_{3} \mathrm{Al}$, is being used for rolls in the heat treating of steels and as metalforming dies. 
- The industrial segment of the economy is substantial and enabling technologies are impacting every industrial sector. New materials are being introduced in the manufacturing of steel, new measurement systems and in situ temperature measurements in harsh environments have been developed and are being used in industry; understanding of chemicals processes is leading to improved processes; and new capabilities in design and modeling methodologies are reducing the energy usage and GHG emissions of production plants.

- The introduction of new technologies is often sensitive to initial cost, and cost benefits must be made on life cycle benefits.

- Success rests on sustained development efforts coupled with implementation efforts. Thus partnering of government, industry, universities, and national laboratories is critical. Industry is eager to deploy cost-effective technologies and improved enabling technologies for process improvements to stay competitive in the world market.

\section{Potential Benefits and Costs}

\section{Carbon Reductions}

(All industrial sector)

$\begin{array}{llllll} & 1997 \text { (base) } & 2010 & 2020 & 2030 & \text { The estimated MtC reductions for the sector } \\ \text { BAU case quads } & 34.4 & 39.7 & 43.8 & 48.5 & \text { have wide ranges to account for uncertainties } \\ \text { Eff. case(mod) quads } & 36.6 & 38.3 & 40.5 & \text { in market adoption and economics. } \\ \text { MtC reductions } & 0 & 25-50 & 65-95 & 100-140 & \end{array}$

(20\% allocation to this pathway)

$\mathrm{MtC}$ reductions $\quad 5-10 \quad 13-19 \quad 20-28$

Assumptions (for all industrial sectors):

- Growth rate in manufacturing output of $2.1 \% /$ year.

- For BAU case, energy intensity decreases by $1.1 \% /$ year $(0.5 \% /$ year-increases in efficiency and .6\%-composition).

- For efficiency case, there is an additional $0.35 \% / y e a r$ increase in energy intensity.

- Additional 10-12, 22-25, and 30-40 MtC/year in 2010, 2020, and 2030, respectively, attributable to accelerated use of new technologies: advanced turbine systems, biomass and black liquor gasification.

- $20 \%$ of energy savings and carbon reductions in industrial sector attributable to this enabling technologies pathway.

\section{RD\&D Expenditures}

- Total federal RD\&D expenditures in FY 1997 are estimated to be approximately \$31M.

- Substantial R\&D resources are required to accomplish the objectives of this technology pathway. A number of promising technologies will need cost sharing from the federal program for industry to obtain the needed information from R\&D process and then commercialize the technologies.

- Annual federal RD\&D budget required for this pathway: 2000-2010, \$80M/year; 2010-2020, \$130M/year; 2020-2030, \$80M/year.

Market

- The energy impacts will be across the various energy sectors. Reductions will occur related to natural gas, electric power, coal, and oil.

Nonenergy Benefits and Costs

- New technologies will be highly valued and also suitable for export. The industrial sector will remain strong due to the use of new and advanced systems and the creation of new intellectual property. The advances will strengthen current industries and generate new industries and areas of commerce.

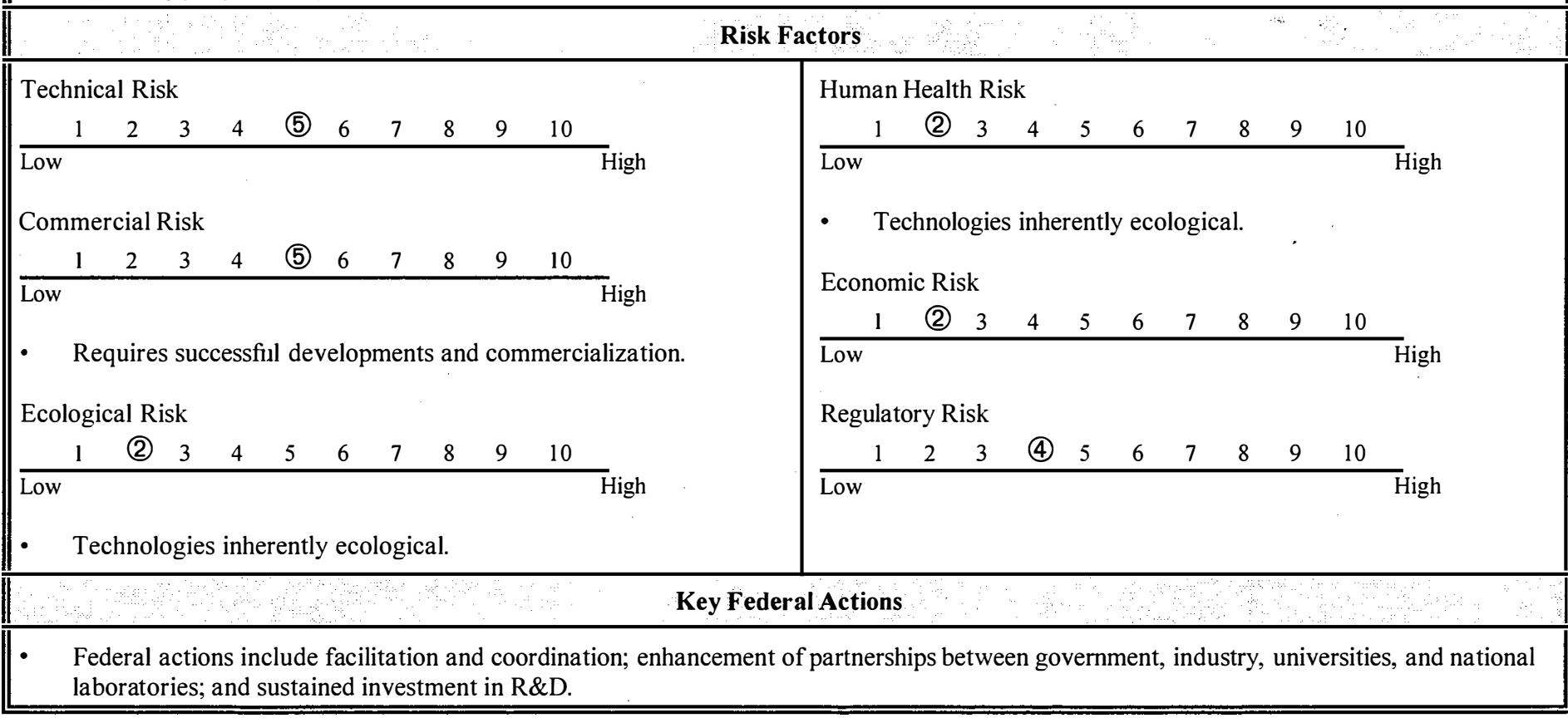





\section{Energy-Efficient Technologies}

3. Transportation

3.1 Advanced Conventional Vehicle

3.2 Freight Vehicles

3.3 Hybrid, Electric, and Fuel Cell Vehicles

3.4 Alternative Fuel Vehicles

3.5 Air and High-speed Ground Transport 


\subsection{ADVANCED CONVENTIONAL VEHICLE}

\section{Technology Description}

The advanced conventional vehicle applies near-term design and technology advances to a light-duty vehicle with a conventional drive train. Fuel economy gains are obtained from a combination of reductions in the vehicle's resistive forces (aerodynamic drag, rolling resistance, and inertial and weight drag) and increases in drive train efficiency (the efficiency with which the vehicle transforms fuel energy into power at the wheels). Benefits include non-drive train improvements to vehicles with unconventional drive trains. The technologies that this pathway addresses will have applications in the other four transportation pathways.

System Concepts

- Weight reduction: lightweight materials; redesign for equal structural integrity with less material.

- Drive train system efficiency improvement: reduced friction and pumping losses, higher thermodynamic efficiency, and so on.

- Reduced aerodynamic drag and rolling resistance: smoother body shape and design, better tires.

Representative Technologies

- Supercomputer structural design, direct injection diesel and stratified-charge gasoline engines, variable valve control (VVC), continuously variable transmissions (CVTs), aluminum and graphite composite materials, underbody panels.

\section{Technology Status/Applications}

- $\quad$ Current mid-size car $\approx 27-28 \mathrm{mpg}($ EPA).

- $\quad$ Best mid-size car $=49 \mathrm{mpg}(\mathrm{EPA}) \mathrm{VW}$ Passat turbocharged diesel with manual transmission, without advanced materials, special tires, advanced aero.

- Cost-effectiveness is a major issue for many of the technologies, especially with low gasoline prices.

Current Research, Development, and Demonstration

\section{RD\&D Goals}

- By 2001, develop and validate a vehicle systems concept that will achieve $45 \mathrm{mpg}$ for a mid-size car without life-cycle cost or performance/reliability/safety/emissions (PRSE) penalty [DISC (direct-injection, stratified-charge) engine, 20\% weight reduction, .006 rolling resistance coefficient (RRC) tires, $.27 \mathrm{C}_{\mathrm{D}}, 5$-speed automatic transmission]; equivalent light truck goal: $33 \mathrm{mpg}$.

- By 2005, develop and validate a vehicle systems concept that will achieve $52 \mathrm{mpg}$ for a mid-size car without cost/PRSE penalty (DISC engine, $30 \%$ weight reduction, $.005 \mathrm{RRC}$ tires, $.24 \mathrm{C}_{\mathrm{D}}$, CVT) or $60 \mathrm{mpg}$ [w/turbocharged direct injection (TDI) diesel with advanced particulate, $\mathrm{NO}_{\mathrm{X}}$ controls]; equivalent light truck goal: $39 / 45 \mathrm{mpg}$.

\section{RD\&D Challenges}

- Cost is an issue for all of the technologies with possible exceptions of $C_{D}$ reduction, advanced tires.

- Cost, recycling, rapid production, repair are critical issues for carbon fiber structures; cost and repair are critical issues for aluminum.

- Control effectiveness, longevity are key challenges to lean $\mathrm{NO}_{\mathrm{x}}$ catalysts, especially for diesels; also, GHG concerns highlight need to reduce $\mathrm{N}_{2} \mathrm{O}$ emissions.

- $\quad$ Reducing particulate emissions from diesels, especially with proposed new EPA standards for fine particulates.

- Combustion control, longevity of high-pressure fuel in jectors, cost are key challenges to DISC engine.

- Successful completion of these challenges will allow the application of these technologies to the full range of surface transportation vehicles, including advanced light-duty vehicles.

\section{RD\&D Activities}

- All enabling technologies are being pursued worldwide by original equipment manufacturers and suppliers.

- American Iron and Steel Institute is pursuing lightweight steel; Alcoa and others are pursuing aluminum bodies.

- DOE recently has expanded research on advanced diesels to light-duty applications.

- DOE is spending about $\$ 13$ million (FY 1997) on lightweight materials for light-duty vehicles: in order of funding, aluminum, polymer composites, cast steel and iron, and magnesium/titanium (material cost).

\section{Recent Success}

- $\quad$ Ford has developed a CVT compatible with larger, high-torque engines such as its Duratec V-6. 
- Most applicable technologies introduced in some commercial application in the United States or overseas: aluminum body/Audi A8; TDI diesel/VW Passat TDI; CVT/Civic HX; DISC engine/Toyota D4 (Japan); VVC/Honda VTEC.

- U.S. market penetration is modest for VVT, TDI diesel (rapid penetration in Europe), low-RRC tires, all-aluminum bodies, CVT; virtually universal for first-generation structural redesign with supercomputers and high-strength/lightweight steel.

- Critical challenges to deployment: lack of strong consumer interest in greater fuel economy (VVT is a case in point-despite Honda's technical success with it, most competing manufacturers have not adopted it because of high cost).

\section{Potential Benefits and Costs}

\section{Carbon Reductions}

- Potential carbon reductions include effects of non-drive train improvements on vehicles with unconventional drive trains (e.g., hybrids and electric vehicles).
2010
$15-25 \mathrm{MtC}$
2020
$40-60 \mathrm{MtC}$
2030
$80-100 \mathrm{MtC}$

RD\&D Expenditures

- FY 1998 DOE RD\&D budget for this pathway is $\$ 31 \mathrm{M}$.

- Annual DOE RD\&D budget required for this pathway: 2000-2030, \$75M/year.

- Advanced lightweight materials research will be needed well into the next century to develop enabling technologies to reduce the total material system life-cycle cost.

Market

- From $300 \mathrm{MtC} /$ year (2010) to $400 \mathrm{MtC} /$ year (2030).

Nonenergy Benefits and Costs

- $\quad$ Reduce pollutant emissions, improve human health, and reduce the nation's dependence on imported oil.

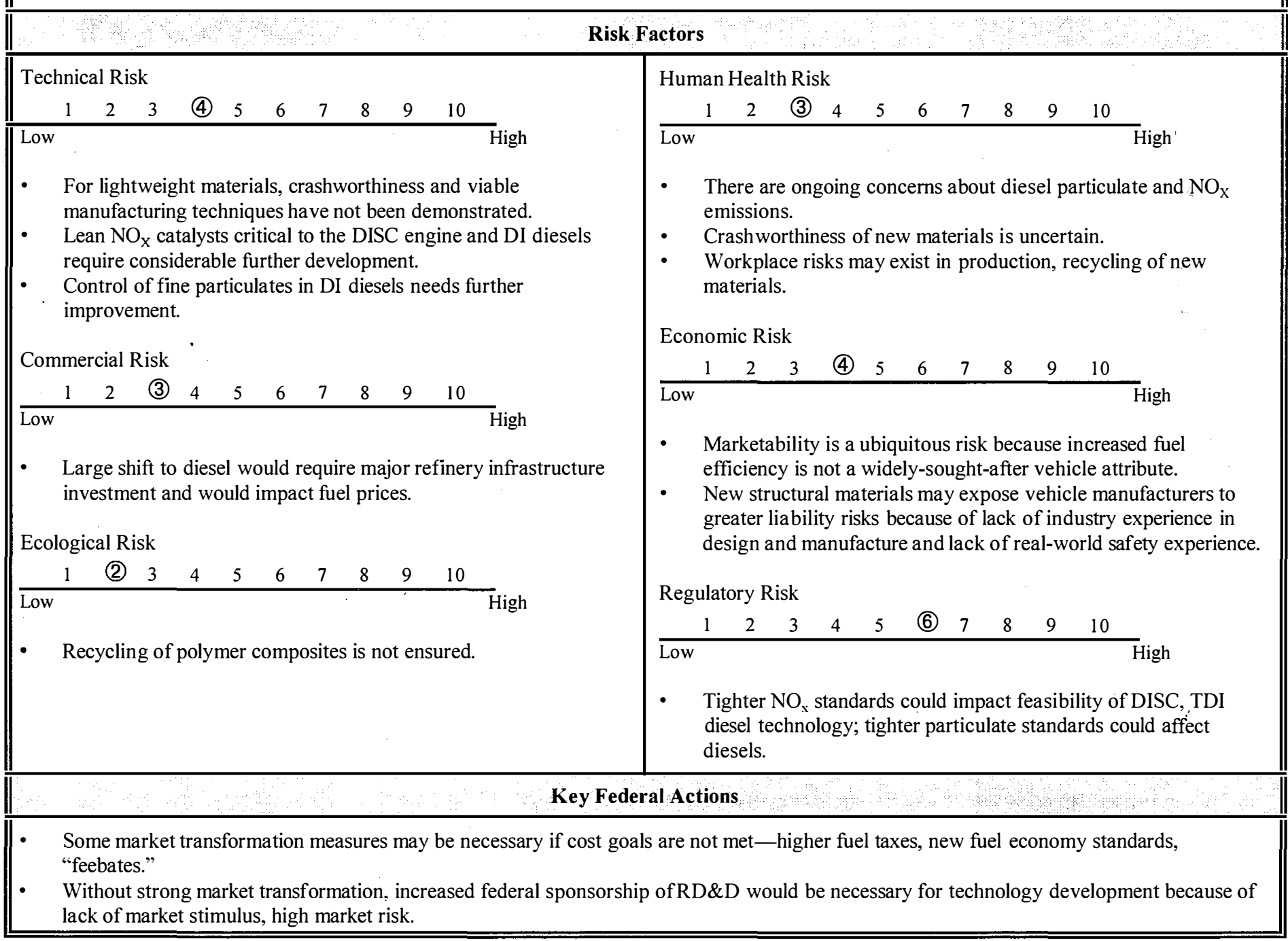




\subsection{FREIGHT VEHICLES}

\section{Technology Deseription}

Freight vehicles (class 7 and 8 trucks and rail) are essential to the economic vitality of the nation. Diesel engines are the dominant motive source for these vehicles. Vehicle efficiency can be increased by as much as $50 \%$ with a new generation of ultra-high-efficiency diesel engines that use advanced emissions control technology, coupled with improved aerodynamics and reduced rolling and parasite power losses. Successful development and commercialization of engines with $50 \%$ efficiency will significantly reduce transportation oil use, emissions (including $\mathrm{CO}_{2}$ ), and related costs to the economy.

\section{System Concepts}

- Four-stroke, direct-injection diesel engines (with high peak cylinder pressures, thermal barrier coatings, high-pressure fuel injection systems, and turbocharging) are being developed.

- Lightweight materials, truck aerodynamics and advanced tires are being developed to improve overall fuel economy.

- Hybrid electric vehicles or regenerative braking may have application in local delivery vehicles.

- $\quad$ Laser glazing of rails, flywheels, diesels with oxygen-enriched air systems and fuels cells are being considered for locomotives.

\section{Representative Technologies}

- High-pressure, common-rail fuel in jection, bottoming cycles, friction and wear reduction.

- Oxygen-enriched combustion air technology for locomotive diesel engines.

- Software technology to improve vehicle aerodynamics.

\section{Technology Status/Applications}

- Virtually all heavy-duty trucks and the entire fleet of locomotives are diesel powered, and there is an increasing trend to dieselize the medium-duty trucks as well. New advanced technologies for emission controls are required.

- Fuel cells are considered a long-term option. An active locomotive fuel cells program is being pursued by industry.

- Software tools are being developed to provide design guidance to reduce aerodynamic drag.

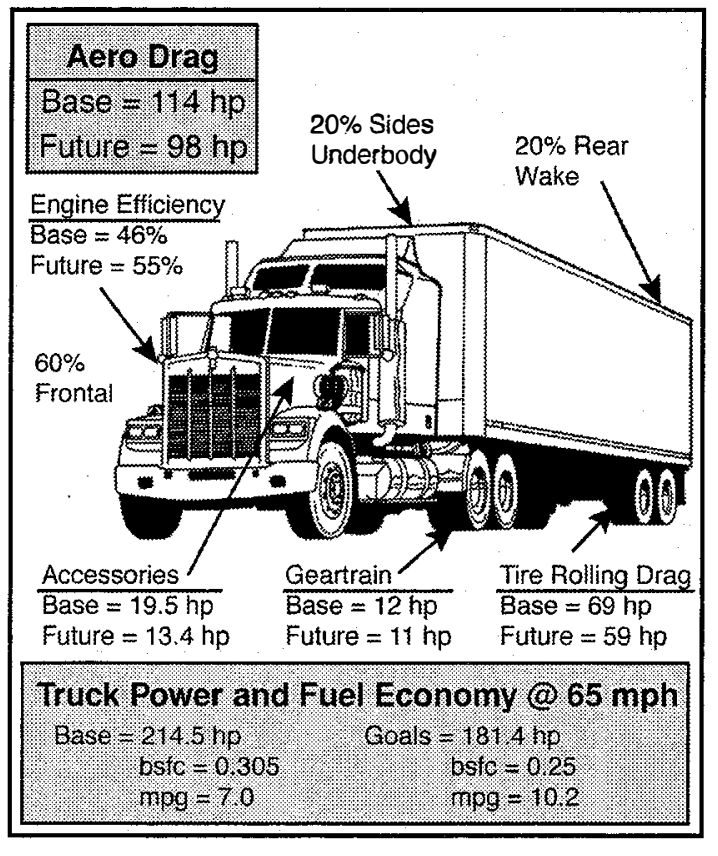

\section{Current Research, Development, and Demonstration}

\section{RD\&D Goals}

- By 2004, develop enabling technologies that will

- Lead to a fuel efficiency of $10 \mathrm{mpg}$ (at $65 \mathrm{mph}$ ) for class 7 and 8 trucks.

- Reduce class 7 and 8 truck emissions to $2 \mathrm{~g} / \mathrm{hp}-\mathrm{h}$ of $\mathrm{NO}_{\mathrm{x}}$ and $0.05 \mathrm{~g} / \mathrm{hp}-\mathrm{h}$ particulates.

\section{RD\&D Challenges}

- The challenge is to improve efficiency (thus reducing $\mathrm{CO}_{2}$ ) and meet emission regulations.

- Engine: high-pressure structural materials, in-cylinder processes and control, fuel effects.

- After-treatment: $\mathrm{NO}_{\mathrm{x}}$ and particulate matter.

- Components: turbochargers, friction.

- Simulation of flows around vehicles.

- Emission control for a wide variety of gaseous and liquid fuels.

RD\&D Activities

- DOE/OTT has a large heavy- and medium-duty diesel engine program for trucks.

- DOD/ARPA, California Energy Commission and the California Air Resources Board co-sponsor R\&D projects with DOE.

- Federal Railroad Administration sponsors locomotive efficiency improvement projects.

- $\quad$ Analytical and modeling work are sponsored by DOE.

\section{Recent Success}

- New conceptual model of in-cylinder soot formation developed.

- Advanced multicylinder engine (expected efficiency of 52-53\%) assembled at Caterpillar and being tested. 
- The diesel engine is the workhorse of all the heavy-duty transport modes that are responsible for most of the nation's intercity freight movement - the lifeblood of the economy. Because of low fuel consumption, high reliability, and long service life, it is widely acknowledged that the diesel engine will continue to dominate heavy-duty transport propulsion well into the next century.

- Strong coupling between efficiency and emissions controls is a significant barrier. Many engine design options currently available to manufacturers for emissions reduction involve a fuel economy penalty of 10 to $20 \%$. In the absence of significant technology advancements, future emission regulations could affect the historical trend toward higher diesel engine efficiency.

- Stiff domestic and international competition from European and Japanese diesel engine manufacturers has reduced domestic market share. U.S. manufacturers have limited resources to identify, research, develop, and commercialize many of the promising advanced emission technologies.

- All new technologies have to meet high durability requirements.

- Fuel cells are at least 10 years from commercialization in any freight vehicle.

\section{Potential Benefits and Costs}

Carbon Reductions

\begin{tabular}{ccc}
\multicolumn{3}{c}{ In MtC/year } \\
2010 & 2020 & 2030 \\
$7-10$ & $15-30$ & $25-35$
\end{tabular}

RD\&D Expenditures

- FY 1998 DOE RD\&D budget for this pathway is \$40M.

- Annual DOE RD\&D budget required for this pathway: 2000-2030, \$50M/year.

\section{Market}

- Approximately $100 \mathrm{MtC} /$ year of carbon reduction.

Nonenergy Benefits and Costs

- These technologies would reduce the nation's dependence on imported oil. Success would improve the global position of domestic heavyduty engine manufacturers and increase the competitiveness of domestic engine manufacturers in the automotive diesel engine market largely lost to foreign producers.

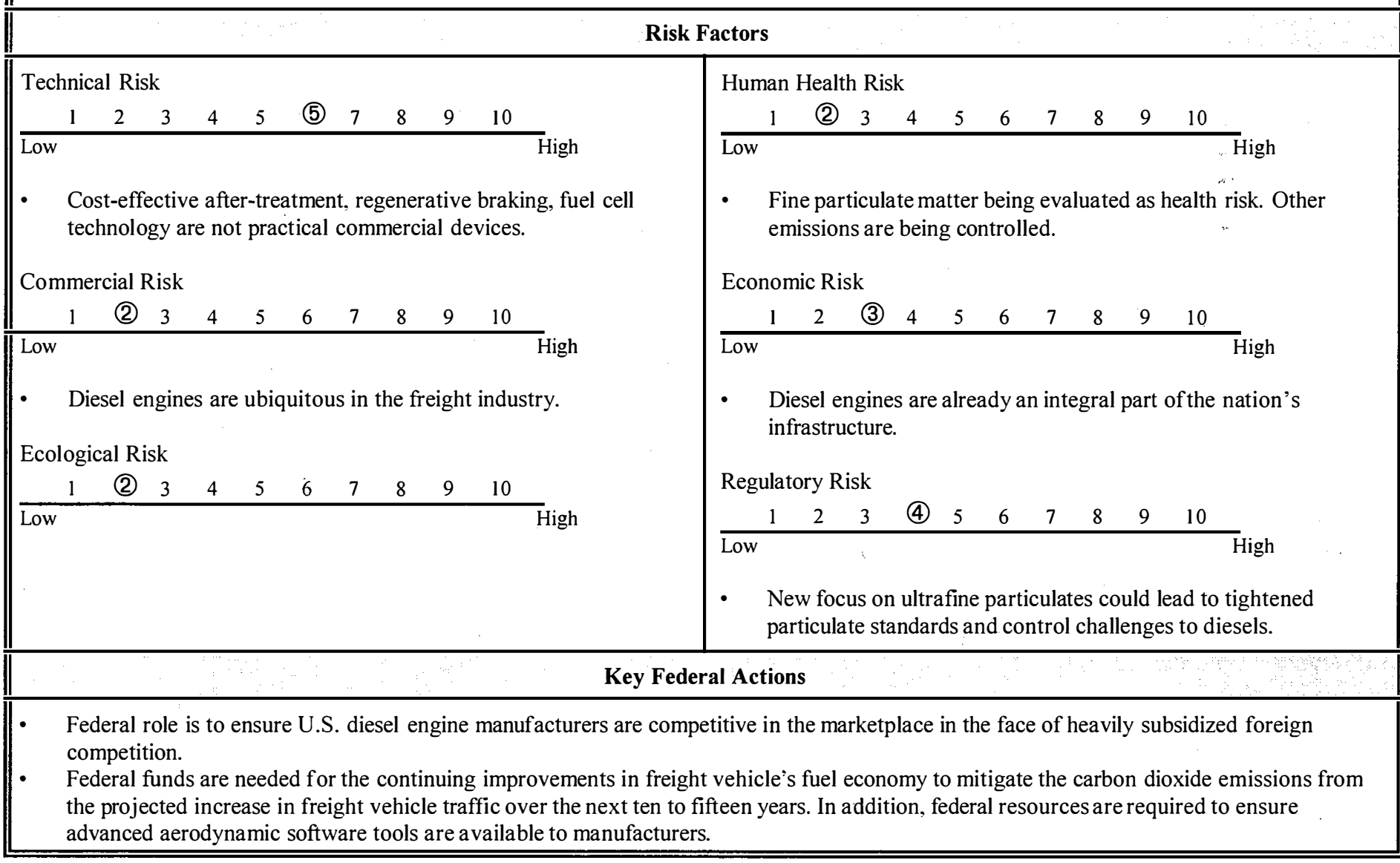


Technology Description

The current PNGV goal is to develop advanced vehicles that are up to three times more efficient than conventional vehicles and meet low emissions standards. Hybrid electric vehicles (HEVs) use a combination of electric propulsion and an auxiliary power unit. They can be designed in either series or parallel configuration. Electric vehicles (EVs) are powered by electric drive systems that receive energy from on-board energy storage devices. EVs emit zero regulated emissions from the tailpipe. With current and projected future average generation mix for 2015, EVs yield little or no carbon reduction. Fuel cell vehicles convert fuels to electricity directly. A vehicle powered by a hydrogen fuel cell may be twice as efficient and produce extremely low to zero tailpipe emissions. Fuel cells may initially run on gasoline or alcohol fuels reformed to produced hydrogen. The fuels used and how they are produced will determine whether carbon emissions are reduced by 50 to $100 \%$ over conventional vehicles.

\section{System Concepts}

- A series HEV drives the wheels using an electric motor while drawing energy from a battery pack, which is charged by a small on-board engine or another type of power unit. A parallel HEV uses both an electric motor and a power unit to drive the wheels.

- An EV uses a rechargeable battery pack, a motor controller, an electric drive motor, and a gear reducer to drive the vehicle.

- For fuel cells, hydrogen can be stored on the vehicle or can be made onboard using gasoline or alternative fuels.

\section{Representative Technologies}

- These technologies can use combinations of high-power energy storage devices (ultracapacitors, flywheels, batteries); small, high-efficiency integrated power units (gas turbines, direct-injection diesel engines, spark-ignited engines, Stirling engines, and fuel cells); and compact electric power systems (electric drive motors, electronic controllers).

\section{Technology Status/Applications}

- As part of a multiyear 50/50 cost-shared program with DOE, GM, Ford, and Chrysler have developed prototype HEVs that are being tested and analyzed. Simulation modeling techniques are being used to optimize components.

- In 1997, several versions of EVs became available for sale/lease in selected areas. However, these cars use batteries with limited range, which prevents widespread consumer acceptance, and there are still issues with the power mix.

- $\quad$ Fuel cells: Proton exchange membrane fuel cells are being demonstrated on vehicles and buses.

\section{Current Research, Development, and Demonstration}

\section{RD\&D Goals}

- HEVs: DOE is striving to develop HEVs with triple the fuel efficiency of conventional vehicles and comparable performance, range, safety, and cost. By 2004, the goal is to have an 80 mpg vehicle that meets Tier II emissions standards.

- EVs: Industry and government are striving to develop advanced batteries with increased range and life-cycles. The long-term EV battery targets are power density of $460 \mathrm{~W} / \mathrm{L}$, specific power of $300 \mathrm{~W} / \mathrm{kg}$, energy density of $230 \mathrm{Wh} / \mathrm{L}$, specific energy of $150 \mathrm{Wh} / \mathrm{kg}$, and a life of 10 years.

- Fuel cells: Stack systems with a power density of $500 \mathrm{~W} / \mathrm{kg}$, specific power of $500 \mathrm{~W} / \mathrm{L}$, efficiency of $68 \%$ at $25 \%$ peak power, durability of 5000 hours, a cold start-up time to maximum power of less than 30 seconds, and a cost of less than $\$ 50 \mathrm{~kW}$ must be developed.

\section{RD\&D Challenges}

- HEVs: System integration and packaging, cost and durability of components, high-power battery packs, and compact high-efficiency engines.

- EVs: Cost, life, performance, weight, and range of EV battery packs. Reducing battery recharge time and optimizing battery thermal management are also important challenges.

- Fuel cells: Tolerance to CO poisoning and reductions in weight, volume, and cost. Lack of an adequate infrastructure system for new fuels (e.g., hydrogen, methanol) also is a problem.

\section{RD\&D Activities}

- HEVs: DOE has related programs that conduct research on advanced gas turbines, engine materials, lightweight materials, advanced energy storage, and fuel cells. These programs are directly linked to DOE's PNGV/Hybrid Propulsion Systems Program.

- EVs: DOE has a High Power Energy Storage Program and Exploratory Technology Research Program. Other federal agencies (NASA, DOD) and private agencies have battery R\&D programs of their own.

- Fuel Cells: DOE is working with industry and other federal agencies to develop fuel cells and fuel processing systems.

\section{|rocent Success}

- GM, Ford, and Chrysler have numerous hybrid and electric vehicles in various stages of development. Technical feasibility of these concepts has matured, although cost and reliability barriers need continued attention.

- The nickel-metal hydride battery is approaching (in some cases attaining or exceeding) all performance goals, although cost remains an issue.

- Demonstration prototypes of fuel cell vehicles have been built and zero-emission fuel cell buses are in operation. 


\section{Commercialization}

- HEVs: The Big 3 automakers are working with DOE to develop production-feasible HEV propulsion systems by 1998 . Vehicle commercialization will begin when the market is ready and a business case can be made. Toyota will soon market a 65-mpg hybrid called Prius.

- EVs: Almost all major manufacturers began selling/leasing some version of an EV to public and/or private fleets in 1997. GM and Honda were the first two companies to lease EVs to private individuals. Consumer leasing figures have been less than anticipated. Additional improvements need to be made to increase the range and reduce cost so that more people will find these vehicles acceptable.

- Fuel cells: Almost all major auto manufacturers are pursuing fuel cell development. Manufacturability and cost are the most significant barriers to commercialization. Size and weight must also be substantially reduced to make them competitive with alternatives.

Deployment

- HEVs: An HEV's biggest competitor is an advanced conventional vehicle. Consumer acceptance and willingness to pay a little more for a more fuel efficient, high-technology vehicle is key. Depending on the fuel used in the HEVs, there will be minimal refueling infrastructure challenges that may affect widespread deployment.

- EVs: An EV's competition is an advanced conventional vehicle and an HEV. HEVs will have low GHG emissions and possibly low criteria emissions along with a range comparable to a conventional vehicle. Society will have to weigh the benefits of having a vehicle with limited range and no tailpipe emissions against the benefits of having an advanced vehicle with possibly lower emissions.

- Fuel cells: Fuel cell vehicles can combine the zero emissions of an EV and the range of conventional vehicles. Fuel cell vehicles have the potential to require less maintenance and have a more durable engine than conventional vehicles. Larger investments and longer lead times for the fuel cells to mature make this technology lag EVs and HEVs.

\section{Potential Benefits and Costs}

\section{Carbon Reductions}

- The combination of advanced vehicles will result in GHG emissions reductions of $10-15 \mathrm{MtC}$ by $2010,25-45 \mathrm{MtC}$ by 2020 , and $50-75 \mathrm{MtC}$ by 2030 .

\section{RD\&D Expenditures}

- The federal government and its industry partners will need to continue to invest in EV, HEV, and fuel cell technologies to make the pathways successful. FY 1998 DOE RD\&D budget for this pathway is \$104M. Annual DOE RD\&D budget required for this pathway: 2000-2010, \$230M/year; 2010-2030, \$250M/year. While the budgets for outyears are speculative, technology-driven opportunities for carbon reductions in this sector will continue to be large well into the next century.

\section{Market}

- From $300 \mathrm{MtC} /$ year (2010) to $400 \mathrm{MtC} /$ year (2030).

Nonenergy Benefits and Costs

- Besides reducing emissions, HEV. EV, and fuel cell technologies will improve human health and reduce dependence on imported petroleum.

\begin{tabular}{||lllllllllll}
\hline \multicolumn{1}{||l}{ Technical Risk } & & & & & & & & & \\
1 & 2 & 3 & 4 & 5 & 6 & 7 & 8 & 9 & 10 & High
\end{tabular}

- $\quad$ Battery improvement, system integration processes, infrastructure availability, and component optimization, are issues.

Commercial Risk

\begin{tabular}{lllllllllll}
1 & 2 & 3 & 4 & 5 & 6 & 7 & 8 & 9 & 10 & \\
\hline Low & & & & & & & & & &
\end{tabular}

- A market needs to be developed. A battery with adequate range is critical. Cost, reliability, and performance are key for acceptability to buyers.

Ecological Risk

\begin{tabular}{lllllllllllll}
1 & 2 & 3 & 4 & 5 & 6 & 7 & 8 & 9 & 10 & \\
\hline Low & & & & & & & & & & & High
\end{tabular}

- Ecological risks are low, but battery recycling must be addressed. The system in place recycles $\sim 98 \%$ of lead acid batteries. Other recycling systems for various advanced batteries are scarce and must be perfected.

\section{Key Federal Actions}

- Continuation of industry/government partnership to develop HEV, EV, and fuel cell technologies.

- Incentives for advanced vehicle purchases, including tax credits, preferential parking, and freeway lane access; reduced electricity rates for EV charging; and purchase discounts.

- Government mandates on vehicle production are a powerful incentive to commercialization although they risk damage to consumer acceptance if technologies are forced into the market prematurely.

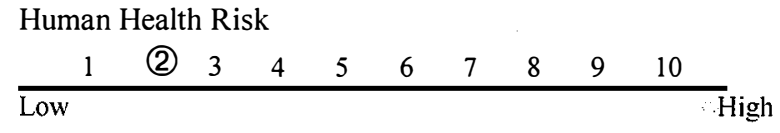

- Human health risks are almost nonexistent for these technologies.

Economic Risk

$\begin{array}{lllllllllll}1 & 2 & 3 & 4 & \text { (5) } & 6 & 7 & 8 & 9 & 10 & \\ \text { Low } & & & & & & & & & & \end{array}$

- Significant capital investment will be required by the automobile manufacturers to introduce these technologies. Continued research will be required to make them cost-effective. It may take many years for any auto manufacturer to gain a return on its investment in these technologies.

Regulatory Risk

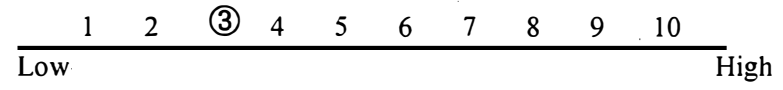

Regulations may be required to encourage and promote battery recycling.

$$
\|
$$




\subsection{ALTERNATIVE FUEL VEHICLES}

\section{Technology Description}

Alternative fuels include compressed and liquefied natural gas, biomass ethanol, liquefied petroleum gas, biodiesel, and dimethyl ether. The real leverage in carbon reductions comes from the use of biomass-derived fuels-ethanol, biodiesel, and dimethyl ether. When biomass ethanol is used purely as a blending agent with gasoline (up to at least $10 \%$ by volume, and possibly higher), no changes in vehicle technology are needed.

System Concepts

- Alternative-fuel vehicles (AFVs) are similar to today's vehicles, except for certain fuel- and emission-related systems.

- Alcohol vehicles require corrosion-resistant fuel lines and fuel tanks, modified fuel injectors, and modified engine lubricants.

- Gaseous-fuel vehicle fuel system components include fuel regulators, air and fuel mixing apparatus, and modified fuel injectors. Fuel tank modifications are also required.

\section{Representative Technologies}

- Flexible-fueled vehicles are available from the three major domestic automobile manufacturers.

- Several models of compressed natural gas and liquefied petroleum gas vehicles are of fered by automakers.

- Heavy-duty alternative-fuel engines are offered as options to the commercial market for trucks and buses.

\section{Technology Status/Applications}

- Light-duty AFVs have shown superior in-service emissions performance and similar levels of fuel economy in federal fleet demonstrations. AFV purchase costs vary significantly depending on the fuel. Flexible-fueled vehicles have been purchased at prices below those of conventional cars, while compressed natural gas vehicles can cost $\$ 5 \mathrm{~K}$ more than conventional vehicles.

- Heavy-duty AFVs have shown dramatic reductions in particulate emissions, with fuel economy near their diesel counterparts. Maintenance costs are higher but will decrease with experience. Alternative-fuel engines should be no more expensive, but high-pressure tanks will raise overall costs somewhat.

\section{Current Research, Development, and Demonstration}

\section{RD\&D Goals}

- Develop light- and heavy-duty engine and fuel technologies to meet future emissions standards.

- Develop technologies that use alternative fuels in conventional vehicles with full range and performance characteristics by 2004 .

- By 2011 , develop automotive technologies that use non-petroleum-based fuels and achieve near-zero emissions while obtaining $100 \mathrm{mpg}$ in lightweight vehicles.

RD\&D Challenges

- AFVs must be developed to meet cost, performance, and future environmental and energy efficiency goals over the lifetimes of the vehicles. Specific areas of concern include cost, range, and refueling convenience; cold-start performance and engine efficiency of alcohol fuels; and fuel-in jection and storage systems for dimethyl ether.

\section{RD\&D Activities}

- The three U.S. automakers have significant ongoing R\&D programs, and several vehicle models are available today.

* With DOE cofunding, heavy-duty engine manufacturers have major alternative-f uel engine R\&D efforts.

- Component manufacturers, national laboratories and research institutions, universities, and state and local governments have sizable alternative-fuel R\&D operations.

- The DOE AFVs funding levels for FY 1996 and FY 1997 were \$29M and \$26.3M.

Note: Fuel production and distribution research is discussed in Renewable Energy technology pathway 8.7, "Biomass Transportation Fuels" and hydrogen production and distributing is discussed in cross-cutting technology pathway 10.2, "Hydrogen."

\section{Recent Success}

- Work on the first-generation ultra-safe and ultra-low emission school bus powered by compressed natural gas has been completed and the bus is now commercially available. More than 100 have been sold in California, and work on the second generation is under way to improve engine efficiency and lower emissions even further.

- Honda has obtained ultralow emission vehicle certification for a compressed natural gas automobile. 
- Domestic automobile manufacturers have been producing AFVs since 1991. Today, 11 light-duty and 19 medium- and heavy-duty vehicle models are available, powered by a number of alternative fuels. The configurations used include flexible-fuel, dual-fuel, and dedicated. Prices for flexible-fuel vehicles have decreased to those of their conventional counterparts. AFV conversion companies are successfully filling any market voids left unoccupied by domestic automakers.

- DOE and GSA are working under an interagency agreement to manage the Federal Light Duty Alternative Fuel Vehicle Project.

- The federal fleet currently contains $\sim 33,000$ light-duty AFVs. Since its inception in 1991, the DOE-sponsored alternative-fuel, heavy-duty truck demonstration program has assisted in placing more than 300 heavy-duty data collection AFVs.

- The DOE Clean Cities Program actively enables deployment of AFVs through its locally-based government/industry partnership.

- AFVs are projected to number 400,000 light- and heavy-duty vehicles by the end of 1997 in the United States.

\begin{tabular}{|c|c|c|c|}
\hline 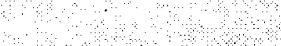 & & & fits and Costs \\
\hline $\begin{array}{l}\text { Carbon Reductions } \\
2010 \\
2-10 \mathrm{MtC}\end{array}$ & $\begin{array}{c}2020 \\
4-12 \mathrm{MtC}\end{array}$ & $\begin{array}{c}2030 \\
15-30 \mathrm{MtC}\end{array}$ & $\begin{array}{l}\text { RD\&D Expenditures } \\
\text { - FY } 1998 \text { DOE RD\&D budget for this pathway if } \$ 18 \mathrm{M} \text {. } \\
\text { - Annual DOE RD\&D budget required for this pathway: } \\
\text { 2000-2010, \$50M; zero in the outyears. }\end{array}$ \\
\hline
\end{tabular}

Market

- The domestic market size for AFVs alone is between $300 \mathrm{MtC} /$ year in 2010 and $400 \mathrm{MtC} /$ year in 2030.

Nonenergy Benefits and Costs

- Deployment of alternative fuels may result in reductions in emissions of $\mathrm{NO}_{x}, \mathrm{CO}$, hydrocarbons, and fine particulates, yielding improvement in urban air quality.

\begin{tabular}{|c|c|c|c|c|c|c|c|c|c|}
\hline \multicolumn{10}{|c|}{ Technical Risk } \\
\hline 1 & (2) & 3 & 4 & 5 & 6 & 7 & 8 & 9 & 10 \\
\hline
\end{tabular}

- Most of the alternative fuels RD\&D is based on modifications to existing vehicle technology, and first-generation vehicles are already in commercial production.

Commercial Risk

$\begin{array}{lllllllllll}1 & 2 & 3 & 4 & \text { (5) } & 6 & 7 & 8 & 9 & 10 & \text { High }\end{array}$

- Commercial success depends not only on cost-effective technical solutions, but also on the creation of infrastructure to produce and supply the alternative fuels.

Ecological Risk
(1)
23
3

5
6
89
10
High

Low

- Alternative fuels are environmentally superior choices to petroleum-based fuels. The stable of alternative fuels includes those that can substantially reduce emissions of toxics, ozone precursors, particulates, and GHGs.

\section{Risk Factors}

Human Health Risk

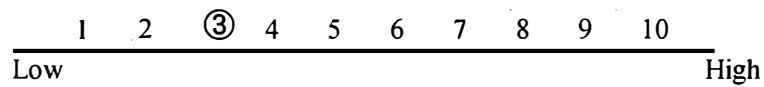

- Alternative fuels are superior to petroleum-based fuels in terms of human health risks from their manufacture, distribution, and use. The agricultural production risk impact on human health is greater.

Economic Risk

$\begin{array}{lllllllllll}1 & 2 & 3 & 4 & 5 & 6 & 7 & 8 & 9 & 10 & \text { High }\end{array}$

- Investment in developing these vehicles is moderate, but the large-scale investment required for the inf rastructure to deliver the fuels is still a concern.

Regulatory Risk

\begin{tabular}{|c|c|c|c|c|c|c|c|c|c|}
\hline 1 & (2) & 3 & 4 & 5 & 6 & 7 & 8 & 9 & 10 \\
\hline
\end{tabular}

- Alternative fuels for which vehicles are being'developed are being used on a large scale. The vehicles themselves are being demonstrated, and in most cases the first generation is commercially available.

\section{Key Federal Actions}

- Vigorous implementation of current federal mandates (e.g., EPAct) could be pursued. Federal RD\&D activities would contribute to development of vehicle technologies that can realize the inherent environmental and energy efficiency benefits offered by alternative fuels. Regulatory and/or tax reforms that reward alternative fuels for these benefits would increase demand for these vehicles. Vehicle cost reductions could also be pursued through continued RD\&D. Finally, federal investment in fuel supply infrastructure would help alleviate fuel/vehicle, chicken-and-egg conundrum. 


\subsection{AIR AND HIGH-SPEED GROUND TRANSPORT}

Technology Description

Carbon emissions from commercial jet aircraft can be cut through reduced drag, improved fuel combustion, and reduced idling. The National Research Council has set as a "reasonable goal" for new commercial aircraft a reduction in fuel burn per seat mile of $40 \%$ compared with current airplanes. Of the total $40 \%, 25 \%$ is expected from improved engine performance and $15 \%$ from aerodynamic and weight improvements.

Electrified high-speed ground transportation modes (speeds $>150 \mathrm{mph}$ ) can reduce carbon emissions by diverting trips from conventional fossilfueled modes and by using more efficient suspension and propulsion system technologies. Since high-speed rail (HSR) and maglev systems derive their power from the utility grid, potential carbon reductions are directly linked to electric generating technology efficiencies and carbon emissions. Passengers are emphasized here, but technologies also apply to cargo.

System Concepts

- HSR (speeds of up to $200 \mathrm{mph}$ ) uses locomotive-drawn coaches supported by steel wheels on steel rails. Single-phase power is transformed from transmission-line voltages at substations, distributed along the right of way, and delivered to locomotives via catenary-pantograph systems, where it is converted by power conditioning equipment to voltages and frequencies needed by the propulsion motors. Regenerative braking systems can be used but generally require energy storage.

- Maglev is a new mode of high-speed (up to $300 \mathrm{mph}$ or more) guided ground transportation that uses magnetic forces for non-contact support, guidance, propulsion and braking. Most of the power conditioning equipment and propulsion system is at wayside, making the vehicles much lighter and automatically controllable.

- Propulsion efficiency in aircraft can be increased by still higher turbo-fan bypass ratios, increased cycle pressure ratios, higher turbine inlet temperatures, improved turbine aerodynamics, and lighter engine parts. The most promising approach for reducing drag appears to be methods for increasing laminar flow next to the surface of aircraft, but turbulence control and reduction in induced drag also can help improve lift-to-drag ratios. A $1 \%$ reduction in empty aircraft weight can reduce fuel consumption by $0.25 \%$ to $0.50 \%$. Maximum use of lightweight, high-strength materials could conceivably increase non-metallic content of aircraft to a maximum of about $80 \%$, with an overall $30 \%$ reduction in weight.

Representative Technologies

- Existing HSR systems include the French TGV, German ICE, and Japanese Nozomi. All require electrified railways. Possible enhancements and alternatives include use of on-board energy storage devices and high-temperature superconducting components. Locomotive designs using advanced prime movers such as fuel cells and high-efficiency gas turbines could conceivably compete with electrified systems for speeds up to about $150 \mathrm{mph}$, but market and emission benefits would be less.

- Foreign maglev technologies: the German Transrapid (conventional electromagnet, attractive-force system); the Japanese Linear Motor Express (superconducting magnet, repulsive-force system).

- $\quad$ Ultra-high bypass turbofans, increasing bypass ratios up to 10 .

- Propfan technology with advanced, counter-rotating prop designs.

- Lightweight, high-strength structural and surface materials.

- Advanced computational fluid dynamics for engine and airframe design.

- Hybrid laminar flow control technology for drag reduction.

Technology Status/Applications

- HSR is a mature technology in several foreign countries; and it is not likely that the United States could compete. Hence, the benefits would derive from implementing that technology in the United States and diverting passengers and cargo from fossil-fueled modes.

- The German Transrapid was certified for application in 1991. Full-scale testing of the Japanese superconducting system on the Yamanashi Prefecture test line is scheduled to be completed in 1998.

Foreign maglev technologies are expensive and have other characteristics that may limit their applicability in the United States.

- Foreign competition is driving new aircraft and engine designs by Boeing, NASA, GE, and Pratt \& Whitney.

- Advanced aircraft technologies are under development by NASA, Boeing, and engine manufacturers.

- Propfan technology has been demonstrated but could benefit from cost reduction and noise and vibration improvements.

- Aspects of laminar flow control have been demonstrated in limited tests, but a practical system has not yet been developed.

\section{Current Research, Development, and Demonstration}

\section{RD\&D Goals}

- For speeds of 90 to $150 \mathrm{mph}$, the DOT/FRA Accelerail Program focuses on passenger rail technologies that can use existing railroad rights of way (mainly owned by the freight railroads).

- Implement electrified HSR systems where commercially viable.

- Develop and test concept of innovative domestic maglev system designs within the next 2 years; refine designs and performance testing within the following 2 years; design and initiate demonstration projects in the following 2 years.

- Develop room-temperature maglev (LLNL contract with NASA to develop its Inductrack System).

- Achieve $40 \%$ overall efficiency improvement in new aircraft by $2025,25 \%$ propulsion efficiency improvement, and $15 \%$ efficiency gain from drag and weight reduction.

\section{RD\&D Challenges}

- Meet or exceed performance of foreign maglev systems at reduced construction costs. Develop manufacturing techniques and lightweight, strong, inexpensive materials for vehicle and guideway components.

- Develop suspension and propulsion system components that will meet the higher performance and lower cost requirements.

- Develop efficient, reliable superconducting magnet designs.

- Reduce $\mathrm{NO}_{\mathrm{x}}$ emissions while increasing turbine cycle temperatures and pressures for thermodynamic efficiency.

- Develop a low-cost, low-maintenance, low-noise and -vibration propfan so that airlines will demand their installation on new aircraft.

- Develop a hybrid laminar flow control system that is practical and maintainable under real world operating conditions (e.g., dust, insects).

- Lower the cost and improve the manufacturability of high-strength, lightweight, non-metallic materials for engines and airframes. 


\section{RD\&D Activities}

- Design and test maglev system components.

- Develop supporting technologies such as high-temperature superconductors, composite materials, power electronics, zero- or low-carbonemitting electric power generating technologies.

- Design transportation systems together with incentives that incorporate maglev and HSR systems cost-effectively and that divert as many trips as possible from privately owned vehicles and short-haul aircraft.

\section{Recent Success}

- New HSR technology has increased the top speed for commercial operation to $200 \mathrm{mph}$ in France. Development of German and Japanese maglev and HSR has been highly successful. Four innovative maglev system designs were developed under the auspices of the NMI.

- High bypass turbo-fan on Boeing 777, advanced propfan able to achieve Mach 0.7 , numerous advances in laminar flow control, and adoption of drag reduction via riblets and winglets on several commercial aircraft.

\section{Commercialization and Deployment}

- Construction on the first commercial route of the Transrapid system (Hamburg to Berlin) is scheduled to begin in 1998. The Japanese will reach a decision on commercialization by the year 2000. Deployment of existing maglev technology in the United States could begin with small pilot projects to introduce the technology and demonstrate its benefits and ability to attract financing.

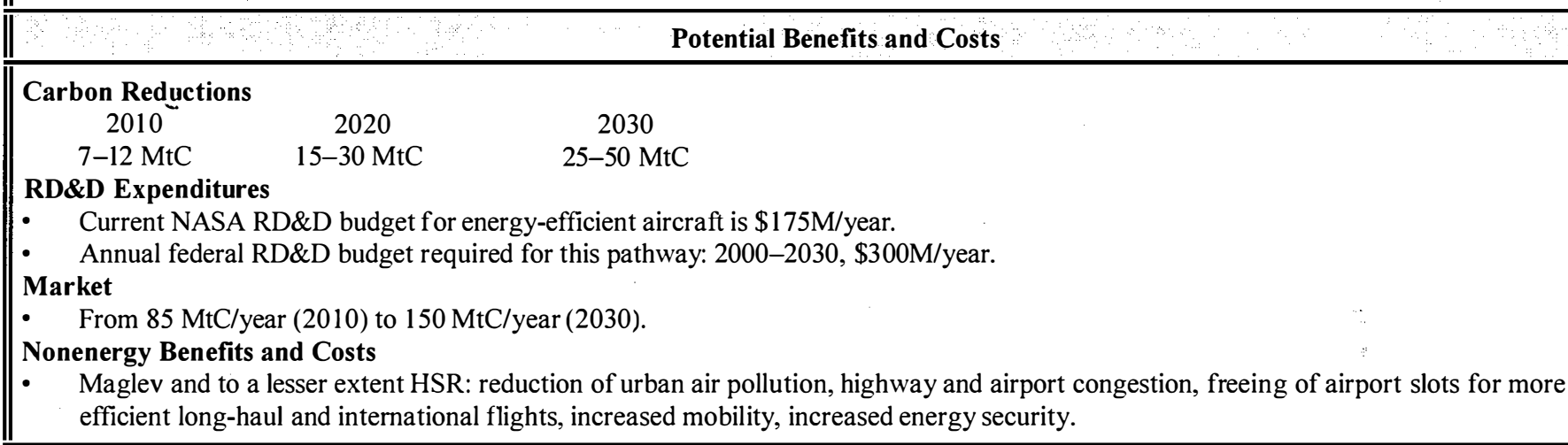

\begin{tabular}{|c|c|c|c|c|c|c|c|c|c|}
\hline \multicolumn{10}{|c|}{ Technical Risk } \\
\hline 1 & (2) & 3 & 4 & 5 & 6 & 7 & 8 & 9 & 10 \\
\hline Low & & & & & & & & & High \\
\hline $\begin{array}{l}\text { - Ja } \\
\text { ris } \\
\text { te }\end{array}$ & $\begin{array}{l}\text { is in } \\
\text { is a }\end{array}$ & $\begin{array}{l}\text { and } \\
\text { olv } \\
\text { id d }\end{array}$ & $\begin{array}{l}\text { Ger } \\
\text { d i } \\
\text { mo }\end{array}$ & $\begin{array}{l}\text { lan } n \\
\text { deve } \\
\text { trati }\end{array}$ & $\begin{array}{l}\text { agl } \\
\text { opi } \\
\text { o i }\end{array}$ & $\begin{array}{l}\text { is } \\
\text { do } \\
\text { com }\end{array}$ & $\begin{array}{l}\text { ear } \\
\text { nes } \\
\text { olet }\end{array}$ & ma & $\begin{array}{l}\text { lication stag } \\
\text { lev options } ~\end{array}$ \\
\hline \multicolumn{10}{|c|}{ Commercial Risk } \\
\hline 1 & 2 & 3 & 4 & (5) & 6 & 7 & 8 & 9 & 10 \\
\hline
\end{tabular}

- Commercial risk can be mitigated by developing two or three well-designed pilot projects with the support of partnerships involving federal, state, and private financing. Short-haul airlines could be significantly impacted in HSR and maglev corridors.

\section{Risk Factors}

Human Health Risk

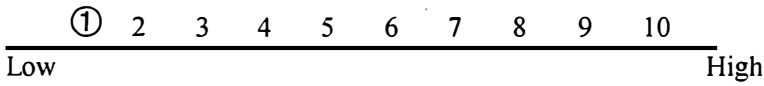

- There are no local emissions and magnetic field exposure does not pose a human health risk.

Economic Risk

\begin{tabular}{lllllllllll}
1 & 2 & 3 & 4 & 5 & 6 & 7 & 8 & 9 & 10 \\
\hline Low & &
\end{tabular}

- $\quad$ Ridership base for high speed rail is uncertain.

Regulatory Risk

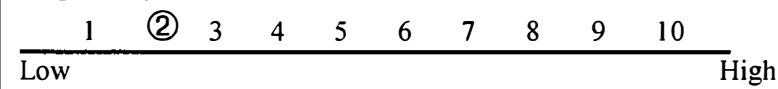

Ecological Risk

\begin{tabular}{|c|c|c|c|c|c|c|c|c|c|}
\hline 1 & (2) & 3 & 4 & 5 & 6 & 7 & 8 & 9 & 10 \\
\hline
\end{tabular}

- $\quad$ Electrified HSR and maglev systems are relatively environmentally friendly compared with conventional trains and aircraft. Elevating tracks reduces ecological risk further.

\section{Key Federal Actions}

- Establish an RD\&D program for next-generation maglev technology in the United States. Identify and fund supporting technologies. Use the existing MOU with DOT.

- Establish a program to demonstrate existing technology through two or three revenue-earning pilot projects, each of about 40 miles.

- $\quad$ Provide leadership for the formation of public/private partnerships to finance and operate such projects. Incorporate programs into NEXTEA legislation. Request and support legislative actions to appropriate funding for programs. 



\title{
Energy-Efficient Technologies
}

\author{
4. Agriculture and Forestry
}

4.1 Conversion of Biomass to Bioproducts

4.2 Advanced Agriculture Systems

4.3 Plant/crop Engineering 


\subsection{CONVERSION OF BIOMASS TO BIOPRODUCTS}

\section{Technology Description}

Annual crops, perennials, and short-rotation woody species represent plant/crop-based resources that are a renewable source material in the food, feed, and fiber industries. The current market of biobased materials exceeds 85 million tons/year. The use of such biobased processes to produce materials and products provides a modest but significant reduction in GHGs by two measurable effects. First, lowering the use of petroleum-based feedstocks reduces the inherent emissions associated with these feedstocks, since biobased products are synthesized from ambient $\mathrm{CO}_{2}$ currently in our atmosphere. Second, the use of biobased processes has shown some potential for emitting roughly the same, or in some cases fewer, GHG emissions as petroleum-based processes.

\section{System Concepts}

- The United States has significant forestry or plant/crop-based resources, including forestry, rangeland, and a highly productive agricultural system. In the past 50 years, these resources have been largely focused toward food, feed, and fiber production.

- Use of forestry/crop resources for energy, or as basic building blocks for industrial production, has been limited because of a poor fit with the current hydrocarbon processing system. However, this is not an either/or system choice.

- The concept being proposed involves developing manufacturing platforms employing the uniqueness of biobased materials to provide society's materials needs or integrated manufacturing platforms that overcome the poor fit scenario described earlier.

Representative Technologies

- New biotechnologies for plant growth and production and biotechnology and benign chemical synthesis for conversion of biomass materials into products.

Technology Status/Applications

- Corn wet-mills, pulping operations, and dimensional lumber facilities represent a significant segment of the industrial community. All are cost-effective. What is not cost-effective or is poorly implemented is the development of broader economic platforms based on forestry/cropderived inputs. DOE and other federal agencies have been applying their technologies to the development of these new manufacturing options.

\section{Current Research, Development, and Demonstration}

\section{RD\&D Goals}

- It is more suitable in this pathway to outline directional goals (i.e., goals that outline a direction rather than an end point).

- To implement at least $10 \%$ of basic chemical building blocks arising from plant-derived renewables by 2020 with development concepts in place to increase this to $50 \%$ by 2050 .

- To develop economically viable manufacturing platforms for selected products (such as plastics, textiles, cosmetics) by 2020 using plantbased (crop, forestry, processing) systems that produce renewable feedstocks.

- To build collaborative partnerships among industrial stakeholders, growers, producers, academia, and federal/state governments to develop small- to large-scale commercial applications such that the distinction between processing biobased materials for food, feed, and fiber and the manufacturing of basic materials will begin to disappear.

\section{RD\&D Challenges}

- There are three major challenges in establishing these biobased manufacturing platforms:

- Using forestry/agriculture-based inputs in modified but existing processing systems.

- Developing new or modified forestry/agriculture-based plant/crop production systems to provide desirable feedstocks.

- Integrating these approaches to create optimized systems that generate these new economic platforms based on the use of biomass-derived inputs.

- What is needed is a larger suite of viable examples to demonstrate the potential for a renewables-based approach. There is simply not enough available technology to establish an even larger role of forestry/agriculture-based products and materials, especially in benign organic syntheses, biotechnology, and new materials development.

\section{RD\&D Activities}

- DOE's OIT is leading the effort in producing biobased products. The FY 1996 and 1997 budgets were about $\$ 8.4 \mathrm{M}$ and $\$ 3 \mathrm{M}$, respectively. The USDA's Agricultural Research Service (ARS) and the Cooperative State Research Extension and Education Service (CSREES) also are engaged in similar work. The ARS budgets in FY 1996 and FY 1997 have been about \$20M/year (exclusive of their effort in ethanol). The CSREES effort in FY 1996 and FY 1997 spent about \$3.5M/year. Industry is sponsoring work. Although the exact numbers are not available, two examples provide some idea of magnitude. Genencor and Eastman Chemicals are pursuing a $\$ 30 \mathrm{M} / 5$ year 50:50 cost-shared project with the NIST/ATP program to develop biocatalysts for chemical processing. DuPont has announced an effort in biological production of 1,3 propanediol from corn syrup as a precursor to new polymers. This is one of several efforts by industry.

\section{Recent Success}

- Citric acid is an acidulent used in food processing and was produced by fermentation using paraffin oils from petrochemical sources until the 1980s. Currently, this 300 million lb/year commodity chemical is produced solely and economically from fermentation of corn syrup. The rayon fabric and cellophane packaging market is based solely on wood and is commercially viable. Recently, the production of high-fructose corn syrup from corn starch for food sweeteners has become a commodity market with more than 12 billion lb produced annually. 
- The current, annual U.S. production market for biobased products and materials is more than 85 million tons. At an average value of $\$ 0.25-0.50 / \mathrm{lb}$, the total annual sales are between $\$ 45 \mathrm{~B}$ and $\$ 85 \mathrm{~B}$. The major manufacturers are the pulp/paper, grain processing, and food processing industries. The concept is the development of new manufacturing platforms compatible with the market drivers, and, where appropriate, integrated with existing chemical, forestry, and agricultural manufacturing operations. There is no attempt to replace efficient hydrocarbon processing, but rather to develop alternative processing capabilities to establish new manufacturing platforms. This involves a paradigm shift, not a battle over competing technologies. Critical challenges to widespread deployment are noted under RD\&D challenges.

Potential Benefits and Costs

\section{Carbon Reductions}

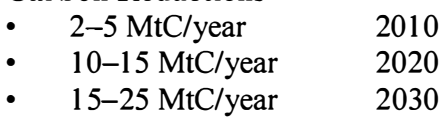

RD\&D Expenditures

- Federal RD\&D funding requirements for this pathway: \$25-50M/year through 2010

- $\quad \$ 50-75 \mathrm{M} /$ year through 2020

- \$10-15M/year through 2030 (should be essentially market driven by then).

- Because of the limited number of examples to demonstrate commercial viability, substantial federal funds are necessary through the year 2020.

Market

- The major contributors to the carbon reduction values noted are reductions related to the displacement of petroleum typically used to manufacture products. In addition, if cogeneration of energy were employed in biomass-based manufacturing analogous to the pulping industry's use of biomass as a fuel, additional energy savings could be achieved. These cannot be calculated exactly but can be estimated. For example, processing energy for chemicals amounts to about 3 quads of energy. If biobased materials processing involved cogeneration of power analogous to the forestry industry $(50 \%)$ on $10 \%$ of the chemicals volume, then purchased energy could be reduced by about 0.15 quads, reducing net GHG emissions.

Nonenergy Benefits and Costs

- This technology involves developing new manufacturing.platforms and not displacing petrochemical platforms. It would lead to development of a new mode of operation within existing infrastructures or development of altogether new infrastructures.

\section{Risk Factors}

\begin{tabular}{|lllllllllll}
\multicolumn{2}{l}{ Technical Risk } & & & & & & & & & \\
1 & 2 & 3 & 4 & 5 & 6 & 7 & 8 & 9 & 10 & High
\end{tabular}

- Much technical information is available, but there are limited numbers of applied technologies.

Commercial Risk

\begin{tabular}{llllllllllll}
1 & 2 & 3 & 4 & 5 & 6 & 7 & 8 & 9 & 10 & \\
\hline Low & & & & & & & & & & & High
\end{tabular}

- Very limited number of examples to demonstrate full commercial viability.

Ecological Risk

\begin{tabular}{lllllllllll}
1 & 2 & (3) & 4 & 5 & 6 & 7 & 8 & 9 & 10 & \\
\hline Low & & & & & & & & & &
\end{tabular}

- Technologies for conversion of biomass to products generally produce fewer negative environmental impacts than do traditional production processes.
Human Health Risk

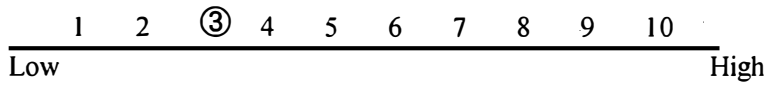

- Farming and agriculture have low human health risks. Chemicals production has slightly higher risk factors.

Economic Risk

\begin{tabular}{lllllllllll}
1 & 2 & (3) & 4 & 5 & 6 & 7 & 8 & 9 & 10 & \\
\hline Low & & & & & & & & & &
\end{tabular}

- If successful, the technologies would strengthen the economy and create American jobs.

- Generally perceived as a "green technology" by the public.

Regulatory Risk

\begin{tabular}{lllllllllll}
1 & 2 & 3 & 4 & 5 & 6 & 7 & 8 & 9 & 10 & \\
\hline Low & & & & & & & & & &
\end{tabular}

- $\quad$ Qualifying bioproducts from biomass for use in commercial manufacturing carries some regulatory risk, but the industries involved are well versed in this area.

\section{Key Federal Actions}

- Establish a federal RD\&D program to develop improved conversion technologies for agricultural/forestry products, and develop viable and economic examples of biobased-product manufacturing technologies.

* Establish stronger interagency and federal agency-industry partnerships with increased involvement with suppliers of feedstocks represented by professional agriculture and forestry societies, cooperatives, and ecological interest groups. 


\section{Technology Description}

Advanced agriculture systems enable a process of collecting and using increasingly detailed site-specific information in conjunction with traditional farm management tools such as agronomy, machinery, finance, and marketing for accessing and applying the best available information to better manage individual farming operations. In addition, these systems provide for improved understanding, control, and, perhaps, manipulation of microbial processes at plant roots and in soils to control flows of carbon and nitrogen. These systems provide an integrated capability to improve environmental quality while enhancing economic productivity by increasing energy efficiency, optimizing fertilizer and other chemical applications, and conserving soil and water resources.

\section{System Concepts}

- Global positioning infrastructure and remote and in situ sensors for soil, crop, and microclimate characterization.

- Cropping system models, data and information analysis, and management tools.

- Variable rate application control systems and smart materials for prescription delivery.

- Biological and chemical methods for manipulating microbial processes to increase efficiency of nutrient uptake and to suppress GHG emissions.

\section{Representative Technologies}

- Global positioning satellites and ground systems, and satellite- and aircraft-based remote and in situ electrical, magnetic, optical, chemical, and biological sensors.

- Advanced artificial intelligence and information networking technologies; autonomous control and robotics systems; and soil, crop, moisture, pest, and microclimate responsive (smart) materials.

- Biological and chemical methods for microbial process manipulation.

Technology Status/Applications

- Many first-generation precision agriculture technologies are available for application and are in use on $\sim 10 \%$ of U.S. farms.

- Information management and networking tools; rapid soil characterization sensors; selected crop stress, yield, and quality sensors; and a systematic integration of all technologies for all major cropping systems are not yet at technical performance levels required for application.

- Strong understanding of soil microbes and relationships exists in the agriculture, energy, and university research community.

- Capability exists to develop smart materials and methods for microbial manipulation.

\section{RD\&D Goals}

- Technologies that improve production efficiencies and reduce energy consumption by $4 \%$ by $2010,16 \%$ by 2020 , and $39 \%$ by 2030 .

- Remote and field-deployed sensors/monitors and information management systems for accurate, real-time monitoring and analysis of crops, soils, water, fertilizer, and agricultural chemicals use/efficiency to meet the fertilizer and energy reduction goals.

- Smart materials for prescription release: four to five main crops by 2010 ( 10 chemicals); 20 crops by 2020 ; and all important crops by 2030 .

- Advanced fertilizers and technologies to improve fertilizer efficiency and reduce nitrogen fertilizer inputs by $20 \%$ by 2020 .

- Methods of manipulating microbial processes to materially increase the efficiency of nitrogen uptake and suppress $\mathrm{CO}_{2}$ emissions.

- Initial systems models and prototype operation by 2000 on selected cropping systems that are major contributors to U.S. food and fiber use and export.

- Deployment of first-generation integrated system models, technology, and supporting education and extension infrastructure by 2002.

- Complete transition of first-generation system development to the private sector by 2004 .

\section{RD\&D Challenges}

- $\quad$ Site-specific agriculture in general requires advances in rapid, low-cost, and accurate soil nutrient and physical property characterization; real-time crop water need characterization; real-time crop yield and quality characterization; real-time insect and pest infestation characterization; autonomous control systems; and integrated physiological model and massive data/information management systems.

- Smart materials that will release chemicals based on soil and crop status depend on modest breakthroughs in materials technology.

- Improved understanding of specific soil microbial processes is required to support development of methods for manipulation.

- Models that represent accurate understanding of plant physiology must be coupled with models that represent soil processes such as decomposition, nutrient cycling, and water storage and flows to understand how ecosystems respond to atmospheric change.

- Detailed and simultaneous examination of biogeochemical reactions that occur in near-surface groundwater is required to improve understanding of nutrient cycling, GHG concentration, and degradation of contaminants.

- Improved understanding of the pathway by which nitrate is reduced to gaseous nitrogen is required to support scaling of emissions estimates associated with the nitrogen cycle.

- The microecological consequences of expanding carbon stock in soils resulting from suppressing $\mathrm{CO}_{2}$ emissions are unknown or uncertain.

\section{RD\&D Activities}

- Complementary efforts are under way in both public and private sectors.

- Sponsors include USDA, DOE, NASA, universities, state agencies, commodity groups, and sensor and satellite developers; the principal funding comes from USDA.

- Current funding level provided by U.S. government sponsors is estimated at $\$ 40 \mathrm{M}$.

\section{Recent Success}

- High-resolution satellite imagery can be used to identify stress and disease in some crops at 1-to-2 m resolution.

- Research programs have related reflectance spectra to disease or nutrient status.

- Technology was developed to coextrude recyclable plastics with ammonium polyphosphate for continuous ammonium release in the presence of water.

- Research programs have demonstrated performance of microbially encapsulated fertilizer.

- Rf-link deployable field sensors exist for ground moisture monitoring.

- Commercial sensors exist for $\mathrm{CO}_{2}$ and ammonia gas monitoring and for accurate yield monitoring of grain and tuber crops. 


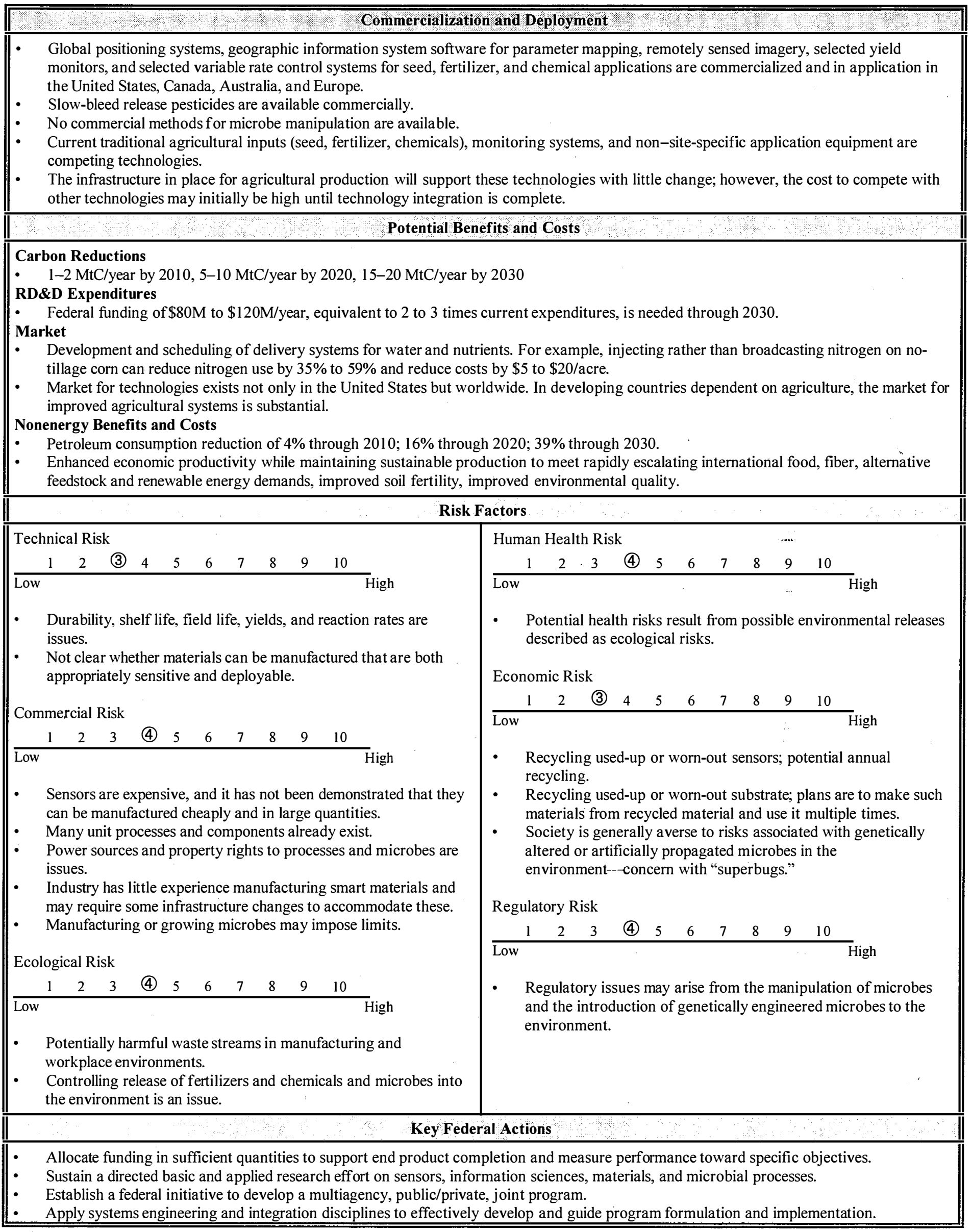




\subsection{PLANT/CROP ENGINEERING}

Technology Description

Plant/crop engineering involves improving plant productivity and utility in capturing solar energy and converting it to chemical energy through traditional and functional genomics; genetic engineering; and developing transgenic plants for the purposes of increased biomass production, increased carbon fixation, improved nitrogen utilization and recycling, and biomass conversion technologies. DOE has invested significantly in understanding energy conversion technologies, hence bringing to bear a significant resource to this most basic of energy storage and conversion needs.

\section{System Concepts}

- Plant genomics: development of genomic maps for detailed studies of genomes, genes, and genetic processes. Traditional genomics includes gene mapping, molecular cloning, large scale DNA sequencing, data management and computational analysis. Plant genomics is necessary for the development of new or improved crop and forest species that promote sustainability and profitability of plant production and improvement of quality.

- Photosynthetic efficiency: physiological and genetic control of photosynthetic pathways for efficient sunlight capture and conversion to biomass.

- Nitrogen fixation and metabolism: genetic control of nitrogen cycling and nutrient use efficiency. Technologies that optimize the efficiency of nitrogen use by plants to ensure site sustainability while minimizing losses of nitrous oxide from soil.

- Functional genomics for high-performance plants: using the tools of traditional genomics to focus on the structure and function of novel gene sequences from a variety of organisms. For example, functional genomics may employ biomass genotypes from extreme environments or biomass genotypes that express novel characteristics to identify and isolate novel gene sequences.

- Gene expression, compartmentalization, and timing: once identified, desirable genes must be introduced successfully into target biomass species and expressed (i.e., make their product). For these genes to be useful in carbon management, technologies need to routinely accomplish stable gene insertion into host genomes, including desirable biomass species that may be difficult to transform, and to prove reliable the expression of these genes over time and in diverse environments.

- Plant engineering for end use: development of new or modified plants that will enable or assist the development of breakthrough biomass conversion technologies and allow plants to serve as biological factories for production of chemicals, enzymes, materials, and fuels.

Representative Technologies

- Use of plant assembly fundamentals to create fast-growing tree crops that produce high-strength structural wood and composites for use in construction.

- High-resolution mapping with techniques such as amplified fragment length polymorphism analysis.

- Genetic transformation: the use of cellular and molecular techniques to insert a single target gene into the DNA of an organism.

- In situ hybridization to determine the location of DNA sequences and genes on chromosomes.

Technology Status/Applications

- With more than 2100 field trials of crops under way in 1995/1996, the technology is obviously viable. However, the time necessary to develop a new plant with desired traits needs to be reduced to bring to bear the full effect of this technology.

- $\quad$ Genetically engineered species comprised nearly $20 \%$ of the cotton crop.

\section{Current Research, Development, and Demonstration}

\section{RD\&D Goals}

- Increasing the ability to express cloned genes by a factor of 10 will reduce cycle time for development of new transgenic field crops from 5-10 years to $2-5$ years and the cycle time for forestry cultivars from 7-15 years to $3-7$ years.

- Increasing the number of completed genome maps of selected plant species from zero to five in 10 years.

\section{RD\&D Challenges}

- Plant genomics; photosynthetic efficiency improvements; nitrogen fixation and metabolism; functional genomics for high-performance plants; gene expression (compartmentalization/timing); and plant engineering for end use. Using high-resolution analytical techniques such as DOE's Advanced Synchrotron Light Source. Employing the potential of advanced sensor technology to correlate performance properties of agriculture/forestry materials with genetic and structural composition (this is being evaluated now with some success by DOE scientists).

\section{RD\&D Activities}

- $\quad$ DOE spends about $\$ 25 \mathrm{M}$ annually on basic plant engineering and about $\$ 8 \mathrm{M}$ annually on sustainable forestry and biomass feedstock development. USDA's budget in their Cooperative State Research Extension and Education Service spent \$57M in 1996/1997 with an additional $\$ 11 \mathrm{M}$ in global change R\&D. The Agricultural Research Service spent about $\$ 30 \mathrm{M}$.

\section{Recent Success}

- Transgenic cotton resistant to the boll weevil comprised 2.5 million acres of 14 million acres planted in 1997 . The following genetic traits have been engineered into plants that are now reaching the commercial market: insect, virus and herbicide resistance, specialty oils, slower ripening, and increased pectin. 
- Fractions of major crops (15-20\% of soybean, cotton, corn) are being planted with transgenic seeds. Industrial funding is significant, with a seed market sales projection of $\$ 6$ billion in 2005 . Increased use of both conventional and hybrid plants (alfalfa, wood wastes, bagasse, willow), for energy production is nearing commercial reality. Forestry and agricultural crops bred for energy use are currently being evaluated. Major seed and agrichemical companies are involved in agricultural systems along with USDA and farmers. Forestry issues are being studied by DOE and USDA. A critical challenge to widespread deployment is economics. The freedom-to-farm capability may drive more development in plant/crop engineering.

\section{Potential Benefits and Costs}

\section{Carbon Reductions}

- Because of the strong interdependency of plant engineering technologies, biomass conversion technologies, and advanced agricultural systems, carbon reductions are incorporated into reductions reported for biomass conversion technologies and advanced agricultural systems pathways.
RD\&D Expenditures

- Most R\&D activities will require federal funds, especially initially until sufficient field data exists to verify technology.

- $\quad$ Current annual federal expenditures exceed $\$ 130 \mathrm{M}$.

- Annual federal RD\&D budget required for this pathway: to 2020, $\$ 155 \mathrm{M} /$ year; 2020 to $2030, \$ 140 \mathrm{M} /$ year.

Market

- For energy production derived from biomass, the current 2-4 quads of energy produced could be impacted by a reasonable fraction with plants engineered for energy production uses (increase in lignin, decrease in alkali salts, etc.). This displaces currently heavy coal dependence. For biomass to bioproducts, the impact would be to reduce oil imports needed to synthesize organic chemicals. The realistic goal is a displacement of about 1 quad of energy embodied in petroleum feedstocks.

Nonenergy Benefits and Costs

- Development of crop plants with improved properties such as nutritional quality and extended storage life.

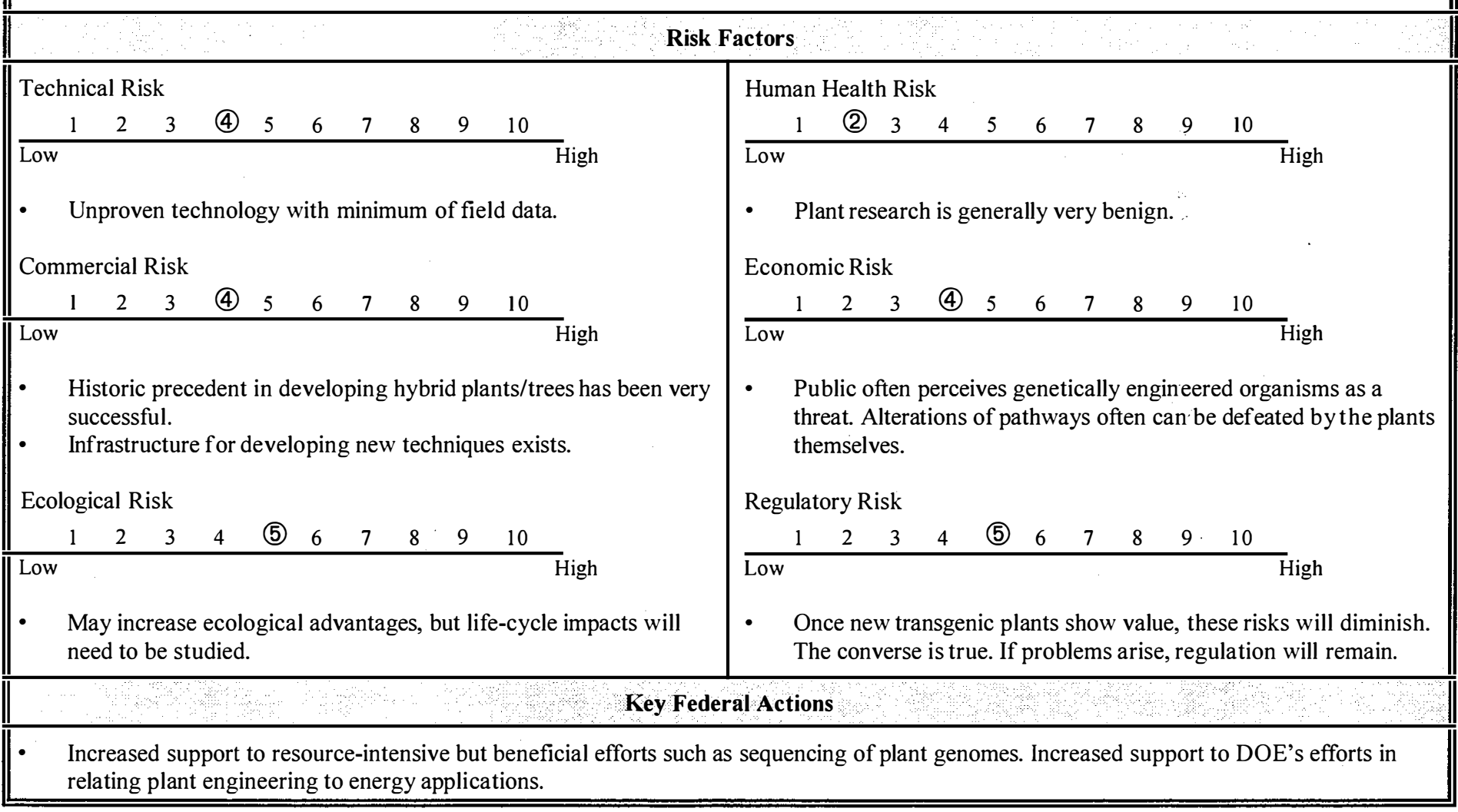





\section{Clean Energy Technologies}

\section{Fossil Resource Development}

5.1 Energy Efficiency for Crude Oil Refining

5.2 Natural Gas to Liquids

5.3 Increased Natural Gas Production

5.4 Co-Production with Integrated Gasification Combined Cycle

5.5 Carbon Dioxide for Improved Oil and Gas Recovery 


\subsection{ENERGY EFFICIENCY FOR CRUDE OIL REFINING}

\section{Technology Description}

Refining of petroleum crude oil remains a dominant and strategic industry for the U.S. economy. Refining involves separating and converting crude oil hydrocarbon stocks to produce transportation fuels such as gasoline, kerosene, and jet fuel and by-product fuels such as petroleum coke. Separation and conversion processes used in refineries are energy intensive; the source of energy is often the combustion of light hydrocarbon gases that produce $\mathrm{CO}_{2}$. Fugitive emissions of light hydrocarbon gases from refining operations are another source of GHGs.

\section{System Concepts}

- Hydrocarbon use can be made more efficient by increasing the efficiency of converting crude oil to transportation fuels and/or separating and using valuable components of refining off-gases (light hydrocarbons). The former leads to higher yields, and the latter prevents useful off-gases from entering a combustion stream.

- Reducing the amount of low-value product (such as fuel grade coke) increases the efficiency of the refining process.

- Several refining processes produce off-gases that have value if they can be separated.

Representative Technologies

- Catalysis improvements

- Advanced separation methods (membranes)

- Mild pretreatment processes

- Refinery process optimization and advanced sensors

Technology Status/Applications

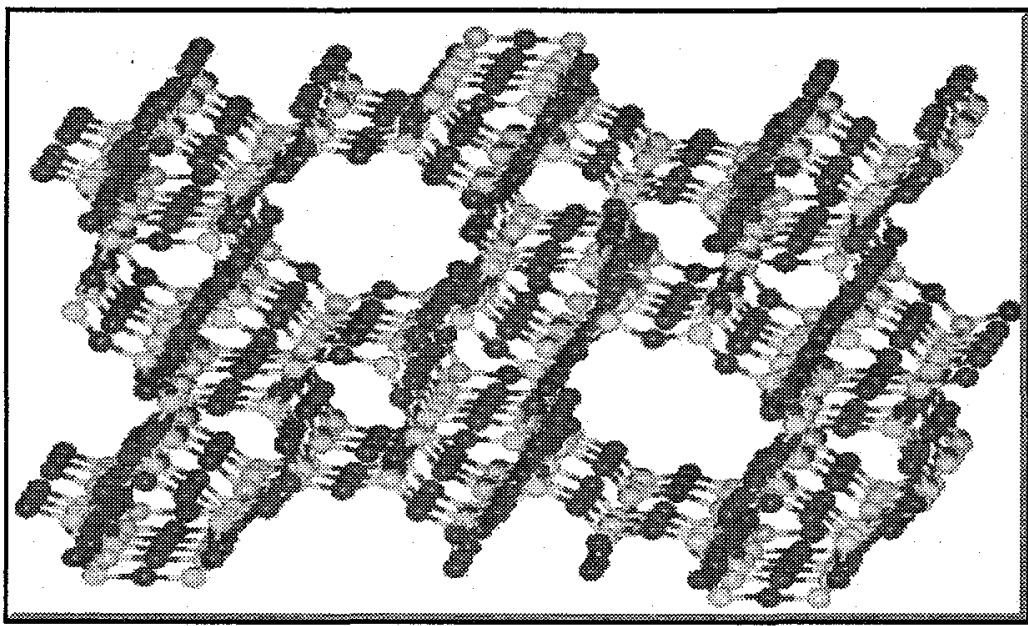

Zeolite ZSM-5 catalyst structure

- Energy-intensive distillation and other

conventional separation processes are still the workhorses of the refinery. However, these suffer in separation efficiency and downtime.

- Energy-intensive steam reforming of methane to synthesis gas followed by methanol synthesis is still uneconomical.

- Heavy oil upgrading process efficiency has plateaued.

- Optimization modeling technology for refining systems is moving toward technologies such as reactive multiphase flow simulations.

\section{RD\&D Goals}

For the near term:

- Demonstrate new refinery catalysts with improved efficiencies and selectivities.

- Test fugitive gas emission identification techniques (tracers and backscatter imaging equipment) in refinery settings. By 2003:

- Demonstrate on a pilot scale that advanced inorganic membranes can be used to separate and use refinery off-gases.

- Demonstrate on a pilot scale that heavy oil processing can be improved by pretreating to remove impurities before catalytic upgrading

- Laboratory test short-contact-time reactors with higher methane conversion and greater carbon selectivity. By 2008:

- Demonstrate through simulations how a combination of advanced sensors, detailed modeling, and process optimization could lower emissions and improve energy efficiency.

\section{RD\&D Challenges}

- To effectively use off-gases, advanced separation methods must be developed. Inorganic membranes offer promise in this area. Membranes made from zeolites, sol-gels, aerogels and combined zeolites-sol-gels offer the potential of tailor-made separation materials (i.e., hydrogen from nitrogen or isolation of methane). With the proper inclusion of different types of metals in these porous materials, olefins from alkanes could also be separated.

- Specific target catalysis areas are alkylation processes, catalytic cracking, heavy oil cracking, and hydrocracking.

- Up to $50 \%$ of heavy oil is of little value to refiners because the nondistillable portion is of poor quality and is difficult to convert to transportation fuels. This material is often converted to low-grade coke. Pretreatment conversion technologies would allow more of the heavy oil to be converted to high-value, more efficiently burning transportation fuels.

- In the case of methane, for full utilization, separation must be followed by a conversion process. This conversion process would serve the same purpose as with natural gas, which is to make liquids that can be handled in a similar manner as refinery distillates.

\section{RD\&D Activities}

- Supporting efforts are sponsored primarily by DOE/FE with some assistance from EE and ER. Funding is typically less than $\$ 10 \mathrm{M} / \mathrm{year}$.

- Newer technology for methane liquifaction involves partial oxidation of methane to synthesis gas that removes the thermodynamic limitations of steam reforming. Partial oxidation followed by methanol synthesis represents a potential solution that is being researched.

- It is estimated that a methane conversion efficiency of greater than $30 \%$ with a carbon selectivity of greater than $85 \%$ is needed. These schemes will require short-contact-time reactors at elevated temperatures, some with novel methods of heating and quenching. These shortcontact-time reactors will involve bed configurations in which the energy to initiate the reactions is supplied to the catalyst by chemical, radio frequency, or microwave energy. 
- The feasibility of nitrogen-methane separation with tailored zeolite materials on glass substrates derived through the sol-gel manufacturing process has been demonstrated in the laboratory.

- The application of barrier membrane technology to separate hydrogen in several different refinery streams is being investigated. The benefit of this technology is a very-high-throughput membrane that can operate at process temperature and pressure with high separation factors.

\section{Commercialization and Deployment}

- Catalysis technology is at various levels of development, from experimental to commercial.

- With modern simulation and analysis technology, better knowledge of unit operations and integrated processes offers the opportunity for true process optimization. The scales run the gamut from molecular level simulations to continuum level analysis to systems level analysis. With improved process sensors and controls, lower emissions and more efficient energy usage can be achieved.

- Tracers can be developed to identify fugitive emissions of methane from refineries and pipelines. Backscatter absorption gas imaging and light detection and ranging (LIDAR) technologies have proved effective in imaging methane plumes at remote distances and ppm concentrations. Recent improvements in LIDAR systems for national security missions should be applicable to fugitive gases as well.

\section{Potential Benefits and Costs}

\section{Carbon Reductions}

- The petroleum refining industry consumes 5.9 quads per year, $80 \%$ of which results from burning fuels in refinery heaters and boilers.

- Improved off-gas separations, more selective catalysts, and effective methane capture could cut GHG emissions 10 to $20 \%$ in a decade. This represents a potential carbon reduction range of 8.5 to $17 \mathrm{MtC} /$ year.

- Carbon reduction estimates from this pathway are 2-4 MtC in 2010,3-6 MtC in 2020, and 4-8 MtC in 2030.

R\&D Expenditures

- Current DOE RD\&D funding for this pathway is approximately $\$ 10 \mathrm{M} /$ year.

- Annual DOE RD\&D budget required to generate the estimated carbon reductions is \$15M/year, 2000-2030.

Market

- This technology pathway is applicable to the entire refining industry.

Nonenergy Benefits and Costs

- The United States is steadily losing refining capacity. Only new technology that addresses all environmental concerns will stabilize this trend.

- The United States produces much heavy oil. An improved refining process could add $\$ 1$ to $\$ 2 / b b l$ to the value of this oil.

\section{Risk Factors}

\begin{tabular}{||lllllllllll}
\hline \multicolumn{1}{||c}{ Technical Risk } & & & & & & & & & & \\
1 & 2 & 3 & 4 & 5 & 6 & 7 & 8 & 9 & 10 & \\
\hline \hline Low & & & & & & & & &
\end{tabular}

Human Health Risk

- Technologies have been demonstrated at small scale. The scale-up challenge cannot be minimized.

Commercial Risk

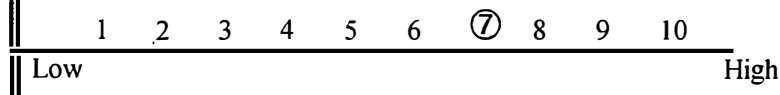

- Refineries have been leaving the United States because of environmental cleanup costs.

Ecological Risk

\begin{tabular}{llllllllll}
1 & 2 & (3) & 4 & 5 & 6 & 7 & 8 & 9 & 10 \\
\hline Low & & & & & & & & &
\end{tabular}

- The technology could be developed and implemented to make crude oil refining and processing facilities consistent with environmental regulations.

\section{Key Federal Actions}

- The federal government could work with the petroleum industry to allow the refining of crude oil to rebound as a high-technology, clean, strategic industry for the U.S. economy.

- Collaborative industry/government/university research efforts on catalysis, membrane separations, heavy crude upgrading, and process efficiency improvements could be increased. 


\subsection{NATURAL GAS TO LIQUIDS}

\section{Technology Description}

Conversion of natural gas to liquids (GTL) has shown considerable advancement in the past 5 years. Novel processes for the physical conversion of gas to liquefied natural gas (LNG) in remote areas have been identified and show good potential at a demonstration level. In addition, recent studies have indicated that diesel fuels produced from natural gas are significantly less polluting than petroleum derived diesel. Economical conversion of gas streams to liquid products such as fuels and commodity chemicals will allow full use of domestic natural gas supplies while addressing the issue of GHGs.

\section{System Concepts}

- $\quad$ LNG production: Thermoacoustic natural gas liquefaction produces $L N G$ at lower costs than conventional technology.

- Natural gas diesel fuels: Diesel fuel derived from natural gas far exceeds conventional diesel fuels in reducing emissions including hydrocarbons, carbon oxides, $\mathrm{NO}_{x}$, and particulates.

\section{Representative Technologies}

- Diesel fuels produced via Fischer-Tropsch conversion of synthesis gas have shown low emissions and good efficiency in engine tests.

- In the case of LNG production, process uses direct gas burning to generate sound waves to drive an orifice pulse tube refrigerator. Does not require the use of electricity.

\section{Technology Status/Applications}

- $\quad$ Production of LNG from natural gas employing thermoacoustics has been demonstrated at $100 \mathrm{gal} / \mathrm{day}$.

- Diesel fuels produced via conventional synthesis gas technology presently have low yields.

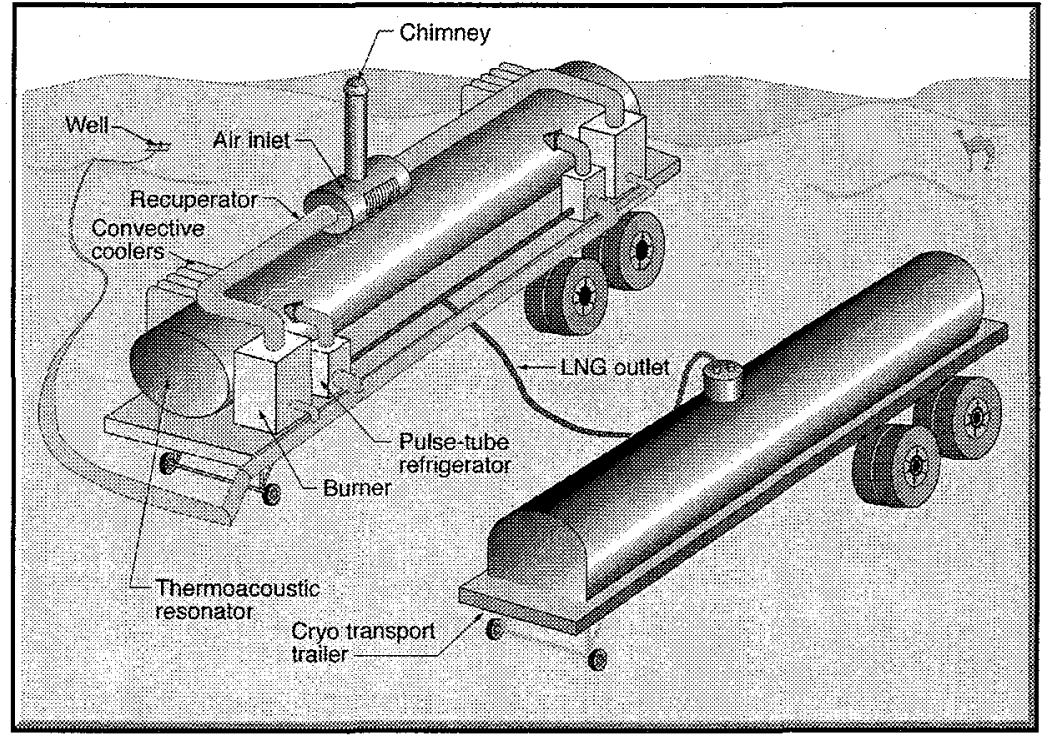

Natural gas liquifier

\section{Current Research, Development, and Demonstration}

\section{RD\&D Goals}

By 2000:

- Demonstrate $500 \mathrm{gal} /$ day production of LNG from natural gas using thermoacoustic processes.

- Identify new catalyst compositions to effectively promote natural gas diesel fuel production. By 2004:

- Scale up technologies to commercial levels.

- Demonstrate natural gas diesel fuel production at a commercial size.

- Optimize an integrated process using ion transport membranes for conversion of natural gas to synthesis gas, followed by synthesis gas conversion to transportation fuels, and demonstrate natural gas diesel fuel production at a commercial size.

By 2011:

- Produce $200,000-500,000 \mathrm{bbl} /$ day of diesel fuel from remote natural gas sources.

\section{RD\&D Challenges}

- Research and technology for process improvements are needed to

- improve modeling of the complex fluid dynamics and nonequilibrium chemistry of the processes to improve process control and process optimization for a variety of input natural gas compositions

- develop relevant process sensors for automated process control and optimization

- provide scale design for commercial implementation

- Catalyst development: Identifying catalytic materials.that selectively promote high-cetane paraffin formation from synthesis gas is a key for producing diesel fuel from natural gas.

\section{RD\&D Activities}

- DOE is actively promoting and funding materials, catalyst, and process development for the direct and indirect conversion of methane.

- Industry has targeted natural gas conversion, to both liquid fuels and LNG, as a major research area.

- Significant government/industry research efforts are under way to more effectively convert natural gas to synthesis gas.

\section{Recent Success}

- Research over the past 10 years has shown significant improvements in all areas of methane conversion.

- Recent reports indicate that improved yields of high-quality diesel fuels from natural gas can be obtained. 
- Examples of commercial GTL processes include Mobil's process of converting synthesis gas to methanol followed by conversion to gasoline (1985), Sasol's slurry phase distillate (Fischer-Tropsch) process (1992), Shell's middle distillate synthesis process (1993). Recently, Sasol signed a memorandum of understanding with Qatar General Petroleum Corp. and Phillips Petroleum to build a 20,000 bbl/day plant (FisherTropsch) in Qatar.

- A team headed by Air Products was selected by DOE to head an $\$ 84 \mathrm{M}$ research program to develop membrane technology for synthesis gas production.

\section{Potential Benefits and Costs}

\section{Carbon Reductions}

- GTL provides an effective way to use methane, a GHG.

- Estimates have placed the GHG reduction potential of eliminated leaks at $12 \mathrm{MtC} /$ year in the United States and approximately $300 \mathrm{MtC} / y e a r$ if applied to stop leaks from pipelines in Russia.

- Carbon reduction estimates are 2--4 MtC in 2010, 5-10 MtC in 2020, and 10-15 MtC in 2030.

\section{Market}

- About 2,000-5,000 Mcf per day of natural gas is used to produce $200,000-500,000 \mathrm{bbl} /$ day of high-quality diesel fuel.

- Approximately 80,000 new jobs are created for each 1 million bbl/day of diesel fuel.

- Existing liquid pipeline infrastructure can be used for transportation and distribution.

- $\quad$ Spinoff for LNG includes use by gas utilities for peak demand spikes and natural gas vehicle gas stations.

Nonenergy Benefits and Costs

- Costs: Thermoacoustic LNG production-additional $\$ 500 \mathrm{~K} /$ year, 5 years, total $=\$ 2.5 \mathrm{M}$; diesel fuel production (catalyst development)_additional $\$ 1 \mathrm{M} /$ year, 6 years, total $=\$ 6 \mathrm{M}$; fuel testing in pilot-scale facility, emission impact analysis and optimization, additional $\$ 1 \mathrm{M} /$ year, 8 years $=\$ 8 \mathrm{M}$.

- $\quad$ Both natural gas to fuels and LNG will reduce dependence on imported oil.

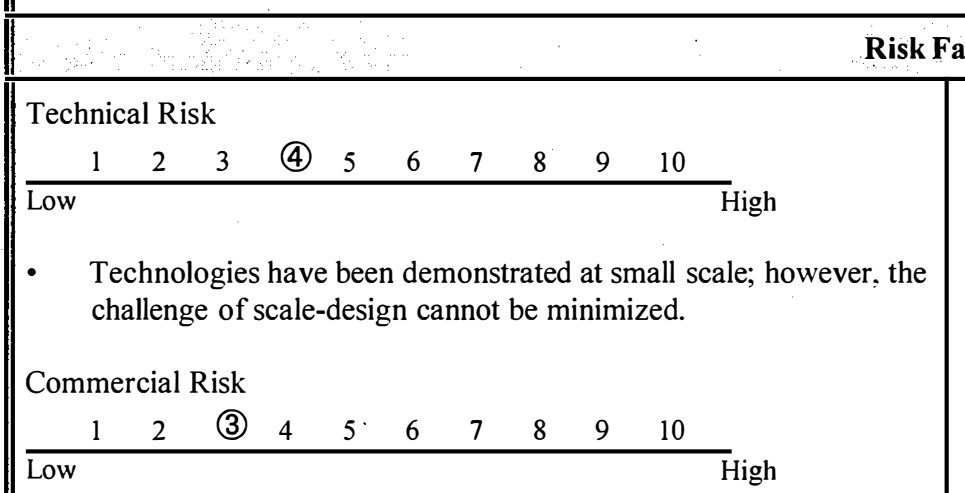

- Liquid hydrocarbon fuels have existing markets, facilities, and infrastructure for transportation and utilization; however, high capital cost facilities may be required.

Ecological Risk

\begin{tabular}{llllllllll}
1 & (2) & 3 & 4 & 5 & 6 & 7 & 8 & 9 & 10 \\
\hline Low & & & & & & & & &
\end{tabular}

- Technologies for construction and operation of oil and gas facilities are well developed. Fuels produced by these processes are clean burning with very low sulfur and nitrogen compound emissions.

\section{$\$ 5 \mathrm{M} /$ year.}

- Required federal funding: 1.5 times the current level, or $\$ 8 \mathrm{M} /$ year through 2030.

\section{RD\&D Expenditures}

\section{isk Factors}

Human Health Risk

\begin{tabular}{|c|c|c|c|c|c|c|c|c|c|}
\hline 1 & (2) & 3 & 4 & 5 & 6 & 7 & 8 & 9 & 10 \\
\hline
\end{tabular}

- Most of the technology for producing and handling natural gas and liquid hydrocarbon products is available, is well understood, and presents no major new risks.

Economic Risk

\begin{tabular}{|c|c|c|c|c|c|c|c|c|c|}
\hline 1 & (2) & 3 & 4 & 5 & 6 & 7 & 8 & 9 & 10 \\
\hline
\end{tabular}

- None currently identified.

Regulatory Risk

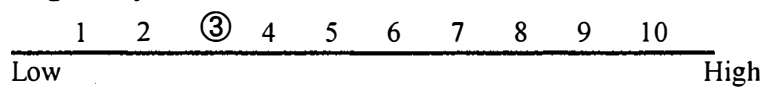

\section{Key Federal Actions}

- Collaborative industry/government research efforts could be developed to identify catalysts and processes to economically convert natural gas to liquid diesel fuels.

- More federal funding is needed to begin to address the broad range of technical issues related to commercial scale up, remote construction, and operations.

- A federal mandate to reduce emissions through fuel switches would accelerate this pathway.

- Significant U.S. and international activity is expected in both the GTL and LNG areas through the year 2010 and beyond. There is opportunity for the United States to be the leader in GTL and LNG technologies and market the technology abroad. 
Technology Description

Natural gas as a fuel has a fundamental advantage over oil and coal in terms of reducing carbon emissions because of its lower carbon-tohydrogen ratio. The United States has an abundant natural gas supply and needs only the development of technology to make it available to displace oil and coal from the power generation and transportation markets. This can be accomplished in the near term through secondary gas recovery (230 Tcf); in the mid-term through low-permeability formation development (500 Tcf), offshore (100 Tcf), and coalbed methane(400 Tcf); and in the long term by exploiting currently untapped methane hydrates (2700 Tcf) and deep source gas (3000 Tcf). Only a small success rate would be needed to effectively meet the expected demand of 28 Tcf in 2010 .

\section{System Concepts}

- Improved knowledge of resources to understand the characteristics of gas-in-place and to quantify what is recoverable.

- Increased production efficiency via drilling, completion, and stimulation.

- Effective deployment of technologies in conventional and unconventional resources.

- Advanced storage concepts in areas of demand to minimize service curtailments.

- Development of technology to recover gas from hydrates and deep gas sources.

\section{Representative Technologies}

- Advancements in 3-D seismic could reduce risks by $10 \%$ for all exploration wells and by $5 \%$ for development wells in 2010 (cumulative reserves of $37 \mathrm{Tcf}$ are possible).

- Advancements in drilling, completion, and stimulation are expected to reduce costs associated with recovery (cumulative reserves of $6 \mathrm{Tcf}$ are

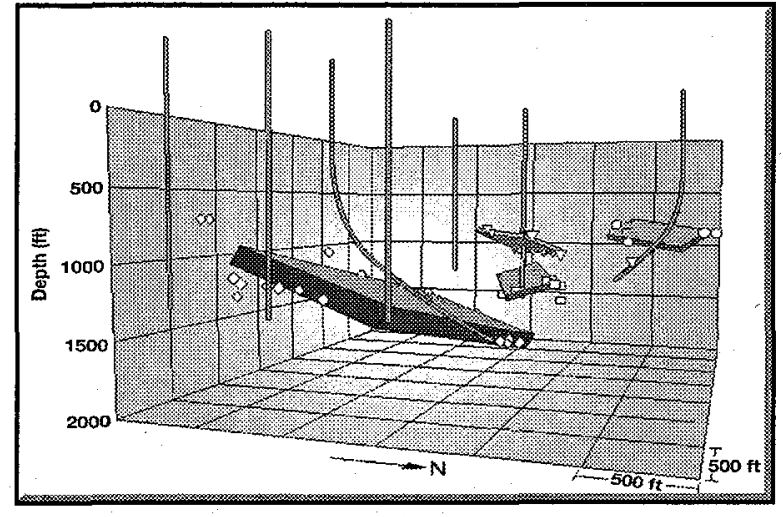

Fracture mapping technology possible in 2010).

- New technology in gas storage could eliminate a 5\% annual loss (cumulative savings of 5 Tcf in 2010).

- Detecting and preventing leaks from natural gas pipelines using backscatter absorption gas imaging and optical methane detectors can detect and prevent leaks from natural gas pipelines (cumulative savings of $5 \mathrm{Tcf}$ in 2010).

\section{Technology Status/Applications}

- Industry focuses on drilling and fracturing with fluids; this technology is not applicable to low-permeability formations.

- Available seismic technology is helpful in locating productive strata but needs improved resolution to locate natural fracture systems that are the "sweet spots."

- Interest in gas hydrates and deep gas is evolving with detection and characterization in both onshore and offshore environments; coalbed methane development remains stagnant.

\section{Current Research, Development, and Demonstration}

\section{RD\&D Goals}

- The goal of the gas supply program is to expand the national reserve base.

- Low-permeability formations and marginally economic reservoirs are the targets for half of the future gas supply.

- $\quad$ Production tests in coalbeds are needed to fully develop this resource.

- Gas hydrates and deep gas sources are targets for the long-term supply.

\section{RD\&D Challenges}

- Developing innovative drilling and subsurface diagnostics to eliminate damage to formations while drilling, to improve recovery efficiency from them, and to reduce costs.

- Developing advanced technologies that increase resolution in naturally fractured formations to reduce risks in locating favorable places to drill.

- Improving diagnostics to detect gas hydrates and deep gas resources.

\section{RD\&D Activities}

- Resource and reserve assessments

- Drilling, completion and stimulation

- Low permeability formations

- Natural gas storage

FY 1997 (\$3.3M)

FY 1997 (\$5.4M)

FY 1997 (\$4.4M)

Note: In the early 1980 s, hydrates, deep gas, and coalbed methane characterization work was conducted, but it ended with the passing of the energy crisis. Data remain archived at FETC.

\section{Recent Success}

- Maps and databases for use in exploration were published and distributed to industry.

- An air hammer was developed with industry to double the drilling rate in horizontal wells.

- A "dry stimulation" process was introduced to industry to avoid formation damage in wells.

- Vast improvements were made in processing complex 3-D data sets.

- Fundamental understanding of hydrates, deep gas, and coalbed methane has been documented. 
Advanced stimulations that avoid formation damage are currently being used in select applications; more customers must be exposed to their merits.

- Improved drilling tools and diagnostics have reached a market plateau over the past 5 years and account for the better recovery efficiency to date with fewer wells.

- $\quad$ Only a limited volume $(5 \%)$ of available coalbed methane is being produced.

- Widespread deployment of technologies is expected by collaborating service companies.

\section{Potential Benefits and Costs}

\section{Carbon Reductions}

- This pathway would expand production of natural gas, which could be expected to decrease gas prices, making gas more competitive for electricity production.

- Reductions of 150-200 MtC/year would be achieved if $25 \%$ of coal-fired power plants were displaced by natural gas-fueled plants in 2030.

- Carbon reduction estimates for this pathway are 10-20 MtC (2010), 75-100 MtC (2020), 100-200 MtC (2030).

Market

- An assured gas supply could displace 2 million bbl oil /day from switchable stationary markets. (25\% of imported oil).

Nonenergy Benefits and Costs

- Energy security at non-disruptible prices in the market.

\section{Risk Factors}

Technical Risk

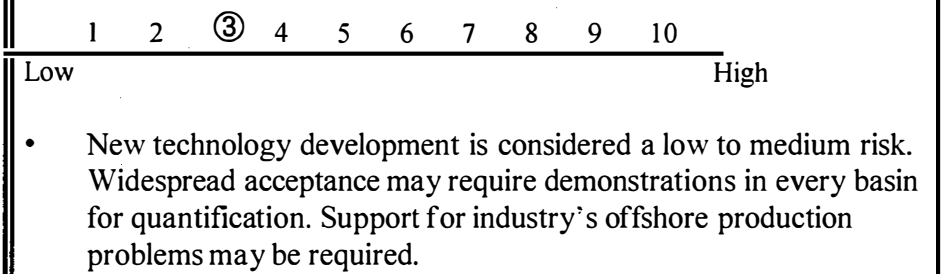

Commercial Risk

\begin{tabular}{llllllllllll}
1 & 2 & 3 & 4 & (5) & 6 & 7 & 8 & 9 & 10 & \\
\hline Low & & & & & & & & & & & High
\end{tabular}

- $\quad$ Drilling and stimulation advances may be hindered by industry's manner of doing business; if patents are not owned by the vendors, new advances may not find their way into the marketplace.

Ecological Risk

\begin{tabular}{lllllllllll} 
& 1 & 2 & 3 & 4 & 5 & 6 & 7 & 8 & 9 & 10 \\
\hline Low & & & & & & & & & & High
\end{tabular}

- Not significant.
Human Health Risk

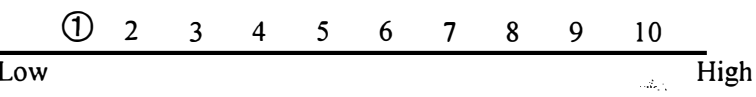

- Not significant.

Economic Risk

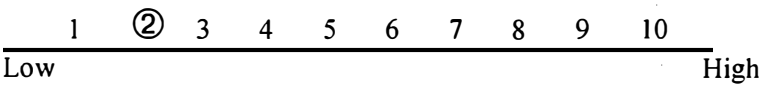

- Not likely.

Regulatory Risk

Low High

\section{RD\&D Expenditures}

- Current DOE RD\&D funding for this pathway is $\$ 14 \mathrm{M} /$ year.

- 1.5 times this current level is required to achieve the estimated carbon emission reductions, or $\$ 21 \mathrm{M} /$ year through 2030 .

\section{Key Federal Actions}

- An optimum funding level (\$300M to 2010 plus $\$ 450 \mathrm{M}$ fiom 2010 to 2030 .

- Federal codes to attain emission reductions may be required to influence fuel switching.

- A federal partnership program may be required to instill confidence in new technology. 


\subsection{CO-PRODUCTION WITH INTEGRATED GASIFICATION COMBINED CYCLE}

\section{Technology Description}

The IGCC process offers industry low-cost, highly efficient options for meeting market requirements. One of the most efficient and environmentally friendly technologies for producing low-cost electricity, IGCC can process many feedstocks including coal, petroleum coke, biomass, and municipal wastes. In combination with synthesis gas conversion technologies, it is the only technology that can coproduce a variety of commodity and premium products in addition to power to meet future market requirements.

\section{System Concepts}

- IGCC for electricity production converts carbonaceous feedstocks in a gasifier into synthesis gas, a mixture of $\mathrm{CO}_{2}$ and hydrogen. The gas is cleaned of particulates, sulfur, and other contaminates to permit further processing and combusted in a high-efficiency gas turbine/generator. The heat from the turbine exhaust gas is extracted to produce steam to drive a steam turbine/generator.

- In coproduction mode, feedstocks can be processed before gasification to extract valuable components, or the synthesis gas can be converted to products. Valuable precursors from feedstocks such as coal can be extracted to manufacture high-strength, lightweight carbon fibers and anode coke. Clean synthesis gas can be catalytically converted into environmentally superior transportation fuels, high-value chemicals, or hydrogen.

\section{Representative Technologies}

- Sasol in South Africa has been converting coal to transportation fuels and chemicals for more than 40 years, but the technologies used are not efficient. Shell has built a plant to convert natural gas to fuels in Malaysia using a combination of new and older technologies. The transportation fuel product is environmentally superior to conventional petroleum products and has commanded a premium price.

- Liquid-phase methanol synthesis is being demonstrated at an Eastman Chemical coal gasification facility. Its design capacity is $80,000 \mathrm{gal} / \mathrm{day}$. The project is demonstrating a new cost-effective route for producing liquid fuels and chemicals in a mode that could be readily integrated with an IGCC plant to coproduce power and fuels/chemicals.

\section{Technology Status/Applications}

- IGCC demonstration projects using coal, petroleum coke, or other petroleum refinery wastes are operating or under construction in the United States and worldwide. Many are designed for coproduction to allow improved thermal efficiencies.

- Conversion of synthesis gas to transportation fuels has been investigated for several decades. Significant advances in catalysis and reactor design are generating interest from industry. The environmental superiority of the resulting transportation fuels-which substantially reduce emissions of hydrocarbons, $\mathrm{CO}_{2}$, and particulates - has been recognized as a key ingredient for meeting future environmental regulations.

- IGCC and IGCC coproduction technologies can be readily integrated into existing refineries and chemical plants to convert waste materials to end products or used to repower inefficient existing plants. The pulp and paper industry produces much biomass waste, most of which is used internally to generate power and steam. Most boilers used in this industry are old and must be replaced, a potential market of 20,000 $\mathrm{MW}$ of capacity. Because of the large steam usage in these plants relative to power consumption, IGCC operating in the coproduction mode offers a unique opportunity for steam and power production while simultaneously destroying hazardous chemicals and generating synthesis gas fuel for kiln operation.

\section{Current Research, Development, and Demonstration}

\section{RD\&D Goals}

By 2004:

- Identify low-cost feedstocks (e.g., biomass, municipal waste, black liquor) available in sufficient quantities for commercial applications.

- Evaluate the gasification of low-cost feedstocks in advanced gasifiers either separately or via co-feeding with other carbonaceous materials.

- Reduce consumption of sorbents, catalysts, and filter elements by $40 \%$ from today's levels. By 2006:

- Reduce the cost of IGCC and IGCC coproduction technologies through the use of advanced air separation technologies, advanced gasifiers, high-efficiency gas turbines, and improved synthesis gas cleanup and CO-to- $\mathrm{H}_{2}$ shift technologies.

- Begin pioneer plant demonstration of IGCC coproduction concept.

By 2010:

- Reduce the installed capital cost of gasifier-based technologies by at least $10 \%$ of current designs.

- Demonstrate the reliability, availability, and maintainability of IGCC and coproduction technologies to secure financing of future facilities. By 2015:

- Demonstrate the modularity for reducing plant cost and demonstrate near-zero discharge of wastes, emissions, and $\mathrm{CO}_{2}$.

\section{RD\&D Challenges}

- $\quad$ Reduce the cost of synthesis gas for both power and fuels production.

- Develop catalysts and sorbents that are mechanically strong and have high activity.

- Optimize the design of process facilities to obtain the lowest total installed cost without sacrificing performance and safety.

- Improve materials for high-temperature gas turbines.

- Identify and develop innovative, cost-effective ideas for sequestering or using $\mathrm{CO}_{2}$.

\section{RD\&D Activities}

- Develop and demonstrate ceramic membranes for high-efficiency, low-cost oxygen production.

- Optimize the process design and engineering, procurement, and construction activities of IGCC and coproduction facilities.

- Develop advanced gasifier technologies for achieving higher throughput and using a variety of low-cost opportunity fuels such as petroleum coke and biomass.

- Develop and demonstrate advanced, high-efficiency gas cleanup technologies for removing impurities from the gasifier product.

- Develop and demonstrate $2600^{\circ} \mathrm{F}$ inlet gas turbines, advanced power cycles and fuel cells, and low-temperature catalysts and processes for conversion of synthesis gas. 
- Two advanced IGCC Clean Coal demonstration projects have been successfully operated using coal.

- An advanced sorbent for removing sulfur from synthesis gas has been developed with sufficient mechanical strength for use in moving bed and transport reactors. Large scale testing is scheduled.

- Operation of the liquid-phase methanol facility is being demonstrated. The design production rate of 260 tons of methanol per day was achieved on the first day of operation.

- Preliminary diesel engine tests on Fischer-Tropsch fuels from indirect liquefaction show exceptional performance. Combustion efficiency is high and emissions tests show no sulfur oxides, lower $\mathrm{NO}_{\mathrm{x}}$, and significantly lower hydrocarbons than in conventional diesel fuels.

\section{Commercialization and Deployment}

- Industry is using slurry reactor and catalyst technology to convert natural gas to methanol, chemicals, and liquid fuels.

- Engine testing done in DOE programs is helping demonstrate the environmental benefits of these advanced fuels.

- Conceptual designs are improving industry's understanding of these processes and reducing the risk of deployment.

- In situ or underground coal gasification can produce high-quality synthesis gas as a feedstock for combined cycle power plants or advanced Fischer-Tropsch processes. The technology has been commercially developed in the former Soviet Union and limited commercial scale testing performed in the United States.

\section{Potential Benefits and Costs}

\section{Carbon Reductions}

- In the cof eed, coproduction mode, carbon emissions are expected to be a third lower than from separate facilities producing the same amount of power and fuel.

- Transportation fuels produced from synthesis gas contain no sulfur and aromatics and reduce hydrocarbon, CO, and particulates emissions by $25-40 \%$ compared with low-sulfur, low-aromatic petroleum diesel.

- If all existing coal-based power plants were replaced with IGCC coproduction technologies, they could produce about 2 million bbl/day of transportation fuels while producing the same power output, but with $15 \%$ lower $\mathrm{CO}_{2}$ emissions (16 MtC/year).

- Coal that is transformed into a liquid using these technologies can sequester excess $\mathrm{CO}_{2}$ at the point of production. Depending on the type of coal, $30-35 \%$ of the carbon from coal could be captured during synthesis gas and liquid fuels production.

- Potential carbon reductions are $245 \mathrm{MtC} /$ year @ 50\% efficiency by 2020 and $325 \mathrm{MtC} /$ year @ 60\% efficiency by 2030.

- Portions of this potential are estimated in those years: 5-10 MtC in 2010; 50--100 MtC in 2020; and 65-130 MtC in 2030. Carbon reduction estimates are already counted in other pathways (3.3 and 6.1). They should not be added again to these pathways because that would involve double counting.

\section{RD\&D Expenditures}

- The IGCC program has been funded at about $\$ 50 \mathrm{M}$ annually. An annual DOE RD\&D budget of $\$ 75 \mathrm{M} /$ year through 2030 is required to generate this pathway's estimated carbon reductions.

\section{Market}

- This energyplex approach presents opportunities to replace a petroleum-based fuel with more abundant coal-based fuels. Currently, $300 \mathrm{GW}$ coal electrical capacity is available in the United States.

\section{Nonenergy Benefits and Costs}

- Improve U.S. industrial competitiveness in new technologies.

- Enhance energy security and reduce the trade deficit through use of domestic resources instead of foreign oil.

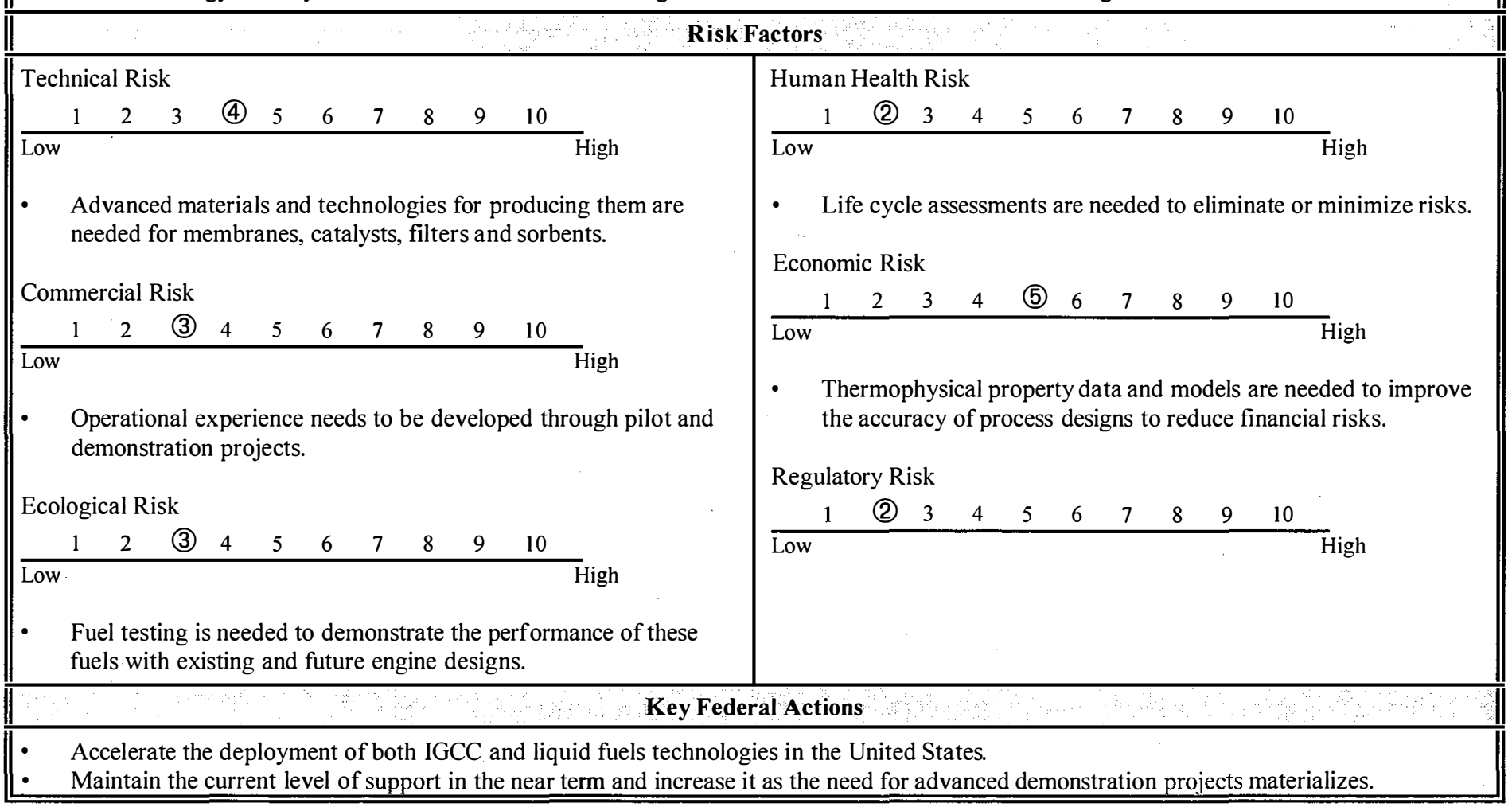


Technology Description

Each day 50 trillion scf of $\mathrm{CO}_{2}$ is vented from power plant stock gases in the United States. Also each day, the United States extracts more than 1.1 billion scf of $\mathrm{CO}_{2}$ from underground deposits and pumps it into oil reservoirs to enhance the recovery of petroleum. Instead, the $\mathrm{CO}_{2}$ that would otherwise be emitted to the atmosphere (from fossil-fueled combustors) could be captured and used. In the future, $\mathrm{CO}_{2}$ contained within powerplant stack gases could also be pumped into coal seams to recover methane economically or to replace base gas in storage wells.

\section{System Concepts}

- Separate $\mathrm{CO}_{2}$ from the stack gas of power plants and other combustors and use it in a number of improved oil and gas recovery methods. The $\mathrm{CO}_{2}$ would have multiple uses for enhanced oil recovery, gas cap maintenance, well stimulation, inert gas replacement in storage, and methane recovery from coalbeds.

- Reject the nitrogen from the air before combustion so that the flue gas is principally $\mathrm{CO}_{2}$ and water vapor, from which the $\mathrm{CO}_{2}$ is either separated for food-grade applications or injected as $\mathrm{CO}_{2}$-rich flue gas to be used in improved oil and gas recovery operations.

- Remove some of the carbon from the fuel (and add hydrogen to fuel) before the fuel is sent to the end user. The removed carbon is available as a concentrated $\mathrm{CO}_{2}$ stream.

- Capture $\mathrm{CO}_{2}$ from low-quality natural gas for injection.

- Combine energy recovery and GHG reduction by either capturing the flue gases or removing the $\mathrm{CO}_{2}$ from stack gases in a setting where a dual fuel (natural gas and coal) power plant is located close to an in situ gassy unmineable coalbed. $\mathrm{CO}_{2}$ from stack gases would be injected

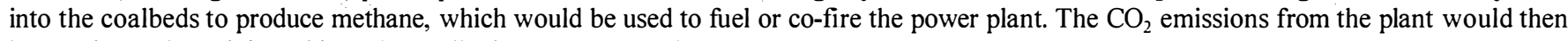
be continuously re-injected into the coalbeds to recover methane.

Representative Technologies

- Passage of flue gas through a solution of monoethanolamine (MEA) (or related compounds.

- The use of an air separation plant in front of an existing power plant.

- Recovery of $\mathrm{CO}_{2}$ from coal gasification and subsequent use for enhanced energy recovery.

- Upgrade low-quality gas into pipeline methane and use the $\mathrm{CO}_{2}$ from higher efficiency membrane separation for other applications.

- Co-produce methane and electricity by using $\mathrm{CO}_{2}$ to produce methane from unmineable coal seams, using the methane to fire a power plant, injecting the $\mathrm{CO}_{2}$ from the plant's stack gases into the coal seams in a continuing cycle.

\section{Technology Status/Applications}

- MEA technology is commercial for applications limited to certain gas streams found at certain chemical plants.

- $\mathrm{O}_{2}-\mathrm{CO}_{2}$ recycling has been pioneered at the pilot scale in the United States and the results have been duplicated in the United Kingdom, Europe, and Japan. It appears technically suitable for electric power plants but has not been applied because natural $\mathrm{CO}_{2}$ deposits are less expensive.

- $\mathrm{CO}_{2}$ recovery from coal gasification produces $\sim 240$ million scfper day of $\mathrm{CO}_{2}$. A project is under way to recover $\mathrm{CO}_{2}$ at the Great Plains Coal Gasification Plant and pipeline $\sim 100$ million scf/per day to the Weyburn oil field in Canada. Additional $\mathrm{CO}_{2}$ from the pipeline could be used in North Dakota, Montana and Wyoming.

- $\quad \mathrm{CO}_{2}$ from stack gases or exhaust gases could be used to recover additional enhanced oil and sequester GHGs. There is an increasing industry awareness of the benefits of well stimulation with $\mathrm{CO}_{2}$ and demand for both low-quality and food-grade $\mathrm{CO}_{2}$ is expected to gain momentum. The potential use of direct flue gas or exhaust gas needs to be further investigated.

- $\quad \mathrm{CO}_{2}$ could be used for base gas replacement in gas storage reservoirs. Natural gas itself or nitrogen is currently used, $\sim 4.3$ trillion scf.

- Several companies have proprietary data and technology for $\mathrm{CO}_{2}$ injection into coal for higher yields of methane recovery. Unofficial information from private sources indicates that the process is technically and potentially economically feasible.

\section{Current Research, Development, and Demonstration}

\section{RD\&D Goals}

For the near term, validate the $\mathrm{CO}_{2} / \mathrm{CH}_{4}$ concepts that will

- Reduce the cost of recovering $\mathrm{CO}_{2}$ from combustors and lead to a reduction of $\mathrm{CO}_{2}$ emissions at targeted power plants.

- Demonstrate the stability and permanence of $\mathrm{CO}_{2}$ storage in coalbeds and gas storage reservoirs and increased production of methane from coalbeds by $\mathrm{CO}_{2}$ injection.

By 2002, develop and validate the $\mathrm{CO}_{2} / \mathrm{CH}_{4}$ concepts that will

- Reduce the cost of recovering $\mathrm{CO}_{2}$ from combustors by $30-50 \%$.

- Demonstrate improved oil recovery from $\mathrm{CO}_{2}$ well stimulation treatments.

- Demonstrate that methane production from unmineable coalbeds in selected coal power plant regions will permit $10 \%$ co-firing, which will further reduce emissions.

By 2005 , develop and validate advanced $\mathrm{CO}_{2} / \mathrm{CH}_{4}$ concepts that will

- Demonstrate the use of stack gas $\mathrm{CO}_{2}$ as direct flue gas for improved oil recovery.

- Exhibit the performance, reliability, and efficiency to store $\mathrm{CO}_{2}$ and optimize $\mathrm{CH}_{4}$ recovery in coals with varying thickness, maturity, and depth.

- Determine the feasibility of directly injecting power plant flue gas to remove stored $\mathrm{SO}_{2}$ and $\mathrm{NO}_{\mathrm{x}}$ as well as $\mathrm{CO}_{2}$.

RD\&D Challenges

- Improve gas-gas separations, particularly the separation of air into oxygen and nitrogen and the separation of $\mathrm{CO}_{2}$ from nitrogen.

- Conduct research to determine (1) where $\mathrm{CO}_{2}$ goes upon injection, (2) how it interacts geochemically with the reservoir rock and fluid, and (3) how these interactions affect the recovery of gas and oil.

- Determine influence of water-saturated coalbeds on $\mathrm{CO}_{2}$ injection and adsorption

- Adapt existing oil and gas well methodologies to $\mathrm{CO}_{2}$ injection requirements.

- Determine the extent to which the concepts can be applied to the full range of unmineable coals.

- Determine the feasibility of direct flue gas injection. 


\section{RD\&D Activities}

- $\quad \mathrm{RD} \& D$ on $\mathrm{O}_{2} / \mathrm{CO}_{2}$ recycling systems has been carried out (international funding probably equivalent to several million dollars in recent years). DOE funded pioneering work in this area in the mid 1980s; funding was approximately $\$ 2 \mathrm{M}$.

- Analytic and laboratory process studies are ongoing.

- Commercial recovery and use of coalbed methane demonstrated by industry.

- Laboratory and field tests are needed to confirm the fundamental relationships supporting $\mathrm{CO}_{2}$ injection and methane recovery in a variety of coals and reservoir environments.

\section{Recent Success}

- The practice of $\mathrm{CO}_{2}$ injection has grown significantly. Petroleum production rose from 30,000 bbl/day in 1986 to $171,000 \mathrm{bbl} / \mathrm{day}$ in 1996 . In 1996, there were $61 \mathrm{CO}_{2}$ injection projects in the United States. $\mathrm{CO}_{2}$ usage associated with well stimulation is increasing as well operators begin to appreciate the benefits, and the service industry begins to capitalize the equipment needed to provide a stimulation service.

- Industry has privately demonstrated the concept of injecting $\mathrm{CO}_{2}$ into coals for enhanced methane production (proprietary data).

- DOE-sponsored laboratory testing on bituminous coal samples shows the affinity factor of $\mathrm{CO}_{2}$ to coal surface is $2: 1$ over $\mathrm{CH}_{4}$.

\section{Commercialization and Deployment}

- $\quad \mathrm{A} \mathrm{CO}_{2}$ pipeline will be constructed in 1999 from the Great Plains Coal Gasification Plant to Canadian oil fields.

- Co-fïring and reburn technologies in several U.S. power plants have been demonstrated in joint DOE-GRI-industry partnerships.

- $\mathrm{CO}_{2}$ is used commercially in enhanced oil recovery, well stimulation, and well remediation applications.

- Industrial $\mathrm{R} \& \mathrm{D}$ on $\mathrm{CO}_{2}$ displacement of $\mathrm{CH}_{4}$ in coal seams.

\section{Potential Benefits and Costs}

\section{Carbon Reductions}

$\mathrm{CO}_{2}$ storage capacity in coals and enhanced production of methane from gassy coals is potentially large. Estimates have placed the sequestration potential of this approach at $50 \mathrm{MtC} /$ year. But it is unclear how much of this potential might be realized.

\section{Market}

- Increased natural gas production from conventional and tight gas formations with emphasis on coalbeds (coalbed gas now furnishes $5 \%$ of U.S. supply at more than 1 Tcf/year and increased reserves and production of domestic petroleum.

\section{Nonenergy Benefits and Costs}

- Avoided need and cost for $\mathrm{SO}_{x} / \mathrm{NO}_{\mathrm{x}}$ control on power plants whose flue gas is recovered and sequestered in oil wells and coal seams; reduced $\mathrm{NO}_{\mathrm{x}}$ and particulate matter through methane use with coal for power; and substantial international market opportunities for the United States.

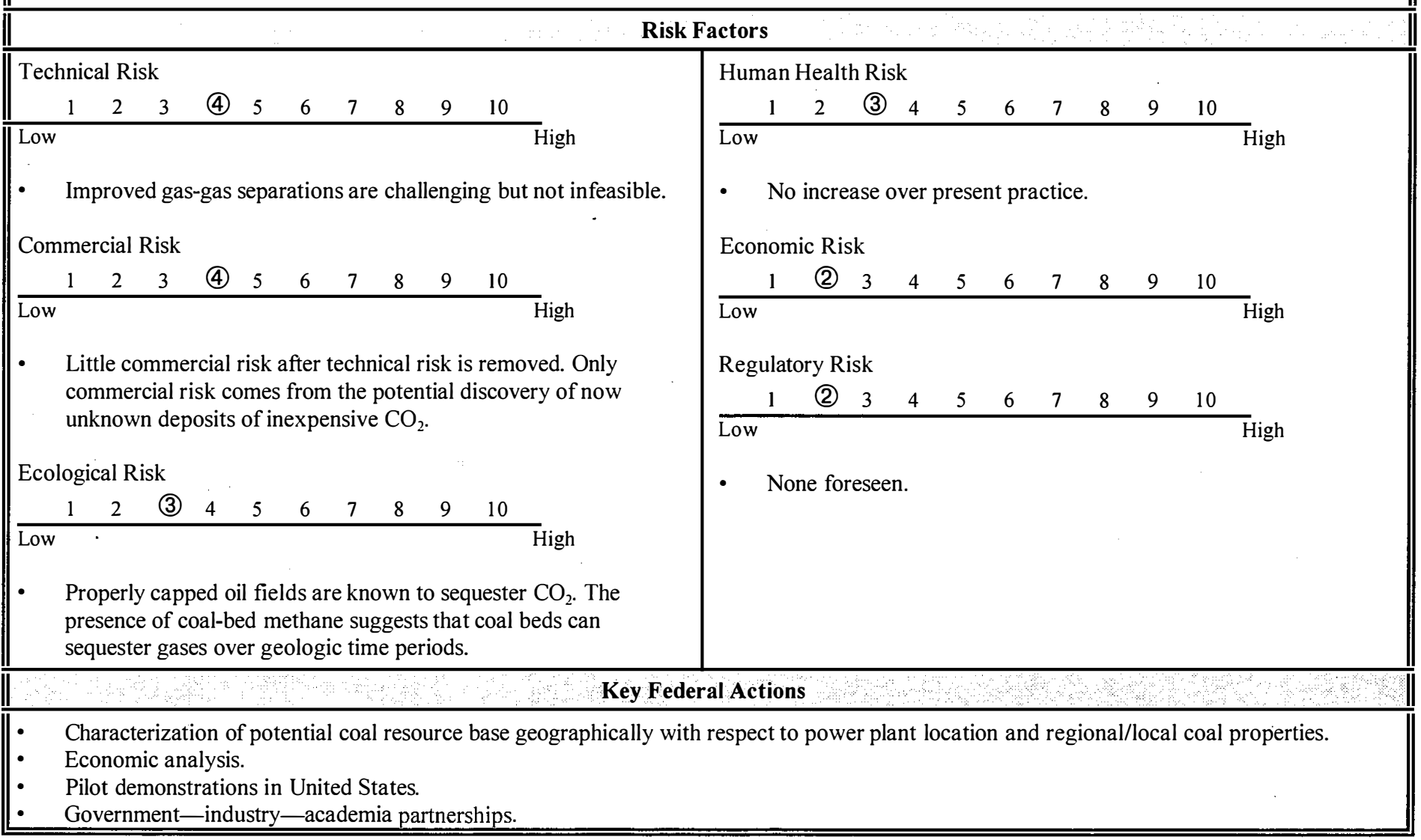





\title{
Clean Energy Technologies
}

\author{
6. Fossil Power Generation
}

6.1 Accelerated Development of High-Efficiency Coal-Based Power Generation Technologies

6.2 Low-carbon Fuels and High-efficiency Power Generation

6.3 Ultra-high Efficiency, Zero-carbon Emission Energyplexes 


\subsection{ACCELERATED DEVELOPMENT OF HIGH-EFFICIENCY COAL-BASED POWER GENERATION TECHNOLOGIES}

\section{Technology Description}

This pathway will accelerate the development and deployment of high-efficiency coal power generation technologies by 3 to 5 years, reducing $\mathrm{CO}_{2}$ emissions while maintaining a reliable, low-cost energy supply. Increasing power plant efficiencies ultimately to $55 \%$ (compared with current efficiencies of around $33 \%$ ) will reduce $\mathrm{CO}_{2}$ emissions by $40 \%$ per unit of electricity. With an accelerated $\mathrm{RD} \& \mathrm{D}$ program, deployment can be achieved in the near term, 2000 to 2010. An added benefit is that these plants may be designed to co-fire natural gas or $\mathrm{CO}_{2}$-neutral biomass fuels with coal and to accommodate other low-cost approaches for $\mathrm{CO}_{2}$ reduction. Although this pathway assumes no $\mathrm{CO}_{2}$ sequestration, future development of $\mathrm{CO}_{2}$ sequestration could reduce carbon emissions to near-zero levels.

System Concepts

- This technology increases power generation cycle efficiency by combining two or more advanced energy conversion cycles.

- System components vary considerably, depending on the specific implementation, but typically include advanced high-temperature, highpressure cycles and a hot gas expansion cycle. which may be a combustion turbine or an exhaust pressure reduction turbine.

- Steam may also be replaced with a more efficient working fluid (e.g., air, advanced binary mixtures).

\section{Representative Technologies}

DOE is currently pursuing:

- Low-emission boiler systems (LEBS).

- $\quad$ Pressurized fluidized bed combustion (PFBC).

- Integrated gasification combined cycle (IGCC).

- High-efficiency power systems (HIPPS) technologies.

Technology Status/Applications

- In DOE plans, LEBS, IGCC, and PFBC technologies with efficiencies of 40--45\% are scheduled to be available for commercial deployment by 2000 .

- A portfolio of LEBS, IGCC, PFBC, and HIPPS technologies with even higher efficiencies, 50-55\%, are scheduled to be available by 2010.

- The cost of electricity for these technologies is expected to be $\$ 0.03$ to $\$ 0.04 / \mathrm{kWh}$.

- Costs are expected to decrease as these technologies mature around 2010.

\section{Current Research, Development, and Demonstration}

\section{RD\&D Goals}

- Current DOE RD\&D program performance and cost goals range from $42 \%$ efficiencies in 2000 to $55 \%+$ efficiencies in 2010 at a cost of electricity of $75-90 \%$ of current PC-based generation.

- Emissions of criteria pollutants are targeted to $1 / 3$ to $1 / 10$ of current new source performance standards.

- An accelerated DOE RD\&D program would make the higher-efficiency technologies available 3-5 years sooner than the 2010 goal.

- DOE efforts will ensure that these goals are met for the technology portfolio and will foster application.

RD\&D Challenges

- Advanced systems need to maintain relatively high temperatures between the combustion/gasification stage and the turbine stage if they are to achieve the efficiency goals.

- High-temperature materials that are stable and resistant to corrosion, erosion, and decrepitation are a primary technology development need.

- Advanced materials are needed for heat-exchangers, turbine components, particulate filters, and $\mathrm{SO}_{x}$ removal.

- Other challenges include the use of alternate working fluids for turbine and heat-exchange cycles, $\mathrm{CO}_{2}$ capture methods, cycle optimization,

RD\&D Activities

- The portfolio of high-efficiency coal power systems under development through DOE is LEBS, HIPPS, IGCC, and PFBC.

- DOE support is supplemented by $40 \%$ cost share from the private sector.

\section{Recent Success}

- In 1996, the IGCC Wabash River project received Power magazine's Power Plant of the Year Award, "a technology to bridge the millennium ... to minimize environmental impact and maximize efficiency."

- As one of 40 projects in the Clean Coal Technology Program, the 260-MW repowering project increased the efficiency of an older pulverized coal unit by one third, to $39 \%$ efficiency.

\section{Commercialization and Deployment}

- This technology pathway is under development with several recent proof-of-concept greenfield and repowering installations.

- Commercial deployment is scheduled for 2000-2010.

- An accelerated RD\&D program could expand deployment and move the deployment time frame up by 3-5 years. Existing plants may be repowered with higher-efficiency coal technologies at or below the price of the natural gas combined cycle (NGCC). Where natural gas is not available (a considerable portion of the United States and a major portion of the international market), high-efficiency coal plants will be the lowest-cost choice. 
- The market for new capacity from now until 2010 is estimated to be more than $120 \mathrm{GW}$ in the United States and more than $230 \mathrm{GW}$ internationally. Domestically, the primary competition for this technology pathway is expected to be NGCC.

- Internationally, where natural gas is not available, the market share for coal is expected to be much higher.

\section{Potential Benefits and Costs}

\section{Carbon Reductions}

- With breakthroughs in $\mathrm{CO}_{2}$ capture in the next 20 years, systems deployed from this pathway could be retrofitted to achieve near-zero $\mathrm{CO}_{2}$ emissions. This technology pathway would reduce $\mathrm{CO}_{2}$ emissions by $40 \%$ per unit of electricity in the near term.

2010: 0-10 MtC; 2020: 20-50 MtC; 2030: 65-110 MtC.

\section{RD\&D Expenditures}

- $\quad$ Funding for the planned DOE RD\&D program (excluding the AR\&TD program) is projected to be $\$ 780 \mathrm{M}$ between 1998 and 2010 , or an average of $\$ 60 \mathrm{M} /$ year (which was also the annual funding level for FYs 1996 and 1997). An additional $40 \%$ in funding will come from private-sector cost sharing.

- Significant increases in funding in the near term would help minimize the technical risk and could accelerate the schedule to commercialization by 3 to 5 years.

- To accelerate this program. it is necessary to move up the commercialization schedule at least 5 years, that is, to provide $\$ 780 \mathrm{M}$ between 1998 and 2005. This would increase annual funding to $\$ 98 \mathrm{M} /$ year; however, the total funding of $\$ 780 \mathrm{M}$ would not increase.

Market

- The major energy impact is to reduce the amount of coal needed per unit electricity, thereby reducing $\mathrm{CO}_{2}$ emissions.

Nonenergy Benefits and Costs

- International implementation of this technology pathway instead of current low-efficiency technologies will result in major carbon reductions globally. Because much of the international power plant base will be installed in the near future, before 2010, there is a near-term critical window of opportunity to capture international market share and ensure that the highest-efficiency technologies are installed. An accelerated R\&D program will enable the United States to capture this larger share of the $\$ 14$ trillion export market for energy technologies between now and 2010. Fossil fuel-fired technologies are estimated to represent more than $70 \%$ of this market. This technology pathway will create an energy technology export business.

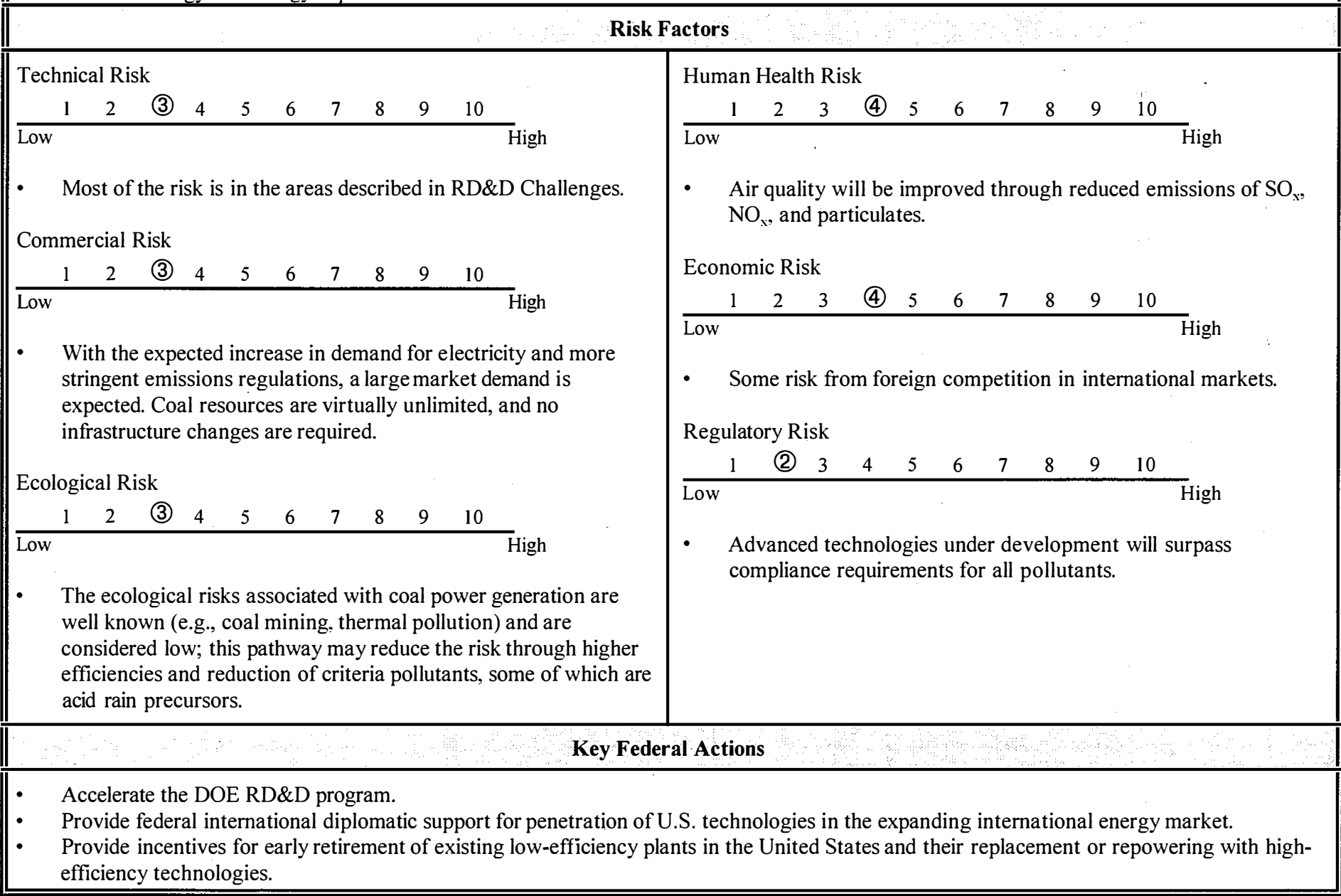




\subsection{LOW-CARBON FUELS AND HIGH-EFFICIENCY POWER GENERATION}

\section{Technology Description}

The ultimate goal for this pathway is to develop systems that use low-carbon gaseous or liquid fuels for highly efficient power generation. These fuels could be natural gas, synthesis gas, hydrogen, or high-hydrogen-content liquids. System components may include fuel cells and ATSs. This pathway also includes stand-alone applications of small to medium ATSs, including cogeneration. Near zero $\mathrm{CO}_{2}$ emissions could be achieved with integration of $\mathrm{CO}_{2}$ capture.

\section{System Concepts}

- High-performance power-generating fuel cells.

- High-performance turbines for alternative fuels (such as hydrogen), ultrahigh-temperature turbines, and smaller stand-alone turbines for distributed power and cogeneration applications.

- Integrated fuel cells and ATSs.

- Adaptation of gasification systems covered in the IGCC pathway to the concepts described here, providing a bridge to the hydrogen economy by using coal, through gasification, as a source of hydrogen.

- Designing systems to accommodate natural gas and other fuels such as hydrogen and liquid fuels.

- Integrating $\mathrm{CO}_{2}$ capture technologies as they become available.

Representative Technologies

- ATSs

- High-temperature fuel cells

- Methane conversion

- Coal gasification, $\mathrm{CO}_{2}$ capture

Technology Status/Applications

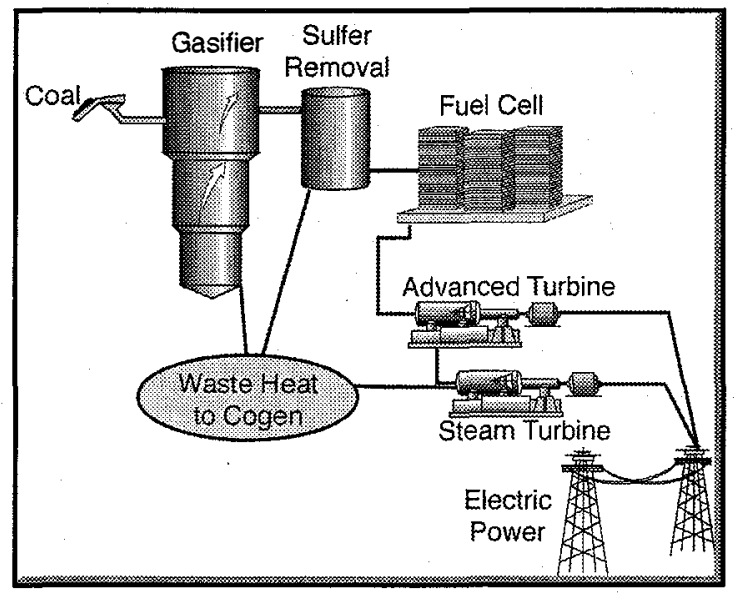

- $\quad$ ATSs (hydrogen and ultra-high-temperature), high-temperature fuel cells, and $\mathrm{CO}_{2}$ capture technologies are under development but not available commercially.

- For coal-based technology, various entrained bed gasification systems are available, and the transport gasifier technology is now being developed by DOE.

- Opportunities still exist to improve gasifier performance significantly for this application.

- Various elements of high-performance cycles that integrate $\mathrm{CO}_{2}$ capture and other environmental controls need extensive development.

- ATSs and fuel cells are expected to be used in industrial applications for both power and heat.

\section{Current Research, Development, and Demonstration}

\section{RD\&D Goals}

- For the ATS program, achieving busbar energy costs that are $10 \%$ less than costs of current technology.

- Developing the ATS and gasification-adaptation technology by 2010 .

- By 2010 , demonstrating integrated fuel cell and turbine systems achieving efficiencies of $70 \%$ on natural gas.

- Also by 2010 , lowering fuel cell power system costs to $\$ 1000 / \mathrm{kW}$.

- Demonstrating a hydrogen-fired turbine after 2020.

\section{RD\&D Challenges}

- Advanced materials.

- Hydrogen transportation and storage.

- Advanced hydrogen separation.

- System-specific energy-efficient environmental controls for $\mathrm{NO}_{x}, \mathrm{SO}_{x}$, and particulates.

- Developing new components required by advanced cycles integrating $\mathrm{CO}_{2}$ capture.

\section{RD\&D Activities}

- Programs for development of

- Solid oxide fuel cell systems

- Advanced gas turbine systems

- Adapting gasification systems from the IGCC pathway

- Hot gas cleanup

- System-specific energy-efficient environmental controls

- The FY 1996 and FY 1997 budgets for fuel cells are about \$30M each. The FY 1996 and FY 1997 budgets for ATSs are about \$40M/year.

\section{Recent Success}

- Westinghouse Electric Corporation has a $25-\mathrm{kW}$ solid oxide fuel cell system that has operated successfully for over 13,000 hours.

- The ATS program has fostered the development of the Westinghouse 501G turbine, which incorporates features developed under this program. 
- Tremendous potential exists for deployment of ATSs because of the low cost of natural gas.

- Fuel cells are becoming viable in niche applications, and increased production rates for fuel cells are expected to lower capital costs.

- More than 120 fuel cell units (mostly 200-kW size) are operating worldwide.

- Some elements of the more advanced technologies need substantial development before commercialization in the 2010-2020 time frame.

- Some reduction in system costs over time is expected.

\section{Potential Benefits and Costs}

\section{Carbon Reductions}

- The integrated gasification/fuel cell/ATS will have an efficiency of about $65 \%$ and low emissions of $\mathrm{CO}_{2}$ and criteria pollutants.

- If a hybrid gas turbine/fuel cell system can achieve $70 \%$ efficiency and is fueled by natural gas, it produces about 0.069 tonnes/MWh of carbon.

- If fueled by coal at the same efficiency, it produces about 0.123 tonnes/MWh of carbon.

- Other advanced cycles described here will have near zero $\mathrm{CO}_{2}$ emissions, pending development of cost-effective $\mathrm{CO}_{2}$ capture technologies.

Until 2010: 0-10 MtC; 2020: 20-30 MtC; 2030: 25-35 MtC.

\section{Market}

- Large domestic and international markets, greater than $200 \mathrm{GW}$ both domestically and internationally.

\section{Energy}

- Reduces the natural gas consumption per unit of energy through efficiency improvement.

- Addition of coal gasification as a source of fuel gas will have a positive impact on U.S. energy independence.

- The projected cost of electricity will be $3.5 \notin$ per kWh without $\mathrm{CO}_{2}$ control.

\section{Nonenergy Benefits and Costs}

- Enhances the market for gas turbines and fuel cells and sustains the market for coal-based power system.

- Creates a portfolio of exportable technologies.

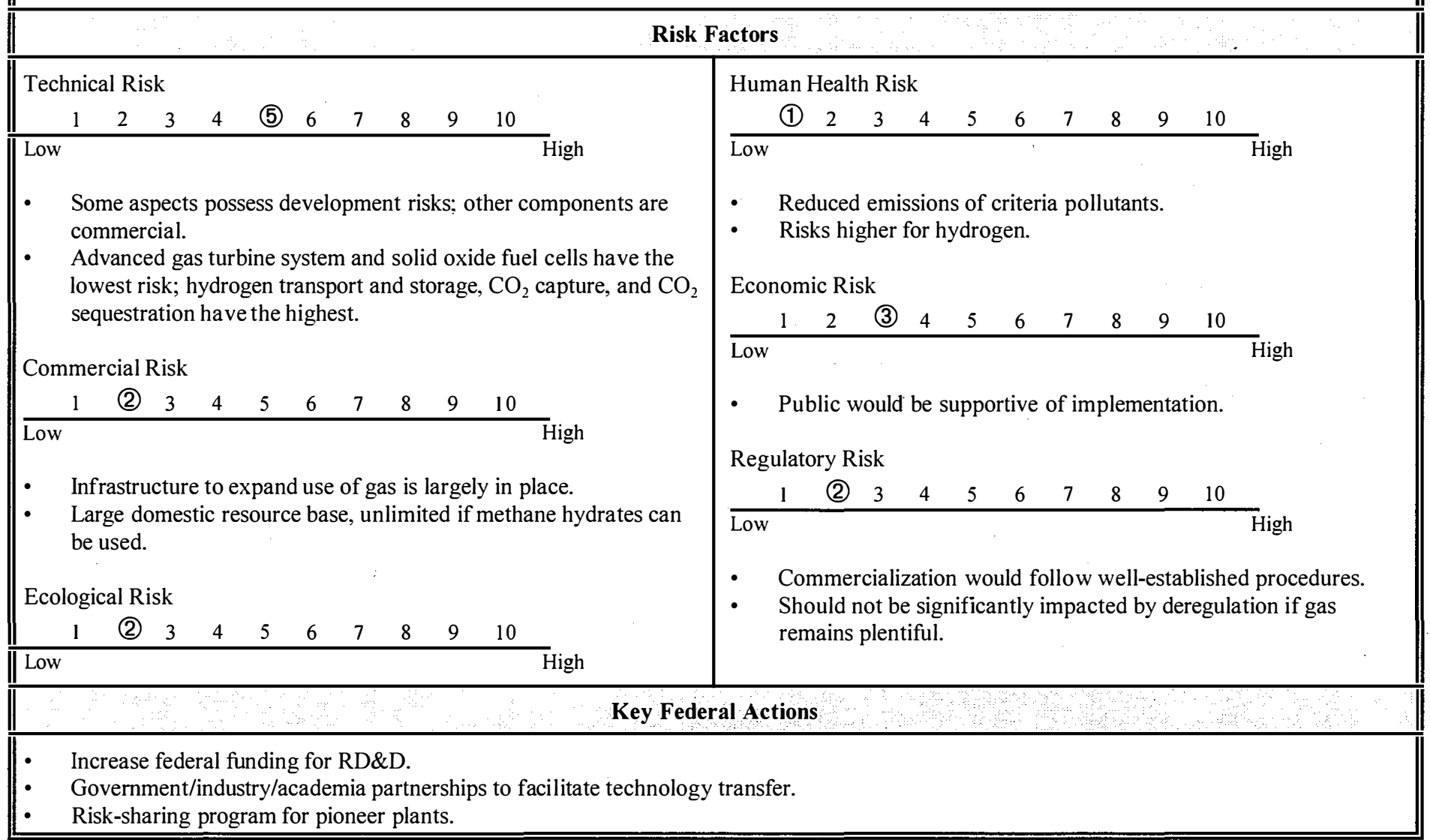

\section{RD\&D Expenditures}

- $\quad$ Current plans call for $\$ 436 \mathrm{M}$ for fuel cells through 2010 and about $\$ 300 \mathrm{M}$ for ATS in the same time period. A substantial technology, and $\mathrm{CO}_{2}$ capture technology-both near-term and long-term. The annual federal RD\&D budget required for this pathway is estimated to be $\$ 160 \mathrm{M}$ throughout the three decades.

- Significant industry cost sharing. 


\subsection{ULTRA-HIGH EFFICIENCY, ZERO-CARBON EMISSION ENERGYPLEXES}

\section{Technology Description}

This pathway aims to take advantage of synergies between energy generation, fuels production, and chemical production by integrating these into a single entity, an "energyplex." Unlike the other pathways in this category, which focus on electricity generation, this one would optimize the entire cycle of carbon utilization by incorporating co-processing concepts, the integral capture of $\mathrm{CO}_{2}$, and leading to incorporation of carbon into useful products or sequestration. It borrows tenets of industrial ecology where the "waste" materials of one process become raw materials for another. This pathway challenges the R\&D community to make significant technology breakthroughs such as novel industrial process configurations, novel power cycles, and coproduction of heat and power.

\section{System Concepts}

- $\quad$ Focus on supplying distributed power and producing high-value products.

- Flexible system design would allow shifting the product slate (from power to fuels to chemicals or any combination) to optimize income while maintaining environmental performance.

- Modularity would allow construction of plants that are adapted to siting requirements and local resource availability.

Representative Technologies

- Fuel cell/gas turbine bottoming combination to achieve efficiencies of over $70 \%$ with integral capture of $\mathrm{CO}_{2}$. Fuel cell exhaust gases are mixed and burned before expansion through the gas turbine.

- IGCC plants or coal liquefaction plants in combination with existing petroleum refineries using coal.

- Power systems with alternate working fluids.

- Three-phase slurry reactors used in integrated fuel, chemical, and power production.

- High-temperature hydrogen separation membranes and advanced oxygen production techniques.

- Extensions of technologies fiom the other pathways in this category.

Technology Status/Applications

- Aspects of industrial ecology are already being explored in Europe.

- Solid oxide fuel cell has demonstrated long term performance of over 13,000 hours on a $25-\mathrm{kW}$ stack. Combining a fuel cell and a gas turbine with integral $\mathrm{CO}_{2}$ capture is still in the conceptualization stage.

- Coal liquefaction is currently in the proof-of-concept stage. Integration with an existing petroleum refinery is still in the concept development stage.

Current Research, Development, and Demonstration

\section{RD\&D Goals}

By 2015, develop a portfolio of breakthrough technologies (e.g., advanced $\mathrm{CO}_{2}$ management schemes, advanced hybrid processes and cycles) that would be further developed into energyplexes that will achieve $65 \%$ or greater efficiency with COE less than $\$ 0.04 / \mathrm{kW}$ and will capture CO safely for reuse. Example subsystem goals are:

- By 2015, develop and verify coal liquefaction technologies that are competitive with crude oil while emitting $20 \%$ less $\mathrm{CO}_{2}$ than current petroleum technologies.

- By 2015 , lower energy consumption by $30-40 \%$ for oxygen separation via membrane separation.

- By 2015 , develop high temperature heat exchanger capable of operating at $2700^{\circ} \mathrm{F}$ and 600 psig.

- By 2020, develop and validate combination of fuel cells and advanced gas turbines to achieve efficiencies over $70 \%$.

- By 2030, validate fuel cell systems incorporating carbon capturing methods that achieve near zero $\mathrm{CO}_{2}$ emissions to the environment, while producing a $\mathrm{CO}_{2}$ stream.

\section{RD\&D Challenges}

- Develop process concepts for power plants resulting in zero $\mathrm{CO}_{2}$ release to the atmosphere.

- Produce hybrid coal and refinery plants to produce fuels, electricity, and chemicals with less $\mathrm{CO}_{2}$ emitted.

- $\quad$ Produce coal derived fuels at lower costs with less energy usage.

- Simplify manufacturing process and materials in fuel cells to lower costs. Broaden the range of applicable fuel cell technologies.

- Integrate power production with fuels and chemicals.

\section{RD\&D Activities}

- Membrane research for cheaper separation of oxygen from air and hydrogen from synthesis gas.

- Initiate R\&D into fuel cell/gas turbine systems.

- Systems studies are under way to identify novel means of integrating power and industrial processes.

- Work under Technology Pathways 6.1 and 6.2 will form the basis for the R\&D to be started in this pathway.

\section{Recent Success}

- Liquid-phase methanol technology is being commercially demonstrated at Eastman Chemicals. 
- This is a long-term futuristic concept and, although certain components are being developed, it is too early to predict the approach to commercialization.

- Westinghouse Electric is the only U.S. solid oxide fuel cell developer.

- Many U.S. developers of gasification technology, including Texaco and Destec.

- First generation likely to impose energy penalty to achieve zero carbon. Energy penalty and cost expected to decline with system refinements.

\section{Potential Benefits and Costs}

\section{Carbon Reductions}

An energyplex system including sequestration will have near zero carbon emissions.

$$
\text { 2010: 0; 2020: 0-10 MtC; 2030: 20--40 MtC }
$$

One process that has been examined would result in attribution of $1 / 3$ of all savings to better thermal integration and the other $2 / 3$ to a particular decarbonization approach. Other concepts could be developed by 2020 which would distribute carbon savings differently between thermal integration and carbon reuse.

\section{RD\&D Expenditures}

- The R\&D budget for fuel cells is about \$30M/year in FY 1996 and FY 1997. The AR\& TD budget for power systems is about \$17M/year in FY 1996 and FY 1997.

- Substantial federal funds needed to complete R\&D and foster demonstration.

- $\quad$ Current plans call for $\$ 450 \mathrm{M}$ for all coal AR\&TD through 2010 . The accelerated budget would add about $\$ 1250 \mathrm{M}$ for this work over the 2100-2030 time frame.

- The annual federal RD\&D budget required for this pathway is estimated to be 2000-2020, \$60M/year; 2020-2030, \$50M/year

Market

- Domestic and international markets could be 100 s of GWs once commercial.

Energy Impacts

- $\quad$ Reduce the amount of $\mathrm{CO}_{2}$ produced per $\mathrm{MWh}$ of electricity generated.

- Displace imported petroleum with coal derived liquid fuels.

Nonenergy Benefits and Costs

- Helps maintain U.S. technological edge in significant technologies.

- Enhances national security by displacing foreign oil with coal-derived liquid fuels.

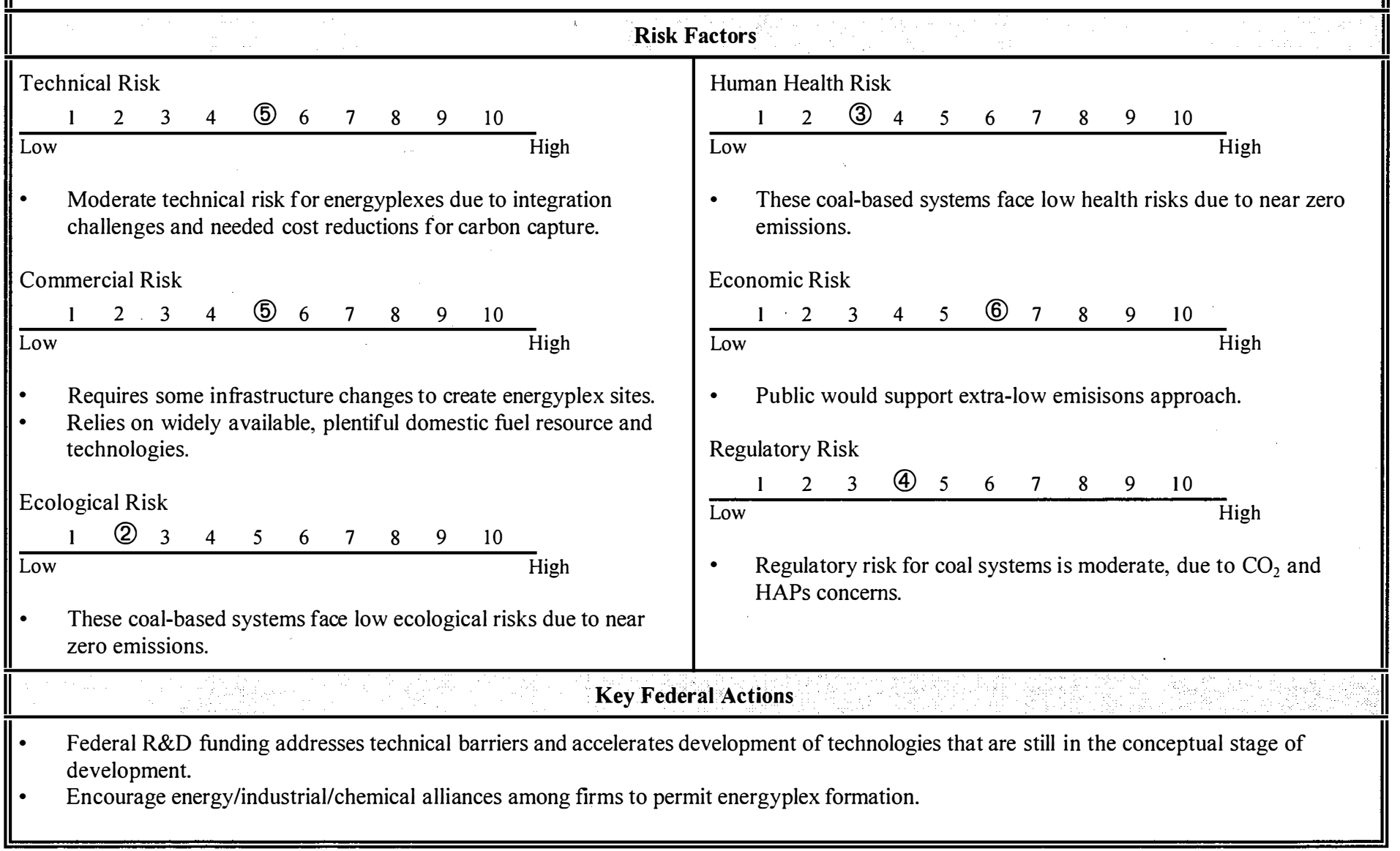





\section{Clean Energy Technologies}

\section{Nuclear}

\subsection{Lifetime Extension and Generation Optimization}

7.2 Next-generation Fission Reactors

\subsection{Fusion Power}




\subsection{LIFETIME EXTENSION AND GENERATION OPTIMIZATION}

\section{Technology Description}

Currently, 107 privately-owned nuclear power plants generate nearly $21 \%$ of U.S. electricity (about 100 GWe installed capacity). Nuclear power plants emit negligible GHGs during operation. Technology can be applied to nuclear and nonnuclear equipment in existing plants to enable them to produce more electricity during their operating lifetimes (generation optimization.). The operating lifetimes of existing plants also can be extended safely. Most nuclear power plant licenses will expire between 2005 and 2030. If these plants are shut down and replaced with fossil-based generation, $\mathrm{CO}_{2}$ emissions will increase by $>100$ million $\mathrm{MtC} /$ year by 2030 (at $160 \mathrm{~g} \mathrm{C} / \mathrm{kW}$ - $\mathrm{h}$ ). Extending the lifetimes and optimizing the generation of these plants for 20 years will avoid 1.4 billion MtC.

\section{System Concepts}

- Improve availability and maintainability of nuclear plants.

- Provide technology to predict and measure the extent of materials damage from plant aging and to repair or replace damaged components.

- Operate plants at higher power levels based on more accurate measurement and knowledge of safety margins and reduced consumption of on-site electrical power.

- Develop high-burnup fuel for longer fuel cycles and up to $5 \%$ higher energy output.

\section{Representative Technologies}

- In situ component and vessel annealing, prediction and monitoring of stress corrosion cracking of reactor internals and steam generators, materials cladding processes

- Advanced technologies for on-line condition monitoring of cables and conventional equipment (pumps, motors, valves, etc.) to minimize production losses from unplanned outages

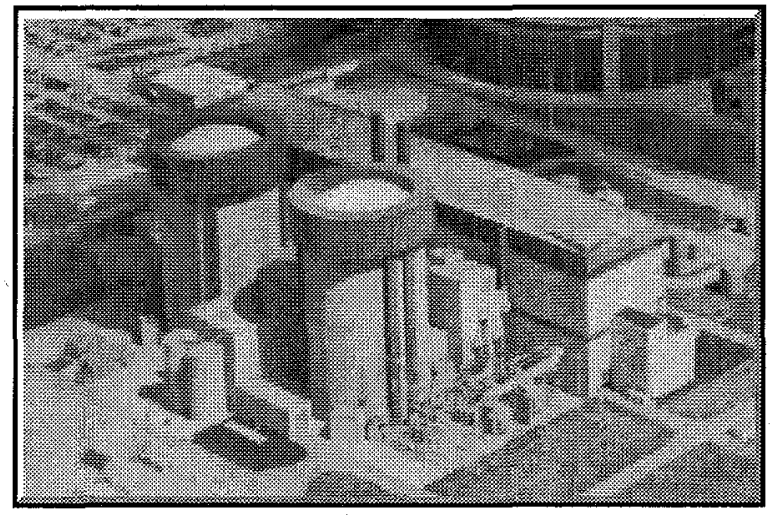

- $\quad$ Replacing aging, hard-to-maintain safety system electronic components with easy-to-maintain advanced electronics

- Materials measurement and diagnostic technologies to determine the condition and fitness of aged materials

- Cost-effective materials and systems repair technologies

- Advanced core loading strategies; nuclear fuel and cladding research

Technology Status/Applications

- Current technology does not adequately determine residual life; overly conservative margins may result in premature shutdown or refurbishment.

- Replacing major components (e.g., steam generators) may be prohibitively expensive; better techniques are needed.

- Some in-service valve testing technology is in place, but current technology fails to detect a significant number of failures.

- Condition monitoring technology has been developed in DOE/EE Motor Challenge Program and for DOE/DP. Advanced electronics technologies have been developed for high energy physics programs. Development is required for application to nuclear plants.

\section{Current Research, Development, and Demonstration}

\section{RD\&D Goals}

- By 2001, provide technologies that can improve the average capacity factor of nuclear power plants to $86 \%$.

- By 2003, provide technologies to measure, diagnose, and repair effects of aging on plant materials, components, and systems, and develop and demonstrate technologies to reduce the regulatory uncertainties of life extension of plants.

\section{RD\&D Challenges}

- Successful introduction of technologies that are cost-effective and acceptable to regulators

- Reliable operation of sensors in harsh environments

\section{RD\&D Activities}

- A previous CRADA between DOE/NE and EPRI started development of advanced electronics to replace Westinghouse safety system components.

- Condition monitoring R\&D supported by DOE/NE, DOE/EE, DOE/DP, and NRC is providing a relevant technology base.

- There is no current DOE funding for application of advanced technologies to existing LWRs or for aging research.

- $\quad$ NRC sponsors about $\$ 16 \mathrm{M}$ of research related to materials aging.

\section{Recent Success}

- Initial industry decision to commercialize DOE electronics technology for replacing Westinghouse safety system components.

- Nonintrusive evaluation of PWR accumulator discharge check valves has reduced testing time and improved reliability.

- Demonstration of gas-fired thermal annealing of Marble Hill reactor pressure vessel completed in 1996.

- Use of hydrogen water chemistry in BWRs to control stress corrosion cracking. 
- Advanced diagnostic techniques are gaining wider acceptance for evaluating the status of safety-related equipment.

- Successful technology may not be sufficient to extend the life of all plants if adverse regulatory or economic factors dominate.

- DOE/EPRI Sustainable Electric Partnership Agreement provides a basis for DOE/industry cooperation and ensures commercial deployment.

- Technology to support plant license renewal needs to be available in the next 5 years to support initial license renewal submittals to NRC.

\section{Potential Benefits and Costs}

\section{Carbon Reductions}

20-year life extension and generation optimization of part or all of existing $100 \mathrm{GWe}$ installed nuclear capacity reduces carbon emissions by 2010 2020

$0-15 \mathrm{MtC} /$ year

20-60 MtC/year

2030

- Carbon emission avoidance from 1996 to 2030 could exceed $1400 \mathrm{MtC}$

\section{RD\&D Expenditures}

- Annual federal RD\&D budget required for this pathway: to $2010, \$ 30 \mathrm{M}$ to $\$ 40 \mathrm{M} /$ year; beyond 2010 , no additional RD\&D funds required.

Market

- Indeterminant at this time. Improved operations and life extension could improve the economics of existing nuclear power plants and thus enhance their market acceptance.

\section{Nonenergy Benefits and Costs}

- Improves reactor safety because of improved component reliability and better information on component conditions.

- Reduces worker exposures to radiation as a result of shorter maintenance durations.

- Improved U.S. energy security and retention of U.S. nuclear infrastructure, international nuclear influence, and U.S. export potential.

\begin{tabular}{|c|c|c|c|c|c|c|c|c|}
\hline \multirow{2}{*}{\multicolumn{9}{|c|}{ Technical Risk }} \\
\hline & & & & & & & 9 & 10 \\
\hline
\end{tabular}

- Technologies require engineering development.

Commercial Risk

$\begin{array}{llllllllll}1 & 2 & \text { (3) } & 4 & 5 & 6 & 7 & 8 & 9 & 10\end{array}$

- Technologies must provide cost incentives for industry.

- Regulatory acceptance is issue.

Ecological Risk

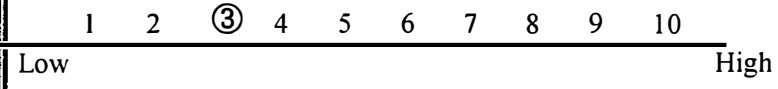

- $\quad$ Reduced wastes and emissions per unit of nuclear energy generated are expected.

\section{Risk Factors}

Human Health Risk

\begin{tabular}{|c|c|c|c|c|c|c|c|c|c|}
\hline 1 & 2 & (3) & 4 & 5 & 6 & 7 & 8 & 9 & 10 \\
\hline
\end{tabular}

- $\quad$ Reduced worker exposure to radiation per unit of nuclear energy generated is expected.

Economic Risk

\begin{tabular}{|c|c|c|c|c|c|c|c|c|c|}
\hline 1 & 2 & (3) & 4 & 5 & 6 & 7 & 8 & 9 & 10 \\
\hline Low & & & & & & & & & \\
\hline - $\quad \mathrm{V}$ & $\mathrm{y}_{\mathrm{h}}$ & h re & arn & in & est & & & & \\
\hline \multicolumn{10}{|c|}{ Regulatory Risk } \\
\hline 1 & 2 & 3 & 4 & (5) & 6 & 7 & 8 & 9 & 10 \\
\hline
\end{tabular}

- Required NRC approval and lack of demonstration of nuclear plant license renewal.

\section{Key Federal Actions}

- Initiate R\&D program for research on existing nuclear plant life extension and generation optimization technologies.

- Continue U.S. support for improved nuclear safety in former Soviet countries to reduce the risk of another major nuclear accident

- Maintain a healthy U.S. nuclear energy technology and education infrastructure. 


\subsection{NEXT-GENERATION FISSION REACTORS}

Technology Description

A new generation of fission reactors is required to replace or to provide extended capacity for existing LWRs in 2020 and beyond. Evolutionary LWRs of standardized design are available and have received NRC licensing certification. These reactors have been constructed (on schedule) in Japan and South Korea. Advanced LWRs of simplified design and with safety performance based on passive inherent processes are at a late stage of detailed design and NRC review. In the long term, reactors and fuel cycles that are more proliferation-resistant, produce less nuclear waste, and make better use of the energy content in uranium need to be developed.

\section{System Concepts}

- Evolutionary and advanced LWR designs: simple, rugged high-design margin, based on proven technologies. Approximately 1300 MWe (evolutionary) and $600 \mathrm{MWe}$ (passively safe), with a design life of 60 years.

- Advanced fission reactors and fuel cycles: concepts that aim to extract the full energy potential of the spent fuel from current generation reactors, while reducing or eliminating potential for proliferation of nuclear materials and technologies and limiting the amount of waste produced.

\section{Representative Technologies}

- Advanced PWR reactor system 80+

- $\quad$ Advanced BWR

- Advanced PWR AP600

- Liquid metal reactors

- High-temperature gas-cooled reactors

- Thorium cycle nuclear systems

- Long-life reactors

Technology Status/Applications

- Several evolutionary fission reactors, including the advanced PWR system 80+ and advanced BWRs, have received NRC design certification and are offered for sale. In addition, the advanced LWR AP600 is expected to receive final design approval and design certification soon.

- Advanced reactors and fuel cycles: development is at advanced stage; demonstration is incomplete.

- High-temperature gas-cooled reactor development is focused on high conversion efficiency through direct use of the high-temperature gaseous reactor coolant to power a gas turbine driving a generator (i.e., direct conversion).

- Advanced fuel cycle development has reached pilot demonstration stage in some cases.

\section{Current Research, Development, and Demonstration}

\section{RD\&D Goals}

- Advanced LWRs are available for construction.

- Future federal research should focus on reactors and fuel cycles that are more proliferation-resistant, produce less nuclear waste, and make better use of the energy content in uranium.

\section{RD\&D Challenges}

- $\quad$ None for advanced LWRs.

- Demonstrate technology for advanced concepts.

- Develop proliferation-resistant fuel cycle concepts.

- Develop safety, waste, and proliferation aspects of advanced fission reactors.

\section{RD\&D Activities}

- Federally funded development of advanced reactors and fuel cycles has been terminated in the United States.

- $\quad$ Mixed oxide fuel for excess weapons plutonium disposition.

- Treatment of selected spent nuclear fuel for waste disposal.

- There is no federal RD\&D budget for reactor development.

|cि Recent Success

- Advanced LWRs have received design certification from NRC.

- An advanced BWR is operating in Japan, having been built in less than 5 years. 
- Advanced LWRs are being developed overseas. Two advanced BWRs are operating in Japan, a system 80+ is under construction in Korea, and two advanced BWRs have been ordered by Taiwan.

- None are foreseen for the United States in the immediate future under present conditions.

- Carbon taxes or other incentives will make advanced LWRs cost competitive.

\section{Potential Benefits and Costs}

Carbon Reductions

- Estimated carbon emissions reductions are as follows:

$\begin{array}{ccc}2010 & 2020 & 2030 \\ 0 & \sim 10 \mathrm{MtC} / \text { year } & 10 \text { to } 40 \mathrm{MtC} / \text { year }\end{array}$

\section{RD\&D Expenditures}

$$
\sim 10 \mathrm{MtC} / \text { year } \quad 10 \text { to } 40 \mathrm{MtC} / \text { year }
$$

- Little or no funding needed for current generation advanced LWRs.

- Annual federal RD\&D budget required for this pathway: to 2010, \$50/M/year; 2010 to 2020, $\$ 100 \mathrm{M} /$ year; 2020 to $2030, \$ 150 \mathrm{M} /$ year.

Market

- Indeterminant at this time. Potentially large international and domestic markets.

Energy Resources

- With full use of the known U.S. uranium resources. nuclear can supply 65,000 quads.

Nonenergy Benefits and Costs

- Energy security; a reduction in dependence on oil.

- Maintenance of U.S. influence in world nuclear arena, facilitating U.S. policy goals.

\section{Risk Factors}

Technical Risk

$\begin{array}{llllllllll}\text { (1) } & 2 & 3 & 4 & 5 & 6 & \text { (7) } & 8 & 9 & 10\end{array}$

Low High

- For advanced ALWRs, the risk is small.

- Advanced fission reactors require large-scale technology demonstration before commercialization in 2030 and beyond.

Commercial Risk

\begin{tabular}{llllllllllll}
1 & 2 & 3 & 4 & 5 & 6 & 7 & 8 & 9 & 10 & \\
\hline Low & & & & & & & & & & & High
\end{tabular}

- Nuclear power has a mature infrastructure. Lack of purposeful progress toward a waste repository for the spent fuel is an issue. If no plant is ordered, the United States will eventually lose the capability to construct reactors.

Ecological Risk

\begin{tabular}{lllllllllll}
1 & 2 & 3 & 4 & 5 & 6 & 7 & 8 & 9 & 10 & \\
\hline Low & & & & & & & & & & High \\
& Small. & & & & & & & & & \\
-
\end{tabular}

Human Health Risk

\begin{tabular}{|c|c|c|c|c|c|c|c|c|c|}
\hline 1 & 2 & (3) & 4 & 5 & 6 & 7 & 8 & 9 & 10 \\
\hline
\end{tabular}

- Small.

Economic Risk

\begin{tabular}{llllllllllll}
1 & 2 & 3 & 4 & (5) & 6 & 7 & 8 & (9) & 10 & \\
\hline Low & & & & & & & & & & &
\end{tabular}

- $\quad$ Moderate for advanced ALWRs because of the economic effects of deregulation and political opposition.

- High for other reactors.

Regulatory Risk

$\begin{array}{llllllllll}\text { (1) } & 2 & 3 & 4 & \text { (5) } & 6 & 7 & 8 & 9 & 10\end{array}$

Low . High

- Low for the advanced ALWRs given NRC design certification.

- Moderate due to required NRC approval and need for demonstration.

\section{Key Federal Actions}

- Achieve purposeful progress toward the creation and licensing of a repository for spent nuclear fuel.

- $\quad$ Restart R\&D on advanced fission reactor concepts, possibly using international collaboration. 


\subsection{FUSION POWER}

Technology Description

Particle inertia or magnetic fields are used to confine a hot plasma to produce energy from deuterium/tritium fuel. Deuterium is abundantly available from water, and tritium is produced within the fusion plant from abundant lithium. The energy of the fusion reactions is used to generate electricity at central power plants.

System Concepts

- $\quad$ Strong magnetic fields produced by superconducting coils confine plasmas with temperatures of several hundred million degrees Celsius. Some heat from the fusion reactions remains in the fuel to sustain its high temperatures; the rest is carried out by neutrons to be absorbed in a surrounding blanket that serves both as a heat source to produce power and as a medium for producing the tritium.

- Compressed fuel microcapsules ignite and burn, producing repetitive pulses of heat in a reaction chamber. Multiple chambers for each beam can improve efficiency, and flowing liquid metal walls in the chamber can serve as blankets.

Representative Technologies

- Large, high-current density superconducting magnets, ion beams (energies 100-1000 keV), millimeter wave high-power microwaves, highpower radio-f requency sources and launchers, and particle fueling apparatus.

- Heavy and light ion beam accelerators, solid-state and exciter-gas lasers, and target fabrication technologies are required for inertial fusion.

- Structural materials with low activation properties will eventually be required to fulfill the ultimate potential of fusion devices. Tritium generation and heat recovery systems are other common nuclear system technologies required for both.

Technology Status/Applications

- Moderate size fusion experiments in tokamaks, with plasmas at temperatures needed for power plants, have produced more than $10 \mathrm{MW}$ of fusion power.

- A commercial power plant scale tokamak ( $1500 \mathrm{MW}_{\text {th }}$ ) is being designed in an international project by the world's major fusion institutions.

- The physics of sub-ignited targets has been developed with glass lasers, and underground test results have resolved feasibility questions of high gain for power plants.

- The target physics of ignition and high gain, using glass lasers, are objectives of the National Ignition Facility (NIF), now under construction.

\section{Current Research, Development, and Demonstration}

\section{RD\&D Goals}

- Optimize the toroidal magnetic option for an attractive fusion power plant; maintain a vigorous search for improved magnetic concepts; and collaborate in an international project to demonstrate sustained fusion power production at the gigawatt (thermal) level in a tokamak.

- Establish the technological basis for an efficient, low-cost ion beam using an induction accelerator, and demonstrate useful gain from compression and burn of NIF targets.

- Qualify low-activation materials that allow fusion plants to achieve their ultimate environmental potential.

\section{RD\&D Challenges}

- Develop magnetic geometries optimal for heat containment that at the same time (1) minimize technical complexity, (2) maximize fusion power density for good economics, and (3) operate in a continuous mode.

- Understand target requirements for high gain; reduce the development cost of candidate drivers; and develop long-life chambers and lowcost microcapsule targets.

- Develop low-activation materials that also meet structural and compatibility criteria.

\section{RD\&D Activities}

- Coordinated world-wide magnetic fusion physics efforts center on improved performance. Programs to advance various technologies are proceeding at different paces, with materials and nuclear technologies lagging.

- Inertial fusion efforts are concentrated on igniting fusion targets.

- Modest efforts to develop beam and laser driver technologies have begun in several programs around the world.

- $\quad$ The FY 1997 U.S. budget is $\$ 232 \mathrm{M}$.

\section{Recent Success}

- More than $10 \mathrm{MW}$ of fusion power was produced in a tokamak for about 1 second, using deuterium-tritium fuel.

- New tokamak modes of operation that could lead to high-performance continuous operation have been discovered.

- Results from underground tests in the United States have resolved fundamental questions of feasibility of high gain for efficient fusion power plants.

- Results from the NOVA laser at Lawrence Livermore National Laboratory have confirmed the validity of computer models used to predict ignition and gain in the NIF.

- Vanadium alloys show promise as a low-activation structural material in magnetic fusion devices, and liquid walls for inertial fusion chambers promise to avoid life-limiting radiation damage. 
- Large central-station electrical generating plants could be commercialized late in the second quarter of the twenty-first century; the timescale depends on a sustained international effort and success in that R\&D.

- Fusion power plants would replace aging and environmentally abusive power generators and fill a potential multi-billion dollar market sector.

- Many technologies developed for fusion are currently used in the commercial sector. Prominent are plasma processing for etching semiconductor chips, hardening of metals, thin-film deposition, and plasma spraying and lighting applications. Other applications arising from this research include medical imaging, heat removal technologies, destruction of toxic waste, X-ray lithography and microscopy, microimpulse radar, precision laser cutting, large-scale production of precision optics, and high-power microwave and accelerator technologies.

\section{Potential Benefits and Costs}

\section{Carbon Reductions}

- By late in the next century, fusion power could reduce carbon emissions by $500 \mathrm{MtC} / \mathrm{year}$.

\section{RD\&D Expenditures}

- $\quad$ FY 1997 federal RD\&D expenditures were \$232M.

- PCAST has recommended the federal budget increase to $\$ 280 \mathrm{M} / y e a r$. This study agrees with that funding estimate. This level would maintain a program focused on three key principles: (1) a strong domestic core program in plasma science and fusion technology; (2) a collaboratively funded international fusion program focused on ignition and moderately sustained burn; and (3) participation in an international program to develop practical low-activation materials for fusion energy systems.

- Present worldwide levels ( $\sim \$ 1.5 \mathrm{~B} /$ year) are required through 2020 . When large-scale pilot or demonstration plants are appropriate, additional funding may be needed.

Market

- Undetermined at this time.

Energy

- $\quad$ Could provide unlimited energy if economically viable.

Nonenergy Benefits and Costs

- Energy security, owing to the easy availability of its fuel, would be ensured. Fusion plants present no proliferation issues and are inherently safe against thermal runaway excursions.

\begin{tabular}{||lllllllllll}
\hline \multicolumn{1}{||}{ Technical Risk } & & & & & & & & & \\
1 & 2 & 3 & 4 & 5 & 6 & 7 & 8 & 9 & 10 & High \\
\hline Low & & & & & & & & &
\end{tabular}

- The scientific risk is moderate. Confidence in producing fusion power will come from the next (international) step in the magnetic fusion program and the NIF research on targets.

- Technology risk is high, given the technical complexity.

Commercial Risk

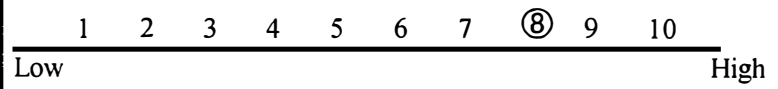

- Marketplace energy cost is $2-3$ cents/kWh; power costs are 6-10 cents $/ \mathrm{kW}$. The cost of fusion power could improve somewhat; competing systems may become more costly if environmental costs are included.

Ecological Risk

$\begin{array}{lllllllllll}1 & \text { (2) } & 3 & 4 & 5 & 6 & 7 & 8 & 9 & 10 & \text { High }\end{array}$

- Operation poses very low ecological risk.

- If low-activation materials are used, plant decommissioning generates low-level waste of low risk to the environment.

\section{Risk Factors}

Human Health Risk

\begin{tabular}{|c|c|c|c|c|c|c|c|c|c|}
\hline 1 & (2) & 3 & 4 & 5 & 6 & 7 & 8 & 9 & 10 \\
\hline
\end{tabular}

- Health risks to the public are low, and worker health and safety should be controlled by procedures.

Economic Risk

\begin{tabular}{llllllllllll}
1 & 2 & 3 & 4 & 5 & 6 & 7 & (8) & 9 & 10 & \\
\hline Low & & & & & & & & & & & High
\end{tabular}

- Plant capital costs will be high

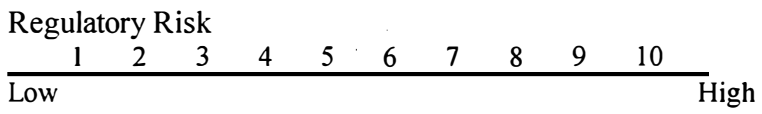

- Not applicable. Fusion should come under regulations different from those for fission.

\section{Key Federal Actions}

- Federal R\&D funding for fusion is essential and requires a long term commitment.

- The United States' part in the international effort needs to be strongly coordinated with all other work in fusion.

- Industrial involvement will be essential once feasibility is established. 



\title{
Clean Energy Technologies
}

\author{
8. Renewable Energy
}

8.1 Biomass Electric

8.2 Wind Energy

8.3 Advanced Hydropower

8.4 Solar Photovoltaics

8.5 Geothermal Energy

8.6 Solar Thermal Electric and Buildings

8.7 Biomass Transportation Fuels

8.8 Solar Advanced Photoconversion 


\subsection{BIOMASS ELECTRIC}

Technology Description

Biomass electric, also called biomass power or biopower, is the generation of electric power from biomass resources ranging from agricultural and forest product residues to crops grown specifically for energy production. Biopower reduces GHG emission by substituting biomass for coal in existing power plants or using biomass alone in plants that displace new fossil plants. Since biomass absorbs $\mathrm{CO}_{2}$ as it grows, the entire biopower process of growing, burning, and regrowing biomass can result in very low $\mathrm{CO}_{2}$ emissions, depending on the amount of fossil fuel used for fertilization, cultivation, transportation, and so on.

\section{System Concepts}

- Direct combustion systems burn biomass in a boiler to produce steam that is expanded to produce power.

- Cofiring substitutes biomass for coal in existing coal-fired boilers. The highest levels of cofiring ( $15 \%$ on a heat input basis) require separate feed preparation and injection systems.

- Gasification converts biomass to a fuel gas that can be substituted for natural gas in combustion turbines.

\section{Representative Technologies}

- For the near term, cofiring is the most cost-effective method. Large coalfired plants are more efficient (35\%) than typically smaller biomass-only plants ( 20\%).

- Biomass gasification combined cycle plants promise comparable or higher efficiencies ( $>40 \%$ ) using only biomass because they are more efficient than steam cycles. Other technologies being developed include integrated gasification/fuel cell concepts.

Technology Status/Applications

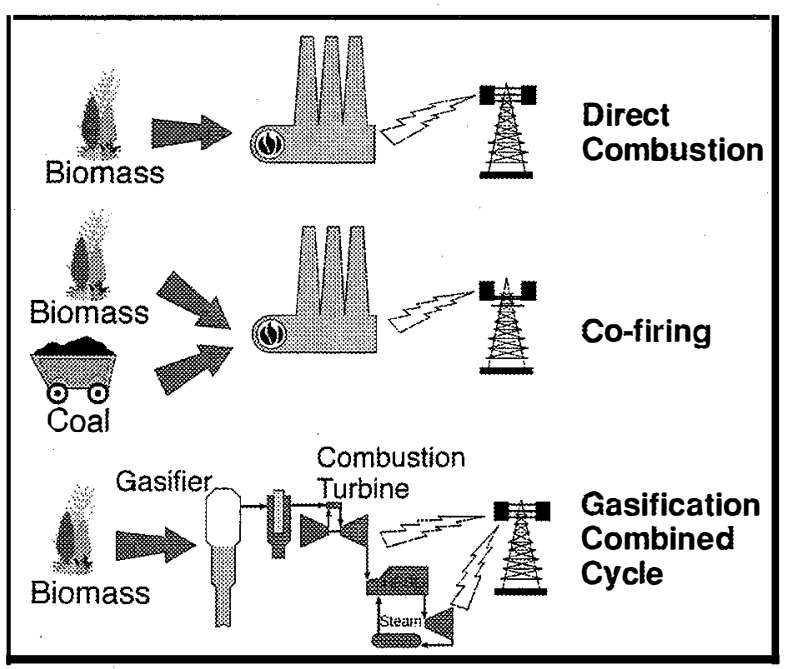

- The existing biopower industry, nearly 1000 plants, consists of direct combustion plants with a small amount of cofiring. Plant size averages $20 \mathrm{MWe}$, and the biomass-to-electricity conversion efficiency is about $20 \%$. Grid-connected electrical capacity has increased from less than $200 \mathrm{MWe}$ in 1978 to over $7500 \mathrm{MWe}$. More than $70 \%$ of this power is cogenerated with process heat in the forest products and sugarcane industries. Wood-fired systems account for $88 \%$, landfill gas $8 \%$, agricultural waste $3 \%$, and anaerobic digestion $1 \%$. In addition, about $2650 \mathrm{MW}$ of municipal solid waste cogeneration capacity exists. Prices range from 8 to $12 \mathrm{c} / \mathrm{kWh}$.

- Biomass gasification for large-scale power production is being commercialized. It will be an important technology for cogeneration in the forest products and sugarcane industries, as well as for new base load capacity. The projected cost of electricity from a gasification plant of $50 \mathrm{MWe}$ or more is $\sim 8 c / \mathrm{kWh}$.

\section{Current Research, Development, and Demonstration}

\section{RD\&D Goals}

By 2005:

- Develop feedstock crops with a yield potential of 6-8 dry ton/acre/year.

- Reduce the capital cost of gasification-based systems to $<\$ 1900 / \mathrm{kW}$.

- Establish $2000 \mathrm{MW}$ of cofired capacity.

By 2010:

- Reduce the capital cost of gasification-based systems to $<\$ 1500 / \mathrm{kW}$, giving an energy cost of $4-5 \notin / \mathrm{kWh}$ using energy crops.

- $\quad$ Expand cofired capacity to over $5000 \mathrm{MW}$.

- Establish approximately $2000 \mathrm{MW}$ of gasification-based capacity.

- Increase the recovery and use of landfill gas significantly at more than 5000 sites.

By 2020:

- Demonstrate advanced gas turbine technologies with biomass gasification.

- Demonstrate biomass-fuel cell power technology

- Reduce the capital cost of gasification-based systems to $<\$ 1200 / \mathrm{kW}$.

- Develop feedstock crops with a yield potential of 8-10 dry ton/acre/year.

- Develop a total biomass-based generating capacity in excess of 30,000 MW.

- Research on advanced concepts such as fuel-cell/thermophotovoltaic hybrids

\section{RD\&D Challenges}

- Resolving ash chemistry and deposition issues in cofiring applications and establishing cofiring ash as an acceptable material for coal ash markets.

- Determining mechanisms of and the best methods to achieve $\mathrm{NO}_{\mathrm{x}}$ reduction in cofiring.

- Demonstrating long-term operation of gas turbines on cleaned biomass synthesis gas.

- Resolving gaps in data required for life-cycle analyses to verify carbon savings (e.g., soil carbon, GHG effects of composting yard waste).

- Resolving materials issues for increasingly severe environments for combustion and gasification/gas turbine systems.

- Fostering successful energy crop business structures.

\section{RD\&D Activities}

- Complementary activities are under way at several DOE laboratories in cofiring and crop development, along with supporting R\&D in USDA. One program has four on-going efforts to establish feedstock provider systems and, in phases, perform detailed plant design, permitting, and eventually technology demonstration for cofiring, direct combustion, and gasification systems.

- DOE Biomass Power Program funding was \$26M in FY 1997. 
- Identifying the fouling mechanisms in commercial combustion equipment provided a way to mitigate the problem and has resulted in innovative approaches to alternative combustion technologies. One approach is applying ceramic filter elements to the hot-gas cleaning process for high-pressure air gasification; it is currently in long-term testing.

\section{Commercialization and Deployment}

- Biopower capacity in the United States is $10 \mathrm{GW} ; 2 / 3$ is grid-connected, and the remaining facilities offset power purchases. Capacity in the rest of the world is about $20-25 \mathrm{GW}$. U.S. investment in equipment is $\$ 300 \mathrm{M}$ to $\$ 500 \mathrm{M} /$ year. At least six major engineering procurement and construction companies and several multinational boiler manufacturers are active. Competing technologies include lowcost subsidized fuels abroad and biomass technologies developed in Scandinavia. Guarantees and warranties are a significant issue, giving established technologies an advantage despite their lower efficiency and higher carbon emissions compared with advanced IGCC and other advanced modular technologies. The critical challenge to widespread deployment is cost and reliability of the fuel supply, especially outside industries such as sugar and pulp and paper. Lack of well-demonstrated performance of advanced technologies continues to be a barrier to implementation.

\section{Potential Benefits and Costs}

\section{Carbon Reductions}

2010: 10-20 MtC/year; 2020: 15-25 MtC/year; 2030:

25-40 MtC/year (not including landfill gas).

- This assumes significant RD\&D investment in crop and infrastructure development, optimizing cofiring benefits and costs, and demonstrating gasification-based technologies.

- It is assumed that cofiring will directly replace coal power generation and gasification systems will replace the average power system carbon emissions.
RD\&D Expenditures

- $\quad$ DOE Biomass Power Program funding: \$24M in FY 1996 and \$26M in FY 1997; no other significant federal funding. U.S. funding including the private sector: $\sim \$ 36 \mathrm{M}$. The largest nonU.S. effort is within the European Union. Total public and private investment in R\&D is about $\$ 50 \mathrm{M}$.

- $\quad$ Estimated federal funding required to achieve the target market penetrations is $\$ 69 \mathrm{M} /$ year in $2000-2010, \$ 87 \mathrm{M} /$ year in 2010-2020, and \$127M/year in 2020-2030.

\section{Market}

- The estimated cofiring cumulative capacity is $5750 \mathrm{MW}$ in 2010 and beyond, including $400 \mathrm{MW}$ of existing capacity. The estimated direct combustion capacity is about $7000 \mathrm{MW}$ currently, 8250 in 2010,8650 in 2020, and 9100 in 2030. The estimated IGCC capacity is 1,950 in $2010,7,100$ in 2020 , and 16,350 in 2030.

Nonenergy Benefits and Costs

- Rural economic development due to employment in feedstock production and transportation. Major export potential (cumulative 3 trillion $\mathrm{kWh}$ demand growth in non-OECD Asia through 2010); potential job reductions in mining industry.

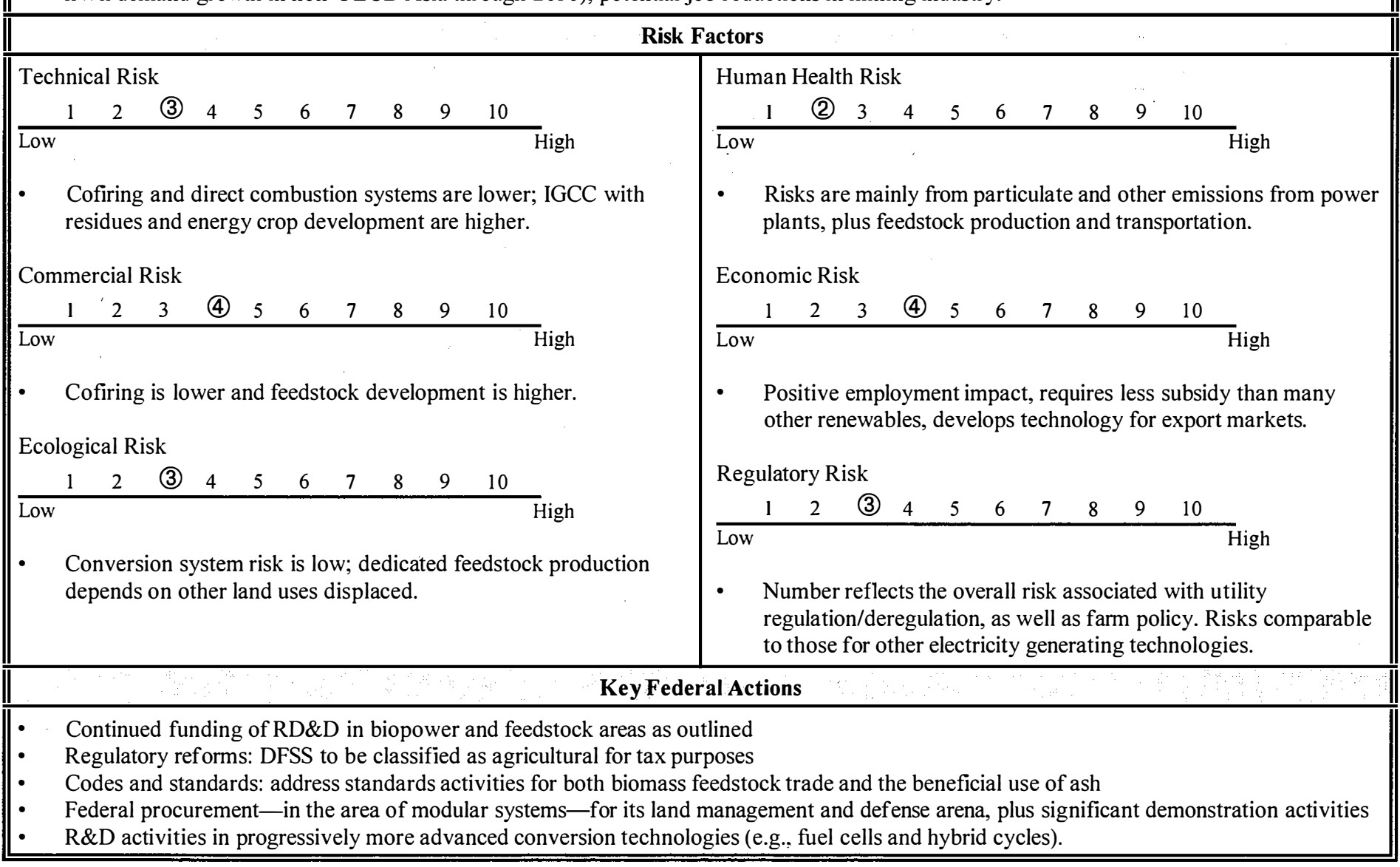




\subsection{WIND ENERGY}

\section{Technology Description}

Wind turbine technology converts the kinetic energy in the wind to mechanical energy and ultimately to electricity. Grid-connected wind power reduces GHG emissions by displacing the need for natural gas- and coal-fired generation. Village and of f-grid applications are important for displacing diesel generation and for improving quality of life, especially

overseas.

\section{System Concepts}

- The principle of wind energy conversion is simple: wind passing over the blade creates lift, producing a torque on the rotor shaft that turns a gearbox. The gearbox is coupled to an electric generator that produces power at the frequency of the host power system.

\section{Representative Technologies}

- Two major design approaches are being used: (1) typical of historic European technology - stiff, heavy machines that resist cyclic and extreme loads, and (2) lightweight, flexible machines that bend and absorb loads, primarily being developed by U.S. designers. Several alternative configurations within each approach are being pursued.

\section{Technology Status/Applications}

- Thirty-seven states have land area with good winds ( $13 \mathrm{mph}$ annual average at $10 \mathrm{~m}$ height, wind class 4 , or better).

- Current performance is characterized by levelized costs of 3 to $7 \phi / \mathrm{kWh}$ (depending on resource intensity and financing structure), capacity factors of 25 to $35 \%$, a vailability of 95 to $98 \%$, total installed costs of $\$ 1000 / \mathrm{kW}$, and efficiencies of 65 to $70 \%$ of theoretical (Betz limit) maximum.

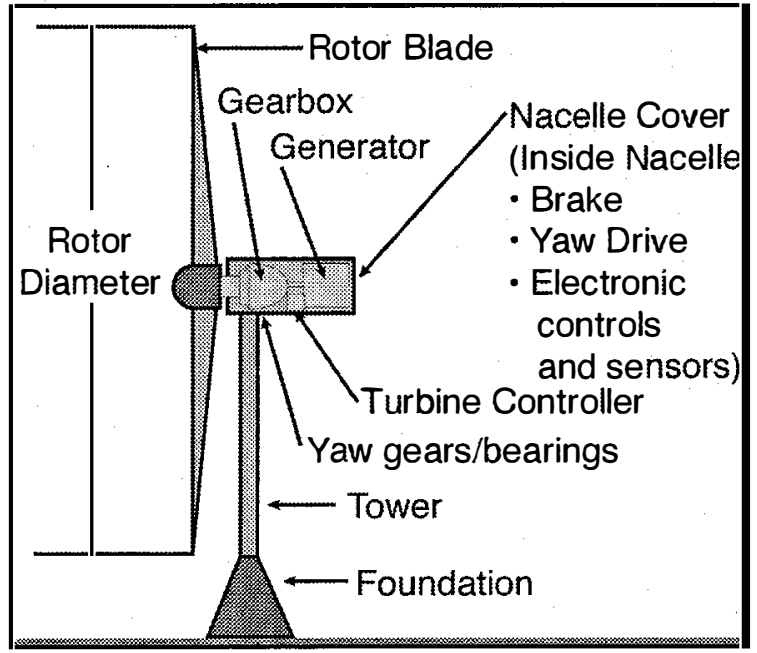

\section{Current Research, Development, and Demonstration}

\section{RD\&D Goals}

- Windfarm cost/performance varies by wind resource class, ownership type, and time. Current costs are 4 to $7 \phi / k W h$; goals in 2000 are 2.5 to $4.4 \mathrm{c} / \mathrm{kWh}$; goals in 2010 are 2.0 to $3.1 \mathrm{c} / \mathrm{kWh}$; goals in 2030 are 1.7 to $2.8 \mathrm{c} / \mathrm{kWh}$.

\section{RD\&D Challenges}

- Optimize a wind turbine system to operate for 30 years in a fatigue-driven environment with minimal or no component replacements using knowledge of the wind inflow, operative aerodynamics, resulting structural dynamics, and optimal control of the turbine and windfarm. Understanding the interactions between the wind input and among components as turbine size increases is the fundamental challenge.

RD\&D Activities

- Core and university research: wind characteristics, aerodynamics, structural dynamics and fatigue, control systems for turbines and hybrid systems. FY 1998 request: $\$ 14.1 \mathrm{M}$

- Turbine research: cost-shared design and testing of next-generation utility-grade turbines, improvements in existing turbine designs, verification of performance of turbine prototypes, and development of small turbines using tools and methods from the larger turbine effort. FY 1998 request: $\$ 19.7 \mathrm{M}$.

- Cooperative research and testing: prototype testing at the National Wind Technology Center, collection of wind turbine performance data and related analysis, support of industry stakeholders such as the National Wind Coordinating Committee, and support for international consensus standards and certification for wind turbines as required in overseas markets. FY 1998 request: \$9.1 M.

- DOE appropriations were \$32M in FY 1996 and \$29M in FY 1997, and there is no other significant federal funding. The European Union and member countries spend about $\$ 120 \mathrm{M}$ per year.

\section{Recent Success}

- In 1989 the wind program set a goal of $5 \phi / \mathrm{kWh}$ by 1995 and $4 \phi / \mathrm{kWh}$ by 2000 . The program and the wind industry met the goals as part of dramatic cost reductions from $25-50 \phi / \mathrm{kWh}$ in the early $1980 \mathrm{~s}$ to $3-7 \phi / \mathrm{kWh}$ today (depending on wind resource and financial structure).

- The National Wind Technology Center (operated by the National Renewable Energy Laboratory in Golden, Colorado), is recognized as a world-class center for wind energy R\&D and has many facilities not otherwise available to the domestic industry or its overseas competitors.

- The worldwide annual market growth rate for wind technology is at a historic maximum of $20 \%$ with new markets opening in many developing countries. Domestic public interest in environmentally responsible electric generation technology is reflected in the success of "green marketing" of wind power across the country. 
Wind technology is competitive today only in high-value niche applications or markets that recognize non-cost attributes. It should be competitive by 2005 without changes in policies and should have no added cost after that. Substantial cost reductions are expected.

- For windfarm or wholesale power applications, the principal competition is natural gas for new construction. Utility restructuring is a critical challenge to increased deployment in the near term because it emphasizes short-term, low-capital-cost alternatives and lacks public policy to support deployment of sustainable technologies like wind energy.

- About $1790 \mathrm{MW}$ of capacity are installed in the United States, principally in California, although projects in Minnesota, Iowa, Vermont, and Texas have recently been installed. Worldwide, $7000 \mathrm{MW}$ is installed and large growth rates illustrate the industry's ability to rapidly increase production with the proper market incentives.

- In the United States, the wind industry is thinly capitalized, except for the acquisition of Zond Corporation by Enron, and there have been two bankruptcy filings recently. About six manufacturers and six to ten developers characterize the U.S. industry.

- In Europe, there are about 12 turbine manufacturers and about 20 to 30 project developers. European manufacturers have established North American manufacturing facilities and are actively seeking sales.

- Initial lower levels of wind deployment (up to $15-20 \%$ of the total U.S. electric system capacity) are not expected to introduce significant grid reliability issues. Inasmuch as the wind blows only intermittently, intensive use of this technology at larger penetrations may require additional backup capacity or ancillary services.

\section{Potential Benefits and Costs}

\section{Carbon Reductions}

- Wind energy produces zero carbon emissions per kilowatt hour.

- Wind energy without additional storage can reduce GHG emissions through displacing coal- and natural gas-fired power plants.

201 0: 3-6 MtC/year; 2020: 15-30 MtC/year; 2030: 30-45 MtC/year

\section{Market}

- The principal market for wind energy is substitution for new natural gas combined cycle plants (expected to be $57 \mathrm{GW}$ in 2010 and $348 \mathrm{GW}$ in 2030) and replacement of coal-generated power plants (expected to be $304 \mathrm{GW}$ in 2010 and $424 \mathrm{GW}$ in 2030).

\section{Nonenergy Benefits and Costs}

- Benefits include no air emissions through use of wind, low fuel risk, short construction times, modular technology, and sustainable development. For village power systems, benefits include displaced high-cost diesel fuel, carbon offsets, and improved rural qualify of life.

\begin{tabular}{||ccccccccccc} 
Technical Risk & & & & & & & & & & \\
1 & 2 & 3 & 4 & 5 & 6 & 7 & 8 & 9 & 10 & High \\
\hline Low & & & & & & & & & &
\end{tabular}

- $\quad$ Risk is mitigated by multiple technical approaches to achieve cost/performance projections.

Commercial Risk

$\begin{array}{llllllllllll}1 & 2 & 3 & 4 & 5 & 6 & 7 & 8 & 9 & 10 & \text { High }\end{array}$

- Near-term, policies are needed that recognize non-cost values such as climate change mitigation and other societal factors. Ultimate impact of green pricing programs is unknown.

Infrastructure changes are virtually none in the near term, but significant in the far term. Resource base is unlimited.

Ecological Risk

\begin{tabular}{|c|c|c|c|c|c|c|c|c|}
\hline 1 & (2) & 3 & 4 & 5 & 6 & 7 & 8 & 9 \\
\hline
\end{tabular}

- Minimal because there are no emissions and minor land use impacts. Visual, avian, and noise impacts must be considered for large projects.

\section{Risk Factors}

Human Health Risk

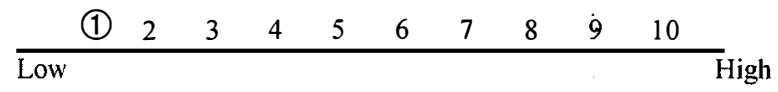

- $\quad$ Properly sited wind energy development should have no impact on human health.

Economic Risk

\begin{tabular}{lllllllllll}
1 & 2 & (3) & 4 & 5 & 6 & 7 & 8 & 9 & 10 & \\
\hline Low & & & & & & & & & &
\end{tabular}

- $\quad$ Near-term utility restructuring issues increase competitive risk. Public perception is positive.

Regulatory Risk

$\begin{array}{lllllllllll}1 & 2 & 3 & 4 & 5 & 6 & 7 & 8 & 9 & 10 & \text { High }\end{array}$

- Many potential impacts from the outcome of utility restructuring, the need for early deployment incentives, continuation of research funding, tax parities, many levels of government involved.

\section{Key Federal Actions}

- Support a strong RD\&D program, including power system integration, transmission, and energy storage needed for high penetration.

- Provide near-term market stimulus to overcome barriers, resulting in several competitive manufacturers with domestic and international sales.

- Develop a restructured electric market that recognizes non-cost benefits of wind and the externalities of conventional fossil/nuclear through incentives, pollution taxes, mandates, etc.

- Ensure U.S. technology is competitive in international market (certification, tied aid). 


\subsection{ADVANCED HYDROPOWER}

\section{Technology Description}

Advanced hydropower technology improves on available techniques for producing hydroelectricity by eliminating adverse environmental impacts and increasing generation and other operational efficiencies. Current technology often has adverse environmental effects, such as fish entrainment/impingement and the alteration of downstream water quality and quantity. The goal of advanced hydropower technology is to maximize the use of water for hydroelectric generation while eliminating these adverse side effects.

\section{System Concepts}

- Conventional hydropower projects use either impulse or reaction turbines to convert kinetic energy in flowing/falling water to turbine torque and power. Source water is either diverted from free-flowing rivers/streams/canals or released from upstream storage reservoirs.

- Improvements and efficiency measures are needed in dam structures, turbines, generators, substations and transmission lines, and environmental mitigation technology to sustain hydropower's role as a clean, renewable energy source.

\section{Representative Technologies}

- Autoventing turbines to increase dissolved oxygen in discharges.

- $\quad$ Reregulating and aerating weirs used to stabilize tailwater discharges and improve water quality.

- Adjustable-speed generators producing hydroelectricity over a wider range of heads and providing more uniform instream flow releases without sacrificing generation opportunities.

- $\quad$ Fish-friendly turbine designs that minimize entrainment mortality during passage.

- New assessment models to determine instream flow needs of fish below hydropower projects.

- Advanced instrumentation and control systems that adapt turbine operation to maximize environmental benefits.

\section{Technology Status/Applications}

- Hydropower currently generates $10 \%$ of the nation's electricity, including $98 \%$ of the electricity produced from renewable sources.

- Existing hydropower generation is declining because of a combination of real and perceived environmental problems, regulatory pressures, and changes in energy economics (deregulation, etc.); potential hydropower resources are not being developed for similar reasons.

- Some new, environmentally friendly technologies are being implemented, but lack of financial incentives are hindering rapid development.

- After a successful conceptual design phase, DOE's Advanced Hydropower Turbine System (AHTS) program is stalled as a result of lack of funding.

\section{Current Research, Development, and Demonstration}

\section{RD\&D Goals}

- By 1999: Develop a quantitative understanding of the responses of fish to multiple stresses inside a turbine and produce biological performance criteria for use in advanced turbine design.

- By 2001: Complete environmental mitigation studies on topics such as instream flow needs to produce more efficient and less controversial regulatory compliance.

- By 2005: Complete full-scale prototype testing of AHTS designs, verifying biological performance.

\section{RD\&D Challenges}

- Develop computational fluid dynamics models of forces inside hydropower turbines that can predict stress levels on fish and can be used in advanced turbine design.

- Demonstrate the cost-effectiveness of retrofitting new technology at existing hydropower plants.

- Quantify the biological response of fish and other organisms so that environmental mitigation can be designed effectively.

\section{RD\&D Activities}

- DOE funding was $\$ 1 \mathrm{M} /$ year in FY 1997 , and there is no other significant federal funding.

- DOE's AHTS program has completed Phase I conceptual designs; industry initially provided approximately $50 \%$ of the funding for this program but has been unable to continue support because of financial pressures from deregulation.

- Large annual hydropower budgets in the Army Corps of Engineers and Bonneville Power Administration are producing important new understanding, but commercial applications are unlikely because of pressures from industry deregulation and environmental regulation.

\section{Recent Success}

- TVA's Lake Improvement Plan has demonstrated that improved turbine designs can be implemented with significant economic and environmental benefits.

- EPRI's CompMech Program has demonstrated multimillion dollar cost savings in regulatory compliance by applying new assessment technology for the New England Power Company. 
Voith Hydro and TVA have established a limited partnership to market environmentally friendly technology at hydropower facilities. Their products were developed in part by funding provided by DOE and the Corps of Engineers, as well as private sources.

- Flash Technology is developing strobe lighting systems to force fish away from hydropower intakes and to avoid entrainment mortality in turbines.

\section{Potential Benefits and Costs}

\section{Carbon Reductions}

- The current trend is to replace hydropower with electricity from fossil fuels. This trend leads to increases in GHG and should be reversed.

- Hydropower generation produces zero carbon emissions and, if fossil fuels were used as the alternative energy source, would displace 5-10 MtC/year in 2010, 10-15 MtC/year in 2020, and $15-30 \mathrm{MtC} /$ year in 2030.

\section{Market}

- Advanced hydropower products can be applied at more than $80 \%$ of existing hydropower projects (installed conventional capacity is now $78 \mathrm{GW}$ ); the potential market also includes $15-20 \mathrm{GW}$ at existing dams without hydropower facilities (i.e., no new dams required for development) and about $30 \mathrm{GW}$ at undeveloped sites that have been identified as suitable for new dams.

\section{Nonenergy Benefits and Costs}

- There would be significant environmental benefits from installing advanced hydropower technology, including enhancement of fish stocks, tailwater ecosystems, and recreational opportunities. These benefits would occur because the advanced technology reverses adverse effects of the past.

- Additional benefits would come from the protection of a wide range of ancillary benefits that are provided at hydropower projects but are at extreme risk of becoming lost in the new deregulated environment.

\begin{tabular}{|c|c|c|c|c|c|c|c|c|c|}
\hline \multicolumn{10}{|c|}{ Technical Risk } \\
\hline 1 & & 3 & 4 & 5 & 6 & 7 & 8 & 9 & 10 \\
\hline \multicolumn{10}{|l|}{ Low } \\
\hline \multicolumn{10}{|c|}{$\begin{array}{l}\text { Existing technology and research methods need to be ap } \\
\text { environmentally oriented objectives. }\end{array}$} \\
\hline \multicolumn{10}{|c|}{ Commercial Risk } \\
\hline 1 & 2 & 3 & (4) & 5 & 6 & 7 & 8 & 9 & 10 \\
\hline
\end{tabular}

- Industry maintains there is a very large market for improved environmental management techniques at hydropower projects in the United States and abroad; however, the barrier of high capital costs for installation would have to be overcome.

Ecological Risk

\begin{tabular}{|c|c|c|c|c|c|c|c|c|c|}
\hline 1 & (2) & 3 & 4 & 5 & 6 & 7 & 8 & $9^{\circ}$ & 10 \\
\hline
\end{tabular}

- The new hydropower technology will eliminate adverse environmental effects - the net programmatic ecological impacts are positive.

\section{RD\&D Expenditures}

- DOE budgets would have to increase from the current level of $\$ 1 \mathrm{M} /$ year up to $\$ 10 \mathrm{M} /$ year and remain at that level through 2010 . Thereafter, through $2030, \$ 1 \mathrm{M} /$ year would be needed.

\section{Risk Factors}

Human Health Risk

\begin{tabular}{lllllllllll}
1 & (2) & 3 & 4 & 5 & 6 & 7 & 8 & 9 & 10 & \\
\hline Low & & & & & & & & & &
\end{tabular}

- $\quad$ Changes in project design and operation would involve the same risks as any comparable construction activity.

Economic Risk

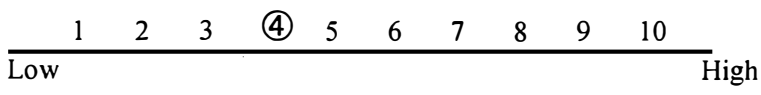

- Public acceptance of multipurpose water projects, including hydropower, should be forthcoming if environmental protection can be demonstrated.

Regulatory Risk

\begin{tabular}{lllllllllll}
1 & 2 & 3 & 4 & 5 & 6 & 7 & 8 & 9 & 10 & \\
\hline Low & & & & & & & & & &
\end{tabular}

- $\quad$ Regulatory and resource agencies are willing to participate in testing programs and accept new technologies if they are proven.

\section{Key Federal Actions}

- Reverse declining research investments in industry and federal government caused by industry deregulation and other economic/regulatory pressures on the hydropower industry.

- Take a leadership role in technology transfer to ensure that new hydropower technologies reach commercial applications and are accepted by environmental regulators, natural resource managers, and the public.

- Build partnerships among industry, regulators, and natural resource agencies to minimize local environmental effects of hydropower while realizing global benefits of increased GHG-free generation. 
Technology Description

Photovoltaic (PV) devices convert sunlight to electricity without moving parts and without producing fuel wastes, air pollution, or GHGs. A PVgenerating station $140 \mathrm{~km}$ by $140 \mathrm{~km}$ in area at an average solar site in the United States could generate all of the electricity needed in the country $\left(2.5 \times 10^{6} \mathrm{GWh} /\right.$ year), assuming a system efficiency of $10 \%$ and an area packing factor of $50 \%$ (to avoid self-shading). A well-planned transition to solar PV for electricity and transportation could make serious inroads in reducing $\mathrm{CO}_{2}$.

\section{System Concepts}

- Flat-plate PV arrays use global sunlight; concentrators use direct sunlight. Modules are mounted on a stationary array or on single- or dual-axis sun trackers. Arrays can be ground-mounted or on all types of buildings and structures. PV dc output can be conditioned into grid-quality ac electricitý, or dc can be used to charge batteries or to split water to produce $\mathrm{H}_{2}$.

- PV systems are expected to be used in the United States for residential and commercial buildings, peak power shaving, and intermediate daytime load following; with electric storage and improved transmission, systems could be used for dispatchable electricity and $\mathrm{H}_{2}$ production in the future.

- Most locations in the United States and worldwide have enough sunlight to make PV usefinl locally.

\section{Representative Technologies and Status}

- Wafers of single-crystal or polycrystalline silicon (cells: $24 \%$ efficiency; commercial modules: $13 \%-15 \%)$. Si modules dominate the PV market and currently cost about $\$ 3 / \mathrm{W}_{\mathrm{p}}$.

- Thin-film materials (e.g., amorphous silicon, copper indium diselenide, cadmium telluride, polycrystalline silicon, and dye-sensitized cells) (cells: $12 \%-18 \%$; commercial modules: $5 \%-7 \%$; best prototypes modules: $9 \%-11 \%)$. A new generation of thin-film PV modules is going through a rapid and high-risk commercialization period.

- High-efficiency single-crystal Si and multijunction GaAs-alloy cells for concentrators (cells: $25 \%-30 \%$ efficient; commercial modules: $15 \%-17 \%$ ).

- PV systems currently sell for about $\$ 5-\$ 10 / \mathrm{W}_{\mathrm{p}}$, including support structures, power conditioning, and land.

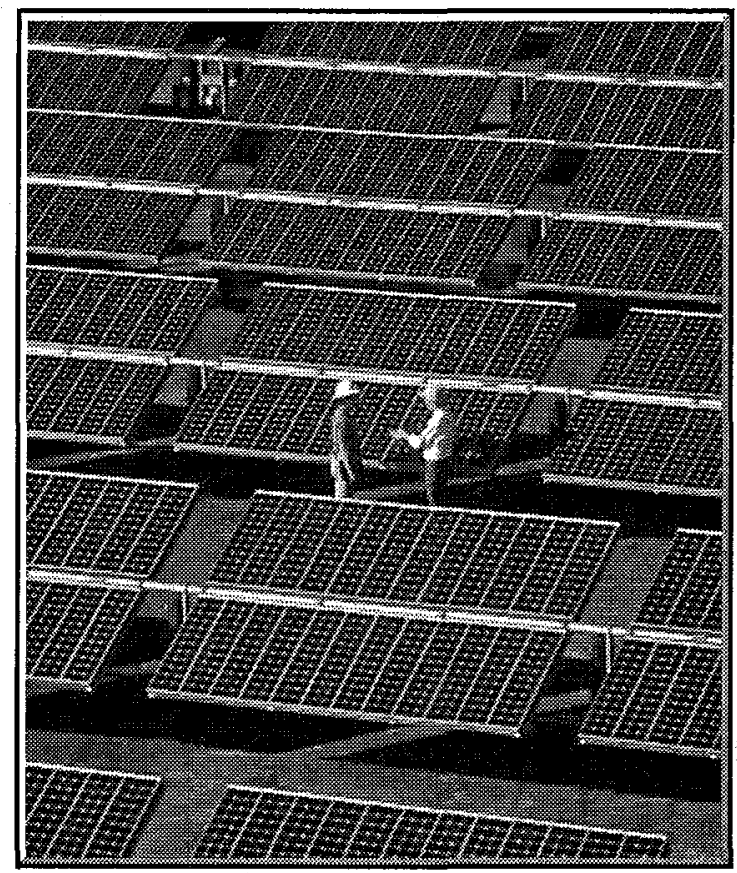

Current Research, Development, and Demonstration

\section{RD\&D Challenges and Goals}

- Improve fundamental understanding of materials, processes, and devices to provide a technology base for advanced PV options.

- Optimize PV cell materials, cell designs, and modules; scale up laboratory cell results to product size ( $10^{4}$ increase in area).

- Validate new module technologies outdoors and in accelerated testing ( goal: 30 years outdoors).

- Improve and invent new low-cost processes and technologies; reduce module and balance-of-systems manufacturing costs.

- Substantial technical risks associated with first-time manufacturing for advanced technologies.

- Develop and validate new, lower-cost systems hardware and integrated applications.

- Meet cost-competitive goal of manufacturing and installing PV systems at under $\$ 1 / \mathrm{W}_{\mathrm{p}}$.

\section{RD\&D Activities}

- $\quad$ DOE maintains the most important RD\&D program in the United States, with funding levels during the 1990 s between $\$ 60$ and $\$ 90 \mathrm{M}$; FY 1997 was \$60M.

- $\quad$ DOD has some funding through special programs in which PV has a role supplying power for military systems.

- NASA has some research funds for PV used for space power. This program has dwindled over the last decade, but advanced PV has become even more important for space missions (e.g., the high-performance GaAs cells on the Sojourner on Mars).

- Japan and Europe have significant funding for PV. The Japanese level is about $\$ 200$ million annually.

- U.S. PV businesses are not yet profitable and are unable to fund their own advanced research.

- Some semiconductor and integrated circuit materials R\&D, flat-panel displays, and production technology developments provide information for PV development, particularly for silicon-based PV technology.

\section{Recent Successes}

- Because of private-public DOE/NREL programs, such as the Thin Film Partnership, U.S. PV technology leads the world. Another partnership, the PVMaT manufacturing program, has resulted in industry cost reductions of $25 \%$ and facilitated a doubling of manufacturing capacity.

- Two thin-film plants by United Solar and Amoco-Enron Solar began production in 1997. Others are expected in the next 2 years. Thin-film PV has been the focus of the DOE/NREL efforts of the last decade, and these particular advances were initially funded under the Amorphous Silicon Research Project.

- During the last 2 years, world record solar cell sunlight-to-electricity conversion efficiencies were set by federally funded universities, national laboratories, or industry in amorphous silicon (12\%), polycrystalline Si (19\%), and copper indium gallium diselenide (18\%). 
- $\quad$ About $120 \mathrm{MW}$ of PV were sold in 1997 (about \$1 billion worth); total installed PV is about 500 MW. The U.S. world market share is about $40 \%$. Annual market growth for PV is $25 \%$ as a result of reduced prices and successful global marketing. Hundreds of applications are costeffective for off-grid needs; the largest market growth area in the United Sates and internationally. More than two-thirds of U.S.manufactured PV is exported. There are about 75 PV module manufacturers worldwide, and hundreds of vendors sell systems. About 25 U.S. companies produce commercial PV. Japan and Europe have strong, competitive PV infrastructures and sales.

\section{Potential Benefits and Costs}

\section{Carbon Reductions}

- $\quad \mathrm{A} \mathrm{GW}_{\mathrm{p}}$ of PV produces about $1600 \mathrm{GWh}$ /year of electricity in an average U.S. solar location (Kansas). Assuming the same carbon content as the U.S. utility mix (160 MtC/GWh), a 1-GW PV system would avoid $8 \mathrm{MtC}$ during its 30 -year lifetime. PV grew at a $25 \%$ rate in 1997 . At an assumed steady $20 \%$ growth rate, about $50 \mathrm{GW}_{\mathrm{p}}$ would be installed in the United States by 2030; assuming a higher early rate ramping down to a much lower, sustainable rate, over $200 \mathrm{GW}_{\mathrm{p}}$ would be installed by 2030 . This projected range of PV installations would save up to $2 \mathrm{MtC} /$ year in 2010, 5-10 MtC/year in 2020, and 15-55 MtC/year in 2030.

\section{RD\&D Expenditures}

- $\quad$ DOE PV budgets were $\$ 60 \mathrm{M}$ in FY 1997. The estimated U.S. budget needed to accelerate PV would be about $\$ 150 \mathrm{M} /$ year for R\&D during the two decades to 2010 and 2020; this could be reduced, as PV reaches maturity, to about $\$ 100 \mathrm{M} /$ year for R\&D during the decade to 2030 . In addition to the $R \& D$ activities, substantial support must be given to market assurance activities during the next two decades.

\section{Markets}

- Electricity economically provided for billions of people worldwide who do not have electricity.

- U.S. markets: retail electricity for residential and commercial buildings; distributed utility systems for grid support; peak-shaving and other high-value daytime uses. Electric and $\mathrm{H}_{2}$ storage: dispatchable electricity, electric car charging stations, and hydrogen production for portable fuel.

\section{Nonenergy Benefits and Costs}

- PV systems operate with zero emissions. PV is modular: installation can be sized from a few watts to many gigawatts. Maintenance needs are low because of the lack of moving parts and the durable components, which is good for uses in developing countries. PV provides power for telecommunications in developing countries and will improve the standard of living for millions who lack electricity, contributing to reduced rural-to-urban population shifts. The taxpayer's investment in RD\&D could be recouped through job creation, expanded tax revenues, economic development (including improved balance of payments with our international competitors), and improved environmental quality.

\begin{tabular}{|c|c|c|c|c|c|c|c|c|c|}
\hline \multicolumn{10}{|c|}{ Technical Risk } \\
\hline 1 & 2 & 3 & 4 & (5) & 6 & 7 & 8 & 9 & 10 \\
\hline
\end{tabular}

- Challenges related to materials properties, low-cost but highquality film deposition processes, diagnostics.

- $\quad$ Advanced storage and large-scale wheeling strategies (to compensate for PV intermittence) are not well-developed.

\section{Commercial Risk}

\begin{tabular}{lllllllllll}
1 & 2 & 3 & 4 & 5 & 6 & 7 & 8 & 9 & 10 & \\
\hline Low & & & & & & & & & & \\
High
\end{tabular}

- Sunlight is intermittent.

- Companies need market assurance to invest large sums in plant capacity expansion.

- Rapid increases in capacity may create unexpected issues.

Ecological Risk

\begin{tabular}{llllllllll}
1 & $(2)$ & 3 & 4 & 5 & 6 & 7 & 8 & 9 & 10 \\
\hline Low & & & & & & & & &
\end{tabular}

- Land use and disposal or recycling of microscopic amounts of heavy metals in some systems

\section{Risk Factors}

Human Health Risk
\begin{tabular}{llllllllll}
1 & (2) & 3 & 4 & 5 & 6 & 7 & 8 & 9 & 10 \\
\hline Low & & & & & & & & & High
\end{tabular}

- In-plant safety issues are familiar from the semiconductor industry.

- Risk reduction: poor, rural communities in developing countries will achieve a higher standard of living and health.

Economic Risk

\begin{tabular}{|c|c|c|c|c|c|c|c|c|c|}
\hline 1 & 2 & 3 & (4) & 5 & 6 & 7 & 8 & 9 & 10 \\
\hline$\overline{\text { Low }}$ & & & & & & & & & \\
\hline
\end{tabular}

Regulatory Risk

$\begin{array}{lllllllllll}1 & 2 & 3 & 4 & 5 & 6 & 7 & 8 & 9 & 10 & \\ \text { Low } & & & & & & & & & & \end{array}$

- Practical issues of electrical standards and codes (PV stand-alone and grid-tied products).

- Utility resistance to consumers selling retail electricity back to them ("net metering").

- Uncertainty stemming from utility deregulation.

\section{Key Federal Actions}

- Support R\&D to improve performance and reduce costs and to build a scientific base for advanced PV technologies.

- Provide R\&D funding to reduce the risk of first-time manufacturing for high-potential PV technologies.

- Level the regulatory playing field and ensure sustained market growth to catalyze private investment. 


\subsection{GEOTHERMAL ENERGY}

Technology Description

Geothermal energy is energy from within the earth. Hot water and steam are used to produce electricity or applied directly for space heating and industrial processes. Geothermal heat pumps (GHPs) use the thermal mass of the earth as a heat sink for air conditioning and heating.

System Concepts

- Geophysical, geochemical and geological exploration locate reservoirs to drill, including highly permeable hot reservoirs, shallow warm groundwater, hot dry rock masses, highly pressured fluids, and magma.

- Well fields and distribution systems allow the hot fluids or secondary fluids to move to the point of use, and possibly back to the earth.

- Utilization systems apply the heat directly, convert it to another form of energy such as electricity, or cool efficiently by dumping heat back into the earth.

\section{Representative Technologies}

- Exploration technologies for the identification of fractures and geothermal reservoirs; drilling, reservoir testing and modeling to optimize production and predict useful lifetime; electric turbines using natural steam or hot water flashed to steam, or binary conversion systems to produce electricity from water not hot enough to flash.

- Direct applications to use the heat from geothermal fluids without

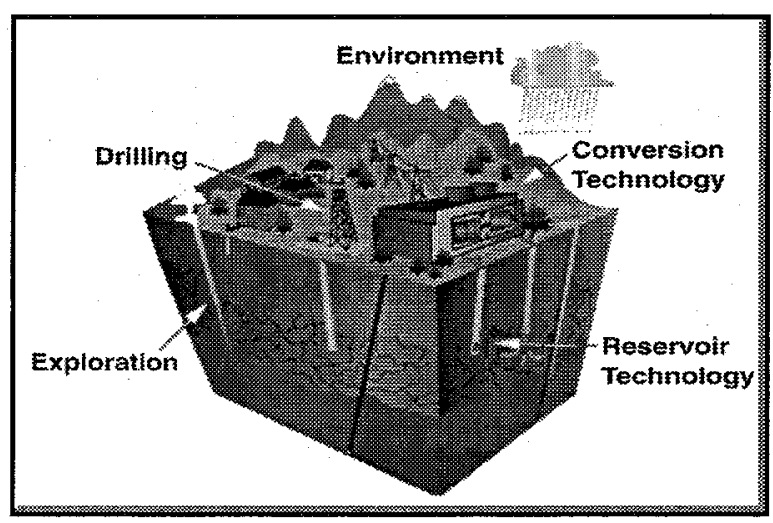
conversion to electricity.

- $\quad$ GHPs that use a shallow ground loop to move heat between the earth and heating/air conditioning systems.

Technology Status/Applications

- The United States has a resource base capable of producing $>25 \mathrm{GW}$ of electricity at $3.5-15.0 \notin / \mathrm{kWh}$.

- Hydrothermal reservoirs are being used to produce electricity with an on-line availability of $97 \%$; advanced energy conversion technologies are being implemented to improve plant thermal efficiency.

- Direct-use applications are successful, but require co-location of a quality heat source and need.

- GHPs produce 20 to $40 \%$ reductions in electricity demands for many residential and governmental installations. They compete favorably with air-source heat pumps and replace gas furnaces in some areas.

\section{Current Research, Development, and Demonstration}

\section{RD\&D Goals}

- By 2010, make geothermal cost-effective so that it provides about $10 \mathrm{GW}$ on line, enough electricity for 12 million homes; by 2020 , develop new approaches to utilization that increase the domestic reserve base by a factor of 10; by 2030, bring new approaches on line.

- By 2020, displace 100,000 barrels of oil (equivalent; 0.5 quads) per year with direct heat use and GHP. Ensure continued growth in use.

RD\&D Challenges

- Develop improved methodologies for predicting reservoir performance and lifetime.

- Find and characterize underground permeability and develop low cost, innovative drilling technologies.

- Reduce capital and operating costs and improve the efficiency of geothermal conversion systems.

- Demonstrate heat recovery methods that allow the use of geothermal areas that are deeper, cooler, less permeable, or dryer than those currently considered as reserves.

\section{RD\&D Activities}

- DOE EERE spends $\$ 30 \mathrm{M}$ per year, promoting collaborations of laboratories, universities, states, and industry. Industry provides access to data, equipment and geothermal materials, and matching funds. Related studies are supported by DOE-OBES and FE, although the amounts have not been estimated. The international research budget is much higher, involving Japan, Iceland, Italy, Mexico, New Zealand, France, and others.

\section{Recent Success}

- Completion — with industry and federal, state, and local agencies-—of an injection research project and water replacement pipeline that will increase production and extend the lifetime of the Geysers Geothermal Field.

- New equipment increasing thermal efficiency and reducing operating and maintenance costs of geothermal power plants, including demonstrations of metastable turbine expansion, improved condenser packing materials, off-stream gas compressor, new materials, and the rolling float meter.

\section{Commer cialization and Deployment}

- Hydrothermal reservoirs produce about $2100 \mathrm{MW}$ in the United States and about $6000 \mathrm{MW}$ worldwide. Direct-use applications produce about $400 \mathrm{MW}_{\mathrm{t}}$ in the United States. There were 120,000 GHPs in the United States with an installed capacity of over $4000 \mathrm{MW}$ in 1996 , and that number is increasing by $25 \%$ per year. United States companies generate 200 to 300 new MW overseas each year.

- Costs are marginally competitive at today's natural gas prices, and investment is limited by uncertainty in prices, long-term viability of production systems, and delay between investment and return. 
- Improvements in cost and accuracy of resource exploration and characterization can lower the electricity cost; demonstration of new resource concepts, such as heat mining, low-temperature use, or deep systems, would allow a large expansion of U.S. use of hydrothermal when economics become favorable. Direct applications can be expensive unless users are located above a geothermal reservoir. GHPs reduce lifetime costs relative to air source heat pumps, but initial cost and consumer uncertainty limits deployment.

\section{Potential Benefits and Costs}

\section{Carbon Reductions}

- Hydrothermal electric and most GHPs displace the average electric power generating mix, which typically generates 160 gram carbon/ $\mathrm{kWh}$ GHPs also displace inefficient local heating units that produce $>14 \mathrm{MtC}$ quad. Direct heat displaces a mix of electric and gas-thermal. All of these methods have on-line records of $95 \%$ or more, reducing the use of carbon-producing backup generation and storage facilities. In total, geothermal energy is expected to reduce GHG emissions by 5-10 MtC/year in 2010, 5-20 MtC/year in 2020, and 5-30 MtC/year in 2030.

\section{RD\&D Expenditures}

- To achieve the RD\&D progress described, RD\&D expenditures need to increase from the current $\$ 30 \mathrm{M} /$ year to an average $\$ 62 \mathrm{M} /$ year in 2000-2010, \$53M/year in 2010-2020, and \$31M/year in 2020-2030.

\section{Market}

- Geothermal will continue production of existing plants (2.1 GW) and be used for new construction (348 GW by 2030$)$. Direct heat and GHPs will replace existing systems and will be new systems in a huge market.

\section{Nonenergy Benefits and Costs}

- The energy production per land area is high for a low-carbon technology. Byproducts are limited to relatively benign steam plumes, waste water, and sludge. Fluid effluents may be mined for minerals or injected back into the reservoir. Some plants using injection have zero emissions. Geothermal plants spend more for personnel and less for fuel than do conventional plants.

\section{Risk Factors}

Technical Risk

\begin{tabular}{|c|c|c|c|c|c|c|c|c|c|}
\hline 1 & 2 & (3) & 4 & 5 & 6 & 7 & 8 & 9 & 1 \\
\hline
\end{tabular}

- Incremental improvements can reduce the risks of exploring and drilling, unpredictability of reservoir performance, and degradation of efficiency. Advanced reservoir utilization strategies have a low to moderate technical risk.

Commercial Risk

\begin{tabular}{|lllllllllll}
1 & 2 & 3 & 4 & 5 & 6 & 7 & 8 & 9 & 10 & High
\end{tabular}

- These technologies require the confidence of lenders, power generators, heating and air conditioning installers, and project planners in order to be accepted.

Ecological Risk

\begin{tabular}{|lllllllllll}
1 & 2 & (3) & 4 & 5 & 6 & 7 & 8 & 9 & 10 & High \\
\hline Low & & & & & & & & & &
\end{tabular}

- Although the potential for modification of natural geysers and features limits its use in very scenic areas, geothermal power produces few emissions and little waste and requires minimal land area. Enhanced injection may require new water sources.
Human Health Risk

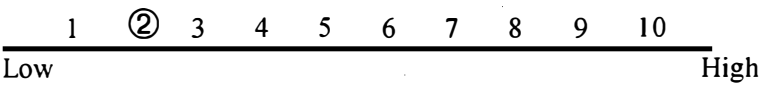

- In general, emissions from geothermal facilities are much less than from fossil fuel plants. Some fields must abate hydrogen sulfide and dispose of residues in hazardous waste sites.

Economic Risk

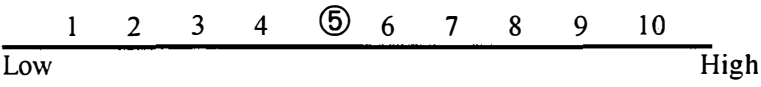

- Because its costs cannot be lowered much below the price of natural gas, geothermal power for electric production will continue to be vulnerable to cost reductions for competing fuels.

Regulatory Risk

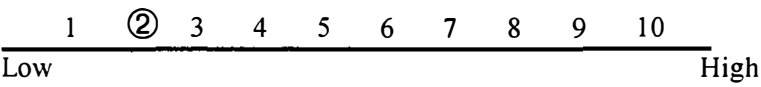

- The principal regulatory risk is that associated with the regulatory changes caused by deregulation of the utility industry. However, several industry analysts say that this will produce a net positive effect.

\section{Key Federal Actions}

- $\quad$ Support incremental and longer-term R\&D as outlined above.

- Ensure that environmental externalities are included in the costs of energy production and use.

- Demonstrate nonelectric geothermal technologies, and educate planners, homeowners, regulators, and suppliers about their merits.

- Develop approach to support U.S. industries that compete with government-supported consultants and developers overseas.

- $\quad$ Continue to allow access to federal lands for geothermal development. 


\subsection{SOLAR THERMAL ELECTRIC AND BUILDINGS}

\section{Technology Description}

Solar thermal systems concentrate solar energy 50 to 5000 times to produce high-temperature thermal energy, which is used to produce electricity for distributed or bulk generation or heat for building and industrial process applications.

\section{System Concepts}

- In solar thermal electric systems, large, highly reflective sun-tracking mirrors produce temperatures of 400 to $800^{\circ} \mathrm{C}$ in the working fluid of a receiver; this heat is used in conventional heat engines (steam or gas turbines or Stirling engines) to produce electricity at system solar-toelectric efficiencies of up to $30 \%$.

- In solar thermal buildings systems, compound parabolic concentrating collectors and nonconcentrating technologies convert solar energy into lower temperature heat at the point of use, usually for domestic hot water and space heating.

\section{Representative Technologies}

- A parabolic trough system focuses solar energy on an oil-filled receiver to collect heat to generate steam to power a steam turbine. When the sun is not shining, steam can be generated with fossil fuel to meet utility needs. Plant sizes can range from 10 to $100 \mathrm{MWe}$.

- A power tower system (see photo) uses many large heliostats to focus the solar energy onto a tower-mounted central receiver filled with a molten-salt working fluid that produces steam. The hot salt can be stored extremely efficiently to allow power production to match utility demand even when the sun is not shining. Plant size can range from 30 to $200 \mathrm{MWe}$.

- The dish/engine system uses a dish-shaped reflector to power a small Stirling or Brayton engine/generator mounted at the focus of the dish. Dishes are 10-25 kW in size and can be used individually or in small groups for remote or village power, or in larger (1-10 MWe) clusters for utility applications, including end-of-line support. They are easily hybridized.

- Building systems use flat-plate or evacuated tube collectors, concentrating evacuated tube or parabolic trough collectors, or unglazed transpired collectors to heat water or air for building applications.

\section{Technology Status/Applications}

- Nine parabolic trough plants, with a rated capacity of $354 \mathrm{MWe}$, have been operating in California since 1985 . Trough system costs of about $12 \phi / \mathrm{kWh}$ have been demonstrated commercially.

- Solar Two, a 10-MWe pilot power tower with 3 hours of storage, is providing all the information needed to scale up to a 30-100 MW commercial plant.

- A number of prototype dish/Stirling systems are currently operating in Colorado and Spain. High levels of performance have been established; durability remains to be proven, although some systems have operated for over 10,000 hours.

- Typical residential systems use roof-mounted flat-plate collectors combined with storage tanks to provide $40 \%$ to $70 \%$ of residential water heating requirements at efficiencies of $35 \%$. Typical systems cost $\$ 2500$ to $\$ 3500$ and achieve payback periods of 5 to 15 years vs electric resistance water heaters and 20 to 30 years vs gas water heaters.

- Industrial systems and large commercial systems using unglazed transpired collectors for preheating ventilation air have achieved payback periods of well under 10 years. A transpired collector is a thin sheet of perforated metal that absorbs solar radiation and heats fresh air drawn through its perforations.

\section{Current Research, Development, and Demonstration}

\section{RD\&D Goals}

- $\quad$ RD\&D goals are to reduce costs of solar thermal systems to 5 to $8 \notin / \mathrm{kWh}$ with moderate production levels within 5 years, and below $5 \notin / \mathrm{kWh}$ at high production levels in the long term.

\section{RD\&D Challenges}

- $\quad$ RD\&D efforts are targeted to improve performance and lifetime, reduce manufacturing costs with improved designs, provide advanced designs for long-term competitiveness, and address barriers to market entry.

- Improved manufacturing technologies are needed to reduce the cost of key components, especially for first-plant applications where economies of scale are not yet available.

- Demonstration of Stirling engine performance and reliability in field use are critical to the success of the dish/engine systems.

\section{RD\&D Activities}

- Key DOE program activities are targeted to support the next commercial opportunities for these technologies, demonstrate improved performance and reliability of components and systems, reduce energy costs, develop advanced systems and applications, and address nontechnical barriers and champion solar thermal power.

- FY 1997 DOE funding levels were about $\$ 25 \mathrm{M}$. Several European countries and Israel have programs 50 to $80 \%$ of this size.

\section{Recent Success}

- The 10-MW Solar Two pilot power tower plant is operating successfully near Barstow, California.

- Operations and maintenance costs have been reduced through technology improvements at the commercial parabolic trough plants in California by $30 \%$, saving plant operators $\$ 50 \mathrm{M}$. 
- Parabolic troughs have been commercialized and nine plants (354 MW total) have operated in California since 1985.

- Successful operation of Solar Two will provide the basis for a partnership to provide the first 30-100 MW power tower plant.

- Dish/Stirling systems are expected to be available by 2000, after deployment and testing of $1 \mathrm{MW}$ (40 systems) over the next 2 years.

- About 1.2 million solar domestic hot water systems have been installed in the United States; 14,000 installations per year $(\$ 47 \mathrm{M})$.

- Ventilation preheat systems using unglazed transpired collectors have made significant progress in commercial/industrial markets with several dozen large-scale projects currently in operation.

- The World Bank's "Solar Initiative" is pursuing solar thermal technologies for less-developed countries. The World Bank considers solar thermal as a primary candidate for Global Environment Facility funding, which could total \$1B to \$2B for projects over the next 2 years.

\section{Potential Benefits and Costs}

\section{Carbon Reductions}

- Carbon reductions are estimated to be 1-5 MtC/year in 2010, 5-15 MtC/year in 2020, and 15-30 MtC/year in 2030.

\section{RD\&D Expenditures}

- Federal R\&D funds for solar thermal electric of $\$ 22 \mathrm{M}$ in FY 1997 have been matched by industry cost sharing of about $\$ 15 \mathrm{M} /$ year. Federal R\&D funds for solar thermal buildings have been about $\$ 3 \mathrm{M} /$ year.

- DOE support of RD\&D has been required because of the specialized technology development, the significant remaining time to market, and barriers (real and perceived) to market penetration. The federal STE program provides expert technical support as well as a catalyst/facilitator role for participation of utilities and manufacturers to assist in driving system costs down.

- Required incremental RD\&D expenditures for solar thermal electric are estimated to be $\$ 30 \mathrm{M} /$ year through 2010 and $\$ 10 \mathrm{M} /$ year through 2030.

- Required RD\&D expenditures for solar thermal buildings is estimated to be $\$ 37 \mathrm{M} /$ year through $2010, \$ 31 \mathrm{M} / \mathrm{year}$ through 2020 , $\$ 28 \mathrm{M} / \mathrm{year}$ through 2030.

\section{Market}

- STE technologies provide firm, nonintermittent electricity generation (peaking or baseload capacity) when coupled with storage.

- Solar building technologies will reduce daytime peak electricity requirements and heating season fuel.

\section{Nonenergy Benefits and Costs}

- Solar thermal building systems can enhance national security by reducing vulnerability to oil supply disruption.

- Solar thermal technologies are environmentally benign with essentially no emissions.

- A near term to mid-term opportunity exists to build production capacity in the United States for both domestic use and international exports.

\begin{tabular}{ll}
\hline & Risk Factors
\end{tabular}

\section{Technical Risk}

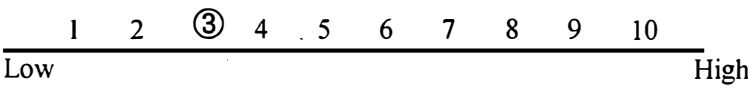

- Parabolic troughs are a proven technology at commercial scale with no significant technical risk; others are expected to be similar.

- Performance of the Stirling engine is crucial for dish systems.

Commercial Risk

$\begin{array}{lllllllllll}1 & 2 & 3 & 4 & 5 & 6 & 7 & 8 & 9 & 10 & \text { High }\end{array}$

- Cost-competitiveness depends on costs of alternatives in the United States, but specific off-grid applications exist internationally.

\section{Ecological Risk}

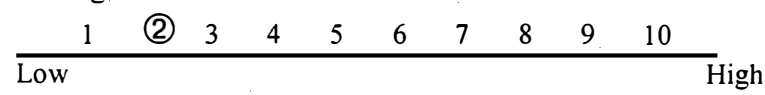

- The only significant impact is use of desert-type land, which is less than equivalent land use of coal and hydro power.

\section{Key Federal Actions}

- Federal support of the first few plants (through buy-downs, power purchase contracts, production credits) would overcome the problem of building the first plants to get costs down until production goes up. The Million Solar Rooftops and ReCAST initiatives are examples.

- Federal support of utility deregulation that would encourage the marketing of "green power" could enhance early solar thermal generation.

- Tax code changes that would not penalize capital intensive projects (which are currently taxed several times higher than fuel-intensive projects) have the potential to dramatically enhance the financial viability of early plants. 


\subsection{BIOMASS TRANSPORTATION FUELS}

\section{Technology Description}

Biomass transportation fuels, or biofiels, are liquid transportation fuels made from cellulosic plant biomass (fibrous materials, as opposed to starch such as corn) that can be used to displace petroleum used in internal combustion engines. In the future, biofuels such as methanol, ethanol, and hydrogen will play a role as energy storage media in fuel cells.

\section{System Concepts}

- Biomass for conversion to liquid fuels can be obtained from wastes, grass, or tree crops grown for energy production, and coproduction and harvesting of biomass feedstocks with other plant products. Growth of microalgae using $\mathrm{CO}_{2}$ from fossil fuel combustion is also a potentially large feedstock for fiuel production.

- The waste products from manufacturing biofuels (mainly lignin) can be used to generate electricity; enough electricity can be generated to power the plant and return an equal amount to the grid.

Representative Technologies

- Biological production of biofiels involves hydrolysis of fibrous biomass to form soluble sugars, using enzymes or acid catalysts, followed by microbial conversion of sugars to ethanol.

- Thermochemical production of biofuels involves gasification to form synthesis gas, from which methanol and other products are made, or pyrolysis to form diesel fuel substitutes.

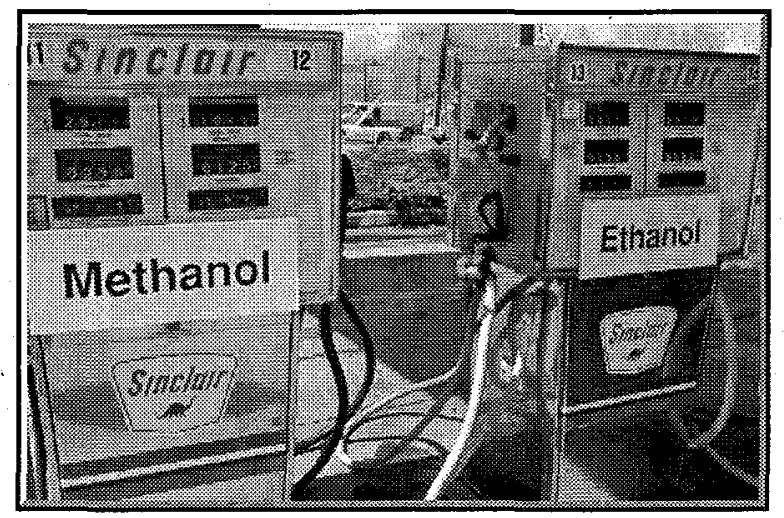

- The use of natural oils from microalgae also has both biological and thermochemical routes that need to be explored.

\section{Technology Status/Applications}

- By 2000 , ethanol made from low-cost cellulosic feedstocks will augment corn ethanol (current price $\sim \$ 1.20 /$ gal) for use as an oxygenate or octane enhancer, but the greatest benefit for reducing GHG emissions is to replace conventional bulk fuels (currently $\sim \$ 0.65 /$ gal). Future R\&D advances have clear potential to lower the cost of biofuels, with commensurately larger fuel markets becoming accessible. The central technological challenge is to advance biomass processing to a level of maturity comparable to that of the existing petroleum industry. Development of a large biomass resource basis is another important challenge.

\section{Current Research, Development, and Demonstration}

\section{RD\&D Goals}

- By the year 2000, demonstrate a biomass waste-to-fuels process with an industrial partner.

- By the year 2005, demonstrate biomass production and its conversion to fuels.

- By the year 2010, demonstrate biofuels technologies that compete with petroleum for direct fiel replacement.

\section{RD\&D Challenges}

- Biological processing: low-cost production of cellulases, microorganism development for consolidated processing, advanced pretreatment and hydrolysis process, coproduct production and recovery.

- Thermochemical processing: improved understanding of reaction fiundamentals, reaction engineering to improve performance, new catalyst development.

- Biomass production: crop development for improved productivity and robustness; improved cultivating, harvesting, and collection technologies; analysis of long-term land availability and crop economics.

\section{RD\&D Activities}

- Industrial partnerships for demonstrating waste biomass-to-ethanol technology.

- Feedstock production research (primarily on switchgrass and hybrid poplar).

- Technology for converting cellulosic materials to ethanol (R\&D on chemical pretreatment, genetic engineering of new enzymes and organisms, and process development).

- FY 1997 DOE EERE funding was \$23M/year. Supportive activities occurred through the DOE ER, USDA, and other agencies, but amounts were not estimated.

(1) Recent Success

- Breakthroughs in genetically engineered microorganisms capable of fermenting the broad range of sugars found in biomass. These advances have led to patents and licensing of organisms to the corn ethanol industry to enable fermenting of the cellulosic waste portions of the corn plant, and other potential cellulosic ethanol producers, as well as an "R\&D 100" award.

- Successful continuous operation of a pilot-scale ethanol process using low-value residual biomass. This testing was done with an industrial partner at DOE's one-of-a-kind user facility for pilot-scale production of ethanol.

\section{Commercialization and Deployment}

- Fuel-grade ethanol from cellulosic biomass is not yet commercial. Fuel-grade ethanol from corn is a 1.5-billion-gal/year industry (\$2B/year in sales) in the United States. Ethanol is used primarily as a fuel extender (gasohol) and secondarily as an oxygenate and an additive for reformulated gasoline.

- Large-scale displacement of petroleum will rely primarily on cellulosic materials. Starch crops such as corn will play an important transitional role. 


\section{Carbon Reductions}

- The $\mathrm{CO}_{2}$ released when biofuels are used is recycled by plants, resulting in net carbon emissions approaching zero; displacing a unit of energy from gasoline with a unit of energy from ethanol in light-duty vehicles results in a $90 \%$ reduction in carbon emissions. Similar reductions can be expected from such biomass fuels as methanol, biodiesel, and other biofuels. Although there are several potential different biofuels, carbon reduction estimates were made only on ethanol using switchgrass as a feedstock at $10 \%$ and $95 \%$ blends, compared with reformulated gasoline. Carbon reduction estimates assume a market penetration for these blends of 4 billion gal in $2010,9.5$ billion gal in 2020 , and 9.5 billion gal in 2030 . With the low projected price of gasoline, and without extra policy incentives, neat ethanol was not considered cost-effective enough to use as a transportation fuel during this 30 -year period. Calculations included carbon reductions from biomass-generated electricity returned to the grid from ethanol plants.

- Carbon reductions were estimated as 5-15 MtC/year in 2010, 20-30 MtC/year in 2020, and 20-35 MtC/year in 2030.

\section{- RD\&D Expenditures}

- Funding of around \$23M/year has been spent in FY 1996 and FY 1997, supporting research by national laboratories, universities, and industry partners.

- Achieving the economical carbon reduction costs described above requires significant funding increases. The technology improvements required call for quickly ramping up the research program from its current level, averaging \$75M/year during 2000-2010. During 2010-2020, an average of $\$ 100 \mathrm{M} /$ year would be needed for work on biomass production to ensure a large and cost-effective resource base for fuel production by 2020 . Fuel production technologies must close the cost gap between petroleum and biomass-derived fuels. During 2020-2030, \$50M/year would be required.

Market

- Biofuels can provide renewable substitutes for both gasoline and diesel fuel, supporting the energy needs of both the light-duty and the heavy-duty market. Diesel fuel usage is expected to grow at a faster rate than gasoline usage. These two uses represent almost a quarter of total energy consumption in the United States.

\section{Nonenergy Benefits and Costs}

- Biofuels provide opportunities for agriculture and rural America. Export of U.S. biofuels technology provides a lever for maintaining U.S. economic and technological leadership in the global marketplace. Biofuels will also address problems of urban air pollution.

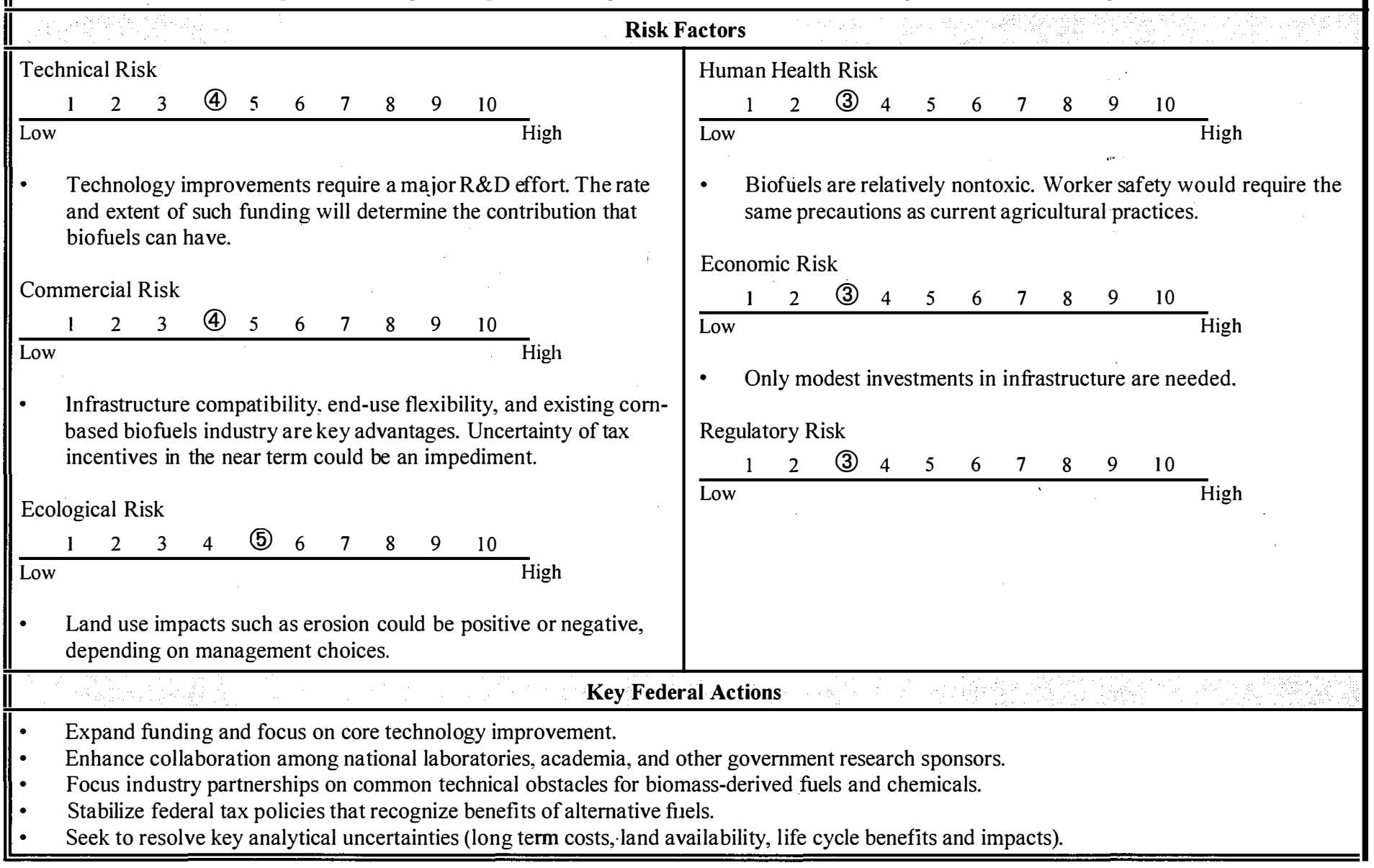




\subsection{SOLAR ADVANCED PHOTOCONVERSION}

Technology Description

Photoconversion technology encompasses sunlight-driven quantum-conversion processes (other than solid-state PVs) that lead to the direct and potentially highly efficient production of fuels, materials, chemicals, and electrical power from simple renewable substrates such as water, $\mathrm{CO}_{2}$, and molecular nitrogen. This technology has the potential to eliminate the need for fossil fuels by substituting renewable sources and conversion processes that are either carbon neutral (any carbon generated is reused during plant growth) or carbon free (e.g., hydrogen from water). These technologies also can convert $\mathrm{CO}_{2}$ into liquid and gaseous fuels via processes that are often termed biomimetic or artificial photosynthesis.

\section{System Concepts}

- Photoconversion processes directly use solar photons to drive biological, chemical, or electrochemical reactions to generate electricity, fuels, material, or chemicals.

- System components include biological organisms or enzymes, semiconductor structures (photoelectrochemical cells, colloids, nanocrystals, or superlattices), biomimetic molecules, dye molecules, synthetic catalysts, or combinations of the above.

\section{Representative Technologies}

- Elements of this future solar technology include photobiological, photochemical, photoelectrochemical, photocatalytic, and dark catalytic processes for energy production.

- Photoconversion technologies can result in electrical power production; hydrogen production and utilization; biodiesel, organic acid, methane, and methanol production; bioplastics; the removal of $\mathrm{CO}_{2}$ from the atmosphere as a consequence of photoreduction of $\mathrm{CO}_{2}$ to fuels, materials, and chemicals production; atmospheric nitrogen fixation (independent of natural gas); and waste or biomass utilization upon photoconversion to fuels, materials, or chemicals. Most of these technologies are at early stages of research, but some are at the development level, and a couple are commercial (those that produce high-value products).

\section{Technology Status/Applications}

- Power production: dye-sensitized, nanocrystalline, titanium dioxide semiconductor solar cells are at the $8-11 \%$ efficiency level and are potentially very cheap. In contrast to solid-state PV solar cells, light is absorbed by dye molecules in contact with a liquid rather than solid-state semiconductor materials. Novel photoelectrochemical cells with integrated fuel cells and in situ storage for 24-h solar power have been demonstrated at 6-7\% efficiency in $4 \times 8 \mathrm{ft}$ panels (Texas Instruments system), and photochargeable batteries that include electrochemical storage have been demonstrated with 24-h power output. Hot-carrier photoconversion technology for increasing solar conversion efficiencies (theoretical efficiency limits of $65 \%$ ) is making progress. The term "hot carrier" refers to electrons initially excited by light, when they have energy higher than their equilibrium levels. This excess energy is given off in the first fraction of a second as heat, and hot-carrier technology attempts to capture this lost heat as useful electricity.

- Fuels production: Photoelectrochemical and photobiological processes that will lead to hydrogen production from water or gasified biomass are at the early stages of research and making good progress; biodiesel, methane, and methanol production from water, waste, and $\mathrm{CO}_{2}$ are at various stages of R\&D; and fuels, such as methanol, produced by the direct electrocatalytic or photocatalytic reduction of $\mathrm{CO}_{2}$, are at the early fundamental research stage. Electrocatalytic concentration of $\mathrm{CO}_{2}$ from the atmosphere is being studied as well; it is of interest to persons involved in atmospheric controls in small spaces (i.e., submarines) and has potential for removing $\mathrm{CO}_{2}$ from the atmosphere in the future.

- Materials and chemicals production: producing materials and chemicals from $\mathrm{CO}_{2}$ and/or biomass will reduce $\mathrm{CO}_{2}$ emissions compared with the fossil fuels used currently.

- Photobiological production of pigments (e.g., astaxanthin), health foods, nutritional supplements (e.g., omega-3 fatty acids), protein, and fish food is commercial. Production of biopesticides and pharmaceuticals is under development. Production of commodity chemicals such as, but not limited to, glycerol, hydrogen peroxide, and bioemulsifiers is possible. Photocatalytic production of specialty or high-value chemicals has been demonstrated.

Current Research, Development, and Demonstration

\section{RD\&D Goals}

- Most photoconversion technologies are at the fundamental research stage where technical feasibility must be demonstrated before cost and performance goals can be assessed. Minimum solar conversion efficiencies of $10 \%$ are generally thought to be necessary before applied programs can be considered. Cost goals need to be competitive with projected costs of current technologies.

- Electrical power and high-value chemicals applications are either currently commercial or will see dramatic growth over the next 5 to 10 years. Large-scale power production should begin about the year 2010. Materials and fuels production will begin in the 2010-2020 time frame and commodity chemicals production in the 2020-2030 time frame.

\section{RD\&D Challenges}

- Develop the fundamental sciences in multidisciplinary areas involving theory, mechanisms, kinetics, biological pathways and molecular genetics, natural photosynthesis, materials (semiconductor particles and structures), catalysts and catalytic cycles, and artificial photosynthesis components. The fundamental science is needed to underpin the new photoconversion technologies.

- Maintain critical mass research groups in vital areas long enough for sustained progress to be made.

\section{RD\&D Activities}

- Basic research activities are currently being funded at a level of $\$ 10-\$ 15 \mathrm{M} /$ year from the DOE Office of Basic Energy Research. 
- Dye-sensitized nanocrystalline semiconductor solar cells have been demonstrated as power sources in small niche markets. Commercial interest is very high since they also can be configured to produce hydrogen.

- Scientific breakthroughs over the past 5 years have been made in microbial and enzymatic R\&D, natural photosynthesis, semiconductor nanostructure and superlattice understanding, $\mathrm{CO}_{2}$ catalysis, and energy and electron transfer in artificial donor/acceptor molecules.

\section{Commercialization and Deployment}

- Large-scale algal ponds are producing high-value chemicals on a commercial basis using photobiological processes. As an example, the current astaxanthin market is $\$ 180 \mathrm{M}$ per year and will rise to $\$ 1 \mathrm{~B}$ in 5 years. Astaxanthin, a pigment synthesized from petroleum, is used as a coloring agent in the poultry and salmon industries. Algal production of the pigment just started in Hawaii and is replacing the fossil version for health and environmental reasons.

- $\quad$ SMH Corporation (a European company) has just started to sell dye-sensitized, nanocrystalline cell-powered watches. The market is estimated to be 100 million units.

\section{Potential Benefits and Costs}

\section{Carbon Reductions}

- Photoconversion processes can ultimately replace (or displace) all fossil fuels as a source of energy, materials, and chemicals. The time scale is uncertain, but significant impacts on reduction of $\mathrm{CO}_{2}$ release could begin in the next 30 to 50 years. It should be emphasized that solar photoconversion produces no $\mathrm{CO}_{2}$ and can in fact remove $\mathrm{CO}_{2}$ from the atmosphere.

\section{RD\&D Expenditures}

- A significant level of basic research activities in solar photoconversion is currently being funded by ER (BES-chemical sciences, material sciences, and energy biosciences) (estimated level: $\$ 10-15 \mathrm{M}$ ); some exploratory R\&D is being funded by EE PV (estimated $\$ 400 \mathrm{~K}$ ).

- Some basic research support by NSF and USDA is complementary.

- Federal R\&D expenditures must be at a sufficient level to fund critical-mass groups to address fundamental problems in key areas, and the support must be consistent over the next 20-30 years to ensure successful R\&D efforts. Suggested levels are a minimum of $\$ 50 \mathrm{M} /$ year for improvements that will help reduce carbon emissions; substantially higher levels will be required to reap benefits that are outside of the scope of a budget driven by carbon reductions. Also, additional funds will be required for applied and production research for technology thrusts that prove worthy of commercialization; given the fundamental nature of the current research, it is not possible at this time to estimate what those requirements might be.

Market

- Photoconversion processes have the potential to replace all fossil sources for power, fuel, materials, and chemicals production.

Nonenergy Benefits and Costs

- Many spin-off technologies are possible. These include opto-electronics, biosensors, biocomputers, bioelectronics, and nano-scale devices.

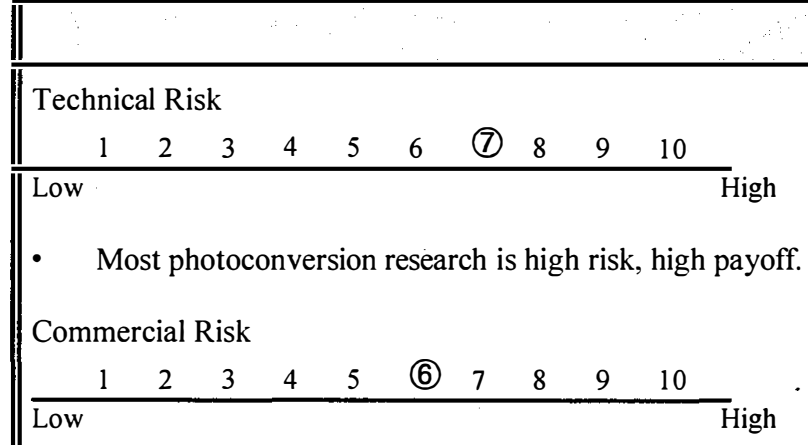

- Initial commercial success in the biological area and solar cell supports the prospects for high payoff of this direction of R\&D.

Ecological Risk

\begin{tabular}{|c|c|c|c|c|c|c|c|c|c|}
\hline 1 & 2 & (3) & 4 & 5 & 6 & 7 & 8 & 9 & 10 \\
\hline
\end{tabular}

\section{Risk Factors}

Human Health Risk

\begin{tabular}{lllllllllll}
1 & 2 & (3) & 4 & 5 & 6 & 7 & 8 & 9 & 10 & \\
\hline Low & & & & & & & & & &
\end{tabular}

- While technologies are still in the early stages of development, human health risk should be low.

Economic Risk

\begin{tabular}{lllllllllll}
1 & 2 & 3 & 4 & 5 & 66 & 7 & 8 & 9 & 10 & \\
\hline Low & & & & & & & & & &
\end{tabular}

- $\quad$ Economic risk will decrease with time and research investment.

Regulatory Risk

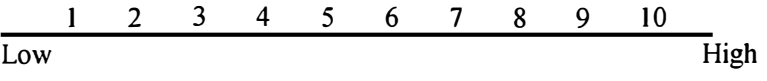

- While technologies are still in the early stages of development, ecological risk should be low.

- Not applicable. Lower than for current fossil technologies.

\section{Key Federal Actions}

- Federal R\&D support enhances the scientific and technology base at the fundamental level where risk is too great for private sector support.

- The critical factor for success is critical-mass support for a sufficient period of time to develop key understanding and technology without large fluctuations in research funding. 



\section{Carbon Sequestration Technologies}

\section{Carbon Sequestration and Management}

9.1 Augmented Ocean Fertilization to Promote Additional $\mathrm{CO}_{2}$ Sequestration

9.2 Advanced Chemical and Biological Conversion and Sequestration

9.3 Terrestrial Storage of $\mathrm{CO}_{2}$

9.4 Carbon Sequestration in Soils

9.5 Elemental Carbon Sequestration

9.6 Ocean Storage 


\subsection{AUGMENTED OCEAN FERTILIZATION TO PROMOTE ADDITIONAL $\mathrm{CO}_{2}$ SEQUESTRATION}

\section{Technology Description}

$\mathrm{CO}_{2}$ can be continually sequestered in the ocean in a variety of ways, one of the most important of which is the deposit on the ocean floor of the carbon-containing skeletal remains of plankton and diatoms. When carbon is thus removed from solution, it is replaced ultimately by $\mathrm{CO}_{2}$ drawn from the atmosphere. Yet the vast majority of ocean area is photosynthetically barren, with littoral areas and parts of the Southern Ocean being the most productive. In these photosynthetically barren areas, usually only one nutrient is missing, commonly iron or nitrogen; the supply of this nutrient causes planktonic growth, and with this growth, the basic building blocks of the food chain are present, enabling carbon deposition on the ocean floor and $\mathrm{CO}_{2}$ drawdown.

The proposal would be to conduct experiments in enriching nutrient-poor sections of the ocean with either iron or nitrogen as a first step to understanding more about the potential to sequester $\mathrm{CO}_{2}$ safely on the ocean floor through stimulation of growth of phytoplankton.

System Concepts/Representative Technologies

- Iron enrichment experiments have delivered iron sulfate in liquid form from vessels.

- For nitrogen enrichment, proposals have been made to use piped ammonia to provide nitrogen to nitrogen-poor ocean areas.

Technology Status/Applications

- Detailed experiments on iron fertilization have been conducted and reported in the scientific press. No such work has been done to date for nitrogen fertilization, but a pilot experiment to sequester 2 million tons of $\mathrm{CO}_{2}$ annually has been proposed. Significant R\&D will be required.

\section{Current Research, Development, and Demonstration}

\section{RD\&D Goals}

- Develop a clear understanding of technical issues:

- What is the ultimate removal rate of the detritus of phytoplankton and their grazers to the ocean floor for different amounts of fertilization?

- To what extent will increased phytoplankton lead to increases in the amount of larger fauna (e.g., fish), and if this leads to a greater harvest, to what extent can/should this be accounted for in atmospheric $\mathrm{CO}_{2}$ reduction?

- Adequate first order cost estimates per ton of $\mathrm{CO}_{2}$ sequestered must be developed: one side of the equation would be the amount of $\mathrm{CO}_{2}$ ultimately removed from the atmosphere per unit of fertilizer. Energy used in making and delivering the fertilizer must be taken into account in this calculation.

- Experimentation will be required to determine the proper depth at which to supply nitrogen. Too shallow a depth will cause loss of some fertilizer to the atmosphere; too great a depth will make the fertilizer unavailable to phytoplankton.

\section{RD\&D Challenges}

- Understanding the entire cycle of growth and decay that will be stimulated by fertilization. Environmental effects will be crucial: there is concern that too much fertilization could cause some ocean layers to become anoxic as long as the experiment continues, if too much fertilization occurs in a given area.

- The ultimate goal is to find a fertilization rate that is both cost effective (and perhaps beneficial in producing more biomass) and without significant adverse environmental impact.

\section{RD\&D Activities}

- To date, FE has not undertaken any experiments directly.

- The International Energy Agency (IEA), partly supported by DOE-FE, has begun a program to research the effects of both types of fertilization.

- Some research on ocean fertilization is also being done by the MARICULT program, a European collaborative on marine cultivation.

\section{Commercialization and Deployment}

- An international treaty will be needed to precede deployment.

\section{Potential Benefits and Costs}

\section{Carbon Reductions}

- Theoretical potential is very large; work needs to be done to define maximum rates of fertilization that will have no significant adverse effects. Iron fertilization, which for practical purposes must occur in the Southern Ocean, has a maximum theoretical sequestration effect of $1-2 \mathrm{Gt}$ C/year, but a realistic maximum of far less.

\section{RD\&D Expenditures}

- $\quad$ FE has not yet proposed funding for RD\&D for either type of fertilization. The IEA, partly supported by FE, has begun a program to research the effects of both types of fertilization. Some research on ocean fertilization is also being done by the MARICULT program.

- It is suggested that research on this technology be part of a newly established carbon sequestration program. It is estimated that an annual federal budget on the order of $\$ 125 \mathrm{M}$ through $2010, \$ 150 \mathrm{M}$ through 2020 , and $\$ 200 \mathrm{M}$ through 2030 is needed for this program.

\section{Nonenergy Benefits and Costs}

- Potential for significant increase in fisheries and other marine flora and fauna (see above). 


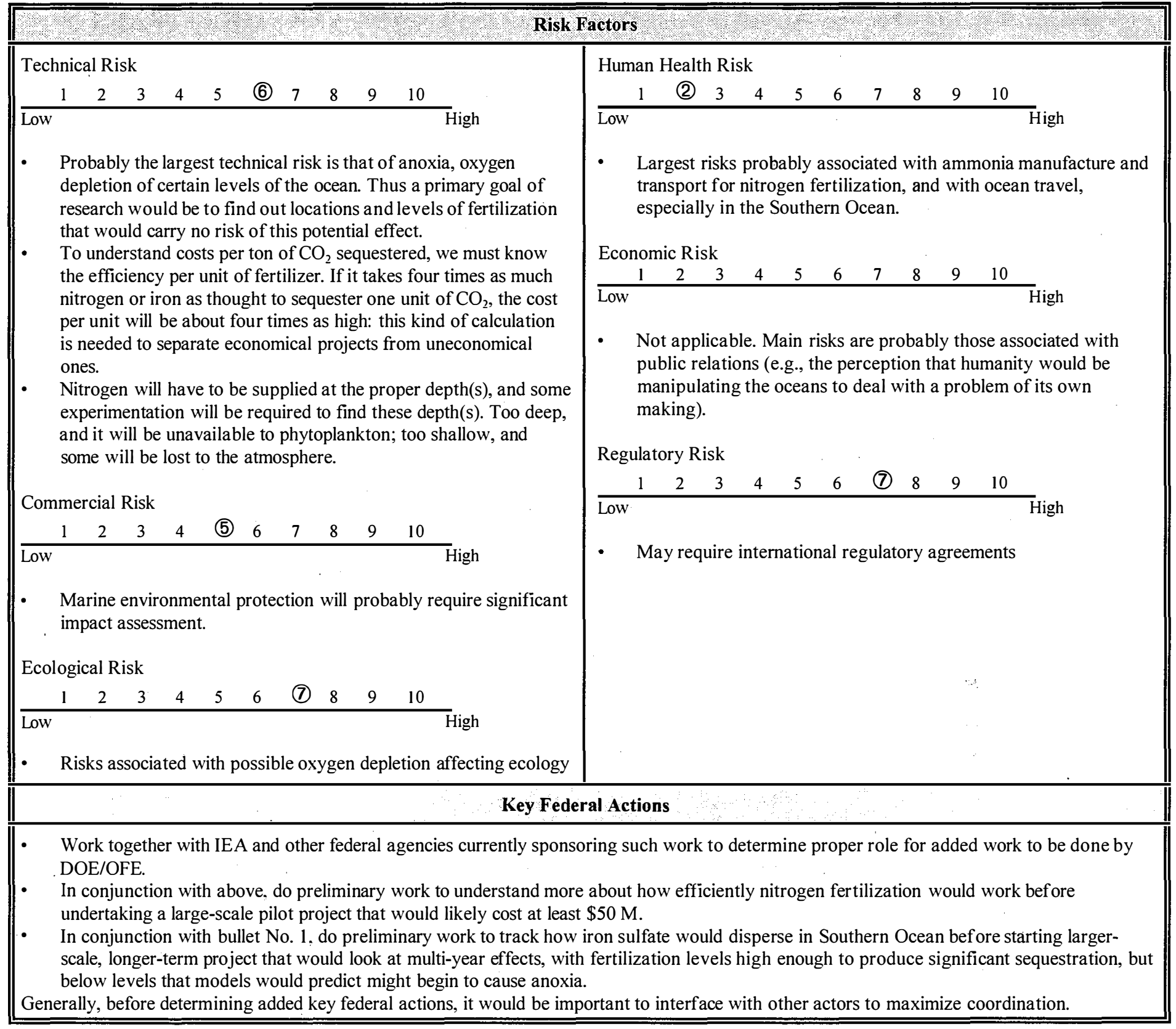


Advanced chemical and biological sequestration and processing is aimed at permanent stable sequestration and recycling of carbon into new fuels and chemical feedstocks. Emissions are reduced through converting $\mathrm{CO}_{2}$ into an environmentally benign product to reduce atmospheric $\mathrm{CO}_{2}$ while generating liquid fuels, generating hydrogen as a fuel from coal without $\mathrm{CO}_{2}$ emissions, and converting $\mathrm{CO}_{2}$ into organic compounds. The major advantage of these technologies is that they eliminate hazards to humans and the environment that are intrinsic in the disposal of gaseous $\mathrm{CO}_{2}$. Carbonate disposal does so by forming environmentally benign and thermodynamically stable waste forms; the other approaches instead generate viable products.

\section{System Concepts}

- The technology comprises four major areas: chemical sequestration as mineral carbonate, direct solar reduction of $\mathrm{CO}_{2}$, conversion of coal to $\mathrm{H}_{2}$ and methanol, and microalagae sequestration. Chemical sequestration takes advantage of the reaction of $\mathrm{CO}_{2}$ with most magnesium- and calcium-bearing minerals to form solid carbonates. Direct solar reduction of $\mathrm{CO}_{2}$ is aimed at producing liquid fuels from atmospheric $\mathrm{CO}_{2}$ by using solar energy to break the $\mathrm{CO}_{2}$ bond, allowing incorporation of the $\mathrm{CO}$ produced into standard fuel synthesis processes. The conversion of coal to $\mathrm{H}_{2}$ and methanol is accomplished by mineralizing $\mathrm{CO}_{2}$ during its reaction with steam to produce $\mathrm{H}_{2}$ and reducing the captured $\mathrm{CO}_{2}$ to methanol by direct solar reduction. Microalagae sequestration involves passing $\mathrm{CO}_{2}$ through bubbling stacks, resulting in incorporation of $\mathrm{CO}_{2}$ to organic carbon.

Representative Technologies

- Chemical sequestration as mineral carbonate

Direct solar conversion of $\mathrm{CO}_{2}$ to methanol

Advanced conversion of coal to $\mathrm{H}_{2}$

Microalagae sequestration

Technology Status/Applications

- Chemical sequestration as mineral carbonate: Simple cost estimates for this technology (compared with existing industrial and mining processes) suggest that $\$ 15 /$ ton of $\mathrm{CO}_{2}$ or $\$ 55 /$ ton of carbon for conversion and disposal is a reasonable cost goal to set. For comparison, at a coal-fired electric power plant with $45 \%$ conversion efficiency, complete $\mathrm{CO}_{2}$ disposal at this cost would add $\$ 0.011$ to the cost of a kilowatt hour--electric. Further research is required; however, with a reasonable level of support, commercial implementation of the process could start before 2010 .

- Direct solar conversion: The process has very promising economics since it produces a useful product. It is estimated that each square meter of mirror involved in the process would produce $3 \mathrm{GJ}$ of fixed energy (44.4 gal of methanol) per year. At this level, methanol production from atmospheric $\mathrm{CO}_{2}$ could be amenable to very rapid growth through mass production and subsequent operation by small businesses. Between now and 2010, this process will reverse very little $\mathrm{CO}_{2}$; by 2020, it might fix one megaton of carbon per year. In its mature state, about 50 megatons to one gigaton of carbon might be fixed per year.

- Advanced conversion of coal to $\mathrm{H}_{2}$ : This process is promising because its products are high in value. For each ton of coal consumed, it avoids the emission of $1 / 2$ ton of carbon and produces instead 440 gal of methanol while using 94 MBtu of solar energy at a cost of \$1.25/MBtu.

- Microalagae sequestration: This technology presents a possible low-cost option for sequestration. So far, it has resulted in a maximum carbon fixation of $100 \mathrm{~g} / \mathrm{m} 3 /$ day with $96 \%$ conversion efficiency of $\mathrm{CO}_{2}$ to organic carbon. The cost is estimated at $\$ 20 /$ ton of $\mathrm{CO}_{2}(\$ 73 /$ ton of carbon).

Current Research, Development, and Demonstration

\section{RD\&D Goals}

- Chemical sequestration as mineral carbonate: The basic principles have been demonstrated. Raw materials exist in vast quantities, and the thermodynamics have been worked out and are favorable, starting from common minerals. The chemistry has been demonstrated but still needs to be optimized. The total cost of R\&D for this technology is estimated to be $\$ 3 \mathrm{M} /$ year for 5 years until a pilot plant is built.

- Direct solar conversion: The process is in the research phase. The spectrum of hot $\mathrm{CO}_{2}$ has only recently been measured. The rates of all of the subsequent reactions are in the literature, but it is necessary to build integral demonstration units to see that all parts of the process play together as expected and to develop a data base for designs. The most basic parts of the R\&D have been completed at a cost of $\$ 600 \mathrm{~K}$. The chemical kinetics proof of principle will cost another $\$ 800 \mathrm{~K}$. The integrated experiment with laser mock-up will cost $\$ 1.5 \mathrm{M}$.

- Advanced conversion of coal to $\mathrm{H}_{2}$ : The concept is in the research stage. It is clear that the $\mathrm{CaO}$ has to be developed to allow quicklime to undergo an indefinite number of cycles without caking. Additionally, the reaction of direct solar reduction of $\mathrm{CO}_{2}$ needs further investigation. The most basic part of the R\&D has been completed at a cost of $\sim 600 \mathrm{~K}$. The chemical kinetics proof of principle will cost another $\$ 800 \mathrm{~K}$. The integrated experiment with laser mock-up will cost $\$ 1.5 \mathrm{M}$. The solar demonstration at the $10^{5} \mathrm{~L} / \mathrm{year}$ level will cost $\$ 5.5 \mathrm{M}$; the first full 50 million L/year plant module will cost $\$ 100 \mathrm{M}$.

- Microalagae sequestration: The technology is in the developmental stage. Initial tests have been positive and merit further review.

\section{Applications and target markets}

- Chemical sequestration as mineral carbonate is applicable to the disposal of $\mathrm{CO}_{2}$ from such large, concentrated, stationary point sources as electric power plants.

- Direct solar conversion is aimed at producing liquid fuels from effluent or atmospheric $\mathrm{CO}_{2}$ by using solar energy.

- The $\mathrm{H}_{2}$ produced during advanced conversion of coal to $\mathrm{H}_{2}$ could be piped short distances to existing power stations for conversion to electricity either by combustion or fuel cell conversion.

- Microalagae sequestration has applications with ongoing biomass programs and co-firing efforts in utilities.

\section{RD\&D Challenges}

- Chemical sequestration as mineral carbonate: Research will be required in a broad number of areas from mineral exploration and mining engineering to research in the fairly complex carbonation chemistry of magnesium and calcium silicates. In addition, further development is needed of the chemistry of extracting magnesium from mineral ores and of chemical processes in chemical engineering research. 


\section{RD\&D Challenges (continued)}

- Direct solar conversion: The spectrum of hot $\mathrm{CO}_{2}$ has only recently been measured. It is necessary to build integral demonstration units to see that all parts of the process play together as expected and to develop a data base for designs. Basic research is needed in $\mathrm{CO}_{2}$ and $\mathrm{CO}$ high-temperature materials, ceramics and metals, advanced combustion, and fluid dynamics and modeling.

- Advanced conversion of coal to $\mathrm{H}_{2}$ : Technology needs include research into the basic nature of the reaction between coal, steam, and quicklime; basic properties, including theoretical understanding of $\mathrm{CO}_{2}$ and $\mathrm{CO}$; and basic research in high-temperature materials, ceramics and metals, advanced combustion, and fluid dynamics and modeling.

- Microalagae sequestration: R\&D is needed in genetic engineering to improve plant uptake and in various feedstream properties to determine the robustness of plants.

\section{RD\&D Activities}

- Programs in mineral fixation, solar-thermal production of methanol, and coal-based production of $\mathrm{H}_{2}$ and methanol are under way at LANL. A program in microalgae supported by EPRI is active at the University of Miami.

\section{Potential Benefits and Costs}

\section{Carbon Reductions}

Carbon reductions from this pathway are not likely to occur without policy changes, and such changes are not considered in this study.

- Chemical sequestration as a mineral carbonate: $\mathrm{I} 00 \%$ ef ficacy at $\$ \mathrm{I} /$ ton for $\mathrm{CO}_{2}$. (@60\% power plant (IGCC) efficiency-395 MtC/year at $300 \mathrm{GW}$ )

- Direct solar reduction of $\mathrm{CO}_{2}: 60 \%$ efficacy assuming recycling at $\$ 7 /$ ton for $\mathrm{CO}_{2}$ with credits for methanol. (@60\% power plant (IGCC) efficiency-236 MtC/year at $300 \mathrm{GW}$ )

- Advanced conversion of coal to $\mathrm{H}_{2}:$ [60 to 80]\% efficacy at $\$ 7 /$ ton for $\mathrm{CO}_{2}$. (@60\% power plant (IGCC) efficiency-270 MtC/year at $300 \mathrm{GW}-70 \%$ efficacy of process)

- Microalagae sequestration: $100 \%$ efficacy at $\$ 20 /$ ton for $\mathrm{CO}_{2}$

- (@60\% power plant (IGCC) efficiency-395 MtC/year at $300 \mathrm{GW}$ )

RD\&D Expenditures

- It is suggested that research on this technology be part of a newly established carbon sequestration program. It is estimated that an annual federal budget on the order of \$125M through 2010. \$I 50M through 2020, and \$200M through 2030 is needed for this program.

Market

- The versatility of the technologies could allow them to capture a large fraction of the $\mathrm{CO}_{2}$ mitigation market if $\mathrm{CO}_{2}$ credits were implemented.

\section{Nonenergy Benefits and Costs}

- These technologies are largely environmentally benign and result in no hazardous byproducts. They also produce commercially viable products that may be used by industry. Finally, the versatility of these technologies will crosscut several major areas of concern relating to $\mathrm{CO}_{2}$ management.

\begin{tabular}{||llllllllllll} 
Technical Risk & & & & & & & & & \\
1 & 2 & 3 & 4 & (5) & 6 & 7 & 7 & 9 & 10 & High \\
\hline Low & & & & & & & & & & &
\end{tabular}

\section{Risk Factors}

- These technologies are novel approaches.

Commercial Risk

$\begin{array}{lllllllllll}1 & 2 & 3 & 4 & \text { (5) } & 6 & 7 & 8 & 9 & 10 & \text { High }\end{array}$

- The technologies are still too young to fully evaluate the commercial risk.

Ecological Risk

\begin{tabular}{|c|c|c|c|c|c|c|c|c|c|}
\hline 1 & (2) & 3 & 4 & 5 & 6 & 7 & 8 & 9 & 10 \\
\hline
\end{tabular}

- No hazardous byproducts are associated with these technologies.
Human Health Risk

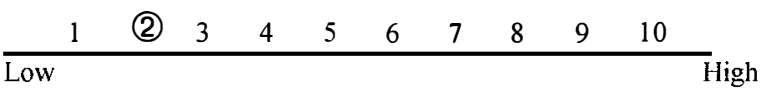

- The risks involved are limited to the individual processes themselves.

Economic Risk

\begin{tabular}{lllllllllll}
1 & 2 & 3 & 4 & (5) & 6 & 7 & 8 & 9 & 10 & \\
\hline Low & & & & & & & & & &
\end{tabular}

- These technologies are still too young to fully evaluate the economic risk.

Regulatory Risk

\begin{tabular}{|c|c|c|c|c|c|c|c|c|c|}
\hline 1 & 2 & (3) & (4) & 5 & 6 & 7 & 8 & 9 & 10 \\
\hline
\end{tabular}

- The regulatory processes are driven at a large scale and by mining; however, this is true of any large-scale comprehensive method.

\section{Key Federal Actions}

- Government/industry partnerships are recommended.

- The establishment of a long-term sequestration R\&D program is recommended. 


\subsection{TERRESTRIAL STORAGE OF $\mathrm{CO}_{2}$}

Technology Description

Terrestrial storage of $\mathrm{CO}_{2}$ involves capturing $\mathrm{CO}_{2}$ and injecting it into subsurface repositories such as deep coalbeds, depleted oil and gas reservoirs, and deep, confined saline aquifers. The technology for subsurface injection is readily adaptable from the petroleum industry for application to $\mathrm{CO}_{2}$ sequestering. These technologies include the drilling and completion of injection wells, compression and long-distance transport of gases, subsurface reservoir characterization, multi-component reservoir simulation, and experience with the operational issues of $\mathrm{CO}_{2}$ injection for enhanced oil recovery. Terrestrial storage in geologic repositories will reduce GHG emissions by long-term sequestration firom the atmosphere. The injection of $\mathrm{CO}_{2}$ into depleted oil and gas reservoirs and deep coalbeds has the potential for storing $\mathrm{CO}_{2}$ and yielding commercially valuable hydrocarbons.

\section{System Concepts}

- $\quad \mathrm{CO}_{2}$ is captured, processed, compressed, and transported by pipeline to a geologic structure having sufficient reservoir porosity and permeability for commercial utility.

- Storage may entail geochemical reactions that tend to form carbonates in silicic host rock, enhancing containment.

Representative Technologies

- Technologies will borrow extensively from the petroleum industry in areas of drilling, stimulation, and completion of injection wells; processing, compression, and pipeline transport of gases; operational experience of $\mathrm{CO}_{2}$ injection for enhanced oil recovery; subsurface reservoir engineering and characterization including multi-component reservoir simulation; and natural gas storage in saline aquifers.

\section{Technology Status/Applications}

- The petroleum technology is readily adaptable to subsurface $\mathrm{CO}_{2}$ storage.

- Natural gas is routinely transported and stored in subsurface reservoirs and aquifers.

- Reservoir storage and containment parameters have yet to be defined.

- Economic feasibility, capital and operating costs for the construction of a $\mathrm{CO}_{2}$ collection and transport infrastructure at varying distances from a stationary sources have yet to be determined.

\section{Current Research, Development, and Demonstration}

\section{RD\&D Goals}

- Conduct geologic and reservoir engineering studies to define required storage integrity, flow properties, and volume capacity of geologic repositories.

- Estimate the costs of infrastructure development for terrestrial $\mathrm{CO}_{2}$ disposal.

- Conduct fate and transport modeling studies, including geochemical reactions with formation fluids and rocks.

- Quantify the safety and environmental requirements of a storage repository.

- . Demonstrate the commercial feasibility of the technology with a field test.

\section{RD\&D Challenges}

- Identify sufficient $\mathrm{CO}_{2}$ storage capacity in economical proximity to large, stationary sources.

- Establish reservoir criteria for storage integrity, quantify storage capacity, and evaluate environmental acceptability.

- Modify existing reservoir simulation codes to included $\mathrm{CO}_{2} /$ carbonate geochemistry for long-term fate and transport studies.

\section{RD\&D Activities}

- DOE/FE has initiated a study of the economic, legal, environmental, and social issues use of the Mt. Simon aquifer underlying portions of the U.S. Midwest.

- Commercial recovery of coalbed methane by $\mathrm{CO}_{2}$ injection has been demonstrated by industry.

- FETC has identified promising sites for $\mathrm{CO}_{2}$ sequestration in Texas where large power plants are close to high-capacity depleted oil and gas reservoirs.

\section{Recent Success}

- Statoil has a project to store 1 million tonnes per year of $\mathrm{CO}_{2}$ from the Sleipner Vest gas field in a sandstone aquifer $1000 \mathrm{~m}$ beneath the North Sea.

- Dakota Gasification Company recently signed a contract to transport 2 million tonnes of $\mathrm{CO}_{2}$ per year captured from the gasification of lignite to PanCanadian Petroleum for enhanced oil recovery in Canada.

- Industry has demonstrated in jection of $\mathrm{CO}_{2}$ into coalbeds for enhanced methane production.

\section{Commercialization and Deployment}

- About 70 oil fields worldwide use $\mathrm{CO}_{2}$ for enhanced oil recovery.

- No commercial aquifer storage sites for $\mathrm{CO}_{2}$ are operating in the United States

- There is commercial and industrial experience with over 400 wells for injecting industrial waste into deep aquifers.

- The Mt. Simon aquifer underlying Illinois, Indiana, Michigan, Kentucky, and Pennsylvania has been approved for industrial waste disposal and underlies a region with numerous fossil energy power plants.

- Injection of $\mathrm{CO}_{2}$ into depleted oil and gas reservoirs and deep coalbeds can provide incremental hydrocarbon recovery. 


\section{Carbon Reductions}

- It might be feasible to inject a large fraction of the $\mathrm{CO}_{2}$ produced from U.S. power plants on site without a long-distance pipeline transportation infrastructure.

\section{RD\&D Expenditures}

- It is suggested that research on this technology be part of a newly established carbon sequestration program. It is estimated that an annual federal budget on the order of $\$ 125 \mathrm{M}$ through $2010, \$ 150 \mathrm{M}$ through 2020 , and $\$ 200 \mathrm{M}$ through 2030 is needed for this program.

\section{Nonenergy Benefits and Costs}

- Injecting $\mathrm{CO}_{2}$ into oil fields could recover incremental oil, boosting U.S. production and reducing oil imports.

- Successful implementation would create domestic and international market opportunities for U.S. companies for site-specific studies and project implementation.

\section{Expected Cost Per Ton of Carbon Sequestered}

- The cost of injecting $\mathrm{CO}_{2}$ into depleted oil and gas reservoirs is typically less than $\$ 10 /$ ton. Costs have been estimated to range from $\$ 2$ to $\$ 8 /$ ton of $\mathrm{CO}_{2}$ for aquifer storage, excluding power plant modifications. The cost of injecting $\mathrm{CO}_{2}$ into depleted oil and gas reservoirs is less than $\$ 10 /$ ton. Costs have been estimated at $\$ 5$ to $15 /$ ton of $\mathrm{CO}_{2}$, equivalent to $\$ 18$ to $\$ 55 /$ ton of carbon. Assuming a $1 \%$ per year reduction in total system costs, the cost per ton of carbon can be reduced to $\$ 17$ to $\$ 52$ by 2000 and to $\$ 16$ to $\$ 47$ by 2010 . Assuming an accelerated RD\&D program goal of a $3 \%$ per year reduction in total system costs, the costs can be reduced to $\$ 16$ to $\$ 47$ by 2000 and $\$ 11.61$ to $\$ 34.82$ by 2010 .

\begin{tabular}{|c|c|c|c|c|c|c|c|c|c|}
\hline \multicolumn{10}{|c|}{ Technical Risk } \\
\hline 1 & 2 & (3) & 4 & 5 & 6 & 7 & 8 & 9 & 10 \\
\hline
\end{tabular}

\section{Risk Factors}

- The technology for subsurface injection of $\mathrm{CO}_{2}$ can be readily adapted from the petroleum industry. Site-specific long-term fate and transport studies are required to demonstrate successfilly sequestration.

Commercial Risk

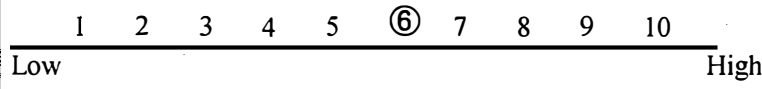

- Individual components of petroleum technology have yet to be integrated and a pilot field test successfully completed for commercial acceptance. The potential domestic and international market for $\mathrm{CO}_{2}$ sequestration services is very large and intimately related to the use of fossil fuels, the implementation of carbon taxation, and regulatory and governmental activities. A significant infrastructure investment for the collection, transportation, and disposal of $\mathrm{CO}_{2}$ would be required.

Ecological Risk

\begin{tabular}{llllllllll}
1 & 2 & 3 & 4 & 5 & 6 & 7 & 8 & 9 & 10 \\
\hline Low & & & & & & & & &
\end{tabular}

- Ecological risk is primarily associated with the collection and transportation infrastructure. $\mathrm{CO}_{2}$ storage in a geologically stable repository presents minimal risk to the biosphere. Land subsidence of uplift over time is a possibility. $R \& D$ needed to find out if there is a possible subsurface ecology risk.
Human Health Risk

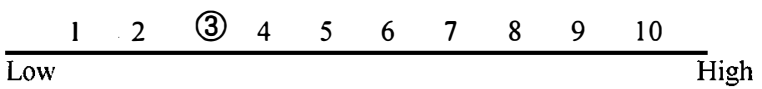

- $\mathrm{CO}_{2}$ is present in low concentrations in the atmosphere. Human health risk is primarily associated with industrial accidents in the collection and transportation of $\mathrm{CO}_{2}$.

Economic Risk

\begin{tabular}{|c|c|c|c|c|c|c|c|c|c|}
\hline 1 & 2 & 3 & 4 & 5 & 6 & 7 & 8 & 9 & 10 \\
\hline
\end{tabular}

- Not applicable. Economic feasibility has yet to be evaluated or demonstrated. A field pilot test with an industrial partner is needed to establish capital and operating costs and operational parameters. The rate of return on capital invested for infrastructure is unknown.

Regulatory Risk

\begin{tabular}{lllllllllll}
1 & 2 & 3 & 4 & 5 & 6 & 7 & 8 & 9 & 10 & \\
\hline Low & & & & & & & & & &
\end{tabular}

- Regulatory requirements are likely to be similar to those for the natural gas transportation and storage industries.

\section{Key Federal Actions}

- Survey data collected by federal and state agencies and industry on the distribution, formation, and potential storage capacity of depleted oil and gas reservoirs, deep coalbeds, and saline aquifers suitable for $\mathrm{CO}_{2}$ sequestration.

- Demonstrate technical and economic feasibility and perform environmental assessment to attract commercial interest and support for using captured $\mathrm{CO}_{2}$ for long-term sequestration.

- $\quad$ Conduct field demonstration projects of $\mathrm{CO}_{2}$ storage in different types of geologic repositories. 


\title{
9.4 CARBON SEQUESTRATION IN SOILS
}

\author{
Technology Description
}

The IPCC (Second Assessment Report, 1995 Chapter 23, Working Group II) estimates that between 400 and 800 Mt C/year could be sequestered in agricultural soils worldwide by implementation of appropriate management practices that also increase agricultural productivity. These practices include increased use of crop residues, reduced tillage and restoration of wasteland soils. Overall, however, the capacity of soils to store carbon is finite and, if best practices are employed worldwide, can lead to a new equilibrium soil organic matter (SOM) content in from 50 to 100 years.

\section{System Concepts}

- When grasslands are broken for agricultural use, SOM in the densely rooted upper half-meter or so of soil is exposed to oxidation with consequent emission of $\mathrm{CO}_{2}$ to the atmosphere.

- When wetlands are drained, their highly organic soils are aerated and exposed to oxidation with consequent $\mathrm{CO}_{2}$ emissions into the atmosphere. Further, the dry surfaces of drained organic soils are exposed to wind erosion, and the dispersed organic particles are quickly oxidized.

- The net effects on SOM of forest land conversions to agriculture are more difficult to estimate and depend on the mineral composition, aeration, and acidity of the original soils. They depend, too, on climate and on the crop or pasture vegetation that replaces the forest. Even though a net gain in SOM is possible in some cases, maintenance of current forests and reforestation offer much greater opportunity for carbon sequestration.

\section{Representative Technologies}

- Minimum tillage, now practiced on more than $30 \%$ of U.S. farmlands, leads to increases in SOM.

- Increased return of crop residues to the soil provides a source of organic matter, some of which remains in the soil and increases carbon sequestration.

- Irrigation and appropriate use of fertilizers increases crop and root biomass, thereby increasing SOM.

- Return of agricultural lands to forests and grasslands initiates recovery of

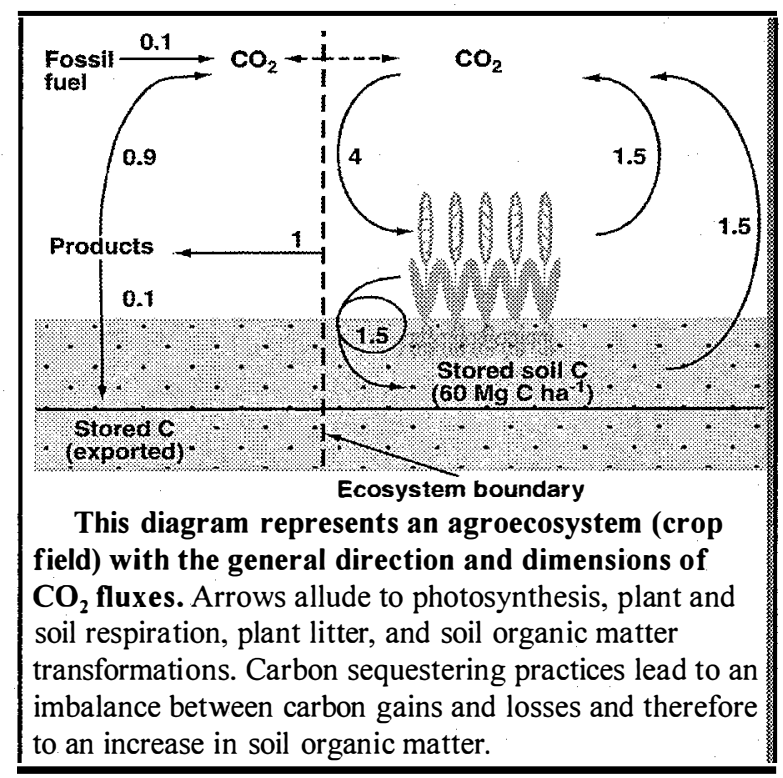
SOM content, and revegetation of degraded lands stabilizes them against further erosion and increases carbon storage in the soil.

- $\quad$ Plant breeding and genetics to increase belowground storage.

\section{Current Research, Development, and Demonstration}

\section{RD\&D Goals}

- Development of minimum tillage and residue management practices that are both sustainable and profitable and adaptable to all climatic regions.

- Understanding the sensitivity of carbon-sequestration techniques to climatic changes.

- Understanding the environmental, social, and economic consequences of large-scale biomass production on lands currently producing food and feed crops.

\section{RD\&D Activities}

- In 1995, USDA supported precision agriculture research at 15 locations for a total of $\$ 4.4 \mathrm{M}$. By 1996,125 people were involved in precision agriculture research, and funding was $\$ 26 \mathrm{M}$ - half for precision agriculture and half for supporting research. About $\$ 9 \mathrm{M}$ was transferred to land-grant universities through the Cooperative State Research Education and Extension Service.

- Private investment in precision agriculture is growing. A University of Georgia home page on precision farming links lists more than 50 companies in Australia, Canada, France, Germany, Sweden, the United Kingdom, and the United States offering precision agriculture services. Companies involved in precision agriculture research include Case IH, John Deere, Leica, Lockheed Martin, Agrium, Farmland Industries, and Monsanto.

\section{Recent Success}

- Aboveground carbon storage is complemented by belowground carbon storage in soil organic matter and roots. Roots of trees, shrubs and herbaceous species can grow considerably deep into the soil profile thereby reducing the possible release of $\mathrm{CO}_{2}$ into the atmosphere. A 1994 article in Nature reported that pasture grasses planted to increase beef production in the South American savannas may remove in a year as much as $2 \mathrm{Gt}$ of $\mathrm{CO}_{2}$ from the atmosphere. Carbon storage occurred as deep as a meter in the savanna soil. 
- The need for increased sequestration of carbon in soils will not, of itself, motivate farmers. The practices cited can be fostered with incentives in the form of subsidies keyed to amounts of carbon sequestered. More practical would be demonstrations that these practices increase farm profitability. Minimum tillage has already been shown to do so. In the developed world, improvements in irrigation and fertilization management can be effected through a range of satellite-based, computer-controlled techniques known as "precision farming." More traditional extension methods may be needed, for now, in the developing countries, although with the development of appropriate institutions, high-tech solutions may be deployable there, too.

\section{Potential Benefits and Costs}

\section{Carbon Reductions}

- $\quad$ The carbon loss from cultivated soils has been estimated at $55 \mathrm{Gt}$ worldwide. The current carbon stock in cultivated soils is $167 \mathrm{Gt}$ to a depth of $1 \mathrm{~m}$. Calculations have been made that $40 \mathrm{GtC}$ can be stored in soil over a 50 to 100 year period (linear rates of 400 to $800 \mathrm{MtC} /$ year).

Market

- At present, there is no market value for carbon in soils. Recognition of such a market would encourage land managers to apply techniques leading to carbon storage (e.g., precision farming, minimum tillage, deep rooted crops, agro-forestry, riparian areas).

Nonenergy Benefits and Costs

- Within range, an increase in soil organic matter leads to improvements in soil tilth, reduction of soil erosion, and improvements in crop nutrition.

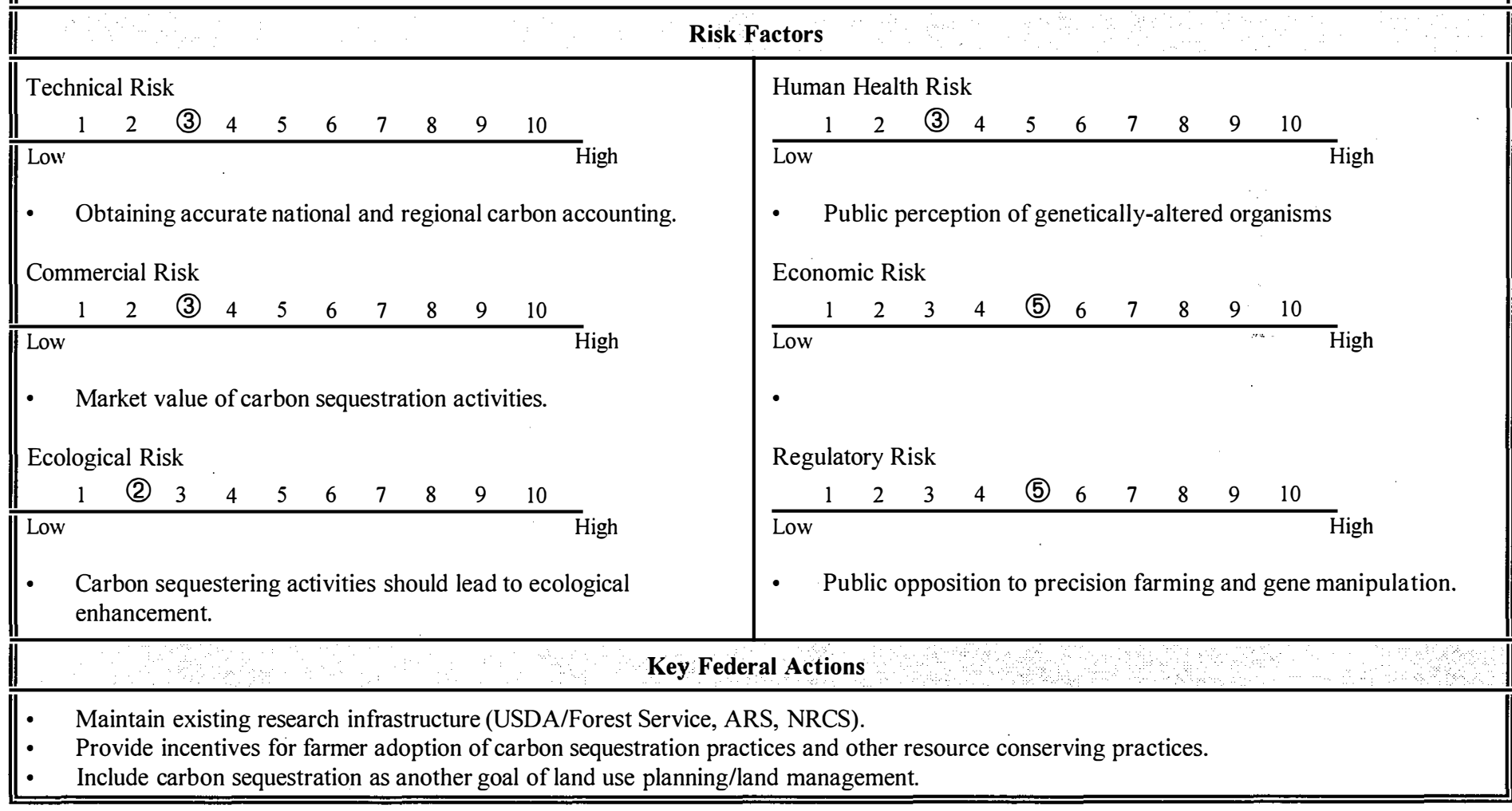

\section{RD\&D Expenditures}

- It is suggested that research on this technology be part of a newly established carbon sequestration program. It is estimated that an annual federal budget on the order of $\$ 125 \mathrm{M}$ through 2010 , $\$ 150 \mathrm{M}$ through 2020 , and $\$ 200 \mathrm{M}$ through 2030 is needed for this program. 


\subsection{ELEMENTAL CARBON SEQUESTRATION}

\section{Technology Description}

The production of hydrogen by the thermal decomposition of natural gas, followed by sequestration or sale of the particulate carbon formed, is an alternative to the conventional method in which steam reforming of natural gas is followed by a water/gas shift and separation and sequestration of $\mathrm{CO}_{2}$.

\section{System Concepts}

$$
\mathrm{CH}_{4}=\mathrm{C}+2 \mathrm{H}_{2}
$$

- The production of hydrogen from fossil and carbonaceous fuels, with reduced $\mathrm{CO}_{2}$ emission to the atmosphere, is key to the production of hydrogen-rich fuels for mitigating the $\mathrm{CO}_{2} / \mathrm{GHG}$ climate change problem. The basic reaction is the high-temperature thermal decomposition of natural gas to elemental carbon and gaseous hydrogen.

- The reasons for setting forth this technology as the basis for a $\mathrm{CO}_{2}$ mitigation process are as follows:

- It would provide a zero- $\mathrm{CO}_{2}$-emissions process for producing hydrogen.

- The process energy required to produce a mole of hydrogen would be lower than for any other production method, including steam reforming of methane.

- It would be a one-step reaction process with separation of hydrogen from carbon.

- The resulting carbon solid could be relatively easily separated from the gas stream.

- The carbon could be more readily disposed of than $\mathrm{CO}_{2}$. It would be a relatively stable and storable solid that could be landfilled, stored in mines, or sunk to the ocean floor. Carbon sequestration may be more acceptable than $\mathrm{CO}_{2}$ sequestration.

- The carbon would be pure and could be marketed as a commodity. Millions of tons of carbon are used yearly as a strengthening agent in rubber tires and as pigments in paints, printing inks, and facsimile machines. It is also possible to use carbon as a soil additive. Another possibility is to use carbon as a construction material in civil works, highways, and housing. Just as ash from coal is a useful product, carbon from methane could be considered the ash of natural gas with respect to the greenhouse problem.

- The projected cost of production of hydrogen from methane decomposition is competitive with the cost of steam reforming of methane. If the carbon produced could be sold as a commodity, the net cost of this process would be much lower than the cost of steam reforming of hydrogen.

- The hydrogen could be used efficiently in fuel cells or reacted with $\mathrm{CO}_{2}$ to produce methanol, which would fit well into the current liquid fuel infrastructure.

- The main negative aspect of this technology is that only a little more than half the energy from the natural gas resource would be extracted in the form of hydrogen. However, this ratio is not much worse than for other $\mathrm{CO}_{2}$ sequestration technologies. Furthermore, the carbon energy, is not destroyed. It may be possible to use it at a later date when atmospheric $\mathrm{CO}_{2}$ is less problematic.

System Components

- Thermal decomposition reactor

- Carbon separation and utilization

Representative Technologies

- High-temperature reactors

- Molten metal reactors

- Particulate removal from the gas stream

Technology Status/Applications

- Thermal decomposition of methane to produce carbon black has been practiced for years in the thermal black process. Hydrogen has been produced from methane decomposition on a demonstration scale in a catalyzed fluidized bed. The plasma decomposition of methane has been performed on a pilot plant scale. However, these are relatively inefficient processes with efficiencies of only about $50 \%$ because they have not been specifically geared to hydrogen production.

\section{Current Research, Development, and Demonstration}

\section{RD\&D Goals}

- To use methane decomposition as a $\mathrm{CO}_{2}$ mitigation technology, it is necessary to develop an efficient reactor that would produce hydrogen continuously at a thermal efficiency of $>70 \%$. Several reactor types have been proposed, including a molten metal reactor. Study is required to investigate the autocatalytic effect of the carbon formed on the kinetics of the methane decomposition reactor as it affects reactor design.

- The possibilities for using large amounts of carbon as a material commodity should be investigated. It could become a new construction material or a soil enhancer for farming. The lifetime stability of terrestrially sequestered carbon needs clarification.

\section{Applications and Target Markets}

- This technology is geared toward marketing decarbonized fuels, hydrogen and methanol. The methanol could be produced from the reaction of hydrogen with $\mathrm{CO}_{2}$ from a coal-fired power plant. The methanol would then be used in either internal combustion or fuel cell vehicles. Thus the carbon would be used twice-once to generate electrical power and a second time to power transportation.

- The carbon would be directed toward material commodity markets-tires, pigments, and construction materials.

\section{RD\&D Challenges}

- Develop a continuous high-thermal-efficiency thermal decomposition reactor for methane.

- Develop efficient separation systems for separating solid carbon from a gaseous hydrogen stream.

- Determine the applications of solid carbon as a materials commodity and the stability of carbon in a sequestered condition.

\section{RD\&D Activities}

- A small conceptual research program funded by DOE has been performed at BNL for $\$ 50 \mathrm{~K}$. Kvaerner Company in Norway has worked on the plasma decomposition of methane but not on the thermal degeneration. The old thermal black process has not been developed further. 


\section{Potential Benefits and Costs}

\section{Carbon Reductions}

- Thermal decomposition of natural gas, storing or using the carbon as a material, and using the hydrogen as such or converting it to methanol for use in fuel cells for transportation could reduce carbon emissions by $80 \%$ compared with using gasoline derived from petroleum to power vehicles. The cost per ton of $\mathrm{CO}_{2}$ deleted from the atmosphere would be negligible because of the revenue from selling methanol or hydrogen as a fuel replacing gasoline to drive engines. The mass of carbon to be sequestered or marketed would be on the order of 400 million tons, which is less than $25 \%$ of the mass of $\mathrm{CO}_{2}$ emissions from coal and oil currently consumed in the United States. (See the Systems Concepts section for further discussion of benefits.)

\section{RD\&D Expenditures}

- It is suggested that research on this technology be part of a newly established carbon sequestration program. It is estimated that an annual federal budget on the order of \$125M through 2010, \$150M through 2020, and \$200M through 2030 is needed for this program.

\section{Market}

- This technology is a basic global technology applied to on a prime large fuel resource for removal of carbon (i.e., natural gas). It would produce a prime carbon-free fuel, hydrogen, that could be used as a basic fuel in all engines and conversion devices. It would supply the hydrogen economy without producing and emitting $\mathrm{CO}_{2}$.

\section{Nonenergy Benefits and Costs}

- This technology produces carbon as a materials commodity for construction and the infrastructure. It produces hydrogen to be used for fuel and for chemical and fertilizer production.

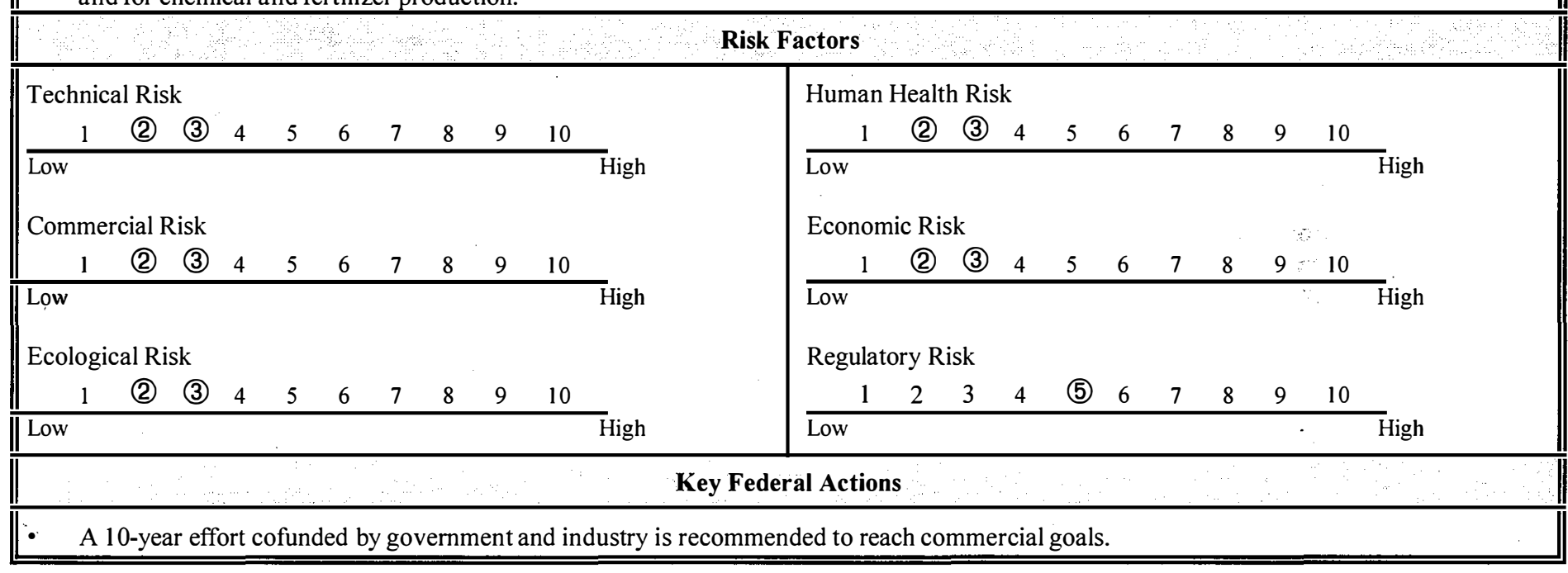




\subsection{OCEAN STORAGE}

Technology Description.

Gas hydrates are nonstoichiometric compounds in which the gas molecules are encaged within a host crystal lattice of water molecules (46 $\mathrm{H}_{2} \mathrm{O}$ tetrahedral coordinated water molecules and eight cavities for $\mathrm{CO}_{2}$ and $\mathrm{CH}_{4}$ ) with an ideal composition of $8 \mathrm{M} \cdot 46 \mathrm{H}_{2} \mathrm{O}(\mathrm{i}$.e., $\mathrm{n}=5.75)$. The water molecules that do not react chemically with the encaged molecules can form $\mathrm{CO}_{2} / \mathrm{CH}_{4}$ mixtures. $\mathrm{CO}_{2}$ could be pumped into regions such as deep oceans where hydrate is stable and sequestered as accumulated gas hydrate. The drawing is a conceptual cross-section of $\mathrm{CO}_{2}$ introduced to deep seafloor or within seafloor sediments. (The diagram shows stability field of gas hydrate relative to hydrothermal and geothermal pressure and temperature gradients in the ocean and seafloor.)

\section{System Concepts}

- In arctic oceans, permafrost regions, and deep oceans, the pressure and temperature conditions favor gas hydrate stability. At deep ocean depths, $\mathrm{CO}_{2}$. hydrates form below temperatures of $10^{\circ} \mathrm{C}$. As a result of these same in situ processes, $\mathrm{CH}_{4}$ hydrates form on the ocean floor and within ocean sediments. This $\mathrm{CH}_{4}$ stabilized as hydrate is a major reservoir of GHGs. The sequestration process is the opposite of systems envisioned to extract $\mathrm{CH}_{4}$ hydrates from the seafloor as an energy source. $\mathrm{CO}_{2}$ could be piped into regions where hydrate is stable and sequestered as accumulated gas hydrate at the seafloor-ocean interface or within the accumulating sediments (the possible reservoir is basically unlimited because of the areal extent of ocean and permafrost regions where hydrates are stable). The advantages of the gas hydrate sequestration pathway are that hydrate formation results in a significant reduction in volume for equivalent mass and that the process may be less rate dependent than relying on $\mathrm{CO}_{2}$ mixing with sea water.

\section{Representative Technologies}

- Performance assessment

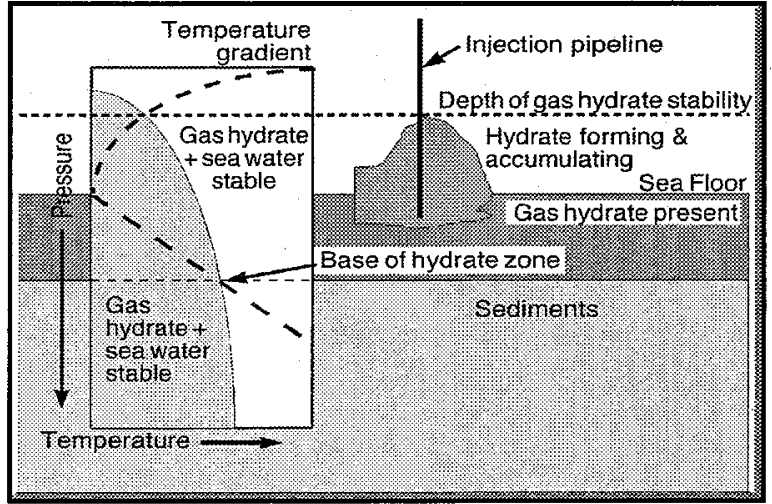

Conceptual cross-section of $\mathrm{CO}_{2}$ introduced to deep seafloor.

- Deep ocean engineering

- Deep ocean science

- Fate and transport geochemistry

- Three-dimensional characterization and monitoring

Technology Status/Applications

- This is a frontier technology. Japan, India, and the United States are investigating the somewhat reverse process of mining the seafloor or arctic gas hydrate for methane. Since this work is still developmental, costs are difficult to estimate. However, since the ambient pressure and temperature conditions at the seafloor form the gas hydrate, the basic cost is for the deep water pipelines to bring $\mathrm{CO}_{2}$ as a gas or liquid to the appropriate location where the pressure and temperature conditions favor clathrate stability. Research suggests that ocean sequestration of $\mathrm{CO}_{2}$ would cost from $\$ 5$ to $\$ 50$ per tonne of carbon depending on the site and other factors.

\section{Current Research, Development, and Demonstration}

\section{RD\&D Goals}

- Understanding of $\mathrm{CO}_{2}$ fate and transport in deep ocean waters and sediments.

- Comparative cost and risk evaluation among this and other technology pathways.

\section{RD\&D Challenges}

- Performance assessment: engineering risk/decision analysis, total system environmental risks, and comparative cost and risk evaluation among this and other technology pathways.

- Deep ocean engineering: completion to targeted areas, size to handle volumes, durability, and cost-effectiveness.

- Deep ocean science: characterization of pressures and temperatures, deep ocean currents and transport, deep ocean sedimentation, and deep ocean ecosystems.

- Fate and transport geochemistry: geochemistry complex mineral and fluid interaction with $\mathrm{CO}_{2}$-bearing phases, fate of clathrates at various temperature and depths (pressures) in the ocean, and modeling of temporal (over 100 years) and spatial behavior.

- Three-dimensional characterization and monitoring: volumes and suitability, location, areal extent, flow and availability, geostatistics. 


\section{RD\&D Activities}

- RD\&D activities for $\mathrm{CO}_{2}$ sequestration as gas hydrates are not currently funded. Ongoing basic science programs, waste storage programs, and engineering development programs for fossil energy extraction may provide an existing foundation for the development of the gas hydrate sequestration pathway. Some of the basic science (e.g., deep ocean science, fate and transport geochemistry) can be leveraged by ongoing general R\&D in these fields. In the broad sense, the level of activity for general research in these related fields is as follows:

- deep ocean science sponsored by NSF $(\$ 20 \mathrm{M})$, NRL $(\$ 100 \mathrm{M})$, IPOD $(\$ 5 \mathrm{M})$, industry $(\$ 10 \mathrm{M})$, and foreign agencies $(\$ 10 \mathrm{M})$.

- fate and transport (e.g., geochemistry and three-dimensional characterization and monitoring) sponsored by NSF ( $\$ 1 \mathrm{M})$, NRL ( $\$ 1 \mathrm{M})$, other government agencies (e.g., USGS) (\$1M), and foreign agencies $(\$ 50 \mathrm{M})$.

- The general components of the RD\&D activities for deep ocean engineering and performance assessment technologies are being developed for fossil energy extraction and waste storage. The current levels of RD\&D for fossil energy extraction and waste storage are as follows:

- deep ocean engineering sponsored by NRL $(\$ 50 \mathrm{M})$, IPOD $(\$ 5 \mathrm{M})$, industry $(\$ 10 \mathrm{M})$, and foreign agencies $(\$ 150 \mathrm{M})$.

- performance assessment sponsored by DOE $(\$ 100 \mathrm{M}), \mathrm{NRC}(\$ 10 \mathrm{M})$, EPA $(\$ 10 \mathrm{M})$, industry $(\$ 100 \mathrm{M})$, and foreign agencies $(\$ 100 \mathrm{M})$.

\section{Recent Success}

\section{Commercialization and Deployment}

\section{Potential Benefits and Costs}

\section{Carbon Reductions}

- $\quad 100 \%$ efficacy (assuming no significant leakage during transport and total conversion to clathrate and mixing with deep waters) at $\$ 0.20$ to $\$ 10 /$ tonne of $\mathrm{CO}_{2}(\$ 0.73$ to $\$ 37 /$ tonne of carbon).

\section{RD\&D Expenditures}

- It is suggested that research on this technology be part of a newly established carbon sequestration program. It is estimated that an annual Market federal budget on the order of $\$ 125 \mathrm{M}$ through 2010 , $\$ 150 \mathrm{M}$ through 2020 , and $\$ 200 \mathrm{M}$ through 2030 is needed for this program.

- The large potential reservoir, the reliance on natural processes (e.g., the enhanced stability field due to the deep ocean or permafi-ost region pressure and temperature conditions), and the areal distribution of deep oceans and arctic region represented in the gas hydrate sequestration pathway would allow this pathway to capture a large fraction of the $\mathrm{CO}_{2}$ mitigation market if $\mathrm{CO}_{2}$ credits are implemented.

\section{Nonenergy Benefits and Costs}

- These technologies are largely environmentally benign and may facilitate the production of ocean methane clathrates as an energy source. For example, the formation of $\mathrm{CO}_{2}$ clathrates may reduce the subsidence related to methane extraction.

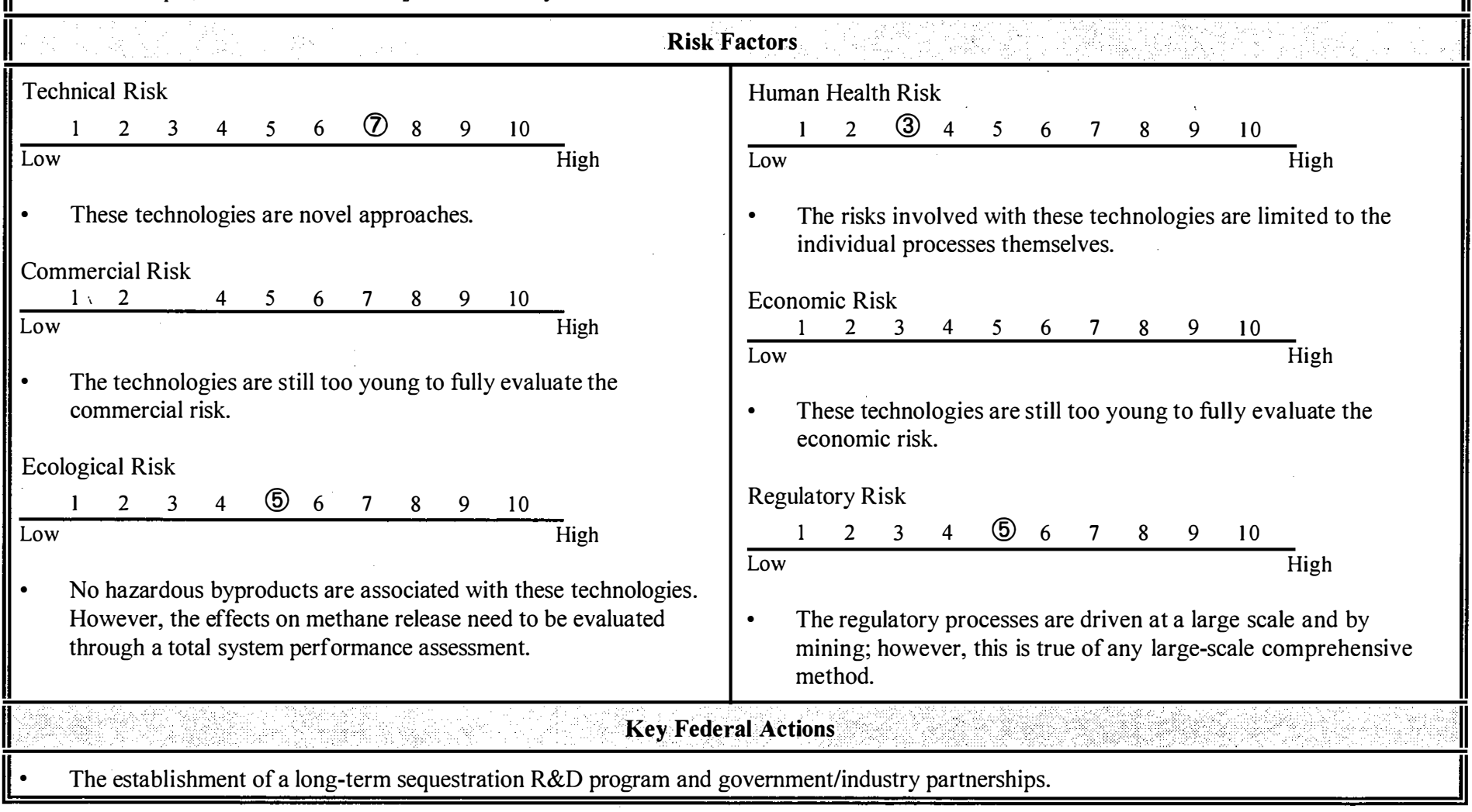





\title{
Crosscutting Technologies
}

\author{
10. Crosscutting
}

10.1 Fuel Cell Systems for Stationary and Transportation Applications

\subsection{Hydrogen}

10.3 Sensors and Controls

10.4 Transmission and Distribution Technologies

10.5 Power Electronics and Electric Machinery

10.6 Energy Storage

10.7 Modeling, Simulation, and Analysis 


\section{Technology Description}

Fuel cells are devices that change chemical energy directly into electrical energy without any combustion. Operating on hydrogen, a fuel cell does not emit $\mathrm{CO}_{2}$ and is projected to be up to two times as efficient as other advanced power generation technologies. A highly efficient enduse/conversion device such as a fuel cell is necessary to offset the energy penalty associated with producing hydrogen and achieve the full benefits of a transition to a hydrogen economy.

System Concepts

- A fuel cell power plant typically consists of three main parts:

- A fuel processor that converts a fuel (e.g., natural gas, diesel fuel, ethanol, methanol, gasoline) to a hydrogen-rich gas. Storage technologies to allow pure hydrogen to be carried aboard vehicles are being developed, as well as fuel cells that operate directly on methanol.

- The fuel cell stack system that converts hydrogen into direct-current (dc) electricity.

- A power conditioner that converts the dc electricity to regulated alternating-current (ac) electricity.

- Along with electricity, fuel cells produce heat, which can be used directly or, if the temperature is high enough, as input to a bottoming cycle to produce additional electricity.

Representative Technologies

- Fuel cells are commonly classified according to the type of electrolyte employed. The United States is actively developing and demonstrating phosphoric acid, molten carbonate, solid oxide, and polymer electrolyte (also known as proton exchange membrane) fuel cells for power generation in stationary applications (including distributed and on-site power) and transportation applications.

Technology Status/Applications

- Large-area fuel cells producing up to several megawatts are being demonstrated by utilities; smaller systems producing up to $100 \mathrm{~kW}$ are being demonstrated for transportation and smaller industrial and residential applications.

- About 100 phosphoric acid powerplants $(200 \mathrm{~kW})$ are in use with very high availability.

- Molten carbonate and solid oxide fuel cells have been scaled up to commercial size cells and stack hardware. Integrated systems are being tested.

- Polymer electrolyte fuel cells (10 to $30 \mathrm{~kW}$ ) have been built and tested in buses and small vans. U.S. automakers have announced they will produce prototype mid-size sedans powered by fuel cells in the 2000-2001 time frame. Performance simulations indicate fuel economy of $80 \mathrm{mpg}$ (gasoline equivalent) is achievable.

Current Research, Development, and Demonstration

\section{RD\&D Goals}

- Utility fuel cell power generation systems cost about $\$ 3000$ per installed kilowatt. The cost goal is $\$ 1000 / \mathrm{kW}$. Other goals are 50 to $70 \%$ energy efficiency (depending on the application), near zero regulated emissions, and a 40,000-hour lifetime. Smaller systems, based on the polymer electrolyte technology, are expected to enter the industrial, commercial, and residential markets at $\$ 1000$ to $1500 / \mathrm{kW}$.

- Costs for transportation systems are projected to be about $\$ 300 / \mathrm{kW}$ (based on high-volume production of current fuel cell technology). Cost and performance goals for the year 2004 are as follows: $\$ 50 / \mathrm{kW}$ (based on high-volume production), $48 \%$ energy efficiency, emissions levels much lower than federal Tier II standards, and a 5000-hour lifetime.

\section{RD\&D.Challenges}

- Reduction of costs through further development and optimization of fuel cell materials, designs, and systems for both stationary and transportation applications.

- Development of small-scale reformers (including microtechnology-based components) that will enable the use of liquid transportation fuels.

- Demonstration of compact, cost-effective, on-board hydrogen storage systems.

- Demonstration of required durability in all applications.

RD\&D Activities

- DOE's fuel cell programs are carried out by the private sector through cost-shared cooperative agreements and by the national laboratories.

- DOT is developing fuel cell-powered transit buses, DOD is funding development efforts on fuel cells operating on jet and diesel fuel, and NASA fuel cell efforts are focused on aerospace applications.

- EPRI and GRI are cooperating with the FE stationary fuel cell program.

- Fuel cell technology is strongly supported abroad by both industry and government.

\section{Recent Success}

- Approximately one hundred 200-kW phosphoric acid fuel cell plants have been delivered.

- Several polymer electrolyte fuel cell-powered buses and light-duty passenger vehicles are being tested.

\section{Commercialization and Deployment}

- Phosphoric acid fixel cell powerplants are at market-entry status (100 have been delivered) for small on-site systems of $200 \mathrm{~kW}$. Plants now operating have achieved up to 20,000 hours of operation. The primary issue is to reduce costs from $\sim \$ 3000 / \mathrm{kW}$ to $\$ 1500 / \mathrm{kW}$.

- Polymer electrolyte fuel cells are in the development phase for systems of up to about $100 \mathrm{~kW}$.

- Molten carbonate and solid oxide fuel cells are expected to be ready for commercial use by the year 2000. Energy Research corporation and M-C Power are the major U.S. suppliers of the molten carbonate technology. IHI, Mitsubishi, Toshiba, and Hitachi (Japan), and the European Direct Fuel Cell Consortium are also developing this technology. 
- Westinghouse is the major U.S. developer of the tubular solid oxide fuel cell; planar solid oxide technology is under development at Allied Signal, ZETEK, SOFCO, and TMI in the United States. The technology is also under development in Europe and Japan.

Gas turbine and diesel power plants are the main competitors to fuel cells in stationary applications; internal combustion engines and various hybrid powertrains are the main competitors to fuel cells in transportation.

\section{Potential Benefits and Costs}

\section{Carbon Reductions}

- The use of fuel cells leads to carbon reductions in both stationary and transportation applications. These could be significant if a fuel cell were used instead of a combustion device for fossil fuels because a fuel cell is more efficient. The reductions could be substantial if the fuel cell used hydrogen as the fuel and the hydrogen production process did not release carbon to the atmosphere. The estimated carbon reductions are accounted for in the pathways that would use fuel cells, principally: 1.2 Building Equipment and Appliances, 2.1 Industrial Energy Conversion and Utilization, 3.3 Hybrid, Electric, and Fuel Cell Vehicles, 6.2 Low-Carbon Fuels and High-Efficiency Generation, 6.3 Ultra-High-Efficiency, Zero-Carbon Emission Energyplexes, and 8.1 Biomass Electric.

\section{RD\&D Expenditures}

- RD\&D on fuel cells is presently conducted by DOE in FE, OTT, and OBT. This present RD\&D funding and estimated RD\&D expenditures in future years are accounted for in the pathways listed under Carbon Reductions. However, a modest stand-alone program funded at $\$ 10 \mathrm{M} /$ year, that would undertake "generic" federal RD\&D would be a valuable complement to the RD\&D carried out in the various DOE offices.

Market

- Fuel cell technology has the potential to achieve large market shares in distributed power and on-site power generation as well as in lightand heavy-duty transportation.

Energy

- Making the same assumptions as earlier, the reduction in petroleum consumption for transportation could be 0.2 quads by $2010,3.1$ quads by 2020 , and 6.9 quads by 2030. Energy reduction for stationary power generation could be 0.4 quads by 2010, 2.2 quads by 2020, and 6.9 quads by 2030 .

Nonenergy Benefits and Costs

- Benefits would be energy security, high export potential, and a reduction in emissions of criteria pollutants. Costs would be associated with installing a non-petroleum infrastructure for transportation.

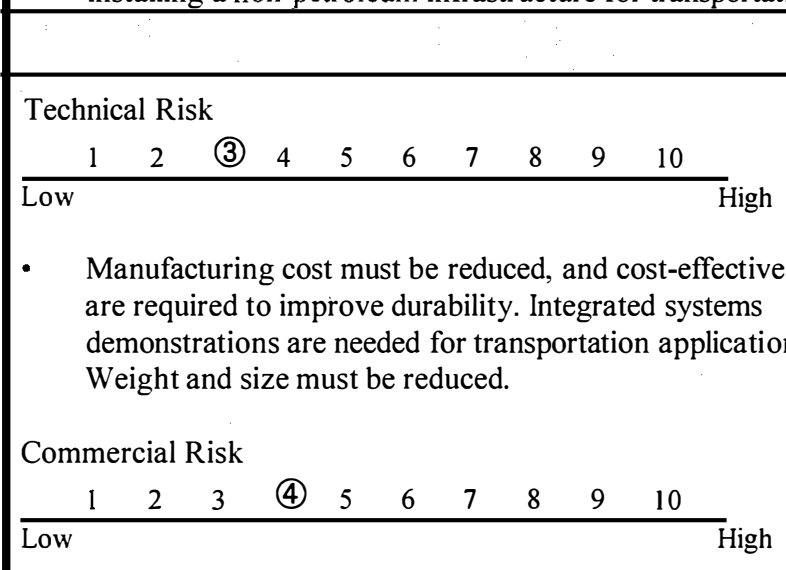

- Currently, a fuel cell power system costs 3 to 10 times more than competing systems in stationary and transportation applications. Lack of industrial experience in designing and manufacturing fuel cells, particularly for transportation, will expose vehicle manufacturers to greater warranty and safety liability. Lack of user familiarity with fuel cell products could hinder deployment. Increased backing by the private-sector investor community is needed.

Ecological Risk

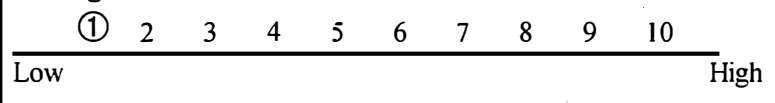

- Zero or near-zero emissions of criteria pollutants from fuel cell power systems will be the net benefit.

\section{Risk Factors}

Human Health Risk

Human Health Risk

\begin{tabular}{llllllllll} 
(1) & 2 & 3 & 4 & 5 & 6 & 7 & 8 & 9 & 10 \\
\hline Low & & & & & & & & & High
\end{tabular}

- Fuel cells do not pose a risk to human health.

Economic Risk

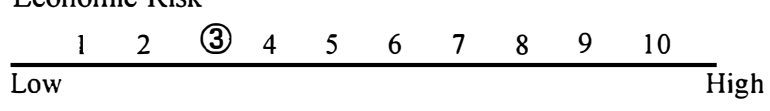

- $\quad$ Large amounts of development funding are required with no assurance of success. Failure to provide funding will result in this country's having to import fuel cell technology if it is successfully developed and commercialized overseas.

Regulatory Risk

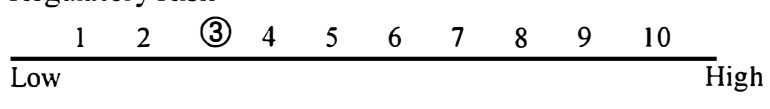

- Recyclability of fuel cells at the end of the useful vehicle life must be considered.

\section{Key Federal Actions}

Fuel cell development and commercialization requires long-term (10-year time frame) funding.

Steady federal R\&D funding is required to address technical barriers and develop enabling technologies.

Government/industry partnerships are needed to further fuel cell acceptance in stationary power generation and in transportation.

Federal procurement could stimulate demand, and incentives could facilitate purchase of fuel cell vehicles and power generators. 


\subsection{HYDROGEN}

Technology Description

Hydrogen is a carbon-free fuel that can be used in vehicles, homes, factories, and power plants. When hydrogen is produced from nuclear or renewable electricity, $\mathrm{CO}_{2}$ is essentially absent from the fuel cycle. When hydrogen is produced from carbon-containing primary energy sources, $\mathrm{CO}_{2}$ appears as a concentrated byproduct; subsequent sequestration can result in low emissions of $\mathrm{CO}_{2}$, depending on the amount of fossil energy used in the hydrogen production process. Hydrogen from biomass or solid wastes can result in very low $\mathrm{CO}_{2}$ emissions, depending on the amount of fossil fuel used for fertilization, cultivation, transportation, and so on. Once produced, hydrogen is an environmentally benign, versatile fuel that requires efficient use technologies to be economically viable. Hydrogen can be used efficiently.in the near term with conventional energy conversion devices, optimized for high efficiency and minimum emissions. In the longer term, hydrogen can be used in fuel cells, which promise potentially higher system efficiency and solid-state operation with water as the only emission.

\section{System Concepts}

- Hydrogen made from excess nuclear or renewable energy can be used as a sustainable transportation fuel and, if necessary, stored to meet peak-power demand and used as a carbon-free feedstock in chemical processes.

- Hydrogen produced by decarbonizing fossil fuels and sequestering the carbon can enable the continued, clean use of fossil fuel during the transition to a future carbon-free hydrogen economy.

- The hydrogen fuel system comprises production, storage, distribution, and use. Technologies are in various stages of development across the system.

\section{Representative Technologies}

- Hydrogen production

- Thermochemical conversion of fossil fuels and MSW to produce hydrogen and $\mathrm{CO}_{2}$ with the $\mathrm{CO}_{2}$ available for sequestration.

- Renewable (wind, solar) and nuclear electricity converted to hydrogen by electrolysis of water.

- Photoelectrochemical and photosynthesis-based processes for producing hydrogen from water.

- Hydrogen storage

- Pressurized gas, cryogenic liquid (commercial today) or cryogenic gas; or chemically bound as metal hydrides, adsorbed on carbon, or encapsulated in micro-capsules.

- Hydrogen distribution

- By pipeline, by decentralized or point-of-use production using natural gas or electricity, by truck ( liquid or compressed are commercially available), by distribution of hydrogen-adsorbent storage media (metal hydride, carbon, or micro-capsules).

- Hydrogen Use

- Transportation: Used by internal combustion engines or fuel cells to power vehicles with electric power trains.

- Potential long-term use as an aviation fuel.

- Industrial: Useful as a reductant in metal production.

- Power plant: Can be used as a fuel for gas turbines and steam generators in combined-cycle fossil fuel plants with carbon sequestration.

\section{Technology Status/Applications}

- Production: Hydrogen production from conventional fossil-fuel-feedstocks is commercial. Large-scale $\mathrm{CO}_{2}$ sequestration options have not been proved and require R\&D. Production technologies from waste and biomass are under development. Current electrolysis technology is $60 \%$ efficient, but costly. Research is needed to increase efficiency and reduce costs.

- Storage: Experimental metal hydrides and liquid hydrogen are used in automobile demonstrations.

- Distribution: In a transitional phase, the electricity grid and the natural gas pipeline system will serve to supply primary energy to hydrogen producers. For a fully developed hydrogen energy system, a new hydrogen pipeline system is envisioned.

- Use: A PEM fuel cell-based propulsion system with on-board storage of pressurized hydrogen has been demonstrated for buses. Liquid hydrogen and hydrides combined with internal combustion engines have been demonstrated in automobiles.

\section{Current Research, Development, and Demonstration}

\section{RD\&D Goals}

- By 2000 , develop (1) an on-board hydrogen storage system capable of an energy density of $4 \mathrm{kWh} / \mathrm{kg}$ and a cost of $\$ 10 / \mathrm{kWh},(2)$ a process demonstrated on the 10-ton/day scale for producing hydrogen from MSW with a thermal efficiency of $50 \%$ (energy content of hydrogen/energy content of feed), and (3) a fuel cell or hydrogen-powered internal combustion engine hybrid vehicle fleet with associated infrastructure for a "clean corridor" development.

- By 2010, develop (1) photobiological and photoelectrochemical processes for hydrogen production; (2) more efficient fuel cells for transportation and distributed electric power generation; (3) advanced storage systems based on carbon structures, metal hydrides, and engineered micro-capsules capable of providing sufficient storage to meet a vehicle range of < 400 miles; and (4) a conversion process for waste and biomass producing hydrogen at a cost of $\$ 10 / \mathrm{GJ}$ (high heat value of hydrogen).

\section{RD\&D Challenges}

- On-board storage systems that make long-range hydrogen vehicles technically and economically feasible.

- Affordable hydrogen production technology from renewable sources and $\mathrm{CO}_{2}$ sequestration technologies to enable the use of existing domestic fossil fuel resources as a transition strategy.

- Stable and safe lean premixed combustion technologies for hydrogen-fueled power production cycle.

\section{RD\&D Activities}

- DOE's hydrogen program is carried out by national laboratories, universities, and the private sector, including CRADA collaborations.

- $\quad$ Federal funding was \$14.5M in FY 1996 and \$15M in FY 1997 and will be \$17M in FY 1998.

- Hydrogen technology is strongly supported abroad. Federal funding in Germany is estimated at $\$ 40 \mathrm{M}$ and in Japan at $\$ 60 \mathrm{M}$. Private-sector European funding exceeds $\$ 350 \mathrm{M}$ in 1998 .

\section{Recent Success}

- A compact process for separating oxygen from air and using the oxygen to convert natural gas to a mixture of hydrogen and CO has been demonstrated on a laboratory scale with $98 \%$ efficiency. 
- A PEM fuel cell with a system efficiency of $46-47 \%$ and a stack power density of $\sim 1 \mathrm{~kW} / \mathrm{l}$.

- Direct conversion of sunlight into hydrogen using a semiconductor-based photoelectrochemical cell was demonstrated with $8 \%$ efficiency.

- A hybrid bus configuration was demonstrated using metal hydride storage and an internal combustion engine/genset with emissions below detectable limits.

- Cryogenic pressure vessels were conceptually shown to be capable of providing 400-800 mile ranges for PNGV-class hydrogen-fueled passenger vehicles.

\section{Commercialization and Deployment}

- Hydrogen is a bulk commodity (annual U.S. production about 1 quad) today but only for "captive" use in refineries and chemical plants such as ammonia/fertilizer plants.

- Hydrogen as a fuel is used only in niche markets such as rocket propulsion and urban bus tests.

- Some $0.2 \mathrm{M}$ tons of merchant hydrogen is produced and shipped annually in the United States.

- Currently hydrogen is provided by all major gas suppliers. In the future, the natural gas and petroleum industries are expected to expand existing hydrogen production facilities to include direct hydrogen sales.

- Pipeline companies are expected to enter the hydrogen distribution business.

- Manufacturers of fuel-cell propulsion systems are on the verge of commercializing their products.

\section{Potential Benefits and Costs}

\section{Carbon Reductions}

- The use of hydrogen could lead to carbon reductions in both stationary and transportation applications. The hydrogen can be used in a combustion device with or without a generator or in a fuel cell. The latter is preferred over the longer term because while combustion devices can be made to operate at $40 \%$ efficiencies and emit few $\mathrm{NO}_{\mathrm{x}}$ emissions, fuel cells have higher inherent efficiency and zero emissions. The carbon reductions could be substantial if the hydrogen production process did not release carbon to the atmosphere. The estimated carbon reductions are accounted for in the pathways that would use hydrogen, principally: 1.2 Building Equipment and Appliances; 2.1 Industrial Energy Conversion and Utilization: 3.3 Hybrid. Electric, and Fuel Cell Vehicles; 6.2 Low-Carbon Fuels and High-Efficiency Generation; 6.3 Ultra-High-Efficiency, Zero-Carbon Emission Energyplexes; and 8.1 Biomass Electric.

\section{RD\&D Expenditures}

- RD\&D on hydrogen is presently conducted by DOE in a "stand-alone" program in OUT. The RD\&D funding was \$15M in FY 1997. Estimated federal RD\&D expenditures in future years are \$40M/year over each of the decades 2000-2010, 2010-2020, and 2020-2030.

\section{Market}

- The fuel markets for power generation and transportation are huge. With the expected combined market penetration, the yearly energy amounts impacted will be 3 quads in 2010. 15 quads in 2020, and 35 quads in 2030.

\section{Energy}

- A hydrogen energy system allows a gradual transition from fossil fuels to non-carbon primary energy sources while reducing $\mathrm{CO}_{2}$ and other emissions. At full market penetration. all conventional use of fossil fuels would be replaced by hydrogen derived from renewable or carbonsequestered fossil-fuel sources. Hydrogen would provide energy security because it can be produced efficiently from any domestic primary energy source.

\section{Nonenergy Benefits and Costs}

- Improvements in air quality wherever hydrogen replaces conventional fossil fuels.

- New hydrogen technologies, such as PEM fuel cell propulsion systems, offer new manufacturing opportunities.

I - Risk Factors

\begin{tabular}{||llllllllll}
\hline \multicolumn{1}{|c|}{ Technical Risk } \\
1 & 2 & 3 & (4) & 5 & 6 & 7 & 8 & 9 & 10 \\
\hline Low & & & & & & & & & High
\end{tabular}

Human Health Risk
- Technical risk is modest because mostly known technology is deployed in a hydrogen energy system.

Commercial Risk

$\begin{array}{lllllllllll}1 & 2 & 3 & 4 & 5 & 6 & 7 & 8 & 9 & 10 & \text { High }\end{array}$

- Commercial risk is significant because direct use of cheap fossil fuels is a strong competitor.

Ecological Risk

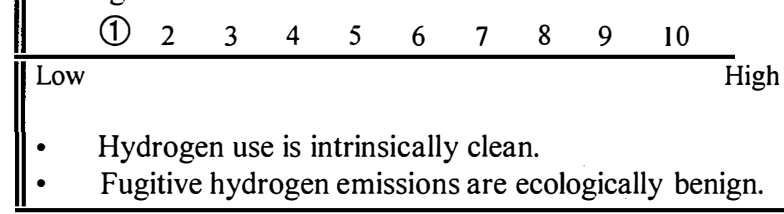

- Fugitive hydrogen emissions are ecologically benign.

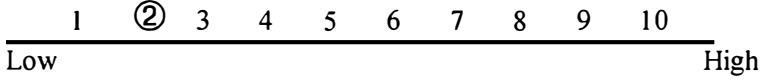

- No negative health effects are associated with exposure to hydrogen. Explosion or fire hazards are possible, but engineered controls can minimize potential hazards.

Economic Risk

\begin{tabular}{llllllllllll}
1 & 2 & 3 & 4 & 5 & 6 & 7 & 8 & 9 & 10 & \\
\hline Low & & & & & & & & & & & High
\end{tabular}

- Cost of hydrogen-fueled vehicles will be higher than costs of conventional vehicles.

- Cost of hydrogen to consumer will be higher than conventional fuels.

Regulatory Risk

\begin{tabular}{|c|c|c|c|c|c|c|c|}
\hline . & 2 & & (5) & 6 & $r$ & 9 & 1 \\
\hline
\end{tabular}

\section{Key Federal Actions}

Federal R\&D funding enhances the technology base by addressing critical technical barriers and developing enabling technologies that are in the precompetitive stages. 
Sensors and controls will play an ubiquitous role in technological advances to reduce $\mathrm{CO}_{2}$ emissions and sequester $\mathrm{CO}_{2}$. Each of the primary areas of clean energy production, energy efficiency, and carbon cycle management will require sensors and controls technologies, either as enabling technologies to meet program requirements or as essential technologies to ensure maximum efficiency at minimal cost. For example, fossil energy extraction could be improved through chemical sensors capable of operating boreholes or through better sensor technology for mapping coal deposits. Refining processes and fossil fuel reforming for $\mathrm{CO}_{2}$ sequestration at the wellhead both require substantial chemical processing that could be enhanced through real-time process sensors and controls. In the area of energy efficiency, novel sensors are needed in the transportation field to enable the use of more efficient engine technologies.

Almost all industrial processes depend on sensors and controls to ensure the quality of goods produced. Advanced sensors could reduce wasted energy and hence $\mathrm{CO}_{2}$ emissions. In carbon cycle management, innovative sensors are needed for analyzing photochemical processes and carbon fixation and may also be required for efficient biomass energy production.

Some underlying fundamental sensor technologies are adaptable to meet needs across different applications. An example is the solid-state oxygen sensor developed through the space program in the 1960s. It is now universally used in gasoline engine control and is common in industrial combustion control, touching virtually every major energy-consuming industry. A large variety of novel sensor technologies that are robust, sensitive, cost-effective, and capable of supporting real-time control-and the commensurate methods of data analysis and fusion for control—will be required in a successful climate change technology development program.

System Concepts

- The full extent of sensor and control technologies will span all approaches to mitigating climate change. Because of the variety of potential applications, generic system concepts are difficult to describe. An example of the system concept follows.

- Transportation is a key area where improving energy efficiency could have a significant impact on $\mathrm{CO}_{2}$ emissions. Transportation uses over $30 \%$ of the fossil fuels burned in the United States and has a commensurate impact on $\mathrm{CO}_{2}$ emissions. To improve the efficiency of personal transportation, new engine technology is required. Oxygen, $\mathrm{NO}_{x}$, and knock sensors and engine control technologies will be necessary to optimize the various lean-burn internal combustion engines, compression-ignited/direct-injection engines, and diesel engines being considered to meet PNGV and other transportation goals.

\section{Representative Technologies}

- Physical sensors for in situ temperature, pressure. viscosity, flow, and other process characterization applications.

- Sensors for chemical speciation in hostile process and combustion control environments.

- Pattern recognition, artificial intelligence, fuzzy logic, and other enabling technologies for real time data analysis and "sensor fusion."

- Sensors with embedded self-diagnostics and calibration.

- Enabling technologies that yield integrated sensors and controls systems that are fast, robust. inexpensive, miniature, and wireless.

Technology Status/Applications

- The variety of transduction methods and the capability to fabricate small, rugged, inexpensive sensor devices has advanced tremendously over the last 5 years. A recent example of high-technology sensing is the Mars probe's miniaturized robotic instrumentation package capable of analyzing the chemical composition of rocks. Substantial effort is under way to continue to develop chemical sensor capabilities either directly through chemically active devices or indirectly through optical, acoustical, or other physical means of determining chemical composition. The development of sensors for measuring temperature, pressure, viscosity, flow, and other physical characteristics continues to be challenging. Modern techniques for fabricating electronic devices allow unprecedented miniaturization of sensors and associated electronic controls. Rapid analysis of sensor data and feedback control is also advancing, often enabled by microprocessor technology.

- The current application of sensors for industrial process control has a tremendous impact on productivity and concurrent savings in energy and $\mathrm{CO}_{2}$ emissions. The direct impact of sensor technologies on $\mathrm{CO}_{2}$ emissions can be illustrated by combustion control through closed-loop feedback. This approach has improved passenger vehicle efficiency by an estimated $15 \%$ and fossil fuel burner efficiency by about $3 \%$, with commensurate decreases in $\mathrm{CO}_{2}$ emissions.

\section{Current Research, Development, and Demonstration}

\section{RD\&D Goals}

- Advanced sensors will be developed and demonstrated for chemical speciation and characterization, as well as for physical measurements. They are targeted at hostile process and combustion control environments. They will provide industrial users with reliable measurements not previously achieved in hostile field environments. In parallel, the capability to test and evaluate sensor functionality and reliability in harsh environments will be developed. We envision the creation of new sensor technologies for inexpensive physical and chemical characterization of modern industrial and chemical processes; these sensors will have embedded self-diagnostics and calibration that provide the necessary qualities of fast response, sensitivity, and robustness.

\section{RD\&D Challenges}

- Technical challenges to achieving these goals include (1) materials selection and development for the capability to withstand harsh environments such as high temperature or strong acid; (2) packaging methods that allow sensitive equipment and systems to operate in destructive environments; (3) signal processing to extract useful and repeatable information from low-level, noisy measurements; and (4) methods of communication that permit whole systems of sensors and controls from multiple manufacturers to operate together with the potential for easy future upgrades. One challenge with high potential pay-off is development of sensor-level wireless communications for wide-area plant deployment. 


\section{RD\&D Activities}

- Within DOE are small sensor and control programs generally aimed at specific objectives with some impact on $\mathrm{CO}_{2}$ emissions. DOE's OIT funds work on exhaust gas sensors for automotive applications. OIT has requested funding for a sensors and controls initiative to support IOF and has funded a study on sensing in harsh environments.

- Numerous programs and projects are under way throughout the federal sector. A thorough analysis of recent and on-going programs should be conducted to identify relevant technologies that can be accelerated to meet $\mathrm{CO}_{2}$ mitigation goals.

\section{Recent Success}

- A low-cost oxygen sensor developed and fabricated by a national laboratory has been incorporated into a commercial combustion control system. This sensor is being tested in industrial settings with particularly harsh smokestack environments and may enable combustion control in previously unacceptably harsh industrial settings.

- A measurement capsule developed and fabricated by a national laboratory has been incorporated in oil well drill bits. The self-contained measurement system, which withstands the harsh down-hole environment, predicts and diagnoses bit failure. The system reduces the time, costs, and lost energy related to broken bit extraction.

\section{Commercialization and Deployment}

- There are more than 4200 sensors and controls companies in the United States. Commercialization of sensor technology depends on demonstrating economic viability at a level commensurate with the risks small businesses can assume.

\section{Potential Benefits and Costs}

\section{Carbon Reductions}

- Sensors and controls technologies enable deployment of new industrial and commercial processes for reduced GHG emissions. Improved sensors and controls also allow operation closer to theoretical materials and process limits, which improves efficiency in processes such as fossil-fired power generation. The impact of sensor and control technologies on carbon reduction is difficult to state as a single estimate because of the wide variety of processes and industries that would benefit from better operation.

\section{RD\&D Expenditures}

- Sensor technology is often a hidden part of DOE programs. An estimate of the current DOE OIT expenditures specifically on sensors and controls is in excess of $\$ 15 \mathrm{M} /$ year. The present RD\&D funding and estimated RD\&D expenditures in future years are accounted for in the various Energy Efficiency and Clean Energy pathways. However, a modest stand-alone program funded at $\$ 10 \mathrm{M} /$ year that would undertake "generic" federal RD\&D would be a valuable complement to the RD\&D carried out in the various DOE offices.

\section{Market}

- The market for improved sensors and controls, especially for harsh environments, cuts across all industries and transportation. Nuclear, fossil, renewable, and end-use efficiency technologies would all benefit.

\section{Nonenergy Benefits and Costs}

- The sensor technologies developed for energy efficiency will often lead to reductions in environmental and health risks.

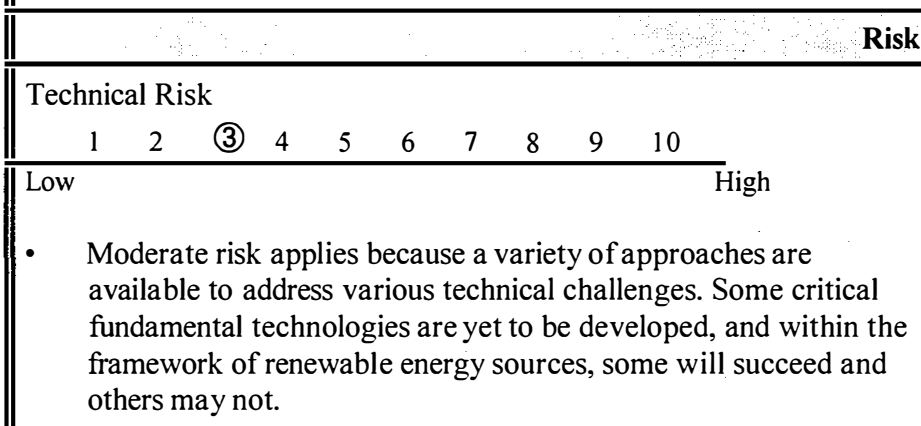

Commercial Risk

$\begin{array}{llllllllll}1 & 2 & 3 & \text { (4) } & 5 & 6 & 7 & 8 & 9 & 10\end{array}$

- Commercial risk is low to moderate because commercialization, especially of revolutionary technologies, requires significant investment

Ecological Risk

$\begin{array}{llllllllll}\text { (1) } & 2 & 3 & 4 & 5 & 6 & 7 & 8 & 9 & 10\end{array}$

\section{Risk Factors}

Human Health Risk

\begin{tabular}{llllllllll} 
(1) & 2 & 3 & 4 & 5 & 6 & 7 & 8 & 9 & 10 \\
\hline High
\end{tabular}

- Direct impact on human health is more likely to be positive-no direct negative health affects are associated with sensors and controls technologies.

Economic Risk

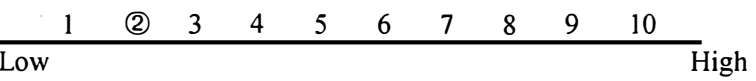

- $\quad$ Cost drivers are relatively high for sensors and controls because the technologies must have a minimal negative impact on final product cost.

Regulatory Risk

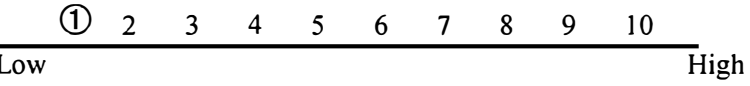

- New regulations may drive the invention of new sensor technologies.

- The introduction of sensor technologies is likely to have a favorable environmental impact.

\section{Key Federal Actions}

- $\quad$ Provide federal R\&D funding to develop key sensors and controls technologies that are generic, precompetitive, and applicable across a variety of commercial market sectors that use large amounts of energy and have a direct impact on GHG emissions. 


\section{Technology Description}

The electric utility industry is restructuring itself into a competitive, open access marketplace. Electric power transmission and distribution (T\&D) are the means whereby the benefits of this new structure will be made available to customers. Construction of U.S. transmission above $230 \mathrm{kV}$ will grow by only $4.4 \%$ from 1996 to 2005 . During the same period, U.S. electric energy sales are projected to grow by more than $17 \%$. The resulting increase in the intensity of use of existing facilities will increase energy losses and transmission congestion, making it difficult for renewable generation to find a secure market position.

Energy losses in the U.S. T\&D system were $7.2 \%$ in 1995 , accounting for 2.5 quads of primary energy and $36.5 \mathrm{MtC}$. Losses are divided $\sim 60 / 40$ between lines and transformers. Technologies that can improve efficiency and reduce carbon emissions are high-voltage dc (HVDC) transmission and power transformers and underground cables that use high-temperature superconductors (HTSs) High-efficiency conventional transformers could have significant impacts on distribution system losses. Real-time system control could improve access to customers for renewable power producers and enable greater use of environmental generation dispatch.

System Concepts

- HVDC lines are more efficient than conventional ac lines. A 250 -mile $500 \mathrm{kV}$ ac line converted to +/- 400kV HVDC operation would have $33 \%$ less energy loss.

- HTS cables have almost no losses except for refrigeration and can transport more than twice as much power as a conventional cable in the same size conduit.

- HTS power transformers have minimal losses, can be $50 \%$ smaller and lighter than conventional units, are nonflammable, and do not contain oil or any other potential pollutant.

- Better core materials and winding design for line transformers can cut losses dramatically.

- Real-time control using measured data and automated controllers improves T\&D reliability, increasing power transfer capacity for renewable generation without new line construction.

System Components

- HVDC converter terminals use solid state power electronic switches to convert ac to dc and vice versa. Dc transmission lines have two sets of phase conductors instead of three or more.

- HTS cables consist of large numbers of tapes containing HTS materials operating at $77^{\circ} \mathrm{K}$, insulated thermally and electrically. Refrigerating equipment maintains the temperature of the cable, extracting heat that manages to leak into the assembly.

- HTS transformers use the same types of materials as cables, formed into coils and mounted on conventional transformer cores. Electrical insulation may be liquid nitrogen or vacuum.

- Such advanced materials as laser-etched silicon steel or amorphous metal ribbon in the iron core of the transformer can cut distribution transf ormer core losses, and advanced winding techniques can reduce load losses.

- $\quad$ Real-time control uses wide area measurement systems, synchronized by satellite clocks to feed system information to artificial neural nets that reconfigure the system in real time, preventing system outages and permitting maximum use of available transmission capacity.

Technology Status/Applications

- HVDC: Conventional thyristor-based systems are commercially available at costs of $\$ 220 / \mathrm{kW}$ for both terminals. Advanced converters have been tested in the lab.

- HTS cables: Under the DOE Superconductivity Partnerships Initiative, a team led by Pirelli Cable successfully tested a 50-m cable assembly. Southwire Company is building a 30 -m prototype cable to power its manufacturing plant.

- HTS transformers: A 750-kVA three-phase low-voltage transformer is being tested in Switzerland on the grid. Waukesha Electric Systems, with partial DOE funding, is leading a team developing a 1-MVA 13-kV single-phase test unit and a 5-MVA three-phase prototype.

- High-efficiency distribution transformers are commercially available, but a cost premium of about $20 \%$ makes them unappealing to commercial and industrial users.

- Wide area measurement units without control capability have been deployed in the western United States power grid to help analyze system disturbances.

Current Research, Development, and Demonstration

\section{RD\&D Goals}

- HVDC voltage source converter terminal that cost $50 \%$ less than conventional units. HVDC markets include high-efficiency line capacity upgrades on existing rights of way and a large export market in the developing world.

- HTS tapes with current densities of over $10^{6} \mathrm{amps} / \mathrm{cm}^{2}$ in kilometer lengths at costs of $90 \%$ less than current materials. Markets include $\$ 500 \mathrm{M} /$ year in medium-power transformers, plus replacement or upgrading of aging urban transmission cable.

- High-efficiency transformer core steel costs must be reduced by $50 \%$ and handling/brittle fracture problems resolved. The existing distribution transformer market is $\$ 1 \mathrm{~B} /$ year.

- Artificial neural net training requirements must be reduced by a factor of ten. The annual market for conventional utility control systems approaches $\$ 300 \mathrm{M}$.

RD\&D Challenges

- HVDC: To achieve a cost reduction goal of 50\%, high-voltage, self-commutating converters. Switching devices made of silicon carbide or diamond are a long-term challenge.

- HTS cables and transformers: The manufacture of promising HTS materials in long lengths at low cost. Materials for cryogenic insulation high-efficiency refrigerators are also required.

- Improved ductility of amorphous metal core steel and high-strength, low-loss winding materials for reduced costs in the manufacture of high-efficiency distribution transformers.

- Neural net networks that can be trained in parallel. 


\section{RD\&D Activities}

- HVDC: There is no active U.S. program for HVDC development. EPRI spends $\$ 3 \mathrm{M}$ to $\$ 5 \mathrm{M} / \mathrm{year}$ on high-voltage power electronics for the related Flexible AC Transmission System technology. HVDC R\&D is taking place at offshore manufacturers aimed at sales in India, China, and South America.

- HTS: DOE funding of HTS utility technology is $\$ 19 \mathrm{M} /$ year, plus an industry cost share of $\$ 8 \mathrm{M} /$ year. Germany and Japan each are spending $\$ 50 \mathrm{M}$ to $\$ 100 \mathrm{M} /$ year each to develop HTS power equipment.

- No active research program is under way on improved distribution transformer technologies. EPRI terminated its program on improvements in amorphous metal core materials in 1995. Allied Signal (the inventor of amorphous metal transformer core material) and an Indian transformer manufacturer have agreed to develop and manufacture high-efficiency transformers in India for the burgeoning Asian market.

\section{Recent Success}

- The development of RABiTS ${ }^{\mathrm{TM}}$ and IBAD technologies for producing high-performance HTS film conductors suitable for cables and transformers, and the involvement of four industry-led teams to capitalize on it, was a major success story for FY 1797.

\section{Commercialization and Deployment}

- Conventional HVDC using thyristor valves is a mature commercial niche product with $30 \mathrm{GW}$ of installations in North America. No expansion is anticipated in North America unless cost reduction targets are achieved. The market in China and India may be up to 100GW. HTS cables and transformers: Commercial deployment awaits improved HTS materials and reduced costs in their manufacture and application.

- High-efficiency distribution transformers have been offered on the U.S. market for over 15 years, but sales have been declining and manufacturers are leaving the market as purchasers move to lower-cost, lower-efficiency transformers.

\section{Potential Benefits and Costs}

\section{Carbon Reductions}

T\&D is crosscutting in that it links electrical generation technologies to energy end-use technologies. The carbon reductions attributed to T\&D are only those of an improved T\&D system itself. They are estimated to be 3-4 MtC/year in 2010, 5- $6 \mathrm{MtC} / \mathrm{year}$ in 2020, and 20-25 MtC/year in 2030.

- Export markets are likely to generate significant savings, but these have not been estimated. Savings do not take into account the effect of secondary benefits such as the enabling of additional renewable generation.

\section{R\&D Expenditures}

- $\quad$ RD\&D on HTS is conducted by OUT at the level of $\$ 19 \mathrm{M}$ in FY 1997. Of this amount. \$12M can be roughly attributed to HTS for T\&D. There is no other DOE funding for T\&D. Estimated federal RD\&D expenditures in future years for the broader program described in this pathway are \$25M/year over 2000-2020 and \$20M/year over 2020-2030.

\begin{tabular}{|c|c|c|c|c|c|c|c|c|c|c|c|c|c|c|c|c|c|c|c|c|}
\hline \multicolumn{21}{|c|}{ Risk Factors } \\
\hline \multicolumn{10}{|c|}{ Technical Risk } & \multicolumn{11}{|c|}{ Human Health Risk } \\
\hline 1 & 2 & (3) & 4 & 5 & 6 & 7 & 8 & 9 & 10 & (1) & 2 & 3 & 4 & 5 & 6 & 7 & 8 & 9 & 10 & \\
\hline Low & & & & & & & & & High & $\overline{\text { Low }}$ & & & & & & & & & & High \\
\hline \multicolumn{10}{|c|}{ Commercial Risk } & \multicolumn{11}{|c|}{ Economic Risk } \\
\hline 1 & 2 & (3) & 4 & 5 & 6 & 7 & 8 & 9 & 10 & 1 & 2 & (3) & 4 & 5 & 6 & 7 & 8 & 9 & 10 & \\
\hline Low & & & & & & & & & High & Low & & & & & & & & & & High \\
\hline \multicolumn{10}{|c|}{ Ecological Risk } & \multicolumn{11}{|c|}{ Regulatory Risk } \\
\hline (1) & 2 & 3 & 4 & 5 & 6 & 7 & 8 & 9 & 10 & 1 & (2) & 3 & 4 & 5 & 6 & 7 & 8 & 9 & 10 & \\
\hline Low & & & & & & & & & High & Low & & & & & & & & & & High \\
\hline
\end{tabular}

\section{Key Federal Actions}

- A T\&D research initiative could be developed to fund HVDC, HTS, and other T\&D technologies. The aim of the federal program could be to develop advanced concepts in conjunction with demonstrations by industrial partners. 


\section{Technology Description}

Power electronics is the technology used to convert one form of available electrical power to the form required by the application. About $60 \%$ to $70 \%$ of the nations' electrical power is used to drive motors, and motors are reasonably efficient at rated speed and load. But efficiencies can be tremendously improved by operating motors at variable speeds to match the system requirements or by replacing the copper wires with hightemperature superconducting (HTS) wires. Motors driven by power electronics to achieve variable speed capability are increasing dramatically in numbers as the technologies become available. Power electronics devices with higher power handling capability and reliability are being developed, enabling more widespread use. HTS motors would pay for themselves in energy savings over the life of the motor because of improved efficiency. Coupled together, inverter-driven HTS motors offer an unprecedented opportunity for U.S. industry and utilities to reduce energy consumption and improve competitiveness.

\section{System Concepts}

- Advanced inverter topologies: Inverter circuitry that accommodates and takes advantage of advanced solid-state devices while further improving the overall efficiency, packaging, and performance of the inverter.

- Advanced electric machinery: Various type of electric motors and generators that are better suited for particular applications, that are more cost-effective, or that provide for the use of new technologies such as HTS wire.

\section{Representative Technologies}

- Soft switching inverters, multi-level inverters, buck/boost converters, induction motors. permanent magnet motors, variable reluctance motors, materials for improved power electronics and electric machinery, superconducting electric motors and generators.

\section{Technology Status/Applications}

- Transportation: Displacement of internal combustion engines and an enabling component of alternate approaches to vehicle systems (traction drives, flywheels, auxiliary drives, alternators).

- Industrial: More efficient motors and introduction of adjustable speed drives to match drives to loads for fans, pumps, and compressors.

- Defense: "More electric" initiatives by various branches of the military.

- Utilities: Power quality systems, HTS motors, high-voltage dc transmission systems.

- Renewable energy: Inverters to convert photovoltaic power to ac power

- Power supplies: Converters embedded in systems to alter the electrical power from one type to another.

\section{Current Research, Development, and Demonstration}

\section{RD\&D Goals}

- Develop HTS wires with engineering current density of $>50,000 \mathrm{~A} / \mathrm{cm}^{2}$ in a field of 2-5 Tesla in liquid nitrogen, with a cost of $\$ 10-100$ per $\mathrm{kA} / \mathrm{m}$.

- Develop and demonstrate a pre-commercial prototype 1000-hp HTS motor by FY 1999.

- By 2004 , under PNGV improve motor efficiency from $85 \%$ to $96 \%$ and inverter efficiency from $92 \%$ to $98 \%$.

- Develop more electric aircraft, military land vehicles, and ships

- By 2008, develop a power electronics building block capable of dramatically improved power density, efficiency, and cost.

\section{RD\&D Challenges}

- Smaller, lighter, more efficient, lower cost inverters and motors are required.

- Reliability, cost, and electromagnetic compatibility must be improved.

- Improved materials for power electronics systems and for HTS electric machinery are required.

\section{RD\&D Activities}

- Navy/ONR and DOE joint program to develop power electronic building blocks.

- Military developments of "more electric" aircraft, ships, and land vehicles.

- $\quad$ PNGV is pursuing the development of electric machinery and drives as an enabling technology.

- The federal initiatives in transmission and distribution system long-range R\&D were canceled.

- The Superconductivity Technology Program funds R\&D of more efficient motor technology under the Superconductivity Partnership Initiative.

\section{Recent Success}

- Soft-switching inverter topologies have been recently developed for improved inverter efficiency, reliability, and performance.

High-power solid-state inverters with improved efficiency and reduced cost and size have been developed.

A multi-level inverter has been developed which when deployed will allow $26 \%$ more energy to be extracted from photovoltaic or other renewable energy sources.

- Superconducting Machinery: Under the DOE's Superconductivity Partnership Initiative, Rockwell Automation demonstrated a prototype 200-HP synchronous motor, and is now designing a $1000 \mathrm{HP}$ motor, to be operational in 1999, and a 5000-HP motor, to be operational in 2001. In 1996 General Electric Co. produced a prototype HTS generator coil. 
- USCAR has been formed so that Ford, GM, and Chrysler can better implement technologies developed under PNGV.

- Major U.S. motor and drive manufacturers are beginning to expand their product lines to include higher efficiency motors and improved power electronics. Superconducting motor prototypes are being produced by Rockwell Automation.

- U.S. power semiconductor manufacturers are expanding product lines and facilities to regain market position from foreign competitors.

- DOE Motor Challenge Program is actively promoting the use of efficient electric machinery in industry.

\section{Potential Benefits and Costs}

\section{Carbon Reductions}

- The use of improved power electronics and electric machinery leads to carbon reductions in virtually all electrical generation technologies and energy end-use technologies. Correspondingly, the estimated carbon reductions are accounted for in the Energy Efficiency and Clean Energy pathways.

\section{RD\&D Expenditures}

- $\quad$ RD\&D on HTS is conducted by OUT at the level of $\$ 19 \mathrm{M} /$ year in FY 1997. Of this amount, $\$ 7 \mathrm{M}$ can be roughly attributed to HTS for Power Electronics and Electric Machinery. Because current DOE funding is not carefully coordinated among its various offices, it is difficult to ascertain the exact level of other DOE funding in this area. The present spending and estimated future RD\&D expenditures in these offices (other than HTS) is accounted for in the other pathways. Estimated expenditures on HTS plus a modest stand-alone program that would undertake "generic" federal RD\&D are \$20M/year over 2000-2020, and \$15M/year over 2020-2030.

Energy

- OIT estimates that by 2010 , annual savings in U.S. industry from more efficient industrial electric motor systems could be roughly 240 billion $\mathrm{kWh} /$ year and up to $50,000 \mathrm{MW}$ of avoided new power plant capacity.

- Directly replacing all motors of over $125 \mathrm{hp}$ with superconducting motors would save U.S. industry $\$ 1.34 \mathrm{~B}$ annually in electric costs. Assuming only motors rated at greater than $1000 \mathrm{hp}$ are replaced, annual savings would be $\$ 420 \mathrm{M}$.

- Electric generator loss reductions through the use of superconducting generators would amount to $36 \mathrm{~B} \mathrm{kWh}$, or over $\$ 1.1 \mathrm{billion}$.

Market

- According to the report from the 4th International Superconductivity Industry Summit, by the year 2010 the annual worldwide market for products based on superconductors and sold to the electric power industry is expected to generate approximately $\$ 12 \mathrm{~B}$ in revenues.

- Based upon the value of the energy savings cited, the market for these new technologies is huge. If $\$ 13 \mathrm{~B}$ per year can be saved in energy alone, then the market for the products to accomplish that should be related to the value of the energy savings.

\section{Nonenergy Benefits and Costs}

- $\quad$ Reduced air pollution.

- International competition.

- HTS motors and generators will be approximately half the size and weight of today's electric machinery, potentially reducing installation costs and reducing the amount of the raw materials used to produce these machines. In addition, superconducting-type ac synchronous generators may have special electrical grid system advantages, such as improved steady-state voltage regulation.

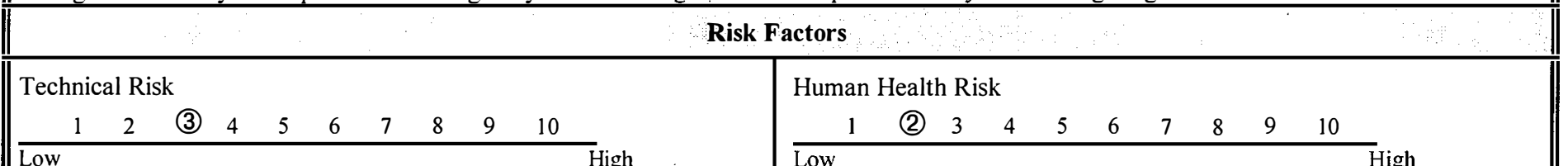

Low High

- Technologies must be developed to reduce size, weight, and cost while improving performance and reliability.

Commercial Risk

\begin{tabular}{|c|c|c|c|c|c|c|c|}
\hline 1 & 2 & 3 & (4) & 5 & & 6 & 7 \\
\hline
\end{tabular}

- New technologies must be introduced in well-known, reliable systems. Previous attempts to commercialize adjustable speed drives were somewhat unreliable, and a stigma has already been created

Ecological Risk

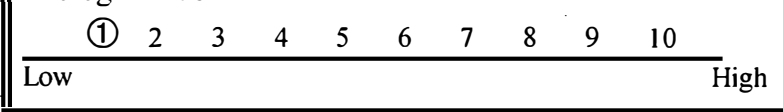

\section{Key Federal Actions}

- High voltage in automobiles presents a risk. Electronic circuit boards and lead solder present some risk.

Economic Risk

\begin{tabular}{|c|c|c|c|c|c|c|c|c|c|}
\hline 1 & (2) & 3 & 4 & 5 & 6 & 7 & 8 & 9 & 10 \\
\hline
\end{tabular}

- Promotes extensive cost savings at little risk

Regulatory Risk

Low

$\begin{array}{llllllllll}\text { (1) } & 2 & 3 & 4 & 5 & 6 & 7 & 8 & 9 & 10\end{array}$

- None is known that would impede these technologies.

- Federal R\&D funding enhances the technology base by addressing critical technical barriers and developing enabling technologies that are in the pre-competitive stages.

- Government/industry partnerships ensure commercialization of technologies developed in long-range R\&D programs.

- A government-wide power electronics initiative has been proposed to Congress but had not been acted upon as of February 1998. 
Advanced storage technologies under active development include processes that are mechanical (flywheels, pneumatic), electrochemical (advanced batteries, reversible fuel cells, hydrogen), and purely electrical (ultracapacitors, superconducting magnetic storage). Adding any advanced storage device to the utility grid usually increases $\mathrm{CO}_{2}$ production because of the less-than- $100 \%$ efficiency. The greatest value of advanced energy storage for utilities is that it can enable the use of intermittent renewable energy sources, such as solar PV and wind, that produce no direct $\mathrm{CO}_{2}$. In light-duty vehicles, both all-electric battery-powered and hybrid powertrains that use batteries, flywheels, or ultracapacitors in conjunction with an engine enable the capture of much of the kinetic energy of the vehicle through regenerative braking during deceleration. In the hybrids, further efficiency improvements may be realized by reducing the engine size and using the energy storage to assist in acceleration.

\section{System Concepts}

- Utilities: The efficiency of a typical steam plant falls from about $38 \%$ at peak load to $28-31 \%$ range at night. Utilities would store electrical energy at off-peak times, allowing power plants to operate near peak efficiency. The stored energy would be used during peak demand times. $\mathrm{CO}_{2}$ emissions would be reduced if the efficiency of the energy storage were greater than $85 \%$. Battery-powered electric vehicles could serve as the off-peak energy storage system, but higher turn-around efficiency than the $70 \%$ of lead-acid batteries is needed. In the long term, as demand grows, renewable sources would be added to the grid that would use the same storage to achieve dispatchable power for peaking.

- Vehicles: Energy storage in automotive electric and hybrid drive trains allows regenerative braking, which can reduce fuel consumption by $25 \%$ on the urban driving cycle. Additional optimization of engine size in hybrids to allow better average-power matching could improve total powertrain efficiency by a factor of 2 over existing automobiles. Energy storage and power density for automotive applications must be lightweight (of the order of $10-20 \mathrm{~W}-\mathrm{h} / \mathrm{kg}$ and $2 \mathrm{~kW} / \mathrm{kg}$ ) and have high cycle life (100,000s of cycles). Bus and delivery heavy-duty vehicles can also benefit from hybrid powertrains, although the improvement is not likely to be as great as for automobiles.

- Home cogeneration: Small amounts of energy storage are a pathway to commercially viable home cogeneration using solid oxide fuel cells or optimized engines coupled to small generators that are fueled with natural gas. Storage of a few kilowatt-hours with power output of 5-10 kW would reduce the start-stop cycles on the fuel-to-electricity converter. Waste heat from the converter would be used for space heating and domestic hot water. Such systems could use $70-90 \%$ of the fuel energy, depending on seasonal heating requirements. If the fuel converter had greater efficiency than central power plants, these systems could be connected to the grid to carry out distributed power peaking.

\section{System Components}

- For utility applications: the energy storage system consists of power conditioning to convert the power into the form required, the storage device, and the reconversion device. For vehicles and home cogeneration applications, power conditioning, the storage device, reconversion device, and safety containment are the major components.

\section{Representative Technologies}

- For utilities, the most mature storage technology is hydro pumped storage; however, it requires elevation changes and thus is not practical in many locations. Superconducting magnetic energy storage (SMES) is under active development by the Japanese in the $100 \mathrm{kWh}$ range. Zincferricyanide fuel cells are not under development but have the potential for 80-90\% turn-around (output/input energy) efficiency. For vehicle applications, advanced batteries, flywheels, pneumatic storage, and ultracapacitors are under development. The U.S. Advanced Battery Consortium (USABC) is developing batteries for electric-drive vehicles; about a dozen companies are actively developing flywheels; pneumatic storage is feasible for energy storage on the order of $0.1 \mathrm{kWh}$; and ultracapacitors have recently become commercially available in prototype units.

Technology Status

$\begin{array}{lllll}\text { Technology } & \text { Efficiency [\%] } & \text { Energy density [W-h/kg] } & \text { Power density [kW/kg] } & \text { Sizes [MW-h] } \\ \text { Pumped hydro } & 75 & 0.27 / 100 \mathrm{~m} & \text { low } & 5,000-20,000 \\ \text { Compressed gas } & 75 & \tilde{N} & \text { low } & 250-2,200 \\ \text { SMES } & 90+ & \tilde{\mathrm{N}} & \text { high } & \text { Vehicles } \\ & & & 0.2-0.4 & 10,000 \text { (goal) } \\ \text { Batteries } & 70-84 & 30-50 & 1-3 & 17-40 \\ \text { Flywheels } & 90+ & 15-30 & & 0.1-2.0 \\ \text { Ultracapacitors } & 90+ & 2-10 & 0.5-2 & 0.1-0.5\end{array}$

Comments

37 existing in US

1 US, 1 German research mostly Japan

USABC, development US \& foreign development Maxwell Technologies

Current Research, Development, and Demonstration

\section{RD\&D Goals}

- Utilities require high reliability, $\geq 85 \%$ efficiency, and per-kilowatt costs less than or equal to those of new power generation $(\$ 400-600 / \mathrm{kW})$. Compressed gas energy storage can cost as little as $\$ 1-5 / \mathrm{kWh}$, while pumped hydro ranges from $\$ 10-45 / \mathrm{kWh}$. SMES has targets of $\$ 150 / \mathrm{kW}$ and $\$ 275 / \mathrm{kWh}$. Vehicles require storage costs on the order of $\$ 300$ to $1000 / \mathrm{kWh}$ to achieve significant market penetration.

\section{RD\&D Challenges}

- The major hurdle for all storage technologies is cost reduction. Superconducting cable design for stability and low loss is an important research area for existing NbSn superconductors. High-temperature (liquid-nitrogen temperatures) superconductors that are manufacturable and can carry high currents could reduce both capital and operating costs for SMES. Flywheels need further development of fail-safe designs and/or lightweight containment. Magnetic bearings could reduce parasitic loads and make flywheels attractive for small uninterruptible power supplies and as a major player in home cogeneration systems. Ultracapacitor development needs improved energy density from the current $1.9 \mathrm{~W}$-h/kg for light-duty hybrid vehicles. Advanced higher-power batteries with greater energy storage and longer cycle-life are necessary for significant electric vehicle market penetration. 


\section{RD\&D Activities}

- The Japanese are spending about $\$ 5 \mathrm{M} /$ year for a 5-year SMES project to build a $100-\mathrm{kWh}$ prototype. Superconducting coils for this project are being tested at LLNL. In a joint DOE/EPRI project, Babcock \& Wilcox is building a 500-kWh SMES unit in Alaska for power quality (not dedicated storage) at a cost of more than \$20M. DOE’s Energy Storage Systems Program (\$4M/year) works on improved and advanced electrical energy storage for stationary (utility, customer side, and renewables) applications. It focuses on system integration using near-term components, field evaluations, advanced component development, and systems analysis. DOE also funds research on ultracapacitors for hybrid vehicles at $\$ 2 \mathrm{M}$. This work is being done by a number of universities and industrial partners. USABC is spending approximately $\$ 7 \mathrm{M} /$ year on advanced battery development for hybrid vehicles. The flywheel storage program for vehicles was funded by DOE at $\$ 600,000$ in FY 1997 and is expected to grow to about \$1.2M. The Defense Advanced Research Programs Agency is supporting flywheel containment development at about \$2M/year in a joint effort with U.S. flywheel manufacturers.

\section{Commercialization and Deployment}

- For utilities, only pumped hydro has made a significant penetration with approximately $37 \mathrm{GW}$.

- There are 140 battery/diesel hybrid buses produced by Hino in Japan.

- GM has recently started leasing a lead-acid battery electric vehicle, soon to be upgraded to higher-performance nickel-metal hydride batteries.

\section{Potential Benefits and Costs}

\section{Carbon Reductions}

- The use of energy storage devices can lead to carbon reductions in both stationary and transportation applications. The reductions can be significant if a storage device enables a renewable or other low-carbon electricity generation technology, or a hybrid vehicle with a smaller and more efficient power source. The estimated carbon reductions are accounted for in the pathways that would use energy storage devices, including 1.2 Building Equipment and Appliances; 3.3 Hybrid, Electric, and Fuel Cell Vehicles; 8.2 Wind; 8.3 Solar Photovoltaics; and 8.6 Solar Thermal.

\section{RD\&D Expenditures}

- RD\&D on energy storage devices is conducted by DOE in OTT, OUT, and other offices. This present RD\&D funding and estimated federal RD\&D expenditures in future years are accounted for in the pathways such as those listed under Carbon Reductions. However, a modest stand-alone program that would undertake "generic" RD\&D would be a valuable complement to the RD\&D carried out in the various DOE offices. The estimated federal RD\&D expenditures are \$25M/year over 2000-2020, and \$20M/year over 2020-2030.

\section{Energy}

- Fuel efficiency improvements of $2-5 \%$ in the utilities (coal and natural gas savings); potential $20-30 \%$ improvement in residual efficiency using cogeneration (natural gas); potential $50 \%$ savings of petroleum in light-duty vehicles (represents $50 \%$ reduction in oil imports).

Nonenergy Benefits and Costs

1. Large-scale storage for utilities enables intermittent renewables to come to the marketplace as dispatchable power.

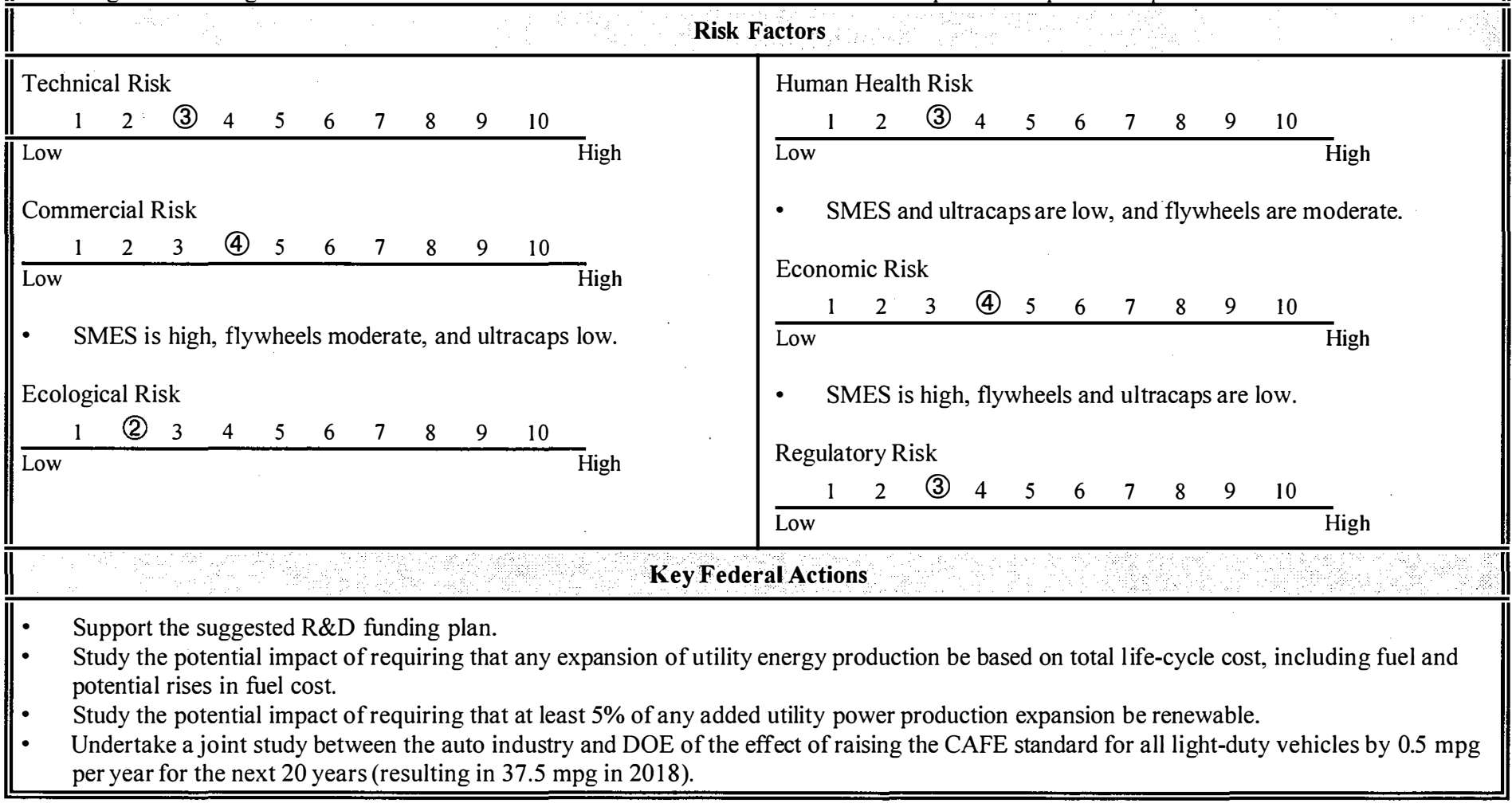




\subsection{MODELING, SIMULATION, AND ANALYSIS}

\section{Technology Description}

Modeling, simulation, and analysis technologies are critical to the successful development and implementation of any climate change technology strategy. For example, it is necessary to be able to develop and apply complex models in order to (1) understand the impact of new technologies or policies on the economy and the environment, (2) evaluate the potential for new technologies to meet GHG reduction goals, and (3) aid in the design and development of new and more efficient energy production, conversion, storage, distribution, and end-use technologies. Mathematical modeling can greatly impact the design of experiments, cost-effective field and production management, and design of remediation strategies and risk assessment. These activities will also facilitate U.S. priorities such as international trading of GHG emissions.

Advanced energy technologies with low carbon emissions can benefit greatly from modern simulation technology. Predictive modeling and simulation involves the use of the most advanced parallel computers-in speed, memory capacity, and I/O capability. High-performance computers also provide the first real opportunity for linkages and couplings among atmospheric, surface water, and groundwater processes. Advanced visualization and analysis techniques will be necessary for scientists and decision makers to understand the large-scale, nonlinear impacts that changing fuel sources, energy conversion technologies, and energy demand patterns will have on economic health.

\section{System Concepts}

- Scientific modeling/complex systems: High-fidelity simulations of manufacturing and power generation operations and the distribution of gases resulting from internal combustion engines can be used to predict the behavior of pollutants in the atmosphere at scales ranging from a few rooms in a building all the way up to global simulation of the buildup of GHGs. The computational capabilities allow more realistic modeling to provide an understanding of the scaling of mechanisms from the microscale to the macro- to mega-scale. Process design and optimization using simulations of complex systems that include social and economic components can result in improved processes and reduced environmental impacts, without the expense of trial-and-error experimental designs. These tools can aid the development of advanced energy technologies by allowing advanced modeling, steering (i.e., real-time adjustment), and visualization of computational experiments where direct experimentation or prototyping is very expensive, inaccessible, or otherwise unfeasible.

- Life-cycle assessment of economic and environmental impacts: The overall viability of new technologies will depend not only on the contribution those technologies make to GHG reductions. They also must be cost-effective and without adverse environmental impacts compared with the technologies or systems they are intended to replace.

- Portfolio analysis: A climate change technology strategy must maintain a balanced portfolio of R\&D. Innovative tools (e.g., decision analysis) are needed to allow decision makers to assess whether the R\&D portfolio is adequately meeting the climate change goals. Modeling and analysis will aide in prioritizing candidate research and technology.

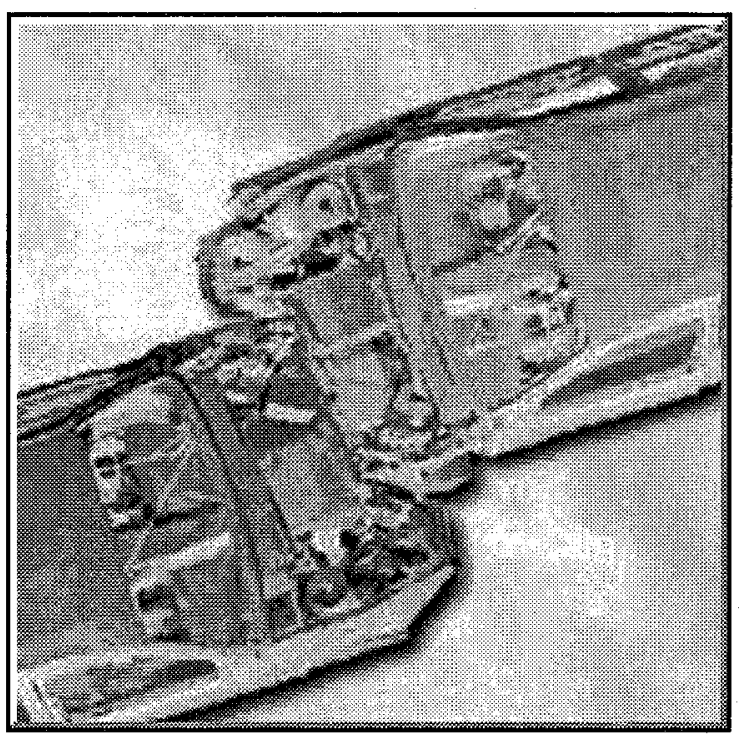

Simulation of an automobile collision to assess the performance of lightweight materials.

\section{Representative Technologies}

- Computer speed has advanced to the point where, by the year 2000, U.S. vendor systems will be capable of 10 trillion floating point operations per second. New, innovative software and tools for distributed and parallel computing will harness the power of this computing technology to reduce development time, identify applications of new technologies, project technology contributions to GHG reductions, and promote the adoption of GHG-reducing technologies via innovative public/private sector partnerships.

\section{Current Research, Development, and Demonstration}

\section{RD\&D Goals}

- Improve global carbon cycle models to minimize uncertainties. Improve resolution to determine regional and local effects.

- Improve the sophistication of energy/economic models, as well as information integration tools, to integrate individual technological processes, emissions characterization, global weather pattern simulation, and key socioeconomic and behavioral elements.

- Improve models to guide processing and aid in developing totally new approaches to manufacturing. Use of these models can reduce GHG emissions and provide new avenues for enhanced processing and manufacturing efficiency.

- Improve the understanding and modeling of combustion processes in manufacturing - a critical need for recovery boilers, furnaces, and direct-fired heat exchangers.

\section{RD\&D Challenges}

- Develop new conceptual and mathematical models that more accurately reflect complex physical, biological, cognitive, behavioral, social, economic, and decision-making processes.

- Develop general and accurate nonlinear numerical algorithms describing the physical models for emissions of GHGs. In addition, efficient solution techniques that scale well on massively parallel computers and/or networks of workstations are needed to handle fine grid resolutions. 


\section{RD\&D Activities}

- Simulation codes: Examples include high-fidelity simulations of manufacturing and power generation operations and hybrid-electric vehicle design codes that optimize designs to reflect efficiency goals.

- A novel methodology for evaluating the performance of advanced lightweight materials for automotive applications is being developed.

- Energy/economic/environmental modeling: EIA has developed and continues to improve the National Energy Modeling System (NEMS), which models the stocks of energy resources and their flows into the economy. The NEMS is used to predict energy pricing under a variety of system constraints (e.g., economic incentives) and the effects of various policies on environmental impact.

- Life-cycle assessment: Several modeling tools have been developed to evaluate the life-cycle costs and environmental impacts of energy production and use technologies.

- Collaborative technologies: Collaborative Management Environment investigates and develops information modeling and integration techniques to integrate scientific, engineering, and economic information across the DOE complex.

\section{Recent Success}

- A collaborative steering system (CUMULVS) was developed and demonstrated for computationally intensive combustion simulation across distributed sites among DOE laboratories and industrial collaborators.

- A state-of-the-art model has been developed to optimize processing parameters for producing materials with designed microstructures, thus reducing energy consumption, processing costs, and materials waste.

- Models of human behavior and cognition have been developed for advanced process control environments (nuclear power plant operation and maintenance).

\section{Commercialization and Deployment}

- Models developed with public funds are typically introduced into the public domain or licensed, making them available for use. Some tools may be used in international settings to promote the use of GHG emissions trading and joint implementation.

\section{Potential Benefits and Costs}

\section{Carbon Reductions}

- The use of modeling, simulation, and analysis is ubiquitous among the DOE offices since it can be the key to successfully developing and implementing new classes of energy technologies. The various pathways implicitly assume such activities are a vital part of the RD\&D. The carbon reductions attributed to a given pathway thus take into account the modeling, simulation, and analysis activities appropriate for that pathway.

\section{RD\&D Expenditures}

- $\quad$ Modeling, simulation, and analysis are presently conducted in virtually all DOE offices. The present RD\&D funding and estimated RD\&D expenditures in future years are accounted for in the corresponding pathways. However, a modest stand-alone program that would undertake "generic" RD\&D would be a valuable complement to the current work. Computational materials science, process design and optimization, and portfolio analysis that can be applied to a broad spectrum of energy technologies merit this stand-alone effort. The incremental estimated federal RD\&D expenditures are \$15M/year over 2000-2030.

\begin{tabular}{|c|c|c|c|c|c|c|c|c|c|}
\hline \multicolumn{10}{|c|}{ Technical Risk } \\
\hline 1 & 2 & (3) & 4 & 5 & 6 & 7 & 8 & 9 & 10 \\
\hline
\end{tabular}

\section{Risk Factors}

- Complex integrating systems modeling hold some technical risk. Some tools and approaches already exist.

Commercial Risk

\begin{tabular}{llllllllll}
1 & (2) & 3 & 4 & 5 & 6 & 7 & 8 & 9 & 10 \\
\hline Low & & & & & & & & & High
\end{tabular}

\begin{tabular}{|c|c|c|c|c|c|c|c|c|c|}
\hline \multicolumn{10}{|c|}{ Human Health Risk } \\
\hline (1) & 2 & 3 & 4 & 5 & 6 & 7 & 8 & 9 & 10 \\
\hline
\end{tabular}

Economic Risk

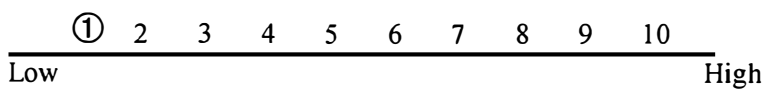

- Will improve the portfolio selection process, facilitating optimal selection of technologies for development, transfer, adoption, and use.

- Some of the tools will require access to high-performance computers. Tools will be available in the public domain.

Ecological Risk

\begin{tabular}{llllllllll} 
(1) & 2 & 3 & 4 & 5 & 6 & 7 & 8 & 9 & 10 \\
\hline High
\end{tabular}

\section{Regulatory Risk}

$\begin{array}{lllllllllll}\text { (1) } & 2 & 3 & 4 & 5 & 6 & 7 & 8 & 9 & 10 & \text { High }\end{array}$

\section{Key Federal Actions}

- Greater use of simulation and modeling in R\&D to facilitate and expedite solutions.

- Greater use of analysis and modeling in federal decision making.

- Development and demonstration of innovative public-private partnerships. 



\section{ACRONYMS AND INITIALISMS}

ac

AFV

AHTS

AIM

ARPA

ARS

ATP

ATS

B

BAU

bbl

BES

BNL

BWR

CAFE

CFC

$\mathrm{CO}$

CRADA

CSREES

CVT

dc

DFSS

DISC

DNA

DOC

DOD

DOE

DOE/EERE

DOT

DP

$\mathrm{EE}$

EPA

EPAct

EPRI

ER

EV

FE

FETC

FRA

FY

GDP

GE

GHG alternating current

alternative fuel vehicle

Advanced Hydropower Turbine System

Advanced Industrial Materials Program

Advanced Research Projects Agency

Agricultural Research Service

Advanced Technology Program

advanced turbine system

billion

business as usual

barrel

Basic Energy Sciences

Brookhaven National Laboratory

boiling water reactor

corporate average fuel economy

chlorofluorocarbon

carbon monoxide

cooperative research and development agreement

Cooperative State Research Extension and Education Service continuously variable transmission

direct current

dedicated feedstock supply system

direct-injection, stratified-charge

dioxyribonucleic acid

Department of Commerce

Department of Defense

Department of Energy

DOE Office of Energy Efficiency and Renewable Energy

Department of Transportation

Defense Programs

Energy Efficiency

U.S. Environmental Protection Agency

Energy Policy Act

Electric Power Research Institute

Energy Research

electric vehicle

Fossil Energy

Federal Energy Technology Center

Federal Railroad Administration

fiscal year

gross domestic product

General Electric

greenhouse gas 


\begin{tabular}{|c|c|}
\hline GHP & geothermal heat pump \\
\hline GIS & geographic information system \\
\hline GM & General Motors \\
\hline GRI & Gas Research Institute \\
\hline GSA & General Services Administration \\
\hline GTL & gas to liquids \\
\hline GW & gigawatt \\
\hline GWe & gigawatt electric \\
\hline GWh & gigawatt hour \\
\hline HCFC & hydrochlorofluorocarbon \\
\hline $\mathrm{HEV}$ & hybrid electric vehicle \\
\hline $\mathrm{HF}$ & HF and sulfuric acid processes \\
\hline HIPPS & high-efficiency power systems \\
\hline HSR & high-speed rail \\
\hline HVAC & heating, ventilating, and air-conditioning \\
\hline IBS & intelligent building system \\
\hline IEA & International Energy Agency \\
\hline IGCC & integrated gasification combined cycle \\
\hline $\mathrm{keV}$ & kiloelectron volt \\
\hline $\mathrm{kW}$ & kilowatt \\
\hline LEBS & low-emission boiler systems \\
\hline LIDAR & light detection and ranging \\
\hline LNG & liquified natural gas \\
\hline LLNL & Lawrence Livermore National Laboratory \\
\hline low-E & low-emissivity \\
\hline LWR & light water reactor \\
\hline M & million \\
\hline Maglev & magnetic levitation \\
\hline Mcf & million cubic feet \\
\hline MEC & model energy code \\
\hline MOU & memorandum of understanding \\
\hline MPG & miles per gallon \\
\hline MSW & municipal solid waste \\
\hline $\mathrm{MtC}$ & million tonnes of carbon \\
\hline MW & megawatt \\
\hline MWe & megawatt electric \\
\hline MWh & megawatt hour \\
\hline MWth & megawatt thermal \\
\hline NASA & National Aeronautics and Space Administration \\
\hline $\mathrm{NCC}$ & National Climate Center \\
\hline NEXTEA & National Economic Crossroads Transportation Efficiency Act \\
\hline NIF & National Ignition Facility \\
\hline NIST & National Institute of Standards and Technology \\
\hline NMI & National Maglev Initiative \\
\hline $\mathrm{N}_{\mathrm{ox}}$ & oxides of nitrogen \\
\hline NRC & Nuclear Regulatory Commission \\
\hline
\end{tabular}


NREL

NRL

NSF

OBES

OECD

OIT

OTT

OUT

PEM

PFBC

PM

PNGV

PPG

PRSE

PV

PVMat

PWR

QM

R\&D

RD\&D

rf

ROI

RRC

scf

Tcf

TDI

TVA

USDA

VVC

$W_{p}$
National Renewable Energy Laboratory

Naval Research Laboratory

National Science Foundation

Office of Basic Energy Sciences

Organization for Economic Cooperation and Development

Office of Industrial Technologies

Office of Technology Transfer or Office of Transportation Technology

Office of Utility Technologies

proton exchange membrane

pressurized fluidized bed combustion

particulate matter

Partnership for a New Generation of Vehicles

Pittsburgh Plate Glass

performance/reliability/safety/emissions

photovoltaic

Photovoltaics Manufacturing Initiative

pressurized water reactor

QM 98 study

research and development

research, development, and demonstration

radio frequency

return on investment

rolling resistance coefficient

standard cubic feet

trillion cubic feet

turbocharged direct injection

Tennessee Valley Authority

U.S. Department of Agriculture

variable valve control

Watts of power 